Portland State University

PDXScholar

\title{
Social Workers in the Community Mental Health Field A Delphi Forecast of Training Priorities
}

\author{
William Boyce Thomas \\ Portland State University \\ Mark L. Clay \\ Portland State University
}

Follow this and additional works at: https://pdxscholar.library.pdx.edu/open_access_etds

Part of the Health Psychology Commons, Social Psychology Commons, and the Social Work Commons

Let us know how access to this document benefits you.

\section{Recommended Citation}

Thomas, William Boyce and Clay, Mark L., "Social Workers in the Community Mental Health Field A Delphi Forecast of Training Priorities" (1975). Dissertations and Theses. Paper 2367.

https://doi.org/10.15760/etd.2361

This Thesis is brought to you for free and open access. It has been accepted for inclusion in Dissertations and Theses by an authorized administrator of PDXScholar. For more information, please contact pdxscholar@pdx.edu. 
AN ABSTRACT OF THE THESIS OF William Boyce Thomas and

Mark L. Clay for the Master of Social Work presented on May 20, 1975.

Title: Social Workers in the Community Mental Health Field A Delphi Forecast of Training Priorities

APPROVED BY MEMBERS OF THE THESIS COMMITTEE:

Lvnn Thompson, Chaizran

Eugene Hakanson

Nancy Kolfoloff

Diane Pancoast

This thesis describes an exploratory research project initiated to facilitate curriculum planning for, and evaluation of, a social work training program in the field of community mental health. The literature concerning community mental health, the historical relationship of social work to this field, and current is sues in social work manpower and education was reviewed as part of the thesis project. On the basis of the review, a study was undertaken to determine appropriate priorities for training Master's lẹvel social workers specializing in this field of practice. The researchers 
decided that these priorities would be determined in terms of the future professional practice and educational needs of social workers in this field, as reflected in the five variables of the roles, functions, and tasks they may be performing in ten years and the skills and knowledge they may be utilizing in this practice.

A population of 160 community mental health practitioners of both social work and non-social work orientations was chosen to address this research problem. They were purposefully selected on the basis of their current positions in Oregon's public community mental health service delivery systems, with an emphasis placed on practitioners involved in the planning, management, and development of services.

The research problem was initially operationalized by generating a forecast of future social work practice and educational needs in this field in terms of the five previously described variables. Items within each of these categories were then rated and re-rated on the basis of projected frequencies of occurrence. The distribution of responses on individual items were analyzed in order to identify group judgments and subsequently to define a generalizing core of social work practice and education in this field in ten years. The components of this core were further classified on the basis of item mean responses in order to produce ranked clusters of items within each of the five categories that would suggest priorities for training Master's level social workers. Nine research objectives were accomplished through utilization of a modified Delphi forecasting technique as a research design. This technique involved a consensus formation procedure requiring the 
development of a three-part survey as a data collection framework. The first round consisted of an open-ended questionnaire. Responses to this instrument were analyzed for content and edited to create lists of items in each category. Two questionnaires were developed for the second round. In this round, participants rated each item individually. The data was tabulated by computer and modal responses were determined, which were reported back to respondents. On the third round, respondents were asked to reconsider their second round ratings in light of this new information.

The first questionnaire was returned by 51 percent of the population of the study. Analysis of these responses resulted in five lists of 262 items which broadly characterized the future practice and educational needs of Master's level social workers in this field. This data was divided into one questionnaire of 129 items concerned with "Roles, Functions, and Tasks" and one of 133 items concerned with "Skills and Areas of Knowledge." Each questionnaire was sent to onehalf of the population. These two questionnaires were returned on the second round by 64 percent and 80 percent of the samples, respectively. There was only a slight additional loss of returns on the third round.

The tabulated data on the third round suggested that there was a noticeable convergence on the mode for 93 percent of the items in the two questionnaires. Analysis suggested that 60 items defined the future core of social work practice indicated by the respondents, and 88 items defined the future core of social work education. These items could be further classified into two ranked clusters of 32 items which suggested training priorities in terms of roles, functions, and tasks; and three 
ranked clusters of 43 items which suggested training priorities in terms of skills and areas of knowledge.

Comparisons between social workers and non-social workers in the population indicated that the two groups appeared, in general, to have two opposing views of future social work practice and educational needs. Comparisons between planners, managers, and developers revealed no consistent pattern of mutually exclusive viewpoints. The researchers concluded that the results of the study therefore represented a compromise between the essentially divergent viewpoints of social workers and non-social workers, rather than a consensus among the two groups on a common forecast and similar training priorities. 
SOCIAL WORKERS IN THE COMMUNITY MENTAL HEALTH FIELD A DELPHI FORECAST OF TRAINING PRIORITIES

\author{
by \\ WILLIAM BOYCE THOMAS \\ MARK L. CLAY
}

A the sis submitted in partial fulfillment of the requirements for the degree of

MASTER OF SOCIAL WORK

Portland State University

1975 
TO THE OFFICE OF GRADUATE STUDIES AND RESEARCH:

The members of the Committee approve the thesis of William Boyce. Thomas and Mark L. Clay presented on May 20, 1975.

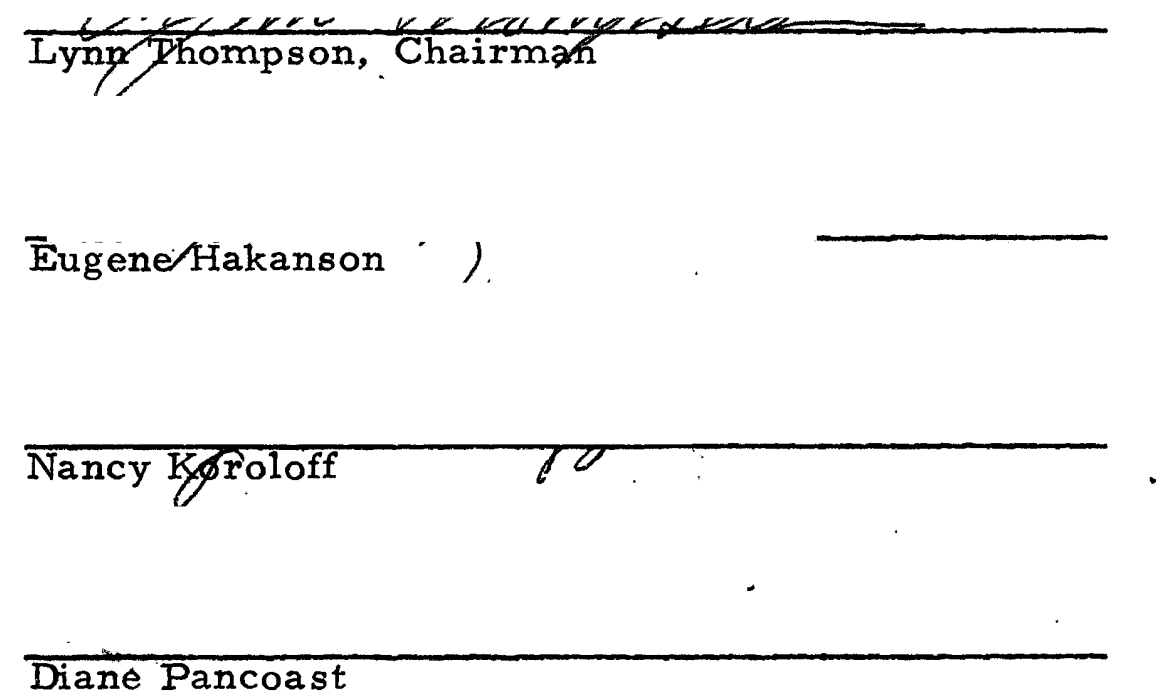

APPROVED:

Gor $\phi$ n Hearn, Dean, School of Social Work

Dafid T. Clark, Dean of Graduate Studies and Research

May 28, 1975 


\section{ACKNOWLEDGEMENTS}

The authors of this thesis would like to express their appreciation to the community mental health practitioners in the state of Oregon who participated in the research study. Without their cooperation and assistance, this thesis would have truly not been possible. We would further like to express our gratitude to Dr. J. D. Bray, Mr. Kenneth Briggs, and Dr. John Estil, of the Oregon Mental Health Division, for the interest they took in this project and the clerical and financial support which they provided through the Division's office of Manpower Development and Utilization. It is our hope that they feel their support was wisely invested. Finally, we would like to express our thanks to Dr. Gordon Hearn, Ms. June Dunn, Ms. Eleanor Koetz, and the faculty of the School of Social Work's Community Mental Health Project for their sponsorship of the research.

An acknowledgements page would be barren without the "thank yous" to friends and family which have real significance to those involved, though they may carry no particular meaning for the casual reader. Consequently, we offer our genuine thanks to the members of our thesis committee for their help, in particular to Mr. Lynn Thompson, who saw us through many struggles in the last fifteen monthis; and to Ms. Nancy Koroloff, who was able to answer so many questions when we often did not know the right question to ask. We thank our wives, Susan Thomas and Judy Clay, for their patience, 
though it occasionally wore thin as the research demanded more of our time. We would like to thank Dr. Norman Wyers, who, as a good friend will, provided support when it was needed. Finally, we would like to thank two people who helped make the thesis a reality; Ms. Jill Wilson, who spent many long hours typing the manuscript and creating a finished product out of a mass of words which often didn't make sense; and Ms. Susan Delos Reyes, who likewise spent many long hours typing, duplicating, and mailing in the early stages of the research, and whose cheerfulness made even the worst times more bearable. Whenever we think back on this experience, we will think of the se people and their unique contributions to it. 
TABLE OF CONTENTS

PAGE

ACKNOW LEDGEMENTS . . . . . . . . . . . . . iii

LIST OF TABLES ................. vii

CHAPTER

I INTRODUCTION ................. 1

II REVIEW OF THE LITERATURE . . . . . . . 3

History and Development of

Community Mental Health......... 3

Development of Community Mental

Health Services in Oregon

Relationship Between Social Workers

and Mental Health Services........

Community Mental Health, Social Work

Manpower, and Social Work Education . . 24

III DESCRIPTION OF THE STUDY . . . . . . 39

Statement of the Research Problem. . . 39

Population . . . . . . . . . . . 42

Selection

Composition

Methodology ...............

The Delphi Technique

Research Design

Research Objectives

Data Collection

Data Analysis 
Instrument Developmen Sampling

Limitations ............... 84

IV RESULTS OF THE STUDY. . . . . . . 87

Round I. . . . . . . . . . . 87

Round II . . . . . . . . . . . . 109

Round III. . . . . . . . . . . . . 114

Social Workers and Non-Social Workers . . 137

Planners, Managers, and Developers . . 160

V SUMMARY AND CONCLUSTONS. . . . . . . 193

Summary of Research Finding.s. . . . . 193

Conclusions ............ 221

Problems Encountered in the Study Discussion of Research Findings Implications for Further Research

SOURCES CONSULTED . . . . . . . . . . . . .

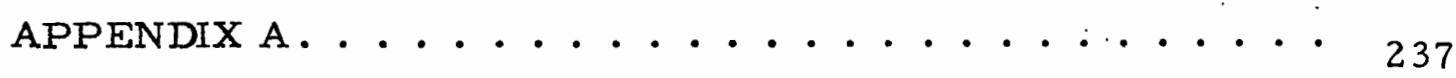

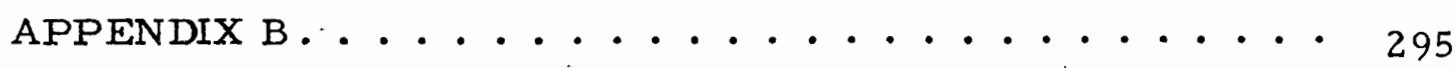




\section{LIST OF TABLES}

TABLE

PAGE

I Comparison of Occupational Groupings and

Professional or Paraprofessional Orientation

in the Population ..............

II Comparison of Target Population Groupings and

Professional or Paraprofessional Orientation

in the Population ..............

III Comparison of Occupational Groupings and Target

Population Groupings in the Population . . . .

IV Characteristics of Respondents on Round II. . . 109-110

V Distribution of Modal Responses on Round III, Frequency and Percentage..........

VI Roles, Functions, and Tasks Questionnaire;

Comparison of Rounds II and III . . . . . . .

VII Skills and Areas of Knowledge Questionnaire;

Comparison of Rounds II and III . . . . . . .

VIII Effect of Fatigue on Round III,

Standard Deviation Totals . . . . . . . .

IX Comparison of Responses of Social Workers and

Non-Social Workers on Rounds II and III .'. .

$\mathrm{X}$ Tenacity Rates of Social Workers and

Non-Social Workers ............

XI Group Judgments of Social Workers and Non-

Social Workers as Compared to Combined

Responses ................... 
XII Comparison of Responses of Planners, Managers, and Developers on Rounds II and III ... . . . 162

XIII Tenacity Rates of Planners, Managers, and Developers......................... 162

XIV Group Judgments of Planners, Managers, and

Developers as Compared to Combined Responses 164

XV Results of Non-Response Bias Questionnaire as

Compared to Results of Complete "Roles,

Functions, and Tasks" Questionnaire...... 


\section{CHAPTER I}

\section{INTRODUCTION}

A pamphlet published by the Southern Regional Education Board (1974a, p. 12) comments that, "Inherent in developing any [training] plan is the need to specify in some way what the social worker in community mental health needs to do, know, and become." The intent of the exploratory research project described in this thesis was to answer some of the questions raised by this need.

What kinds of skills and knowledge will a social worker at the Master's level need in order to practice effectively in the field of community mental health in the future? What tasks will the social worker be required to perform? What are the roles and functions the social worker will carry out? These are questions. which social work educators need to answer in order to develop training programs that will prepare professional social workers to assume responsible positions in community mental health service delivery systems.

In 1974 the Portland State University School of Social Work initiated a special training project that was funded by the National Institute of Mental Health. The purpose of this project was to prepare Master's level social workers for work in community mental health programs. Consequently, the project faculty sought to develop a curriculum which would be responsive to the manpower needs of the community mental health service delivery systems in Oregon. 
The authors of this thesis became interested in the problem of developing and evaluating a viable curriculum for the School of Social Work community mental health training project. Subsequently, they offered to undertake a research project to determine the roles, functions, and tasks which social workers may be performing in the field of community mental health in ten years and the skills and areas of knowledge which they may utilize in this practice. It seemed appropriate to the researchers to generate this data by asking practitioners who were currently active in the field of community mental health to forecast future social work practice and educational needs. On the basis of this forecast, the researchers were able to suggest appropriate priorities for training Master's level social workers who will be involved in community mental health practice in Oregon. This research project is described in the pages which follow. 


\section{CHAPTER II}

\section{REVIEW OF THE LITERATURE}

In order to put this research into proper perspective, the researchers would like to provide the reader with background information on the development of the community mental health movement in the United States, the historical relationship between social workers and mental health services, and some of the current issues involved in social work manpower development and education as they relate to practice in the field of community mental health.

\section{HISTORY AND DEVELOPMENT OF COMMUNITY MENTAL HEALTH}

The official beginning of the national community mental health movement in the United States was marked by the passage of Public Law 88-164, the Community Mental Health Center Construction Act, by the United States Congress on October 31, 1963. The roots of this movement, however, lie in the community-care tradition in colonial America.

In eighteenth and nineteenth century America, the responsibility for the care of the mentally ill rested with the affected individual's family and local community. The facilities which existed for mental

health care were limited to the rich who could afford such care. Those who could not pay faced the alternative of home care, communitysupported boarding homes, poorhouses, or, in many cases, prison. 
In the middle of the nineteenth century, crusading Dorothea Dix started a new tradition in mental health care with the founding of the state-supported mental hospital. The state hospital movement began as a protest against the deplorable conditions of community programs for the mentally ill. Ironically enough, however, by the turn of the century the conditions in most state hospitals had so deteriorated that they were not much better than the earlier community programs which they had been designed to replace.

State hospitals remained the major source of mental health care in this country for the next half century, even though their conditions continued to deteriorate until after the Second World War. Most state hospitals were continually plagued with inadequate financing, overcrowded conditions, and staff insufficient to provide any more than minimal custodial care (Bloom 1973).

In the 1920s an important new approach was introduced in the mental health field with the emergence of the child guidance clinic movement. In 1922 the National Committee of Mental Hygiene established demonstration clinics in a number of cities across the nation. The clinics were staffed by an interdisciplinary team composed of a psychiatrist, a clinical psychologist, and a psychiatric social worker and were seen as a means of preventing mental illness and delinquency through providing for early detection and treatment. The far-reaching significance of the child guidance movement was that it reintroduced the concept of community responsibility for the health and welfare of its members, while adding a new model of preventive mental health to services at the community level. 
The 1930 s saw a new factor emerge in the field of mental health. In this period the Public Works Administration spent $\$ 10$ million in federal aid for the construction of mental hospitals throughout the country. This was the first time that the federal government had become involved in this area, which had been previously left to the states alone. As a result, the precedent was set for increasing federal involvement in the field of mental health during the next four decades. The period of World War II brought about a dramatic development and expansion of mental health services. A nationwide network of psychiatric hospitals and outpatient clinics was set up by the Veterans Administration to treat mental problems among World War II veterans. The development of the se psychiatric services acted as a stimulus to the growth of the professional specialties of psychiatry, clinical psychology, psychiatric social work, and psychiatric nursing.

The 1940s was the beginning of a new era of federal involvement in the area of mental health. The first significant piece of fiederal legislation was the enactment of the National Mental Health Act, Public Law 79-487, in July of 1946. The importance of this legislation lay in the recognition by the federal government of its responsibility for dealing with the problems of mental illness, rather than leaving all responsibility in the hands of state governments. The purpose of the 1946 Act was to provide a method of financing research into the causes and treatment of mental illness, to promote training programs in the treatment of psychiatric disorders, and to assist the state $s$ in establishing community-based mental health services. As can be seen, an emphasis on a community-oriented approach to treatment was 
already emerging.

The 1946 Act created the National Institute- of Mental Health (NIMH) to administer funds and to place staff members in regional offices who could provide leadership and consultation services to states and thereby improve their quality of mental health care. Bloom (1973, p. 8) asserts that, "... during the ten years following its foundation, the National Institute of Mental Health became both the intellectual and financial source for much that was innovative in American mental health training, research, and practice."

Several developments occurred in the 1950 s that were to pave the way for the era of community mental health in the 1960s. First, in the early 1950s, tranquilizing drugs were introduced into the treatment of psychiatric disorders. With the use of the se new drugs, not only was the length of time required to recover from mental disorders reduced, but also many patients were able to be maintained in their own communities by use of these medications at home (Pasamanick, Scarpitti, and Dinitz 1967). Second, in 1955 the Congress enacted legislation enabling NIMH to provide demonstration grants to state hospitals for the purpose of upgrading their the rapeutic programs. Prior to this time, state hospitals had been the least affected by NIMH's input into the mental health system. Third, during the $1950 \mathrm{~s}$ many state hospitals began adopting the concept of geographic decentralization.' Patients were assigned to particular wards according to their home communities. One of the effects of this type of reorganization was to offer treatment, and sometimes discharge, to some of the more chronic patients who had been 
confined to the hospital's "back wards." These wards had functioned primarily as custodial care units. Further, communication links were improved between the hospital staff and community-based agencies. This improved liaison provided a better transition for the patient from hospital to home community. Also, decision making was decentralized to the level of these geographic units, thus replacing the lengthy processing of decisions through the monolithic hierarchy of the state hospital (Bloom 1973). Fourth, starting in the 1950 s state hospital populations began declining. This was due in part to new tranquilizing drugs, improved treatment programs, and decentralization. Even though there was a yearly increase in the number of admissions, there was a corresponding decrease in the length of hospitalization (Bloom 1973). Fifth, during this period Congress responded to the growing pressure for a reassessment of mental health programs in the United States and the growing need for a national mental health program. This response took the form of the 1955 Mental Health Study Act, Public Law 84-182, which set up the Joint Commi ssion on Mental Illness and Health. Congress directed the Commission to analyze and evaluate the needs and resources of the mentally ill in the United States and, most importantly, to make recommendations for a national mental health program (Joint Commission 1961).

The final report of the Joint Commission, which was presented to Congress and President Kennedy in 1961, documented the urgent need for improved mental health services throughout the nation. The Commission recommended that the federal government as sume the 
major proportion of the cost entailed in expanding the inadequate mental health system. According to the Commission (Joint Commission 1961), funds were needed for basic and applied research, manpower training, and expanded services for the mentally ill. The report suggested that expanded services should include one outpatient community mental health center per 50,000 population, inpatient psychiatric units in every general hospital, and conversion of state hospitals into intensive psychiatric treatment centers with no more than a thousand beds. Also required would be improvement and expansion of aftercare, intermediate care, and rehabilitation services, which were sadly lacking in the mental health system as surveyed by the Commission. The report further recommended that funds should be appropriated to expand public programs which could educate the general populace as to the nature of mental illness, and to reduce the public's tendency to reject the emotionally disturbed.

President Kennedy was very receptive to this report. He appointed a task force to study it and to make recommendations for the implementation of a new national mental health program. After careful consideration of these recommendations, the President (Kennedy 1963, p. 1) gave a special message to Congress on February 5, 1963, in which he as serted that "... mental illness and mental retardation are our most critical health problems." This special message was of historic importance, as it was the first time that a President had addressed the Congress on the subject of mental health.

The goal of the President's proposal was to set up mental health centers in every major community so that all Americans would have 
access to high-quality, comprehensive, therapeutic services. The President (Kennedy 1963, pp. 2-3) outlined three objectives in what he called a "bold new approach" to mental health care in the United States. First, "... we must seek out the causes of mental illness and of mental retardation and eradicate them... For prevention is far more desirable for all concerned. It is far more economical, and it is far more likely to be successful." Second, "... we must strengthen the underlying resources of knowledge and, above all, of skilled manpower," and third, "... we must strengthen and improve the programs and facilities serving the mentally ill."

The specific recommendations that the President made to Congress were 1) to authorize grants to the states for the construction of comprehensive mental health centers;2) to set up short-term project grants for the initial staffing costs; and 3) to appropriate funds for planning grants to assist communities in developing a total community plan for mental health prior to construction of new facilities or granting of staffing funds. In addition, the President proposed grants to assist in improving the care in state mental hospitals and to increase funding for research and training programs.

Congress responded quickly to President Kennedy's challenge that the problems of mental illness at the community level be attacked on a nationwide scale. The Community Mental Health Centers Act of 1963 authorized $\$ 50$ million, which was to be spent over a three-year period for grants to construct public and voluntary non-profit community mental health centers. Subsequent amendments authorized additional money to extend the program, to establish grants for the 
initial staffing of centers, and to add provisions for special programs for children, drug addicts, and alcoholics.

The Director of the National Institute of Mental Health (Yolles 1968), which was responsible for administering the 1963 Act, has pointed out that the goals of the Act were to learn to prevent mental illness, to promote positive mental health, and to provide a continuity of care for those who are already emotionally disturbed. He added that, central to the entire national mental health concept, was the premise that treatment is best provided within the patient's home community. The purpose of the Act, according to Yolles; was to provide community-based mental health services as an alternative to the institutionalization of persons in large state hospitals.

The 1963 Act required that, in order to receive federal funds, a community mental health center must offer five basic service components within its catchment area: inpatient care; outpatient care; partial hospitalization càre; emergency services; and consultation and education services. Every state was subsequently subdivided into a group of catchment areas, each with a population of 75,000 to 200,000 . In addition to the five mandated services, it was expected that eventually five other services would be provided by each center: diagnostic services; rehabilitation services; precare and aftercare services; training; and research and evaluation. These services were to be readily available to all persons living within the catchment area, regardless of ability to pay. The intent of the wide range of required services was to ensure continuity of care. This allowed the patient to transfer easily between services and yet maintain a continuity of 
relationship with the primary therapist. These facilities were also to act as a resource for other agencies serving the community.

Bloom (1973, pp. I-2) has pointed out the following characteristics as distinguishing community mental health practice from traditional clinically-oriented practice. First, it emphasizes practice in the community, rather than in institutional settings. Second, it focuses on the total community, rather than on the patient only. Third, it emphasizes preventive services in coordination with therapeutic services. Fourth, it emphasizes services such as consultation and education, rather than direct services alone. Fifth, it utilizes innovative clinical strategies, such as crisis intervention, to reach larger numbers of people in times of need. Sixth, it emphasizes rational planning in making decisions about mental health programs. This planning takes into consideration demographic analyses of the catchment area, unmet mental health needs, and the identification of high-risk sub-populations within the area. Further, this planning seeks to coordinate the mental health services and to establish priorities within the community for dealing with problems directly or indirectly related to mental illness. Seventh, community mental health practice emphasizes the identification of stress points within the community, instead of assuming that the sources of psychopathology rest solely within the identified patient. Eighth, it utilizes innovative new sources of manpower, such as "paraprofessionals" and "indigenous non-professionals." Ninth and finally this practice is committed to community control, which means that staff and representatives of the community work together to identify needs, 
propose and evaluate programs to meet these needs, and to plan for future program developments.

To date there are 515 community mental health centers across the nation. This number is far short of the Congressional goal of 1500 centers During the Democratic administrations of the 1960s, there was a rapid expansion of centers. However, policies of the Republican administrations of the 1970s have slowed the development of new facilities. Many of the funds slated for center construction have been diverted by the administration to finance staffing in centers already built.

Recent White House policy has been to phase out federal support for community mental health and to shift the responsibility for funding to the state and local mental health delivery systems. Federal attention in the current decade has been turning to more general health issues, of which mental health is only one part. How mental health will fit into a total health care service delivery system, organized and financed on a national scale, remains unclear. I

[At the state and local level, the key is sue for community mental health programs in this decade has been accountability. Community mental health centers have been faced with the problem of demonstrating their effectiveness to legislative bodies. In order to compete with other publically supported programs for limited funds, it has become increasingly necessary for these programs to statistically demonstrate their viability and degree of success in meeting mental health needs. 


\section{Development of Community Mental Health Services in Oregon}

Oregon's first mental health program began in 1883 with the opening of Oregon State Hospital in Salem. In 1908 Fairview Home was established as a separate institution for the mentally retarded. Eastern Oregon State Hospital was established in 1913 to offer a mental health program to the eastern part of the state. The two remaining state hospitals were not established until much later. Thus, Dammasch State Hospital in Wil sonville was opened in 1961 to serve the Portland tri-county area, while Columbia Park. Hospital and Training Center at The Dalles was converted from a tuberculosis hospital in 1959 to provide long-term care for the adult mentally retarded.

Two national trends in mental health were reflected in Oregon's state mental hospitals during the late 1950 s and the early 1960 s. First, there was a consistent decrease in the overall hospital populations. Oregon's mental hospitals experienced a peak population in 1958 with 5,065 patients (Mental Health Planning Board 1965). Since that time, the population has been decreasing dramatically. despite the increase in admissions. No doubt this reversal can be attributed, in large part, to the introduction of the new tranquilizing drugs during this period.

The second national trend seen in Oregon's state hospital system was that of decentralization. In the early 1960s, an effort was made to decentralize the state hospitals by relating the hospitals to specific geographic areas serving a discrete population. Accordingly, Dammasch State Hospital was established to service the greater 
Portland metropolitan area; Oregon State in Salem, the western part of the state; and Eastern Oregon in Pendleton, the eastern part of the state.

Until the $1930 \mathrm{~s}$, state hospitals were the only public resource in Oregon for the treatment of mental illness. Community-based services for mental health problems had their beginning in 1932 when the first child guidance clinic was established at the University of Oregon Medical School. Traveling clinics were set up to provide services to various parts of the state.

The enactment of the 1946 Mental Health Act which provided grant-in-aid money to states for establishing community-based mental health services, resulted in the availability of federal aid to Oregon in 1947. At this time, the child guidance services provided by the Medical School were transferred to the administration of the Oregon State Board of Health. In 1953 the traveling clinjcs were discontinued, and a program was initiated to develop child guidance clinics were established (Mental Health Planning Board 1965).

Responsibility for mental health services continued under the State Board of Health until July 1, 1962, when the Mental Health Division was created by the Oregon Legislature. The Mental Health Division was charged with the responsibility for developing a coordinated state mental health program, supervising the state hospital mental health services, and assisting counties in establishing local mental health services.

At the time the Mental Health Division was formed, there were only eight small community mental health clinics serving eleven 
Oregon counties. With the growth of the community mental health movement in Oregon, that number expanded to the present level of 32 locally-administered clinics serving all of Oregon's 36 counties. These programs have been funded through a state-county partnership in which 50 percent of their budget comes from the state and 50 percent from the counties.

In 1968 Lane County developed a Comprehensive Community Mental Health Center. This was financed under the 1963 Federal Community Mental Health Center Act with additional state and local financing. The Center provides the five federally mandated services; that is, inpatient, outpatient, day treatment, 24-hour emergency services, and consultation and education services; and is governed by an administrative board representing the community. This board monitors the Center's compliance with federal requirements (Bray 1973).

In 1972 the Eastern Oregon Community Mental Health Center was established under a federal Community Mental Health Center staffing grant, supplemented by state and local funds. The Center's catchment area includes the thirteen counties in eastern Oregon. All of the federally mandated services are provided, plus in-service training for the staff. Based in Pendleton is a core team which administers the Center and offers consultation, education, and program evaluation services to the six local mental health clinics circumscribed within the catchment area. Improved services at Eastern Oregon Hospital and Training Center are another phase of the Center's operation (Bray 1973). 
In an effort to develop a comprehensive state system for the coordinated delivery of mental health services in Oregon, the Mental Health Division was reorganized in 1973. The reorganization of the Division brought together all of the community mental health clinics, contract programs, and state hospitals under the direction of three regional offices. These regions coincide with the catchment areas of the three state hospitals for the mentally ill. Region I is the tri-county area of Portland. Region II includes the coast and the central valley. Region III is comprised of the thirteen eastern counties of Oregon.

Currently, Regional Directors are responsible for all the mental health services provided in their respective regions. Thus, the Superintendents of state hospitals for the mentally ill and mentally retarded report to the Director of the region in which they are located. The community clinics, child study and treatment centers, community services for the mentally retarded and developmentally disabled, alcohol and drug services, and community mental health centers, which contract with the Mental Health Division, are also accountable to these Directors. In turn, it is the responsibility of the Regional Director and his staff to assure coordination of services and continuity of care between state hospitals and the various community programs under.his jurisdiction.

The responsibility for planning and evaluating all mental health programs in the state currently resides with three Program Directors at the Division level in Salem. The three program areas are concerned with the care and treatment of 1) the mentally. and emotionally disturbed; 2) the mentally retarded and developmentally 
disabled; and 3) those with alcohol and drug problems. Since August of 1974, the program office for mentally and emotionally disturbed has also included a child study and treatment section which handles statewide planning for the six children's residential and day treatment centers which contract with the Division.

The three Program Directors have no direct responsibility for provision of services, which is the Regional Directors' concern. The Regional Directors act to implement the programs developed by the Program Directors in accordance with the standards set by them. It is the Regional Director's duty to relay the needs of local areas and the results of local planning to the Program Directors for consideration.

One of the features of the current organizational structure of the Mental Health Division is the state-local partnership for funding. This offers a high degree of local autonomy and ensures that community needs are incorporated into state plans. At the same time, the Division is able to ensure that plans are developed and carried out in an integrated manner in accordance with a comprehensive state plan. The Division also acts as a check on program quality and fiscal a ccountability.

Lastly, key decisions and policy matters are currently dealt with at the Division level by the Executive Council. The Council, which meets weekly, is composed of the Mental Health Division Administrator, the three Program Directors, the three Regional Directors, and the Director of Administrative Services. The ultimate responsibility for all decisions rests with the Division.Administrator. 


\section{RELATIONSHIP BETWEEN SOCIAL WORKERS AND MENTAL HEALTH SERVICES}

The relationship between social workers and mental health services began in the early 1900s. Social workers were employed as early as 1905 by neurological clinics in New York City and in Boston's Massachusetts General Ho spital (Woodward 1960). In the following years, state hospitals established social service departments. The social worker's position at this time was that of an ancillary to the medical doctor or psychiatrist, and their activities centered around resource mobilization for mental patients and their families. In the child guidance clinic movement of the 1920 s, social workers developed a new relationship to mental health services as members of a clinical team comprised of a psychiatrist, a psychologist, and a social worker. Each member of the team had clearly defined duties. The psychiatrist was responsible for treatment; the psychologist, testing; the social worker, intake and community liaison. The duties of the social, worker included explaining the program to patient and family, gathering a social history, and acting as a bridge between the clinic, the family, and the community:

As child guidance clinics further developed their organizational structure, social workers expanded their activities to include the organizational tasks of the clinics, particularly supervision, and, to a more limited extent, training and administration. Until World War II, however, the child guidance clinic movement represented only a small part of the mental health movement. Thus, during this period, the 
function of the social worker within the overall mental health delivery system could be considered as primarily that of service provision in an ancillary relationship to psychiatry (Clark 1966; Woodward 1960).

During the World War II era, there was a dramatic expansion of mental health services, especially by the Veterans Administration, to meet the needs of returning veterans. With the increased manpower demand, social workers became involved for the first time with treatment under the supervision of a psychiatrist (Krugman 1952; Woodward 1960). Social workers also moved more into admini strative positions. As Woodward (1960) pointed out, while social workers were administratively responsible to the psychiatrist, in practice, within the Veterans Administration structure, social workers often organized and operated the clinics.

As the demand for psychiatric services increased in the post-war years, there was also an expansion of mental health clinics in the public sector, many of which patterned themselves after the Veterans Administration model. Social workers responded to the manpower shortage in the public sector by filling positions in both mental health clinics and psychiatric hospitals.

A 1947 study (Krugman 1952) of 327 mental health settings revealed the new roles social workers were playing in mental heal th delivery systems. The study showed that in 55 percent of the settings, social workers shared treatment responsibilities with the psychologist and the psychiatrist. There was also.evidence that social workers were engaged in administration, supervision, training, and consultation. However, in 80 percent of the settings, psychiatrists were the 
Directors, while social workers were Directors in only 4 percent of the settings. Further, a major trend in the late 1940 s and $1950 \mathrm{~s}$ was for social workers to engage in private practice, either directly under the supervision of a psychiatrist, or with access to a psychiatrist for medical consultation (Woodward 1960). Beginning in the 1950 s and expanding in the $1960 \mathrm{~s}$, social workers became increasingly involved in consultation activities for schools and other community angencies (Rosenblum 1968; Caplan 1971). A 1962 report (Rice 1962) on the educational qualifications for social workers emphasized the increasing use of consultation, along with other indirect services. The report listed seven activities of social workers in community health and mental health programs, 1) social work consultation; 2) program planning, implementation, and policy formation, including primary administrative responsibilities in mental health agencies; 3) casework to individuals and families; 4) group work; 5) services to communities; 6) research; and 7) educational supervision. As indicated by the report, social workers were still involved in direct services, but they were also expanding their involvement in indirect, facilitative activities.

With the rapid expansion and development of the community mental health centers program in the 1960 s, social workers became increasingly in demand to provide outpatient treatment and consultation services as mandated by the federal 1963 Community Mental Health Center Act. But as indicated by earlier trends, social workers also became involved in the planning, administration, and development of community mental health center programs. This trend was 
strengthened by the manpower deficiencies in the professional fields in the $1960 \mathrm{~s}$. The shortage in available personnel enabled social workers to fill some of the gaps in leadership traditionally provided by psychiatrists and, to a lesser extent, by psychologists.

A 1968 study (Spray 1968) of mental health practitioners provided evidence concerning social workers'increasing performance of indirect service activities related to mental health organizations. The study further made a clear distinction between the social workers' position in the public sector as opposed to the private sector. Social workers in private settings provided treatment as their primary activity. Social workers in public settings provided treatment as a secondary activity to their primary involvement in program planning, administration, supervision, training, and consultation.

During the $1960 \mathrm{~s}$, in both community mental health centers and state hospitals, a new practice trend developed among social workers, due to the manpower squeeze. One answer to this shortage was to sidestep the tradition that only professionally-trained social workers with a Master of Social Work degree could assume positions in the mental health field. This was done by employing workers trained only at the Bachelor degree level in direct service positions. The effect of this trend was to push the professionally-trained social worker into supervisory and training positions for the paraprofessionals. It also freed other professionals to move into administrative and planning positions within the community mental health service delivery systems. Barker and Briggs (1968) pointed out that studies demonstrate that there has been no drop in the quality of service when paraprofessionals 
and professionals work together. This has been especially true when paraprofessionals have had good undergraduate preparation, or when there has been an adequate inservice training program.

The utilization of paraprofessional workers in mental health was not limited to those at the Bachelor degree level. Starting in the mid1960 s and continuing into the $1970 \mathrm{~s}$, community colleges, supported by funds from the National Institute of Mental Health, developed programs to offer an Associate of Arts degree in mental health (Teare and McPheeters 1972). There was also the phenomenon of the "indigenous practitioner"! who may have had no specific educational background, but through experience or natural ability is effective in working with patients.

The trend of social workers becoming increasingly involved in indirect service positions continued in the 1970s. However, this was true only of the professional level social workers, as paraprofessionals continued to be primarily involved in direct services. A 1972 study (Barker 1972) suggested that M.S.W. social workers were more involved in directing rather than providing service, while B. A. social workers were more likely to be providing direct services under the supervision of a M.S.W. social worker.

Briggs (1973, p. 28) has contended that during the 1970 s, "The graduate-trained social worker will become a middle manager, team leader, supervisor, or staff developer, or a high-level specialistconsultant-planner in social problem areas (e.g., aging, family integrity, or mental health). " This projection is substantiated by a 1973 Canadian survey (Kadushin 1974) of M.S.W. social workers, 
which revealed that over half were employed in admini strative, supervisory, consultative, or other non-direct service positions. It might be said that, due to the community mental health movement, social workers came of age as autonomous professionals in the mental health field. In a 1957 study of role relations in mental health professions (Zander, Cohen, and Statland 1957), it was noted that even though social workers wanted more responsibility in mental health services, they readily accepted their status as an ancillary group to psychiatry. In contrast, Mueller and James (1972, p. 179), in their 1968 study of social workers in mental health services, reported that Master's level social workers "... assumed a degree of autonomy in making professional decisions, "and that "... they tended more clearly to reject (in contrast to Zander's finding) psychiatric domination in the mental health field." 


\section{COMMUNITY MENTAL HEALTH, SOCIAL WORK MANPOWER, AND SOCIAL WORK EDUCATION}

There is extensive literature available on community mental health practice and considerable literature which addresses issues of social work manpower and social work education. To this date, however, not a great deal has been written which focuses on the intersection of these two areas of concern; that is, on the relationship of social work practice in the field of community mental health and social work education designed to meet the manpower needs of this field. The researchers found, however, that much of the general literature concerned with manpower and education was quite relevant to a consideration of this relationship. Their review of this material subsequently led them to nine is sues which seemed to have implications for the development of social work training programs in the field of community mental health.

\section{Role Diffusion and Professional Differentiation} in Community Mental Health

There is evidence (Rosenblum and Hassol 1968; Gottesfeld 1972) that practice in the field of community mental health has resulted in a blurring of professional distinctions and a diffusion of practice roles between the traditional mental heal th professions. In some areas of the country (Santa Clara County 1974), for example, systems of generic job classifications such as Community Mental Health Worker I-IV are being proposed as alternatives to classification systems 
based on professional identifications such as Social Worker I-IV. In response to these trends, a few generic training programs in community mental health (e.g. , Powell 1969) have been developed. Some authors (Henry, Sims, and Spray 1971; Pattison and Elpers 1972; Hilgard and Riecken 1970) have, as a result, concluded that traditional professional distinctions will disappear altogether and that a fifth generic mental health profession should and/or will emerge. These predictions, however, have not yet been borne out by any major changes in the patterns of manpower development for this field, except at the paraprofessional Associate of Arts level (Dangerfield 1975).

It could be argued that the se conclusions have not been substantiated because they do not take into account the vested interests of the professions in continuing existing professional differentiations between psychiatry, psychology, social work, and nursing. Such differentiations maintain the long-standing patterns of hierarchical authority, status, and rewards within the field of mental health (Zander, Cohen, and Statland 1957; Barker and Briggs 1968; Pattison and Elpers 1972). This professional hierarchy appears (Spray 1968), in fact, to have been strengthened rather than weakened by the community mental health movement, presumably because of the dependence of this movement on psychotropic medications which, currently, oṇly physicians can prescribe.

On the basis of this argument, the researchers concluded that training for professional practice in the field of community mental 1 health will continue, to be based on existing professional differentiations 
for some time to come, regardless of role diffusion and other practice trends.

\section{Manpower Trends and the Social Work Profession}

There has been a tremendous infusion of paraprofessional and non-professional practitioners in all social welfare fields in the last fifteen years (Teare and McPheeters 1970, p. 2): This paraprofessional explosion has been a product not only of the expansion of social services, but of changes in manpower utilization (Pins 1971), and the increasing cost of social work professionals (Pattison and Elpers 1972) as well. The trend has been particularly true in the field of community mental health (Levenson and Reff 1970). One concrete result (Kadushin 1974) of this explosion has been recognition of the Bachelor's level degree in social work as a professional degree for entry level positions by both the National Association of Social Workers (NASW) and the Council on Social Work Education (CSW E).

Evidence in the community mental health field (Gottesfeld, Rhee, and Parker 1970; Mueller and James 1972), and in other fields of social welfare (Kadushin 1974), strongly suggests that Bachelor's level social workers, as well as paraprofessionals, perform significantly different activities than Master's level social workers. The former appear to be more involved in providing services, and the latter appear to be more involved in directing services (Barker 1972, p. 92). Further, despite increasing interest (Siporin 1973) in the Doctorate as a social work practice degree, the emphasis of most Doctoral programs in social work continues to be on teaching and research and, consequently, most social workers possessing 
Doctorates are found in these activities (Lowenberg 1972a). A result of the differing practice demands placed on social work professionals at the three degree levels has been that social work training at the se levels has been qualitatively, as well as quantitatively, different (Reichert 1970; Schoor 1971; Ripple 1974).

On the basis of theise manpower and education trends, the researchers concluded that the activities of social workers will continue to differ with degree level and that, as a consequence, professional social work training at different degree levels will continue to be qualitatively different.

Social Work Education and Community Mental Health

Until 1969 (Pins 1971), the key organizing principle of social work' education programs was the method of service delivery which would be employed by the social worker. Initially, this consisted only of casework; later groupwork was added, and by 1962 community organizing was recognized as the third practice method. By 1971 (Gurin 1973, p. 186), this organizing framework was no longer the dominant model. The organization of social work education programs by fields of social welfare (e.g., health, employment, corrections, mental health) or by practice function (e.g., service delivery; supervision and management of services; planning and development of services) appeared to be gaining increasing popularity as alternatives to the traditional approach (Ripple 1970; Main 1971).

The field of practice approach to organizing social work education assumes that the knowledge ba se and experiential components of practice differ from one field of social welfare to another. Many 
social work training programs (CSWE 1974; e.g., Dunn 1974) have been developed in the last several years, with funding from the National Institute of Mental Health (Parad and Rapoport 1972), that have attempted to utilize this field of practice approach with community mental health. These programs have been developed on the assumption (Powell and Riley 1970; Wittman 1972) that knowledge and practice in this field are, in fact, somehow different from knowledge and practice in other fields. How to best define and operationalize this uniqueness is still, however, a subject of much debate in social work and one in need of research (SREB 1974a, b).

On the basis of these trends, the researchers concluded that specialized training programs in the community mental health practice field will continue to be an integral part of social work education in the foreseeable future.

Social Work Education and Social Work Practice

According to Glick and Clinch (1974, p. 1), professional education is "... by definition, preparation for practice." Yet, as Glick (1975b, p. 1) has further indicated, "[Social work] practice and education in the past have had nothing to systematically bring them together." This has been an issue, both at the physical level (Pins 1971 ) in terms of contact and communication between social work educators and practitioners, and at the conceptual level (Dolgoff 1974) in terms of how practice and education are understood and approached. Thus; social welfare is often (Gurin 1973, p. 183; Teare and McPheeters 1970) analyzed in terms of the concepts "of "roles," "functions," and "tasks" performed by the practitioner, while social 
work education is most often (Lowenberg and Dolgoff 1971) thought of in terms of the concepts of "skill" development and growth in "knowledge."

Many authors (Glick 1975b; Arkava and Brennen 1974; SREB 1974a) have suggested that the lack of congruence between social work education and social work practice has had detrimental effects on the development and effectiveness of the profession as a whole. It has been argued (Dolgoff 1974) that this lack of congruence will continue to affect the profession detrimentally unless social work educators, on their part, seek to both increase communication with the practice community and to more effectively integrate practice concepts and educational concepts in designing social work training programs.

On the basis of this argument, the researchers concluded that training programs in the field of community mental health, in order to bridge the gap between education and practice, need to address professional practice in the field in terms of the following five areas of concern:

a) Roles which social workers need to be prepared to assume in the field;

b) Functions within the service delivery systems of the field which social workers need to be prepared to carry out;

c) Tasks which social workers need to be prepared to perform in the field;

d) Skills (including service delivery methods) which social workers need to be prepared to utilize in this practice;

e) Areas of knowledge which social workers need to be prepared to apply in this practice. 
Social Work Education and the Future

It has been suggested that one of the detrimental effects of the incongruence between social work education and practice is that professionals-to-be often receive training that is preparation for practice as it was years before the student entered school. Thus, one social worker (SREB 1974a, p. 2) asserted that "...much social work education today is turning its students into living anachronisms...." Keeping pace with changes in practice is, of course, problematic for training programs in any profession, but this problem seems to be particularly acute in social work (Gurin 1973, pp. 169, 187).

This situation is compounded in the field of community mental health because a considerable lag exists between the time when all mental health professionals begin training and when they are judged by the professions to achieve professional autonomy. This period (Heck, Gomez, and Adams 1973) ranges from four years for the ACSW Certified social worker to nine years for the Board Certified psychiatrist. Thus, even a social work training program which is designed for the demands of practice in the field at the time the practitioner begins training will, at best, prepare the autonomous professional to cope with the demands of the field as they were four years in the past.

One alternative to the existing situation would be to design training programs that are focused on the projected demands of social work practice in the future. Andrew (1974, p. 3) described this alternative model, in an article entitled "Forecasting Social Work Practice as a Base for Curriculum Development," as follows: 
Ideally, a school of social work should establish a sound basis for identifying possible directions of practice in the future, for discriminating among these to select the most probable directions, and a program of research to test the techniques these probable directions suggest for practice. The results of that process should then be translated into the curriculum, which means that curriculum planning would always be ahead of that which is currently being taught in the classroom and in field practice. Transformation of the planning into present educational content would occur systematically around a well-worked-out, organizing rationale provided by the outcome of the developmental program.

Such programs would presumably have a higher likelihood of preparing social workers for the actual practice demands of a field of social welfare in the future, perhaps even beyond the time when professional autonomy is achieved. Moreover, such training would have a higher probability of preparing the practitioner to actually help shape the future of practice in such fields as community mental health (SREB 1974b, p. 1). Developing an ability to challenge present concepts and to help shape practice would seem to be a genuine exercise of the responsibility of social work education to train practitioners for professional leadership (Schoor 1971; SREB 1975a, p. 8; Dolgoff 1974, pp. 19-20).

The concept of training the future-oriented practitioner has been (Longres 1973) described as preparing the functionally-disfunctional professional. This position would seem to receive support as an appropriate alternative to present-or past-oriented training from authors (Toffler 1970; Kahn 1973) who point to the rapid changes in society in general, and the resulting rapid changes which are necessitated in the character of social work practice. Some authors (Grosser 1973; Specht 1972) have even gone further to. suggest, 
directly or indirectly, that social work as a profession may disappear altogether if it does not become relevant to the demands of the future. Thus, preparing social workers for practice in the future is advocated as a critical necessity for the profession's very survival.

Fellin (1974, p. 27), in examining the implications of futureoriented planning for social work education, has concluded that such long-range planning is both "... possible and desirable for social work education, and will facilitate and improve educational decision making." This author (Fellin 1974, p. 33) further points out that "... because it requires inputs from the field of practice, the longrange planning process can serve as a primary link between the professional school and the social work profession.

On the basis of these arguments, the researchers concluded that it is not only possible, but becoming increasingly important, to develop future-oriented social work training programs in community mental health.

Competency-Based Social Work Education

The adoption of a competency-based educational system by social work has been proposed (Glick 1975a) as one alternative to the existing dilemma of the separation of education and practice. Glick (1975b, p. 3) suggests that

The starting point for competency-based education is the discipline or profession rather than the teacher or the educational institution itself. In the case of social work, it is clear that [practitioners] and/or the professional organization, in collaboration with schools, must articulate the competencies which are necessary [for practice]...

This approach to articulating competencies on the basis of practice 
seems particularly appropriate to community mental health as a field of practice. Bandler (1972, p. 7), for example, states that "In the health and mental health service delivery fields, the questions most insistently asked are: What is the nature and order of tasks...? What knowledge, skills, and attitudes are necessary to perform these tasks?"

The articulation of competencies necessary for social work practice in community mental health is complicated by the fact that practice in this field is not the exclusive province of social workers, but of professionals and paraprofessionals from disciplines such as medicine, nursing, psychology, and education as well. Evidence (Rushing 1964; Mueller and James 1972) indicates that practitioners with these orientations not only have strong opinions about the practice of social workers in the field, but al so considerable influence in shaping the character of that practice.

On the basis of these arguments, the researchers concluded that the development of future-oriented, competency-based social work training programs in community mental health requires the articulation of competencies necessary for practice by practitioners who are active in this field with both social work and non-social work orientations.

\section{Social Work Practice and the Future}

Projections in the literature (Pattison and Elpers 1972; Teare and McPheeters 1972) about future professional practice in the field of community mental health have suggested that significant changes will be occurring in the character of social work practice in this field. 
Wittman (SREB 1974a, pp. 1-2) has emphasized the increasing demand for social workers who can participate in macro as well as micro systems, for social workers who not only know treatment but who can also get involved in community organizations and planning in this field. More generally, Briggs (1973, p. 28) has suggested that during the $1970 \mathrm{~s}, "$ "...the graduate-trained social worker will become a middle manager, team leader, supervisor or staff developer, or a high-level specialist-consultant-planner in social problem areas." Recent trends reflecting increased employment of Master's level social workers in administrative, supervisory, consultative, and other non-direct or indirect service positions have been pointed to (Kadushin 1974; SREB 1974a, p. ii) as evidence supporting these latter projections.

These forecasts about future social work practice were quite thought provoking because they suggested significant changes in the utilization of social work manpower in the field of community mental health. They were, however, quite general and suggested only broad trends in social work practice. They did not provide the specific data which would be needed to develop competency-based social work training programs. For that matter, the character of present social work practice in the field of community mental health has not yet been clearly delineated with the specificity required to bridge the gap in the present between education and practice (SREB 1974a), though the work of Teare and McPheeters (1969, 1970, 1972) for the Southern Regional Education Board has provided the closest approximation to such a comprehensive approach (see aḷ so Federico 1973, pp. 143-156). 
The researchers consequently concluded that while the present character of social work practice in community mental health is likely to be changing in the near future, there is presently insufficient information to predict the likely directions of that change with the specificity and comprehensiveness needed to develop future-oriented, competency-based training programs for the field.

\section{The Generalizing Core of Social Work Practice and Education}

The concern expressed by the Southern Regional Education Board in the opening lines of this thesis has been shared by many writers and researchers (Greenwood 1957; Arkava 1967; Richan 1973) who have attempted in the last half century to determine the boundaries of what social workers do, know, and are in order to justify the existence of social work as a profession. One course this effort has taken has been an attempt to identify activities which constitute the core of professional social work practice. Thus, Pincus and Minahan (1973, p. xi) state in the development of their model of practice that

A basic assumption... was that regardless of the many forms social practice can take, there is a common core of concepts, skills, tasks, and activities which are essential to the practice of social work and represent a base from which the practitioner can build.... Such a framework should reflect and readily make apparent the essential unity and cohesiveness of the profession and provide the basis for a professional identity for those who practice social work.

This has been referred to (st. George-Henry 1974) as the generic approach to social work practice.

Social work educational programs (Ripple 1974, pp. 39-41; e.g. , PSU School of Social Work 1974) have, as a result of these trends, often required a core of academic and field experiences for all students 
in order to develop skills and knowledge that will provide a common foundation for autonomous social work practice. These core educational experiences have been generally built around some concept of the current or future core of social work practice. Within such a framework, training programs for specialization in a field of social welfare would presumably reflect not only this generalizing core of social work practice and education, but also the knowledge and practice components which may be idiosyncratic to that particular field.

On the basis of these concepts, the researchers concluded that it should be possible to identify the elements of a generalizing core of social work practice and education in the field of community mental health, a core which could serve as the framework for developing competency-based training programs for the field.

\section{Training Priorities and the Generalizing Core}

The Master's degree has historically been the practice degree for social workers (Siporin 1973). The general absence of Bachelor's level programs in social work until recent years thus necessitated the provision of all training for professional practice within a two-year period. This was very little time to prepare and socialize professionals and, consequently, graduating social workers were seen (Boehm 1971) as beginners who learned their trade in the first two years of work and who required several more years of direct service practice to become an administrator or policy planner. In order to provide the additional training needed for supervisory and administrative positions, and specialization in fields such as public health (Rice 1962), "third 
year" post-Master's programs were often developed.

The recent widespread growth in Bachelor's level programs has sharpened a long-standing debate (Main 1971) as to whether the Master's degree should be a beginning practice degree or an advanced practice degree. The present trend (Gurin 1973, p. 194) is moving toward specialized practice at the Master's level. In many schools (Lowenberg 1972, p. 31 ), this process of redefinition has resulted in àn "...emphasis on training Master's degree students for middle level management and supervisory and administrative positions. "It has even brought forth proposals (Bisno I974) that the Master's degree should be virtually eliminated and, as with other mental health professions, the Doctorate degree considered the terminal practice degree in social work.

As a result of these trends, Master's degree programs are now caught in a transitionary period between training for beginning practice and training for advanced or specialized practice, at a time when their very usefulness is being seriously challenged. During this period, beginning practitioners at the Master's level will presumably need to be trained in those competencies which will be most fundamental to social work practice and thus most basic to the generalizing core of practice and education. For advanced practitioners at this level, on the other hand, additional emphasis would need to be placed on preparation for the competencies characterized by all the activities, skills, and knowledge which define this generalizing core. Specialization in a particular field of social welfare practice would similarly require differentiated training priorities within the components of the 
generalizing core for that particular field.

On the basis of this argument, the researchers concluded that those elements of the future generalizing core of social work education and practice in community mental health which would be considered the highest priorities for training beginning Master's degree candidates specializing in this field of practice. It was further concluded that the competencies characterized by all other activities, skills, and knowledge which define this generalizing core could be further grouped into priority clusters for training more'advanced candidates, depending on previous experience, skills, and knowledge associated with higher priority competencies. 


\section{CHAPTER III}

\section{DESCRIPTION OF THE STUDY}

\section{STATEMENT OF THE RESEARCH PROBLEM}

The problem addressed by this research study was the need to determine appropriate priorities for training Master's level social workers who will be involved in the field of community mental health in Oregon. These priorities were to be determined on the basis of a forecast of the future professional practice of social workers in this field, both in terms of the roles, functions, and tasks which they are likely to be performing in ten years, and in terms of the skills and areas of knowledge which they are likely to be utilizing in this practice. The parameters of this research problem were established by five conclusions of the researchers that resulted from the preceding review of the literature.

\section{Conclusion I: Role Diffusion and Professional Differentiation}

It was concluded that social workers will continue to constitute a distinguishable professional group within community mental health delivery systems. Therefore, it was decided that research in the area of training for this field would need to focus on professional rather than "generic" identifications; that is, on the social work practitioner rather than on the community mental health practitioner. 
Conclusion II: Manpower Trends and the Social Work Profession

It was concluded that the professional practice and professional training of social workers possessing a Master's degree is distinguishable from the practice and training of social workers with other than a Master's degree. Thus, as Bandler (1972, p. 7) suggests, research in the area of social work training would need to address each degree level separately. As a Bachelor's level program will not be formally started at the PSU School of Social Work until fall 1975, and as there is no Doctorate program, an attempt to conduct a comparative study of training priorities for the different degree levels, while desirable, would present practical difficulties well beyond the scope of a Master's thesis. Therefore, it was decided that the focus of the research would need to be limited to the professional practice and training of Master's level social workers, as distinguished from non-Master's level social workers.

Conclusion III: Social Work Education and Community Mental Health

It was concluded that training for professional practice in the field of community mental health can be treated as a viable specialization within social work education. Therefore, it was decided that the focus of the research could be limited to training for social work practice in community mental health alone, exclusive of social work practice in other fields of social welfare.

\section{Conclusion IV: Social Work Education and Social Work Practice}

It was concluded that social work training programs need to develop greater integration between traditional educational concepts 
and actual social work practice. It was therefore decided that the research would need to be operationalized through exploring both the professional practice and educational needs of Master's level social workers in the field of community mental health, in terms of the roles, functions, and tasks which they perform in this field, and the skills and areas of knowledge which they utilize in this practice.

Conclusion V: Social Work Education and the Future

It was concluded that preparing social workers for professional practice as it is likely to be in the future is a critical function of social work education. It was therefore decided that the research would need to be operationalized through forecasting the character of the future practice of Master's level social workers in this field.

Ten years was chosen as an arbitrary point of projection in the belief that it was far enough away to encourage creative speculation about the future, yet near enough to be within the planning horizon of most people. This latter concern was related to a desire to reduce the impact of the general tendency to apply a "discount rate" to the future (Linstone 1973). This discounting phenomenon is explained as an inverse relationship between the separation in time and space of an observer from an occurrence and the perceived importance of that occurrence. It was also believed that a time framework of ten years would be appropriate for generating forecasts which could facilitate the development of future-oriented, competency-based social work training programs for this field that would have applicability for at least several years. 


\section{POPULATION}

Selection of the Population

The population which was selected to address the research problem under study was composed of 160 community mental health practitioners of both social work and non-social work orientations. Collectively, these practitioners were involved in service delivery systems for all major target populations of the public sector of Oregon's community mental health movement. Members of the population were purposefully chosen on the basis of their current position in these systems, with a greater emphasis placed on practitioners involved in planning, managing, and coordinating services, rather than on those involved in actually providing services. The selection of this population was based on five assumptions, two of which were based on the preceding review of the literature concerned with competency-based education, and three of which were related to the nature and make-up of the community mental health movement, both generally and in Oregon.

Assumption 1. It was as sumed that the most appropriate approach to developing a forecast about the future character of social work practice in a field of social welfare, and for articulating the competencies necessary for this practice, would be to ask social work practitioners active in the field. On the basis of this assumption, it was therefore decided that the population of the research study would need to include social work practitioners currently 
involved in Oregon's community mental health movement.

Assumption 2. It was as sumed that professionals and paraprofessionals from all the various disciplines involved in the field of community mental health would have opinions about the future practice of social workers in this field and influence in shaping the character of this practice. On the basis of this assumption, it was therefore decided that the population of the research study would also need to include community mental health practitioners of nonsocial work orientations.

Assumption 3. It was as sumed that mental health practitioners in the private sector will have little influence in shaping the future characte $r$ of social work practice in the field of community mental health. This as sumption was based on the view that the community mental health movement has primarily been an organized response of the public sector to provide mental health services. (The public sector is composed of agencies and programs of municipal, state, and federal governments, while the private sector is composed of private clinics and agencies, and professionals acting as private entrepreneurs.) This view suggests that while the private sector has made many contributions to mental health theory and techniques, it has had little significant impact on the actual development and organization of community mental health delivery systems. Assuming that this pattern will continue, then the view further suggests that practitioners in the private sector can be considered largely peripheral to the development of community mental health practice in the future. On the basis of this assumption, it was therefore 
decided that the population of the research study could be limited to community mental health practitioners in Oregon's public sector.

An exception was made to this decision in the case of practitioners in privately incorporated childrens' treatment centers, throughout the state which have been created and funded as mental health facilities under specific mandate of the Oregon legislature. It was believed that these centers operate for all intents and purposes as public agencies. No attempt, however, was made to necessarily include practitioners in other private agencies which contract with state and municipal bodies to provide mental health services, but which operate without such specific mandate.

Assumption 4. It was as sumed that social workers will continue to be involved in community mental health service delivery systems for a wide variety of target populations and that this will be a factor in shaping future practice in this field. This assumption grew out of the fact that the community mental health movement, from its inception, has been concerned with the provision of services to people affected by mental retardation and developmental disabilities, as well as people affected by mental or emotional disturbances. This has been attributed (Black 1967) to the federal legislation resulting from President Kennedy's major policy address on community mental health in 1963. In recent years, in addition, these concerns have been broadened to include the provision of services to people affected by alcohol and drug problems as well. In 1973 (Bray 1973), the Oregon legislature specifically mandated that counties must provide comprehensive community 
mental health services for all three of these target populations. Until that time (Collins 1974), community mental health programs in this state had consisted principally of mental health and child guidance clinics for people affected by mental or emotional disturbances, backed up by a system of state hospitals. For this reason, social workers have historically had a great deal of involvement in community programs for the Mentally or Emotionally Disturbed; that is, MED programs, while they have had minimal involvement in community programs for the Mentally Retarded and Developmentally Disabled; that is, MRDD programs, and in programs for people affected by Alcohol and Drug Problems; that is, A\& DP programs. In the last five years, as more publically funded community programs have been developed for the latter two populations, social workers have tended to remain minimally involved with these groups, and the programs have tended to be dominated by community mental health practitioners from the fields of education and psychology, respectively. Social work participation in these service delivery systems at present, however, seems to be on the increase.

On the basis of these trends, it was assumed that community mental health practitioners would continue to be involved in programs for all three major target populations of the public sector of the community mental health movement in Oregon and that this would be reflected in future social work practice. Therefore, it was decided that the population of the research study would need to include practitioners specifically involved in A\&DP service delivery systems, in MED service delivery systems, and in MRDD service delivery systems. 
Assumption 5. It was as sumed that community mental health practitioners primarily involved in planning, managing, and developing services will have more influence in shaping future social work practice in the field than will practitioners primarily involved in delivering services. This assumption grew out of the discovery that professionals and paraprofessionals involved in the public sector of Oregon's community mental health movement presently fall into four occupational groupings. The first group consists of practitioners employed by the state of Oregon as system and program planners, system managers, and consultants to programs for various target populations. The second group consists of practitioners employed by counties, by the state, and by state mandated and funded private agencies as program managers and administrators. The third group consists of practitioners employed by the counties as developers and coordinators of services for specific target populations. The fourth group consists of practitioners employed by the counties, the state, and state mandated and funded private agencies as service providers and therapists. Because of the small population size of many counties in Oregon, it was further discovered that there is often considerable overlap between groups two, three, and four in these communities. It was found that the memberships of occupational groups one, two, and three, while they have grown with program expansion in response to federal and state legislation, have been relatively stable in their composition. Thus, generally these are practitioners who have been involved in community mental health for some time. It was further found that there is a relatively high turnover of practitioners 
in group four, in addition to the growth and frequent changes in this group resulting from program expansion. Specifically because of this situation, the State Mental Health Division maintains no centralization of information on service providers throughout the state, though information is available concerning the other occupational groupings.

The four occupational groups have, as well as differential employment trends, differential responsibilities; that is, members of groups one, two, and three will be planning and developing future services and hiring and supervising personnel. It was therefore assumed that both by virtue of relative stability and of position, practitioners falling into the se groups will have substantially more influence on shaping the character of future practice in the field of community mental health than those practitioners falling into group four. It was therefore decided that the population of the research study could be limited to occupational groupings of community mental health practitioners primarily involved in planning, managing, and developing services. This decision was strengthened by the knowledge that a number of practitioners involved in managing and developing services, and primarily in the latter group, would also reflect the opinions of practitioners involved in providing services.

\section{Composition of the Population}

The number of active practitioners in occupational group one was found to be 46 , based on a current employee roster of the State Mental Health Division. The number of active practitioners in occupational group two was found to be 48 , based on records of the Division concerning county community mental health programs, state hospitals, 
and state-funded childrens' residential and day treatment centers. The number of active practitioners in occupational group three was determined to be 66 , based on information provided by the Division's Regional Specialists. In terms of absolute representation in the population, it was decided that the larger number in occupational group three was appropriate because two points of view actually were being represented by this group; that is, views of both service developers and providers. Thus, the total population consisted of 160 community mental health practitioners who, as a group, were primarily involved in planning, managing, and developing services.

In terms of target population groupings, A\&DP programs were the concern of 39 of these practitioners, MED programs the concern of 43 , and MRDD programs the concern of 33 . In addition, services for all populations were the concern of 45 of these practitioners. In terms of orientation, 49 members of the population were trained as social workers, all at the Master's level, and the remaining 111 nonsocial work practitioners were professionals and paraprofessionals trained in psychiatry, psychology, nursing, education, and business administration, as well as non-professionals with no specific training. Thus, the requirements established by assumptions 1,2 , and 4 were all fulfilled by this population. A picture of the population comparing occupational groupings, target population groupings, and professional or paraprofessional orientation can be found in Tables I, II, and III.

In terms of sex, 105 members of the population were male and 45 female. Of the female practitioners, 14 were in occupational group one, 3 in group two, and 28 in group three. The number of female 
practitioners concerned with $A \& D P$ and MED programs were approximately the same (11 and 13 respectively), while approximately 40 percent more were involved in MRDD programs (17). In terms of geographical orientation, 94 of the members of the population were concerned with the provision of services to predominantly small town and rural areas, 11 to predominantly metropolitan areas, and 55 to a mixture of both types of areas. This distribution was not surprising, for though nearly half of Oregon's population is located in the three metropolitan areas of Portland, Eugene, and Salem, Oregon is primarily a rural state in terms of land mass. 
TABLE I

COMPARISON OF OCCUPATIONAL GROUPINGS AND PROFESSIONAL OR PARAPROFESSIONAL ORIENTATION

IN THE POPULATION

\begin{tabular}{l|c|c|c|c}
\multirow{2}{*}{ Orientation } & \multicolumn{4}{|c}{ Occupational Groups } \\
\hline Social Work & 13 & 17 & Developing & \\
\hline Non-Social Work & 33 & 31 & 19 & 49 \\
\hline & 46 & 48 & 67 & 111 \\
\hline & & & $\begin{array}{l}\text { Totals } \\
\text { N=160 }\end{array}$
\end{tabular}

TABLE II

COMPARISON OF TARGET POPULATION GROUPINGS AND PROFESSIONAL OR PARAPROFESSIONAL ORIENTATION IN THE POPULATION

\begin{tabular}{l|c|c|c|c|c}
\multirow{2}{*}{ Orientation } & All & A\&DP & MED & MRDD & \\
\hline Social Work & 16 & 3 & 28 & 5 & 49 \\
\hline Non-Social Work & 29 & 36 & 15 & 28 & 111 \\
\hline & 45 & 39 & 43 & 33 & $\begin{array}{c}\text { Totals } \\
\text { N=160 }\end{array}$
\end{tabular}

TABLE III

COMPARISON OF OCCUPATIONAL GROUPINGS AND TARGET POPULATION GROUPINGS

IN THE POPULATION

\begin{tabular}{l|r|r|r|r|r}
\multirow{2}{*}{$\begin{array}{l}\text { Occupational } \\
\text { Groups }\end{array}$} & All & A\& DP & MED & MRDD & \\
\hline Planning & 8 & 12 & 14 & 12 & 46 \\
\hline Managing & 37 & 2 & 6 & 3 & 48 \\
\hline Developing & 0 & 25 & 23 & 18 & 66 \\
\hline & 45 & 39 & 43 & 33 & $\begin{array}{c}\text { Totals } \\
\text { N=160 }\end{array}$
\end{tabular}




\section{METHODOLOGY}

The problem under study was researched through use of a design that facilitated classification of the components of a projected generalizing core of social practice and education in the field of community mental health in ten years. This generalizing core was to be defined in terms of the five variables of the roles, functions, and tasks which are likely to be performed by Master's level social workers in this field, and the skills and areas of knowledge which are likely to be utilized in this practice. The components of this core were to be determined on the basis of consensually validated group judgments by the participants in the study. The classification of the se components was to result in ranked clusters within the group of projections for each variable. These clusters would suggest the priorities for training Master's level social workers specializing in this field, while the total body of data would provide a foundation for developing a future-oriented, competency-based social work training program in community mental health.

A modified Delphi forecasting technique was used as the model for the research design, and nine research questions were addressed in the course of the study's implementation. A three-part survey was employed as the data collection framework. Data analysis consisted of analyses of content, of response frequencies, and of tenacity rates of certain subgroups within the population. 
The Delphi Technique

The Delphi forecasting technique (so-named after the Oracle of Delphi) was originally developed by researchers at the Rand Corporation as a consensus formation procedure. They sought to reduce the negative influence of certain psychological and interpersonal factors (Dalkey, et al. 1972, p. 19) common to more traditional methods for achieving consensus, such as round table discussions. Research evidence (Rasp 1972, p. 1) indicates that "... often a consensus arrived at in [traditional] fashion does not reflect the full participation of all members of the group and may be weakened to the degree that this is true." Of particular concern are distortions of consensus related to the influence of dominant individuals (Maier 1967) and to group pressure for conformity (Asch 1958). The Delphi technique, as proposed by its designers (Helmer and Rescher 1959, p. 47), eliminates the need for face-to-face group activity altogether and ... replaces direct debate by a carefully designed program of sequential individual interrogations (best conducted by questionnaires) interspersed with information and opinion feedback derived by computed consensus from earlier parts of the program.

The technique was initially utilized as a predictive tool for achieving consensus among panels of experts concerning forecasts about future technological developments. Subsequently, however, it has been used (Cyphert and Gant 1970) in predictive studies concerned with topics as diverse as future developments in international relations and educational planning. In this latter area, the technique has been widely employed (Judd 1972) in the last eight years for developing educational goals and objectives for curriculum and campus 
planning and for the development of evaluation criteria. One author (Weaver 1971 , p. 270) has suggested that, although the technique was intended as a forecasting tool, one of its more promising applications in the field of education is as "... a planning tool which may aid in probing priorities held by members and constituencies of an organization."

As a research method (Judd 1972, p. 1; cf Dalkey, et al. 1972, p. 20), the Delphi technique has been generally characterized by "... 1) anonymity of response; 2) multiple iterations; 3) convergence of the distribution of answers; [and] 4) a statistical group response (median, interquartile range) preserving intact a distribution that may still remain wide." As Judd (1972, pp. 1, 3) has noted, however, the technique is not an "... unchanging approach to problem solving about the future," and "...there is no single monolithic structure to the Delphi technique." Thus, significant modifications of the technique have been made by various researchers. A modification of interest to this present study was developed at the University of Virginia to identify and reach consensus on educational goals for the School of Education. Though three of the four previously-mentioned features of the technique were maintained in this research (Cyphert and Gant 1970, p. 421), it differed significantly from earlier studies utilizing Delphi in that

1) the technique had usually been used with groups of 50 or fewer respondents rather than with the 400 involved in the present survey; 2) most of the participants in prior studies have felt some greater degree of expertise in the field being surveyed than did participants in this study; 3 )... the technique has generally been used to produce what will happen rather than to seek agreement on what should happen; 
4) consensus in this study was defined as the mode of distribution of ratings on each goal where most other studies ... have defined consensus as the interquartile range.

The population for the Virginia study (Cyphert and Gant 1970, p. 420) was purposively selected on the assumption that "... what those persons in positions of influence believe will happen or should happen is the best indication of what actually will occur in the near future." They were surveyed through use of a series of four questionnaires, the first of which was utilized to generate goal statements. These statements were rated and re-rated during the next three rounds on a five-point scale representing low to high priority as a goal. Between the second and third, and third and fourth rounds, the responses were processed by computer to determine the distribution and mode of the priorities assigned to each item. The researchers (Cyphert and Gant 1970, p. 423) found that "... virtually all (99 percent) of the respondents' change in opinion from their initial rating of the items occurred on questionnaire 3, which informed them of the initial consensus reached by the total group...." This led them to question the need for a fourth questionnaire.

Cyphert and Gant (1970, p. 421) found that a greater percentage of their panel was lost on the first round than in all other rounds combined, which they concluded was in part due to the decision of lay participants that they had insufficient expertise in this area. As Judd (1972, pp. 8-9) points out,

The original doctrine of Delphi panel composition, aimed as it was at technological forecasting, called for a small panel of highly regarded experts who were compensated for their services... The use of nonexpert and noncompensated panel members introduced a new dimension into the Delphi technique... one of the hazards of depending on a broadly 
representative panel selection is that the loss in panel participation may vitiate the careful attempts to avoid inbreeding, and the Delphi exercise winds up with participants who are not broadly representative of the larger public that was sought...

Thus, a potential problem related to composition and management of the expert panel is inherent in the Virginia modification of the Delphi technique.

A further refinement of the University of Virginia's research design was made in a study (Rasp 1972) conducted by the Office of the Superintendent of Public Instruction of the State of Washington. The purpose of this study was to identify desired outcomes for the public schools of Washington, which would serve as a basis for a statement of educational goals. A representative sample of 866 people throughout the state was surveyed. This study differed from the Virginia survey on three dimensions, as follows: 1) the size of the population was doubled; 2) a six-point rather than a five-point scale was used for rating items; and 3 ) only three questionnaires were developed rather than four, following Cyphert and Gant's conclusion that a fourth round was unnecessary. Otherwise, the research design and data collection framework was virtually identical to that utilized in the earlier study.

Research Design

It was decided that the modified Delphi technique developed by the University of Virginia and further refined by the State of Washington provided an appropriate research design for addressing the problem being studied in this thesis. Choice of this technique was based upon its congruence with five assumptions which had been made by the researchers that established the parameters for the research 
design of the study. Four of the se assumptions were based on the preceding review of the literature, while one assumption was related to the concept of group judgment.

Assumption 1. It was as sumed that in ten years the profes sional practice of Master's level social workers in the field of community mental health will differ in some degree with present social work practice in this field. Further, as no single study could be found which specifically and comprehensively delineated the present professional practice of social workers in this field, there was no adequate baseline that could be provided to participants for basing their forecasts on how practice would differ from the present. It was therefore decided that the research design would need to facilitate the generation of a comprehensive data base of projections about the future professional practice of Master's level social workers in community mental health.

Assumption 2. It was assumed that in ten years the professional practice of Master's level social workers in the field of community mental health will require the performance of some roles, functions, and tasks and the utilization of some skills and areas of knowledge more frequently than others. Thus, as evidence in the literature suggested that Master's level social workers as a group presently, for example, occupy some roles more frequently than others, it was assumed that this pattern will be likely to continue in the future. Moreover, it was believed that the likely frequency of occurrence is an important determinant of the exact character of this future practice. Therefore, it was decided that the research design would need 
to facilitate the individual rating of items in the data base by likely frequency of occurrence for Master's level social workers involved in this field in the future.

Assumption 3. It was as sumed that in any group of forecasters there will be greater agreement on some predictions about the future than there will be on others and, consequently, on some predictions a group judgment is likely to be made, while on others no such judgment will or can be made. This assumption was based on an understanding that each individual's judgment in predicting the future is shaped by a multitude of unknown variables. Thus, it is reasonable to expect that the amount of agreement and disagreement on predictions about the future among any group of individuals will vary with the composition of the group and the nature of the events being predicted.

The nature and amount of disagreement on such predictions has significant implications for determining when a group judgment on a prediction can be said to have been made. Thus, Dalkey, et al. (1972, p. 57) suggest that necessary conditions for determining the existence of a group judgment are the absence of the following situations:

If the distribution of group responses... is flat, indicating group indifference, or if it is U-shaped, indicating either that the question is being interpreted differently by two subgroups, or there is an actual difference of assessment by the two subgroups, then it seems inappropriate to assert that the group considered as a unit has a judgment on that question.... More generally, if members of the group do not utilize the information in reports of the group response on earlier rounds when generating responses on later rounds, it seems inappropriate to consider these responses as judgments. 
It would follow from this argument that if there is unipolar agreement among a group on a prediction about the future, and if there has been change and convergence of opinion on iteration, the strength of consensus can be considered a measure of the face validity of the projection as a group judgment. On the basis of the preceding assumption, it was therefore decided that the research design would need to facilitate assessment of the amount and nature of agreement on frequency ratings of individual items in the data base to determine whether it is appropriate to consider that group judgments have been made on projections about the future practice of Master's level social workers in community mental health.

Assumption 4. It was assumed that in ten years, some activities of Master's level social workers in the field of community mental health will define a core of social work practice in the field, and some skills and areas of knowledge utilized in this practice will define a core of social work education for this field. It was therefore decided that the research design would need to facilitate identification of the components of the future generalizing core of Master's level social work practice and education in the field of community mental health.

Assumption 5. It was assumed that preparation in some components of this future generalizing core would constitute higher priorities than others in social work training programs at the Master's level in community mental health. It was therefore decided that the research design would need to facilitate the classification of the components of this generalizing core in terms of priorities for training beginning and advanced Master's degree 
candidates specializing in this field of practice.

Choice of the Delphi Technique. The modified Delphi forecasting technique, which was previously described, completely satisfied the five requirements for the research design resulting from the preceding assumptions. First, the first round could be utilized to generate a comprehensive data base of projections about the future professional practice of Master's level social workers in community mental health. Specifically, this data base would delineate and establish the boundaries for all the possible roles which they might be occupying, functions which they might be carrying out, and tasks which they might be performing in ten years, as well as skills which they might be utilizing, and areas of knowledge which they might be applying in this practice.

Second, the second round could be utilized to rate the individual items in the data base by likely frequency of occurrence for Master's level social workers involved in community mental health in the future. Specifically, the items would be rated in terms of the projected frequency of performance of the role, function, or task in ten years and in terms of the projected frequency of utilization of the skill or area of knowledge in this practice.

Third, the distribution of responses on the second and third rounds could be utilized to assess the amount and nature of agreement on frequency ratings of individual items in the data base to determine whether it is appropriate to consider that group judgments have been made on projections about the future practice of Master's level social workers in community mental health. Specifically, the movement 
School of Education. In the Washington study, the purpose was to determine educational outcomes of the public schools in terms of the performance of each student. Both studies thus sought to determine what the participants in the research believed should happen, through a sking them to rate items on a scale of low to high priority.

The purpose of the present study was to determine training priorities for Master's level social workers in terms of the future character of their practice in the field of community mental health. The interest of this study was therefore in what will happen; that is, in what social workers will be doing in the opinions of community mental health practitioners, rather than in what they should be doing or should be trained to do. Thus, it had been decided that the use of the Delphi technique as a forecasting tool for projecting the future, as it was originally developed, was more congruent with the purposes of this study and with the five requirements for the research design than was its use as a goal-setting tool for directly determining priorities of the participants. Consequently, participants were to be asked to rate items on a scale of frequency of occurrence, rather than on a scale of priorities.

\section{Research Objectives}

The objectives of this study were to provide answers to nine research questions.

1. What roles, functions, and tasks do current practitioners in the public sector of Oregon's community mental health movement believe that Master's level social workers will be performing in this field in ten years? 
2. What skills and areas of knowledge do these practitioners believe that Master's level social workers will be utilizing in this practice?

3. What roles, functions, tasks, skills, and areas of knowledge do these practitioners indicate will define a generalizing core of social work practice and education at the Master's level in the field of community mental health in ten years?

4. How would the components of this future generalizing core cluster into ranked groups within each category that would suggest priorities for training Master's level social workers specializing in community mental health as a field of practice?

5. Which groups within the population are most tenacious in holding to their views?

6. Do social workers and non-social workers among these practitioners view the components of the generalizing core differently?

7. Do social workers and non-social workers among the practitioners view the components of the training priority clusters differently?

8. Do the occupational groups among these practitioners composed of a) planners and consultants; b) program managers; and c) developers and coordinators view the components of the generalizing core differently?

9. Do the three occupational groups among the practitioners view the components of the training priority clusters differently?

\section{Data Collection}

The framework for collecting data for this study was similar to 
that used in the Washington study. A three-part survey was thus conducted. The first questionnaire was open ended, requesting participants to consider and describe the activities of Master's level social workers in community mental health in the decade 1975-85. The second questionnaire was then developed from the responses to the first through a process of editing.

On the second round, participants were asked to rate roles, functions, and tasks in terms of what they believe will be their frequency of performance by Master's level social workers in this field in ten years and, in like fashion, to rate skills and areas of knowledge in terms of frequency of utilization. As in the Washington study, a five-point scale was used. The scale ranged from very low frequency to very high frequency of occurrence. Responses from the second round were tallied by computer to determine the mode, mean, and frequency and percentage distributions on ratings of individual items.

As in the other two studies, the modal responses on round two were reported back to participants as part of the third questionnaire, together with their original ratings. They were asked on this third round to reconsider their projections based on the information about the modal responses. Otherwise, questionnaires two and three were identical. Data was again processed by a computer to determine modes, means, and distributions on this final round of data collection.

\section{Data Analysis}

The content of the data collected in round one was analyzed as part of the editing process for constructing the questionnaire for use 
round two. As Judd (1972, p. 10) points out, "... one of the least understood areas of Delphi practice is the editing or content analysis phase of treating responses from panel members in round one." Thus, while the intent of the researchers was to insure that this content analysis was as rigorous and exhaustive as possible, little could be anticipated at the outset of the study as to the exact form this analysis would take. The products of this work were lists of roles, functions, tasks, skills, and areas of knowledge which participants believed Master's level social workers would be performing and utilizing in the community mental health field in ten years.

The data collected on round two, in addition to being utilized in the construction of the questionnaire for round three, was also used to determine the amount of change between rounds two and three. The mean number of response changes and mean amount of percentage increase in agreement on the modal responses were determined. In addition, the tenacity rate, a statistical measure developed by Rasp (1972), was computed for certain subgroups to determine which were more tenacious in holding to their views between round two and round three.

The data collected on round three was first used to determine the items on which no group judgments were made, through analyzing the distribution frequencies and percentages of responses on individual items. The scale was dichotomized into two points: responses falling on the mid-point and low nodes on the one hand, and responses falling on the two high nodes on the other. Response distributions on either the 1-2-3 side or the 4-5 side of the scale which constituted more than 
60 percent of the total number of responses, and on which the distribution was unipolar; that is, toward the mode, were said to exhibit consensus on a group judgment for the item. This 60 percent figure was chosen arbitrarily. If the distribution was bipolar, then it was said that there was clear group disagreement on the item. A flat response distribution was taken as a sign of no group judgment based on these criteria. Responses of subgroups were similarly analyzed.

The data collected on this round was next used to define the generalizing core of Master's level social work practice and education in the field of community mental health in ten years. Items on which a group judgment was made and on which there was a modal response rating of 4 or 5 were considered components of this generalizing core. The researchers assumed that the stronger the consensus on the item, the greater the confidence with which the item could be treated as a consensually validated component of this generalizing core. Responses of subgroups were likewise analyzed.

The third use of data collected on round three was to classify the components of this generalizing core into ranked groups within each category that would suggest priorities for training Master's level social workers specializing in the field of community mental health. The mean response on an item, which was more sensitive than the mode to the overall distribution of responses, was utilized in this analysis. Items in a category which had an identical or close mean response were considered clusters, and clusters with the highest mean responses were considered the highest training priorities, with other clusters following by rank order. In general, clusters with 
means over 4 were considered the highest training priorities, as they indicated high agreement in the direction of the top of the scale. The use of the mean in this manner was an arbitrary decision based on the need to present the data in some coherent format that would suggest priorities. Responses of subgroups were similarly analyzed.

Finally, a content analysis of the projected generalizing core of social work practice and education in this field in ten years was carried out, as well as a content analysis of the priority clusters for training Master's level social workers specializing in the field. In this content analysis, subgroup differences were taken into account. The analysis considered the implications of the study for suggesting the future character of social work practice in community mental health, and the implications for curriculum and educational planning in this field. Projections which have been made by manpower analysts and social work educators on these same topics were also considered in this analysis. 


\section{IMPLEMENTATION}

\section{Feasibility Strategies}

Five major strategies were adopted in order to increase the feasibility of successfully implementing the research design. Considerable time and effort was expended on this aspect of the study, some three to four months altogether, as compared to six months for the actual data collection.

The first strategy was to become an officially sanctioned project of the Portland State University School of Social Work. It was believed that with this sanction, the study would have greater credibility with the wide range and number of participants involved. Consequently, a proposal describing the study was presented to the faculty of the School's Community Mental Health Project, who adopted it as an integral part of the evaluation design for the first year of the Project. Additional sanction was secured from the Dean of the School.

The second strategy was to secure the support and cooperation of the State Division of Mental Health while, at the same time, remaining an autonomous project of the School. This concern stemmed from an understanding that the relationship between the State Division and the county community mental health programs was 
at once a partnership and an adversary relationship. Thus, the possibility existed that the study would receive less cooperation from the county employees if it were an official project of the Division. At the same time, it was equally important to insure that the proposed research would not duplicate any on-going studies being conducted by the Division. Fortunately, the Division's staff viewed the present study as complementary to their interests and subsequently offered the researchers financial and clerical support.

The third strategy was to plan an approach to each of the subgroups within the population of the study that would facilitate the maximum amount of cooperation and participation from the se community mental health practitioners. The approach to the employees of the Division was to secure the approval and support of the Division's Administrator. The approach to the county community mental health Program Directors was to discuss the project with the President of the Program Directors' Association. The approach to the state hospital Superintendents was through the Regional Directors. The approach to the child treatment center Directors was again through the President of their Association. Finally, the approach to the county developers and coordinators was through the community mental health Program Directors, who were asked to request the cooperation of their respective staffs.

The fourth strategy was to maximize the personal contact of the researchers with the participants in the study. In the Division, this was accomplished by personal presentations to nearly all of the staff. For the county Program Directors, a presentation was made during 
their annual meeting. Personal contact had been established several months earlier with many of the childrens' treatment center Directors. Formal personal contacts were not made with either the hospital Superintendents or the county developers and coordinators.

The fifth and final strategy was to provide a maximum number of participants with a written description of the study. Thus, a four-page explanation of the background, purposes, sanction, research design, proposed implementation, and potential usefulness of the study was written. This was personally made available to all Division employees and some Program Directors and was mailed to the other county Directors, Superintendents, and childrens' treatment center Directors. Program Directors were asked to make the description available to their staffs.

\section{Instrument Development}

Round I. The development of the open-ended questionnaire for round one was fairly straightforward. As Judd (1972, p. 3) explains, "...the usual first step in a Delphi forecast [is] that of asking the panel to generate responses that are not structured beyond being responsive to a general question...." It was decided that four general questions would be asked to facilitate gathering projections about the future practice of social workers. These were:

a) What jobs do you think Master's level social workers will be performing in Oregon's community mental health system in the decade 1975-1985?

b) What tasks do you believe will be involved in these jobs?

c) What areas of knowledge do you believe a social worker will need to be familiar with to carry out these jobs? 
d) What skills do you believe will be needed to carry out these jobs?

The decision to organize the questionnaire around the concept of jobs, rather than around the concept of roles and functions, grew out of a belief that the latter two terms were too abstract and global to produce useful data on this first round. In addition, it was thought that the concreteness of the concept of jobs would encourage participants to be more specific. It is interesting to note that Andrew (1974, p. 8) used a similar rationale to explain the use of task as opposed to function in her abbreviated Delphi study about future social work practice. This decision was further corroborated by the conclusion of Scheibe, Skutsch, and Schofer (1975, p. 360) that "... the tendency towards upward drift in generality can be minimized if Delphi participants are first asked to work at a more specific level."

Each question was accompanied by a request to follow a prescribed format in responding. These formats were illustrated with three or more examples to encourage some uniformity in the return of answers. Thus, participants were requested to give a brief behavioral description of the job, including both role and organization; to state both the action and purpose of a task; to designate areas of knowledge as theories, principles, concepts, methods, or factual information; and to identify both large categories of skills and component skills within each category.

The first questionnaire was accompanied by instructions which had several functions. First, the instructions described the purpose and design of the questionnaire. Second, they provided definitions of 
the terms; that is, of job, task, area of knowledge, and skill, as they were being utilized in the questionnaire. Third, they requested participants to be as specific as possible and to list as many items in response to each question as possible. Fourth, they established a frame of reference for the questionnaire in the future. Linstone and Turoff $(1975,1.677)$ stress the vital importance of this step of "bringing the participants into the future" in order to minimize the discounting which is common to projections about the future. Consequently, the instructions requested that the participants think about the community mental health system in Oregon in 1975-85 in terms of its structure and organization, the needs and problems it will be addressing, and the programs and services it will encompass, and then to project the jobs which Master's level social workers may be performing in this system.

A cover letter was enclosed with the questionnaire which described the background, purpose, and population of the study and the sequencing of rounds. The questionnaires were coded to preserve anonymity of participants' responses. The mailing of this three-page questionnaire, together with stamped, self-addressed envelopes, was staggered over a period of several weeks between October 14 and 28, 1974.

Round II. The development of the instrument for this round required considerably more time than had been anticipated, a period of over two months. This experience confirmed Judd's (1972, p. 10) observation that, "Clearly the magnitude of the editing process following a traditional round one is much larger than generally 
realized." The considerable time involved was a direct result of the need to reduce a great amount of information from the first questionnaire to the proportions of a manageable instrument. Ultimately, the second round had to be conducted with two separate questionnaires to accomplish this objective.

The process which was followed for compiling and editing the responses to each of the four questions on the first round was essentially the same. All the responses to a question were initially written on a large sheet of butcher paper, eliminating only obvious duplications. The subsequent collapsing of this information into a finite number of questionnaire items then followed four general principles. The first principle was that each item should be generic. This assumed applicability to any target population (A\&DP, MED, MRDD), any service category (inpatient, day treatment, outpatient, emergency, consultation, and education), and any organizational level (city, county, regional, or state agency). The second principle was that each item should be well defined, independent, and discrete. The third principle was that each category (role, function, task, skill, areas of knowledge) should be as exhaustive and comprehensive as the data indicated. The fourth and final principle was that the overall instrument should be internally consistent, both within and between categories. In two categories, tasks, and areas of knowledge, there were large numbers of items and, consequently, an attempt was further made to organize the data into logical groups for presentation. This process of collapsing the responses to the first questionnaire required a minimum of four separate editing rounds for each category. 
Responses to the question about future jobs were utilized to develop items both for the role and function categories. These were developed by recognizing that any one job is likely to require the performance of several roles (Teare and McPheeters 1970), and that any one function would encompass many jobs. The resulting list of roles were alphabetized to prevent skewing the data, and examples of jobs which would involve the performance of the particular role accompanied each item. The resulting list of functions was subdivided on the basis of the target populations which would be the focus of jobs related to that function. Examples of roles which would be associated with each function accompanied the items. The list of functions was alphabetized, as were the items into which each function had been divided.

For the task category, the process of developing generic, welldefined statements which eliminated reference to a specific target population, service category, or organizational level was indeed formidable. In this process, it became apparent that it was very difficult to make generic statements which encompassed both direct services (for individuals and groups) and indirect services (organiza-. tional and system concerns). For example, it seemed inappropriate, because of the generally perceived divergence of outcomes, to speak of planning a strategy for intervention with individuals and groups as the same activity as planning a strategy for intervention in an organization or system.

Twelve classifications, loosely based on the problem-solving process, were utilized to organize the list of tasks resulting from the 
editing process. These were: Identification; Data Collection; Analysis; Assessment; Planning; Implementation: Organization and Development, Education and Training, Service Delivery, Consultation, Program Management, Systems Maintenance; and Evaluation. This schema was chosen arbitrarily to facilitate presentation of items in the que stionnaire in a more conceptually coherent format than simply listing them. It was not necessarily intended to reflect any organizational schemas for the data suggested by participants. These classifications were alphabetized in an attempt to eliminate any possible biasing of responses on the second round which might result from use of this schema. The items within each classification were in turn alphabetized, and when it seemed appropriate or necessary for clarification purposes, examples accompanied the items.

For the skill category, the participants' responses were similarly collapsed into generic statements, in this case, of a skill which could be applied to several different tasks. Examples of such tasks were developed for each item. The resulting list of skills, as with the other categories, were alphabetized.

For the areas of knowledge category, it became necessary to collapse the responses into both general and specific concepts. Five classifications we re utilized to organize the resulting lists, which were loosely based on the organization of social work education (Reichert 1970). These were: Academic Disciplines, The Human Organism and the Social Environment, Individual and Social Problems, Social Welfare Policy and Services, and Social Work Application and Practice. This schema, like the classifications used for the task 
category, was developed only to facilitate the presentation of the data in a more conceptually clear format than simple alphabetical listing, rather than to reflect any such schemas suggested by participants. Subsequently, the classifications were alphabetized, as were the items within each one. Examples accompanied items in need of amplification or clarification as to meaning.

Following the editing of responses to the first round, the scale for rating items in the second round was developed. A balanced, Likert-type interval scale was chosen, with the points defined as follows: 1) Very Infrequently; 2) Infrequently (seldom); 3) Occasionally; 4) Frequently (often); and 5) Very Frequently. Scheibe, Skutsch, and Schofer $(1975$, p. 371) point out the importance to data analysis of utilizing a reliable interval scale with the Delphi technique, but this scale was not definitively tested to establish this property. There was, in fact, some criticism from participants that the scale was not flexible enough, and that it would have benefited from more points. In any case, these same authors $(1975$, p. 358) assert that the use of an abstract scale, such as the one used, is much superior to a concrete interval scale, utilizing, for example, the number of tasks performed per month.

The construction of the instrument for the second round was completed with the development of questions for rating the items. A single format was utilized to develop the question for all five categories, as follows:

Ten (10) years from now, how frequently will Master's level social workers who are involved in Oregon's community mental health system be: 
a) performing the following roles?

b) performing the following functions?

c) performing the following tasks?

d) utilizing the following skills?

e) utilizing the following areas of knowledge?

Participants were asked to indicate their projections by circling the rating which most closely approximated their response to the question for that item. Finally, a brief description of the parameters of concern for each category was developed. Though jobs was not used as a formal category in this instrument, each of the se introductions tied the items which were to follow with the concept of future jobs within the community mental health field. This precaution was taken both to provide continuity with the first questionnaire and to again emphasize the concrete focus of the study.

At this point the instrument consisted of some 260 separate items. Previous research (Judd 1972, p. 12) on the effect of the fatigue factor in a Delphi study had indicated that there was no discernable impact on responses to a questionnaire of 118 items on which two questions were answered for each item. No information could be found which would suggest the impact of fatigue on questionnaires of greater length, and furthermore, no provisions were being made in this study to determine such an impact. Therefore, it was thought that it would be best to divide the instrument in half, and thereby place each questionnaire in range of known research data on the relationship of questionnaire length and fatigue, rather than risk skewing the data or causing a higher attrition rate than necessary. Consequently, the instrument was divided into two questionnaires of 
approximately equal length. One ten-page questionnaire was concerned with roles, functions, and tasks and consisted of 129 items. The other eight-page questionnaire was concerned with skills and areas of knowledge and consisted of 133 items. Thus, one questionnaire focused exclusively on practice concerns, while the other focused exclusively on educational concerns.

The division of the round two instrument into two questionnaires necessitated the development of two separate sets of general instructions. Each set reiterated the purpose of the survey, emphasized its focus on the future, and stressed that its interest was in the activities of Master's level social workers in this field considered as a group. The categories which were the focus of each different questionnaire were defined. Both sets of instructions further stressed that the questionnaire was only interested in the activities of Master's level social workers, and not the activities of social workers at other degree levels, nor the activities of members of other professions. A glossary of terms used in both questionnaires was also constructed and attached to each set of instructions.

A cover letter was prepared which discussed the decision to create two questionnaires for the second round and requested a response to the enclosed questionnaire regardless of whether or not the first instrument had been completed. Finally, provisions were made on each questionnaire to collect basic identification data, including current job title, highest academic or professional degree and field, year degree obtained, age, and sex. The questionnaires were coded, and the material was mailed out on January 21, 1975. 
Round III. The development of the instrument for the third round was relatively simple. The participants' responses to the second round questionnaires were first keypunched on computer cards, together with coding numbers and identifying data. A simple fortran program was then utilized to tabulate the response distributions for each item by frequency and percentage, and the mean response and standard deviation. On the basis of the rating distributions, the modal response for each item was determined.

The instrument for the third round utilized the same format as the second round questionnaires. The modal responses were thus indicated on the lists of items prepared for the second round in the form of black diamonds surrounding the appropriate rating. Ties on modal responses were indicated with two diamonds. The individual participant's responses on the second round were indicated by red "Y"s, meaning your response, for comparison with the modal responses. When a participant's response coincided with the modal response, the red "Y" was simply superimposed over the black diamond. For the third round, the instructions for each category also were slightly modified. Participants were asked to reconsider their projections in light of the modal responses. For items on which they wished to change a rating, they were asked to circle the new rating, and for items on which they did not wish to change, they were to do nothing. Other than these additions, the third questionnaires were identical to the second ones.

A new cover letter was prepared for mailing with the third round questionnaires which stressed that the purpose of this final 
round was to measure the strength of agreement on the ratings of items. No general instructions were sent with this questionnaire on the assumption that the previous round was still relatively fresh in participants' minds. These questionnaires were coded and mailed on March 15, 1975.

\section{Sampling and Returns}

It was decided, if possible, to utilize the entire population as the Delphi panel of experts for this study, rather than taking a sample. The fact that the population contained both social workers and non-social workers, however, raised the question as to whether the varying expertise of the two groups on the subject of social work practice might justify a stratified sampling. However, the successful experience of the University of Virginia study in utilizing participants of varying expertise suggested that this factor need not be taken into account in a decision on sampling. The earlier study had, in fact, concluded that this problem was more of an appropriate concern for the actual conduct of data collection. Cyphert and Gant (1970, p. 421) thus suggested that "... in order for prospective participants [of varying expertise] to take part in the study, they must be made to feel that their response is valid." This factor had been consequently taken into account in both the feasibility strategies and the development of instruments.

The second question related to involvement of the entire population was concerned with its size. Again, however, the successful experiences of the University of Virginia study, which involved 
some 860 respondents, suggested that size was not a critical variable with the modified Delphi technique. Moreover, it was believed that a large number of participants might lessen the possible impact of the attrition that was anticipated because the study involved multiple questionnaires.

As it was decided that 160 respondents seemed to be a manageable size for the study, the first questionnaire was sent to the entire population. The sluggish response rate on this round necessitated both the mailing of a reminder letter to non-respondents and follow-up phone calls. Ultimately, 82 responses were received on the first round, for a 51 percent return rate. The response of occupational group one was 32 questionnaires for a 70 percent return rate for this group. For group two, the response was 21 for a 44 percent return rate, and for group three, the response was 29 questionnaires for a 44 percent return rate.

The construction of two separate questionnaires for the second round forced an abandonment of the plan to utilize the entire population as a single panel of experts throughout the study and not to sample. As a result, a random sample of approximately 50 percent of each of the occupational groups in the population was chosen to receive one questionnaire, while the other half would receive the second one.

The que stionnaire concerned with "Roles, Functions, and Tasks" was sent to 78 members of the original population. (Two practitioners in this half of the sample had refused on the first round to participate in the study.) Practitioners in occupational group one received 23 questionnaires, those in group two received 24 
questionnaires, and those in group three received 31 questionnaires. The questionnaire concerned with "Skills and Areas of Knowledge" was sent to 80 members of the original population. Practitioners in occupational group one similarly received 23 questionnaires, those in group two similarly received 24 questionnaires, and tho se in group three received 33 questionnaires.

A sluggish response rate on this second round was again a problem, and a reminder letter was sent out to non-respondents, follow-up phone calls were made to all of them, and the deadline date was extended several times. Ultimately, 50 "Roles, Functions, and Tasks" questionnaires were received, for a 64 percent return rate on this round, and a loss of 28 responses. At the same time, 64 "Skills and Areas of Knowledge" questionnaires were received for an 80 percent return rate, and a loss of only 16 responses.

It was decided, because of the relatively lower return rate on the "Roles, Functions, and Tasks" questionnaire on this round, that it would be important to ascertain if a bias could have existed in the responses of the 28 participants who did not return this questionnaire. Such a bias could have skewed the data that was collected. Consequently, a random sample of seven of these non-respondents was chosen to receive an abbreviated form of the questionnaire. This 15item questionnaire was constructed by choosing a random sample of three of the role items, three of the function items, and nine of the task items. The selected non-respondents were contacted and agreed to participate, and subsequently all seven of the abbreviated questionnaires were returned. On the basis of these returns, it was concluded 
that no detectable pattern of non-response bias existed for this questionnaire (see Chapter IV. Results of the Study: section II, Round II).

The researchers decided that it would not be necessary to test for a non-response bias among the 16 participants who did not return the "Skills and Areas of Knowledge" questionnaire because their numbers were insufficient to skew the data collected in any significant direction.

For the third round, the sample frames for the "Skills and Areas of Knowledge" questionnaire remained the same. Two participants who had received the "Roles, Functions, and Tasks" questionnaire on the second round were, however, no longer employed. This reduced the sample frame of occupational group two to 23 and of group three to 30, and the overall sample frame for the questionnaire to 76 .

Third round questionnaires were sent only to participants who actually responded on the second round. Of the 50 "Roles, Functions, and Tasks" questionnaires, 16 were sent to occupational group one, 14 to group two, and 20 to group three. Of the 64 "Skills and Areas of Knowledge" questionnaires, 21 were sent to group one, 15 to group two, and 28 to group three. These questionnaires were generally returned quite promptly, and no reminder letter was required.

Ultimately, 49 "Roles, Functions, and Tasks" questionnaires were returned on the third round, for a net loss of one, and an overall return rate of 64 percent within the survey sample frame. As the loss was in occupational group one, this resulted in a 65 percent overall return rate for this group, 61 percent for group two, and 67 percent 
for group three. There was a loss of three on the "Skills and Areas of Knowledge" questionnaire for the third round. The 61 who responded represented a 76 percent overall return rate within the survey sample frame for this questionnaire. Two of these non-responses were from group one, resulting in an overall return rate of 83 percent for this group, a 63 percent return rate for group two, and an 82 percent return rate for group three, from which the third loss came. 


\section{LIMITATIONS}

The results which were obtained from this research study must be placed in the context of certain limitations imposed on the reliability of the data research design itself and by the implementation of this design.

The first limitation on the reliability of the study's results was that, as a methodology, the Delphi technique was designed as a consensus formation procedure and not a tool to discriminate significant differences of opinion within a population. Therefore, the discriminatory procedures which were employed in this study to separate some components of the Delphi forecast into a generalizing core of practice and education and to further classify these components into training priority clusters did not have the statistical validity which they might have had if this study were not designed to promote convergence of opinions. Moreover, as has been indicated, the criteria utilized in these procedures were arbitrary, and it would. be inappropriate to as sert that the resulting discriminations between any two items were definitive.

This initial limitation did not suggest that the content of the resulting discriminations had no face validity. In fact, the researchers believed that the se discriminations did reflect gross differences in assessments of clusters of items and gross differences of opinion between subgroups within the population. Further, as Judd (1972, p. 12) points out, 
One of the little understood elements of a Delphi is its potential for delineating differences and the extent of differences. Perhaps because of early attention focused upon consensus, the counterpart phenomenon, divergence, has been paid less attention. It seems likely that Delphi studies can be effectively used to discover differences of opinion within a constituency. These differences can then be a known input before a decision is made.

Thus, despite the inherent limitation within the methodology itself, the researchers believed that it was important to attempt to discriminate differences between items and differences of opinion within the population, both as they were reflected in the ratings of individual items, and in the aggregate ratings of subgroups. They further believed that these discriminations of gross differences within the Delphi forecast were necessary for intelligent decision making about curriculum planning and evaluation.

The second limitation on the study's results was imposed, in implementing the research design, by the editing process employed to develop the instrument for the second round. In the interests of time and manpower, the researchers decided to utilize a simple consensus between themselves as a measure of the inclusion or exclusion of items in the lists prepared from the responses on the first round. Consequently, no inter-judge reliability checks were employed in this process, though other Delphi studies such as one described in some detail by Judd (1972, pp. 10-11) have utilized such procedures to increase the reliability of the second round instruments.

The third and final limitation was similarly a result of the implementation of the research design rather than inherent in the design. This was the fact that, also in the interests of time and manpower, no pilot study was conducted to check the reliability of the Lichert-type 
scale used on the second round. Such a pilot study would have needed to include verbal feedback in order to determine if the points on the scale were truly discriminatory. Another strategy which could have been utilized to further test this scale could have been the inclusion of "ringer" statements in the second round questionnaires. If such statements had not been rated any differently than other statements, then the reliability of the scale would have come into question. This strategy could also have been utilized, as described by Cyphert and Gant (1970), to purposefully skew the modal responses to such items which were reported on the third round questionnaires, in order to determine if convergence on these modes was as great as convergence on other modes in the questionnaire. This would have been another useful test of the discriminatory capacities of the consensus formation procedure utilized in this research study. 


\section{CHAPTER IV}

\section{RESULTS OF THE STUDY}

In the course of the three rounds of the survey, sufficient data was collected to satisfy all nine research objectives of the study.

The first round developed a picture of the roles, functions, and tasks which, in ten years, Master's level social workers would be performing in the field of community mental health in Oregon. It also developed a picture of the skills and areas of knowledge which would be utilized in this practice. The data collected in the second and third rounds defined a future generalizing core of social work practice and education in this field. Further, data from the third round was utilized to form ranked clusters of items within each of the five categories of the generalizing core which suggested priorities for training Master's level social workers specializing in this field of practice. In addition, comparisons of the responses of certain subgroups within the study revealed a number of substantial differences between groups in the conceptualization of this generalizing core, and differences in the clustering of items in the ranked training priority clusters. The se

subgroups were a) social workers and non-social workers; and b) planners, managers, and developers.

\section{ROUND I}

The responses to the first round, as previously explained, were 
analyzed as part of the development of the second round questionnaires. The purpose of this content analysis was to develop a comprehensive picture of the future practice and educational needs of Master's level social workers in the field, and to thus accomplish the first two research objectives of the study. As this data was not analyzed by tabulating the number of times any particular component of this future practice was mentioned, the primary concerns of the researchers were that all the members of the population had an opportunity to contribute their views on this round and that the viewpoint of all three occupational groups and other subgroups were represented in the picture which finally emerged. Therefore, the fact that the response rate of occupational group one was 26 percent greater than the response rate of either of the other two occupational groups (that is, 70 percent as compared to 44 percent) was not of concern to the researchers.

The considerable difference in return rates of the three groups was attributed to the greater personal contact which the researchers had with the members of the first group. Since responses were not being tabulated but only viewpoints gathered, additional viewpoints among the non-respondents would have had the effect of enlarging the data pool rather than skewing the data. Therefore, the researchers did not believe there was need to test for non-response bias among the 48 percent of the population who did not return the first questionnaire. This overall low return rate of responses was attributed directly to the demanding nature of this particular open-ended questionnaire. 
Identifying Data

The professional and paraprofessional orientations of the participants were requested on the first questionnaire. The number of responses received from social workers on this round was 36 , or 73 percent of the number of social workers in the population. The remaining 46 respondents represented 41 percent of the non-social workers in the population. Of this latter group, 17 were trained in psychology, 12 in education, 8 in medicine, and 9 in various other fields, including administration. Both social workers and non-social workers were, in general, evenly distributed in absolute numbers among the three occupational groups represented in the returns.

The differing response rates of social workers and non-social workers was attributed to either the greater interest of social workers in the subject of the study or a felt lack of expertise on the part of nonsocial workers. This latter possibility raised the issue of Cyphert and Gant's experience with varying expertise and, consequently, more effort was put into later rounds in making the non-social workers feel that their responses were valid. Once again, the differing return rates of the two groups was of less concern than that all points of view were at least represented.

\section{Description of Future Practice}

The picture of future practice which emerged from the responses of participants on this round was, as has been indicated, divided into five categories: roles, functions, tasks, skills, and areas of knowledge. Some participants returned quite comprehensive responses 
which contributed suggestions to all five categories. An example of one such questionnaire is included in Appendix B. Other participants drew much sketchier pictures, responding to only one or two que stions. Further, projections more appropriate to one category, such as skills, were occasionally found listed in responses to other questions, such as tasks.

Roles. The respondents suggested 25 roles which, in ten years, they believe Master's level social workers will be occupying in the field of community mental health. Roles were defined by the researchers as the major patterns of behavioral expectations contained in jobs. The responses indicated that jobs in this field will be found in various public and private, direct and indirect, service settings within community mental health delivery systems. These 25 roles, as presented on the second round questionnaire, we re as follows:

1. Administrator - e.g., fiscal administrator, personnel administrator, program administrator

2. Advocate - e.g., client advocate, target population advocate

3. Analyst - e.g., fiscal analyst, policy analyst, systems analyst

4. Assessor - e.g., client needs assessor, community needs assessor, pre-commitment assessor

5. Care Taker - e.g., behavior manager, client care taker

6. Case Manager - e.g., aftercare/follow-along/placement specialist, intake/screening specialist, referral specialist

7. Coordinator - e.g., interagency coordinator, service coordinator

8. Consultant - e.g., administrative consultant, case consultant, program consultant, resource consultant

9. Developer - e.g., case developer, manpower developer, policy developer, program developer 
10. Diagnostician - e.g., behavior diagnostician, psychiatric diagnostician, psychological tester

11. Educator - e.g., college educator, community educator

12. Evaluator - e.g., personnel evaluator, program evaluator

13. Group Facilitator - e.g., community group facilitator, task force facilitator

14. Lobbyist - e.g., political lobbyist, program lobbyist

15. Mediator - e.g., client/agency mediator, personnel mediator

16. Mobilizer - e.g., fund raiser, political mobilizer, resource mobilizer

17. Organizer - e.g., community organizer, social action organizer, task force organizer

18. Planner - e.g., community planner, program planner, service planner

19. Publicist - e.g., program publicist, resource publicist

20. Researcher - e.g., community researcher, program researcher

21. Service Provider - e.g., employment assistance provider, income maintenance provider, legal assistance provider

22. Supervisor - e.g., personnel supervisor, service/treatment supervisor

23. Therapist - e.g., behavior therapist, psychotherapist

24. Trainer - e.g., client trainer, staff trainer

25. Writer - e.g., grant writer, proposal writer, report writer

Functions. The respondents suggested 12 functions which, in ten years, they believe Master's level social workers will be carrying out in their jobs in community mental health service delivery systems. Functions were defined by the researchers as the major classifications of activities relating to system performance into which jobs can be grouped. The researchers consequently discerned three such major 
classifications; that is, a) manager; b) service enabler; and

c) service deliverer. Further, it was found that these activities could be concerned with four distinct population groupings; that is,

a) comprehensive services for all target populations; b) services for people affected by alcohol and drug problems (A\&DP); c) service for people affected by mental or emotional disturbance (MED); and d) services for people affected by mental retardation or developmental disabilities (MRDD). These functions, as presented on the second round questionnaire, were as follows:

MANAGER: includes such roles as Administrator; interagency Coordinator; Evaluator; and Supervisor.

26. Manager of A\&DP program settings

27. Manager of comprehensive mental health program settings

28. Manager of MED program settings

29. Manager of MRDD program settings

SERVICE ENABLER: includes such roles as community needs Assessor; administrative and program Consultant; Developer; college Educator; Lobbyist; Organizer; Publicist; Planner; Researcher; and staff Trainer.

30. Service Enabler for A\&DP program settings

31. Service Enabler for comprehensive mental health program setting $s$

32. Service Enabler for MED program settings

33. Service Enabler for MRDD program settings 
SER VICE DELIVERER: includes such roles as Advocate; precommitment Assessor; Care Taker; Case Manager; case Consultant; services Coordinator; Diagnostician; community Educator; Mediator; Service Provider; Therapist; client Trainer.

34. Service Deliverer in A\&DP program settings

35. Service Deliverer in comprehensive mental health program setting $s$

36. Service Deliverer in MED program settings

37. Service Deliverer in MRDD program settings

Tasks. The respondents suggested 92 tasks which, in ten years, they believe Master's level social workers will be performing as part of their jobs in community mental health service delivery systems. Tasks were defined by the researchers as the discrete, goal-directed activities which make up jobs. The researchers, as has been indicated, thought there was a need to further subdivide this list into 12 classifications, each reflecting a common purpose for all the tasks contained in the group. These classifications were intended to facilitate a clear presentation of this information. The resulting list of tasks, as presented on the second round questionnaire, were as follows:

\section{Analytical Tasks}

1. Analyze a decision-making process (e.g., administrative process, legislative process, political process)

2. Analyze a policy, program, or budget

3. Analyze a relationship with a client (e.g., dynamics, interactions)

4. Analyze a system or organization (e.g., structure, process)

5. Analyze research data (e.g., statistical analysis) 
6. Analyze the structure of a community, county, or the state (e.g., social, economic, political)

7. Conduct a diagnostic analysis (e.g., behavioral diagnosis, psychiatric evaluation, psychological testing, psychosocial diagnosis)

\section{As se s sment Tasks}

8. Assess client needs for mental health services (e.g., intake screening, pre-eommitment investigation)

9. Assess mental health services and delivery systems (e.g. , adequacy, quality)

10. Assess self (e.g., personal and professional strengths and weaknesses)

11. Assess the educational needs of students preparing for mental health occupations

12. Assess the mental health service needs of a community, region, or the state

13. Assess the training needs of mental health personnel

Consultation Tasks

14. Provide administrative consultation to community groups or mental health agencies (e.g., fiscal and personnel management and organization)

15. Provide case consultation to mental health service providers or community resources (e.g., agencies, care takers, courts, professionals, schools)

16. Provide consultation about resources to mental health service providers or community groups (e.g., availability, funding mechanisms and sources, community resources)

17. Provide consultation on mental health issues to business and industry

18. Provide consultation regarding a target population to community groups or mental health service providers (e.g., needs, intervention strategies)

19. Provide expert testimony (e.g., court proceedings, pre-commitment hearings, legislative hearings)

20. Provide program consultation to community groups or mental health agencies (e.g., design, development, evaluation) 
Data Collection Tasks

21. Design and conduct research studies (e.g., community studies, program studies)

22. Design tools for collecting information (e.g., data collection forms, record-keeping systems)

23. Gather information about social or mental health resources (e.g. , availability, location)

24. Interview people (e.g., clients, personnel, research subjects)

25. Maintain records (e.g., case records, services provided, income and expenditures)

26. Observe behavior (e.g., client behavior, organizational behavior) Education and Training Tasks

27. Disseminate information about mental health programs and services (e.g., brochures, program descriptions, resource directories)

28. Educate and train students preparing for mental health occupations

29. Engage in ongoing personal and professional growth and learning

30. Provide a community education program for the general public or a target population

31. Train clients in coping, management, and maintenance skills (e.g., mentally retarded, parents of disabled and disturbed)

32. Train personnel in mental health agencies

Evaluation Tasks

33. Design instruments for as sessment and evaluation (e.g., clients, personnel, program)

34. Monitor and evaluate the progress and needs of clients

35. Monitor and evaluate the performance of mental health personnel, programs, and agencies (e.g., cost effectiveness, productivity)

Identification Tasks

36. Identify communities and populations in need of mental health services 
37. Identify people in need of mental health or social services (e.g., case finding, outreach)

38. Identify problems in need of research

$$
\text { Organization and Development Tasks }
$$

39. Advocate on behalf of communities and target populations for funds and services

40. Develop comprehensive mental health service centers

41. Develop an emergency mental health service

42. Develop a mental health information and referral service

43. Develop new mental health resources (e.g., funding sources, manpower)

44. Develop policies, procedures, and guidelines for mental health services and agencies

45. Develop programs to prevent mental and emotional disturbances, developmental disabilities, mental retardation, or alcohol and drug addiction

46. Mobilize community support for mental health services and target populations (e.g., funds, political support, volunteers)

47. Organize new mental health services or programs in communities

48. Organize social actions (e.g., demonstrations)

49. Organize task forces (e.g., advisory committees, boards of directors, planning bodies

50. Participate in community groups and task forces (e.g., agency, community, state)

51. Lobby on behalf of mental health programs for changes in funding, laws, or policies (e.g., administrative lobbying, legislative lobbying)

52. Write proposals for public or private funding of a mental health service (e.g., grant application, program proposal)

Planning Tasks

53. Plan a budget for a mental health agency or program 
54. Plan and design a coordinated system of mental health services for a community, region, or the state

55. Plan and design an educational program for students preparing for mental health occupations

56. Plan and design a training program for mental health personnel

57. Plan and design the program of a mental health agency

58. Plan an evaluation design for a mental health service or delivery system

59. Plan goals and measurable objectives for mental health agencies, delivery systems, or services

60. Plan goals and measurable objectives with clients

61. Plan intervention strategies for working with clients

62. Plan intervention strategies for working with communities, organizations, and systems

63. Plan services for a client (e.g., normalization, rehabilitation, social services, treatment)

\section{Program Management Tasks}

64. Coordinate mental health programs and agencies (e.g., interagency and intra-agency coordination)

65. Establish priorities for allocating limited resources (e.g., money, personnel, time)

66. Establish standards of performance for mental health agencies, personnel, and services (e.g., evaluative criteria, productivity indicators)

67. Explain and justify the programs of a mental health agency to funding or administrative bodies (e.g., board of directors, legislature, foundations, governmental agencies)

68. Explain programs of mental health agency to personnel

69. Manage a budget for a mental health agency or program

70. Modify a plan, policy, or program on the basis of research and evaluative feedback

71. Monitor the implementation of laws, regulations, policies, or procedures (e.g., monitor contract agencies, monitor personnel) 
72. Negotiate contracts with public or private funding bodies or service providers

73. Recruit, hire, and organize personnel in a mental health agency

74. Supervise personnel (e.g., coordinate workloads, provide support and feedback)

75. Supervise/monitor the provision of services to clients

$$
\text { Service Delivery Tasks }
$$

76. Advocate on behalf of clients for improved benefits and services

77. Coordinate services for clients to insure continuity of care

78. Mediate between client and service systems (e.g., mental health services, social services)

79. Mobilize community resources on behalf of client

80. Negotiate contracts with clients

81. Prescribe and supervise therapeutic medications for clients (e.g., antabuse, methadone, psychotropic drugs)

82. Provide assessment services (e.g., diagnosis, evaluation, problem identification)

83. Provide care-taking services (e.g., behavior management, living environment maintenance, personal care)

84. Provide follow-up services (e.g., after-care, follow-along, placement, supervision)

85. Provide outreach services (e.g., home visits, neighborhood canvas sing)

86. Provide screening services (e.g., information and referral, match client to resources)

87. Provide social services to facilitate social survival (e.g., employment/housing assistance, income maintenance, legal aid)

88. Provide therapeutic intervention services to facilitate behavior change, conflict resolution, and growth (e.g., counseling, rehabilitation, therapy) 
Systems Maintenance Tasks

89. Design and prepare visual descriptions of mental health programs or agencies (e.g., flow charts, graphs, organization plans, PERT charts)

90. Form working relationships with other professionals (e.g., interdisciplinary team)

91. Provide leadership to agencies or community groups (e.g. , delegate responsibility, make decisions)

92. Write reports (e.g., client histories, community assessments, program evaluations)

Skills. The respondents suggested 45 skills which, in ten years, they believe Master's level social workers will be utilizing in the performance of their jobs in community mental health service delivery systems. Skills were defined by the researchers as the ability to effectively apply some process in the performance of a task. These skills, as presented on the second round questionnaire, were as follows:

1. Advocacy skills - e.g., applied to clients, consumers, target populations

2. Analytical skills - e.g., applied to behavior, budgets, communities, policies, political processes, relationships, research data, systems

3. Arbitration skills - e.g., applied to personnel

4. As ses sment skills - e.g., applied to client or community service needs, problems, service adequacy, training needs

5. Care-taking skills - e.g., applied to behavior management, client personal care, living environmental maintenance

6. Case management skills - e.g. , applied to follow-up, referral, screening

7. Communication skills - e.g., applied to feeling, listening, physical communication, verbal communication 
8. Conceptualization skills - e.g., applied to constructs, ideas, relationships

9. Consultation skills - e.g., applied to administration, cases, resource availability, program development

10. Coordination skills - e.g., applied to agencies, programs, services

11. Design skills - e.g., applied to curricula, evaluation instruments, graphics, programs, record-keeping systems, research studies

12. Development skills - e.g., applied to cases, manpower, policies, programs, resources, services

13. Diagnostic skills - e.g., applied to behavioral diagnosis, psychiatric diagnosis

14. Evaluation skills - e.g., applied to personnel, programs

15. Fiscal management skills - e.g., applied to accounting, budgeting, record keeping

16. Forecasting skills - e.g., applied to needs, social trends

17. Group facilitation skills - e.g., applied to community groups, task groups

18. Interpretation skills - e.g., applied to behavior, projective tests, psychotherapy

19. Interviewing skills - e.g., applied to clients, personnel, research subjects

20. Leadership skills - e.g., applied to decision making, delegating responsibilities

21. Lobbying skills - e.g., applied to funds, laws, services

22. Mediation skills - e.g., applied to agencies/clients, personnel

23. Mobilization skills - e.g., applied to fund raising, resources, volunteers

24. Negotiation skills - e.g., applied to program contracts, personnel contracts, treatment contracts

25. Observation skills - e.g., applied to client behavior, organizational activities

26. Office management skills - e.g., applied to equipment, supplies, work flow 
27. Organizing skills - e.g., applied to communities, social actions, task forces

28. Outreach skills - e.g., applied to case finding, case development

29. Personal coping skills - e.g., applied to job survival, selfrenewal

30. Personal management skills - e.g., applied to information, time, workload

31. Per sonnel management skills - e.g., applied to hiring, staff organization, supervision

32. Planning skills - e.g., applied to budgets, delivery systems, programs; normalization, rehabilitation, treatment; service priorities, goals, objectives, strategies

33. Problem-solving skills - e.g., applied to client problems, community problems

34. Program management skills - e.g., applied to client problems, community problems

35. Public relations skills - e.g., applied to disseminating information

36. Public speaking skills - e.g., applied to program presentation, testimony

37. Record-keeping skills - e.g. , applied to cases, expenditures, services

38. Relationship-building skills - e.g. , applied to professional relationships, therapeutic relationships

39. Research skills - e.g., applied to clients, communities, organizations

40. Service provision skills - e.g., applied to income/social services

41. Teaching skills - e.g., applied to college education, community education

42. Therapeutic intervention skills - e.g., applied to counseling, behavior change, psychotherapy, rehabilitation

43. Training skills - e.g., applied to clients, personnel

44. Writing skills - e.g., applied to grants, proposals, reports 
45. Identification skills - e.g., applied to needs, problems, resources

Areas of Knowledge. The respondents suggested 88 areas of knowledge which, in ten years, they believe Master's level social workers will be applying in the performance of their jobs in community mental health service delivery systems. Areas of knowledge were defined by the researchers as disciplines, constructs, theories, concepts, methods, principles, strategies, and empirically derived information. The researchers believed that there was a need to further subdivide this list into five classifications, each reflecting a conceptual unity among the items contained in the group. The se classifications were intended, as in the tasks category, to facilitate a clear presentation of this information. The resulting list of areas of knowledge, as presented on the second round questionnaire, we re as follows:

Academic Disciplines

1. Anthropology

2. Economics

3. Philosophy

4. Political Science

5. Psychology

6. Religion

7. Social Psychology

8. So ciology 
The Human Organism and the Social Environment Constructs, Theories, and Concepts

9. Abnormal psychology/psychopathology

10. Anatomy and Physiology

11. Child rearing

12. Environmental/ecological psychology

13. The Family - e.g., history, structure, dynamics

14. Government - e.g., organization, operation, allocation of resources

15. Groups - e.g., behavior, dynamics

16. Human growth and development

17. Human sexuality

18. Law and legal systems - e.g. , courts

19. Mental health

20. Organizations and bureaucracies

21. Personality theories - e.g., defense and coping mechanisms

22. Political/legislative process

23. Social change

24. Social structure and institutions

25. Systems theory

26. Social deviancy

Individual and Social Problems

27. Alcohol abuse - e.g., types, incidence, causes

28. Developmental disabilities - e.g., types, incidence, causes

29. Drug abuse - e.g., types, incidence, causes

30. Learning disabilities - e.g., types, incidence, causes

31. Mental, emotional, and behavioral disturbances - e.g., types, incidence, causes 
32. Mental retardation - e.g., types, incidence, causes

33. Poverty - e.g., causes, incidence

34. Racism - e.g., causes

Social Welfare Policy and Services

35. Community mental health - e.g., history, philosophy, principles

36. Mental health delivery systems - e.g., allocation of resources, operation, organization

37. Mental health financing - e.g., availability, mechanisms, sources

38. Mental health laws, legislation, and guidelines

39. Mental health manpower - e.g., distribution, paraprofessional roles, professional roles

40. Social policy

41. Social service delivery systems - e.g., allocation of resources, operation, organization

42. Social service financing - e.g., availability, mechanisms, sources

43. Social welfare laws, legislation, and guidelines

Social Work Application and Practice

Concepts, Methods, Principles, Strategies, and Theories

44. Administration

45. Accountability

46. Behavior analysis and modification

47. Business management

48. Cas ework

49. Citizen/consumer participation

50. Client/consumer advocacy

51. Community organization

52. Confidentiality and civil rights 
53. Conflict resolution

54. Consultation

55. Continuity of care

56. Crisis intervention

57. Demography

58. Epidemiology

59. Evaluation - e.g., goal attainment scaling

60. Family psychotherapy

61. Group psychotherapy

62. Group work

63. Individual psychotherapy

64. Interper sonal communication and relations

65. Intervention with alcohol abusers - e.g., needs, treatment modalities

66. Intervention with drug abusers - e.g., needs, treatment modalities

67. Intervention with the developmentally disabled - e.g., needs, strategies

68. Intervention with the mentally retarded - e.g., needs, strategies

69. Intervention with the mentally or emotionally disturbed - e.g. , needs, treatment modalities

70. Medical model - e.g., etiology, diagnosis, treatment

71. Normalization and life span planning

72. Parliamentary procedure

73. Personnel management

74. Prevention - primary, secondary, tertiary

75. Problem-oriented record keeping

76. Program development 
77. Program management - e.g., management by objectives, management information systems

78. Problem-solving process

79. Psychiatric classifications and nomenclature

80. Psychometric testing and interpretation

81. Psychopharmacology - e.g., medication effects and side effects

82. Public relations

83. Rehabilitation

84. Research

85. Social forecasting

86. Social planning

87. Social work principles and code of ethics

88. Supervision

General Projections About the Future

There were several respondents who chose to ignore the format of the first questionnaire and instead wrote general statements about the future of community mental health and social work practice. Other respondents, in addition, supplemented their answers to the questions with such observations. The resulting picture was both interesting and instructive.

The first subject of the se forecasts was future developments in the community mental health field. One participant wrote that

I expect that the $\mathrm{CMH}$ system will be undergoing some drastic changes in the next few years [because of the impact of national health insurance]... I expect that many if not most patients treated in $\mathrm{CMH}$ clinics now will in the future be treated by therapists in private practice. It could well be that the Division of Mental Health will only be providing custodial services for alcoholics..., providing programs for 
the developmentally disabled, and carrying out programs in primary prevention.... I see the role of the MHD moving away from treatment and toward program planning. The $\mathrm{CMH}$ clinic will become a "clearing house" for contracts and program budgets.

A second respondent concurred on the movement of therapists toward private practice and suggested that "CMH programs will attend more to chronic populations and to developing and maintaining community systems to avoid institutionalization." Another suggested that community organizing will generally be more important in this field in the future than at present. A fourth writer suggested that there will be much greater emphasis on delivering services to people in their own homes in ten years.

The second subject of these general forecasts was the future position of the social worker in this field, and these projections were much more contradictory than those in the first group. One participant saw no role at all for social workers in this field but more need for educators and paraprofessionals, particularly with the MRDD population. Several suggested that social workers will be found increasingly in major administrative roles in community programs as supervisors, as coordinators, as community planners, and as evaluators. Others suggested that there will be fewer social workers involved in administration and that professionals with business backgrounds will be employed in the se positions.

One participant suggested that social workers will be "swallowed up in the administrative umbrella being created by the state," while another believed that social workers will be taking more leadership responsibility in the field. Finally, one respondent indicated that the 
clinical social worker role will become increasingly specialized around alcoholism, family life education/treatment, crisis intervention, and residential treatment, while another suggested that social. workers will have increasingly more responsibility for supervising and training paraprofessionals who, in the view of this respondent, will be providing most of the direct services. As can be seen, there was not a great deal of agreement in these forecasts about the position of social workers in either direct or indirect services. This is perhaps not surprising in a field which will be undergoing major and rapid changes according to these projections. 


\section{ROUND II}

The responses to the second round, as previously explained, were analyzed as part of the development of the third round questionnaires.

\section{Identifying Data}

The current position, degree, profession, age, and sex of the participants were requested on the second round questionnaires. The data received indicated that the characteristics of the participants who responded to the "Roles, Functions, and Tasks" questionnaire and those who responded to the "Skills and Knowledge" que stionnaire were remarkably similar on all dimensions except population focus. These characteristics are compared in Table IV.

\section{TABLE IV}

\section{CHARACTERISTICS OF RESPONDENTS ON ROUND II}

Total

Occupational

Group

Planners

Managers

Developers

Age

mean

range

\section{RFT Questionnaire}

$$
50-100 \%
$$$$
16-32 \%
$$$$
14-28 \%
$$$$
20-40 \%
$$

SK Questionnaire

$$
64-100 \%
$$

$$
21-33 \%
$$$$
15-23 \%
$$$$
27-44 \%
$$
37 years
38 years
$26-62$ years
24 - 59 years 
$\underline{\text { Sex }}$

RFT Questionnaire

Male

Female

$\underline{\text { Degree }}$

B. A.

M.S.W.

Ph. D. /M. D.

Other

Training

Social work

Psychology

Education

Medicine

Other

Year Graduated

median

range

Location of

Responsibilities

Small Town/Rural

Metropolitan

Mixed
$32-64 \%$

$18-36 \%$

$7-14 \%$

$35-70 \%$

$5-10 \%$

$3-6 \%$

$22-44 \%$

$10-20 \%$

$6-12 \%$

$2-4 \%$

$10-20 \%$

1967

$1942-1974$
SK Questionnaire

$$
\begin{aligned}
& 45-70 \% \\
& 19-30 \%
\end{aligned}
$$

$10-16 \%$

$42-66 \%$

$9-14 \%$

$3-5 \%$

$28-44 \%$

$11-17 \%$

$4-6 \%$

$6-9 \%$

$15-23 \%$

1967

$1941-1974$

$38-59 \%$

$6-9 \%$

$5-10 \%$

$14-28 \%$

$20-31 \%$ 
Population Focus

$\begin{array}{lrc}\text { All populations } & 13-26 \% & 13-20 \% \\ \text { A\&DP populations } & 9-18 \% & 15-27 \% \\ \text { MED populations } & 14-28 \% & 23-36 \% \\ \text { MRDD populations } & 14-28 \% & 11-16 \%\end{array}$

RFT Questionnaire
SK Questionnaire

$-16 \%$

The data indicated that 50 social workers responded on the round two questionnaire, one more than the number in the population. This figure represented seven questionnaires sent to non-social workers which were completed by social workers. These respondents were designated to represent the views of four hospital superintendents, two community mental health program directors, and one business officer. The number of social workers in the population was consequently increased to 56, and the adjusted return rate for social workers was 89 percent, compared to a return rate for non-social workers of 62 percent. The two groups were consequently almost evenly represented on both questionnaires in terms of absolute numbers.

\section{Modal Responses}

The responses to the second round were tabulated by computer. The frequency and percentage distributions of ratings on each item were computed in order to determine the modal responses, which would be reported on the third round questionnaires. The distribution of the modal responses on the two questionnaires was quite similar, with all the modal responses but one item falling on or between the 3 , 4 , and 5 nodes. 
TABLE V

DISTRIBUTION OF MODAL RESPONSES ON ROUND II FREQUENCY AND PERCENT AGE

MODAL RESPONSE

\begin{tabular}{lllllllll}
\hline RFT QUESTIONNAIRE & & & & & & & \\
& 1 & 2 & 3 & tie & 4 & tie & 5 & Total \\
\hline Total & 1 & 0 & 36 & 6 & 78 & 3 & 5 & 129 \\
& 1 & 0 & $28 \%$ & $5 \%$ & $60 \%$ & $2 \%$ & $4 \%$ & $100 \%$ \\
\hline Roles & 0 & 0 & 9 & 1 & 14 & 0 & 1 & 25 \\
& 0 & 0 & $36 \%$ & $4 \%$ & $56 \%$ & 0 & $4 \%$ & $100 \%$ \\
Functions & 0 & 0 & 3 & 0 & 7 & 0 & 2 & 12 \\
& 0 & 0 & $25 \%$ & 0 & $58 \%$ & 0 & $17 \%$ & $100 \%$ \\
Tasks & 1 & 0 & 24 & 5 & $57 \%$ & 3 & 2 & 92 \\
& $1 \%$ & 0 & $26 \%$ & $5 \%$ & $62 \%$ & $3 \%$ & $2 \%$ & $100 \%$ \\
\hline \multirow{2}{*}{ SK QUESIONNAIR E } & & & & & & & & \\
& 1 & 2 & 3 & tie & 4 & tie & 5 & Total \\
\hline Total & 0 & 0 & 32 & 3 & 76 & 4 & 18 & 133 \\
& 0 & 0 & $24 \%$ & $2 \%$ & $57 \%$ & $3 \%$ & $14 \%$ & $100 \%$ \\
\hline Skills & 0 & 0 & 14 & 1 & 24 & 2 & 4 & 45 \\
& 0 & 0 & $31 \%$ & $2 \%$ & $53 \%$ & $4 \%$ & $9 \%$ & $99 \%$ \\
Areas of & 0 & 0 & 18 & 1 & 52 & 2 & 14 & 88 \\
Knowledge & 0 & 0 & $20 \%$ & $2 \%$ & $59 \%$ & $2 \%$ & $16 \%$ & $99 \%$ \\
\hline
\end{tabular}

Non-Response Bias

An abbreviated "Roles, Functions, and Tasks" questionnaire of 15 items was constructed in order to test for the existence of a bias in the views of non-respondents on the second round. Such a bias presumably could have skewed the tabulated results of this questionnaire. These were four social workers in the sample of seven nonrespondents. 
It was found that, while there was a tendency in these responses to rank items higher than on the complete questionnaire, this tendency was within reasonable limits on all but one of the items. "Reasonable" limits was considered a difference in the distribution of responses of less than 25 percent between the abbreviated questionnaire and the complete questionnaire, with the scale dichotomized into two points: 1-2-3 and 4-5. On the abbreviated questionnaire, 7 of the 15 items had response distributions which were between 10 and 20 percent greater on the 4-5 nodes than were distributed on these nodes on the complete questionnaire. Only one item exceeded a 25 percent difference, which was considered substantial. However, a comparison of the item mean responses between the abbreviated and complete questionnaire revealed that all of the means were within 0.4 of one another, which was not considered a substantial difference.

On the basis of this data, which can be found in Appendix B, it was concluded that no general pattern of significant differences existed in the responses of non-respondents as compared to respondents to the questionnaire, other than a general tendency to rate the items higher. This tendency was attributed to the unbalanced number of social workers in the sample who, on the complete questionnaire, tended as a group to rate items higher than non-social workers. (See this chapter, section IV, Social Workers and Non-Social Workers.) Thus, the researchers believed that the tabulated data on the complete "Roles, Functions, and Tasks" questionnaire could be considered an accurate reflection of the opinions of the entire sample selected to receive the second round questionnaire. 


\section{ROUND III}

The responses to this round, as with the second round, were tabulated by computer to determine the distribution of responses, the means, and the standard deviations. This data was utilized for a number of analytical purposes. It was first compared with the data collected on round two to determine the changes between rounds two and three. Second, it was utilized to determine the items on which no group judgments were made during the two rounds. Third, it was utilized to define the generalizing core of Master's level social work practice and education in this field in ten years. This accomplished the third research objective of the study. Fourth, it was utilized to determine the ranked clusterings of items within each category that would constitute priorities for training Master's level social workers specializing in this field of practice. This accomplished the fourth research objective of the study.

\section{Comparison With Round II}

The distribution of modal responses on round three was, with the exception of broken ties, identical to the distribution on round two. At the same time, the data indicated that on the third round there was, for both questionnaires, actual convergence on the modal responses of the second round. In fact, there was a net convergence on the modal response for 93 percent of the items contained in the two questionnaires, and this convergence involved, on the average, 5 to 6 percent 
of the responses to each question. The data further indicated that there was more general change on both questionnaires toward the mode than was reflected in the figures for actual convergence on the modal responses.

Data collected from the "Roles, Functions, and Tasks" questionnaires on both rounds is summarized in Table VI. This table reflects an average convergence on the mode of 5.9 percent of the responses on the third round of the RFT questionnaire. Of the 49 questionnaires returned on this round, 36, or 73 percent of the questionnaires, contained items which were re-rated. The greatest change was 47 items. The mean change for all the questionnaires returned was 11 items per questionnaire. Since Table VI shows that the net change in modal responses per questionnaire was 7.8 items, there was a movement of three items per questionnaire accounted for. An item-by-item analysis revealed that on 118 of the 129 items in the questionnaire, there was a net increase in the percentage of responses on the mode of from 2 to 14 percent per item. Only two of the remaining 11 items showed a net decrease, and that of only 2 percent. As this latter figure was insufficient to account for the three-item difference per questionnaire, it was concluded that there was more movement on the average toward the mode than was reflected in actual convergence on the mode for this questionnaire.

Data collected from the "Skills and Areas of Knowledge" questionnaire on both rounds is summarized in Table VII. This table reflects a convergence on the mode of 5.3 percent of the responses on the third round of the SK questionnaire. Of the 61 questionnaires which 
TABLE VI

ROLES, FUNCTIONS, AND TASKS QUESTIONNAIRE COMPARISON OF ROUNDS II AND III

\begin{tabular}{cccc} 
Mean & \multicolumn{2}{c}{ ROUND III } & \\
& Standard & Modal Responses & Percent \\
Deviation & Per Questionnaire & Responses \\
at Mode
\end{tabular}

\begin{tabular}{lrrrr} 
Total & 3.56 & .96 & 62.1 & $48.0 \%$ \\
\hline Roles & 3.47 & .88 & 12.5 & $50.0 \%$ \\
Functions & 4.10 & 1.09 & 5.9 & $49.0 \%$ \\
Tasks & 3.51 & .96 & 43.7 & $48.0 \%$ \\
& & & & \\
Total & 3.56 & 1.04 & 54.3 & $42.1 \%$ \\
\hline Roles & 3.47 & .98 & 10.7 & $43.0 \%$ \\
Functions & 3.80 & 1.31 & 5.3 & $44.0 \%$ \\
Tasks & 3.55 & 1.02 & 38.3 & $41.7 \%$
\end{tabular}

NET CHANGE

\begin{tabular}{lcccc} 
Total & 0.0 & -0.08 & +7.8 & $+5.9 \%$ \\
\hline Roles & 0.0 & -0.10 & +1.8 & $+7.0 \%$ \\
Functions & +0.3 & -0.22 & +0.6 & $+5.0 \%$ \\
Tasks & -0.4 & -0.06 & +5.4 & $+6.3 \%$
\end{tabular}


TABLE VII

SKILLS AND AREAS OF KNOW LEDGE QUESTIONNAIRE COMPARISON OF ROUNDS II AND III

\begin{tabular}{|c|c|c|c|}
\hline Mean & $\begin{array}{l}\text { Standard } \\
\text { Deviation }\end{array}$ & $\begin{array}{l}\text { Modal Responses } \\
\text { Per Questionnaire }\end{array}$ & $\begin{array}{l}\text { Percent } \\
\text { Responses } \\
\text { at Mode }\end{array}$ \\
\hline
\end{tabular}

\begin{tabular}{lcccc} 
Total & 3.78 & .86 & 64.7 & $48.7 \%$ \\
\hline Skills & 3.68 & .83 & 21.6 & $48.0 \%$ \\
$\begin{array}{l}\text { Areas of } \\
\text { Knowledge }\end{array}$ & 3.83 & .87 & 43.1 & $49.0 \%$ \\
& \multicolumn{4}{r}{ ROUND II }
\end{tabular}

\begin{tabular}{lllll} 
Total & 3.74 & 0.97 & 57.8 & $43.4 \%$ \\
\hline Skills & 3.67 & 0.99 & 18.9 & $42.0 \%$
\end{tabular}

Areas of

$\begin{array}{lllll}\text { Knowledge } & 3.77 & 0.96 & 38.9 & 44.2 \%\end{array}$

NET CHANGE

\begin{tabular}{lllll} 
Total & +.04 & -.11 & +6.9 & $+5.3 \%$ \\
\hline Skills & +.01 & -.16 & +2.7 & $+6.0 \%$
\end{tabular}

Areas of

$\begin{array}{llll}\text { Knowledge }+.06 & -.09 & +4.2 & +4.8 \%\end{array}$


were returned, 42 , or 69 percent of the questionnaires, contained items which were re-rated. The greatest change was 88 , and the mean change for all the questionnaires returned was 10 items per questionnaire. Since Table VII shows that the net change in modal responses per questionnaire was 6.9 items, there was also a movement of three items per questionnaire unaccounted for on the SK questionnaire. An item-by-item analysis revealed that there was a net increase in the percentage of responses on the mode of from 2 to 14 percent per item on 125 of the 133 items on the questionnaire, and no net movement away from the mode on any of the items. It was therefore concluded that there was more movement on the average toward the mode than was reflected in actual convergence on the mode for this questionnaire.

Effect of Fatigue. In comparing the responses between rounds two and three on both questionnaires, it appeared to the researchers that there was more general change on the earlier items in the questionnaires than on the later items. It was suspected that the length of the questionnaires resulted in more effect on the responses from fatigue than had been anticipated. While no formal provisions had been made in the research design for testing the impact of this effect, the researchers attempted some rough intra-questionnaire comparisons, which are revealed in Table VIII.

The noticeable decline in the change in standard deviation totals between the initial 11 items in each questionnaire and the last 11 items, while hardly conclusive, did suggest that fatigue may have been a definite factor in round three responses. 
TABLE VIII

EFFECT OF FATIGUE ON ROUND III STANDARD DEVIATION TOTALS

ROLES, FUNCTIONS, AND TASKS

$\begin{array}{rccc}\text { Items } & \text { Round II } & \text { Round III } & \text { Change } \\ 1-11 & 11.0 & 10.1 & -.9 \\ 75-85 & 10.8 & 10.2 & -.6 \\ 119-129 & 11.2 & 10.9 & -.3\end{array}$

\section{SKILLS AND AREAS OF KNOW LEDGE}

$\begin{array}{rccc}\text { Items } & \text { Round II } & \text { Round III } & \text { Change } \\ 1-11 & 10.0 & 8.3 & -1.7 \\ 75-85 & 10.5 & 8.8 & -1.7 \\ 123-133 & 12.1 & 11.2 & -.9\end{array}$

\section{Group Judgments}

For the purposes of determining group judgments, responses on the third round were analyzed by dichotomizing the scale into two points: 1-2-3 responses and 4-5 responses. Group judgments were not considered to have been made for items a) on which 60 percent of the responses did not fall on one of the two points of this scale; b) which were bipolar in response distribution; or c) on which there was no change and convergence between the two rounds. The figure of 60 percent, as previously indicated, had been chosen arbitrarily as a cut-off point, since it seemed to indicate fairly strong agreement in one direction. Further, an exception was made to condition c) for those items on which initial convergence was high ( 80 percent) on 
round two. Use of these criteria revealed 65 items in the two questionnaires, or 24 percent of the total items, for which no group judgments can be said to have been formed. Further, there were no bipolar distributions of answers on either questionnaire.

On the "Roles, Functions, and Tasks" questionnaire, there were 41 of the 129 items, or 32 percent, for which no group judgments were formed. Within the roles category, there were two such cases, or 8 percent of the items. These were numbers 10. Diagnostician; and 25. Writer. Within the function category, there were three such cases, or 25 percent of the items. These were numbers 29. Manager of MRDD program settings; 30. Service Enabler for A\&DP program settings; and 37. Service Deliverer in MRDD program settings. Within the tasks category, there were 36 cases, or 39 percent of the items, on which no agreement was reached. These tasks, which have been shortened in the interests of brevity, were as follows:

1. Analyze a decision-making process

4. Analyze a system or organization

6. Analyze the structure of a community, county, or the state

13. Assess the training needs of mental health personnel

14. Provide administrative consultation

19. Provide expert testimony

24. Interview people

30. Provide a community education program

31. Train clients in coping, management, and maintenance skills

32. Train personnel in mental health agencies 
35. Monitor and evaluate the performance of mental health personnel, programs, and agencies

37. Identify people in need of mental health or social services

39. Advocate on behalf of communities and target populations

40. Develop comprehensive mental health service centers

41. Develop an emergency mental health service

42. Develop a mental health information and referral service

43. Develop new mental health resources

44. Develop policies, procedures, and guidelines for mental health services and agencies

45. Develop programs to prevent mental and emotional disturbances, developmental disabilities, mental retardation, or alcohol and drug addiction

52. Write proposals for funding of a mental health service

53. Plan a budget for a mental health agency or program

54. Plan and design a coordinated system of mental health services

57. Plan and design the program of a mental health agency

58. Plan an evaluation design for a mental health service or delivery system

66. Establish standards of performance for mental health agencies, personnel, and services

67. Explain and justify the programs of a mental health agency to funding or administrative bodies

68. Explain programs of a mental health agency to personnel

70. Modify a plan, policy, or program on the basis of research and evaluative feedback

71. Monitor the implementation of laws, regulations, policies, or procedures

72. Negotiate contracts with funding bodies or service providers

73. Recruit, hire, and organize personnel in a mental health agency 
78. Mediate between client and service systems

79. Mobilize community resources on behalf of a client

80. Negotiate contracts with clients

82. Provide assessment services

87. Provide social services

The reader's attention is drawn to the increasing proportion of nongroup judgments in the latter portions of the questionnaire. This again suggested that fatigue may have been a more important factor in response distribution than had been anticipated.

On the "Skills and Areas of Knowledge" questionnaire there were 24 of the 133 items, or 18 percent, for which no group judgments were formed, a considerably smaller percentage than un the RFT questionnaire. Within the skills category, there were nine such cases, or 20 percent of the items. These were numbers 12. Development skills; 16. Forecasting skills; 22. Mediation skills; 24. Negotiation skills; 28. Outreach skills; 30. Personal management skills; 31 . Personnel management skills; 36. Public speaking skills; and 37. Record keeping skills. Within the areas of knowledge category, there were 15 such cases, or 17 percent of the items. These items were numbers 1. Anthropology; 2. Environmental/ecological psychology;

14. Government; 22. Political/legislative process;24. Social Structure and institutions; 32. Mental retardation; 33. Poverty; 50. Client/consumer advocacy; 67. Intervention with the developmentally disabled; 68. Intervention with the mentally retarded; 71. Normalization and life span planning; and 85 . Social forecasting. 
Generalizing Core of Practice and Education

For the purposes of defining a future generalizing core of Master's level social work practice and education in the field of community mental health, the data was analyzed to determine those items which a group judgment had rated on the 4-5 point of the dichotomized scale. Agreement had thus been reached among the respondents that, in ten years, these roles, functions, and tasks will be performed frequently or very frequently, and that these skills and areas of knowledge will be utilized frequently or very frequently. Analysis revealed that 146 of the 262 items in the two questionnaires defined the generalizing core of practice and education in this field. The strength of agreement on these items, indicated by the percentage of respondents who listed the item as a 4 or 5 , was assumed to be a measure of consensual validation of the item's frequent occurrence in the future. This measure was therefore used as a measure of confidence in the item as an element of this core.

On the "Roles, Functions, and Tasks" questionnaire, 60 of the 129 items, or 47 percent, were suggested by the responses of participants as components of the core of social work practice in this field in ten years. For the 60 items, there was a mean strength of agreement of 71 percent.

Within the roles category, 14 roles, or 56 percent of the items, were suggested as components of this core of practice. These items, listed with their respective strengths of agreement, were as follows: 


\begin{tabular}{|c|c|c|c|c|}
\hline Agreement & Role & Agreement & & Role \\
\hline $74 \%$ & 1. Administrator & $60 \%$ & 12. & Evaluator \\
\hline $72 \%$ & 2. Advocate & $78 \%$ & 13. & $\begin{array}{l}\text { Group } \\
\text { Facilitator }\end{array}$ \\
\hline $78 \%$ & 4. Assessor & $62 \%$ & 17. & Organizer \\
\hline $\begin{array}{l}68 \% \\
74 \%\end{array}$ & $\begin{array}{l}\text { 6. Case Manager } \\
\text { 7. Coordinator }\end{array}$ & $66 \%$ & 18. & Planner \\
\hline $78 \%$ & 8. Consultant & $82 \%$ & 22. & Supervisor \\
\hline $78 \%$ & 9. Developer & $68 \%$ & 24. & Trainer \\
\hline
\end{tabular}

Within the functions category, eight functions, or 67 percent of the items, were suggested as elements of this core of practice. These items, listed with their strengths of agreement, were as follows:

\section{Agreement Function}

$62 \%$ 26. Manager of A\&DP program settings

$76 \%$ 27. Manager of comprehensive mental health program setting $s$

$88 \%$ 28. Manager of MED program settings

70\% 31. Service Enabler for comprehensive mental health program settings

$76 \%$ 32. Service Enabler for MED program settings

$61 \%$ 34. Service Deliverer in A\&DP program settings

$76 \%$ 35. Service Deliverer in comprehensive mental health program settings

$82 \%$ 36. Service Deliverer in MED program settings

Within the tasks category, 38 tasks, or 41 percent of the items, were suggested as part of this core of practice. These items, listed with 
their strengths of agreement, were as follows:

\begin{tabular}{|c|c|c|}
\hline Agreement & & Task \\
\hline $65 \%$ & 2. & Analyze a policy, program, or budget \\
\hline $81 \%$ & 3. & Analyze a relationship with a client \\
\hline $65 \%$ & 7. & Conduct a diagnostic analysis \\
\hline $72 \%$ & 8. & Assess client needs for mental health services \\
\hline $77 \%$ & 9. & Assess mental health services and delivery systems \\
\hline $72 \%$ & 10. & Assess self \\
\hline $71 \%$ & 12. & $\begin{array}{l}\text { Assess the mental health service needs of a } \\
\text { community, region, or the state }\end{array}$ \\
\hline $84 \%$ & 15. & $\begin{array}{l}\text { Provide case consultation to mental health service } \\
\text { providers or community resources }\end{array}$ \\
\hline $73 \%$ & 16. & $\begin{array}{l}\text { Provide consultation about resources to mental health } \\
\text { service providers or community groups }\end{array}$ \\
\hline $64 \%$ & 18. & $\begin{array}{l}\text { Provide consultation regarding a target population to } \\
\text { community groups or mental health service providers }\end{array}$ \\
\hline $68 \%$ & 20. & $\begin{array}{l}\text { Provide program consultation to community groups or } \\
\text { mental health agencies }\end{array}$ \\
\hline $70 \%$ & 25. & Maintain records \\
\hline $68 \%$ & 26. & $\begin{array}{l}\text { Observe behavior (e.g., client behavior or } \\
\text { organizational behavior) }\end{array}$ \\
\hline $72 \%$ & 29. & $\begin{array}{l}\text { Engage in ongoing personal and professional growth } \\
\text { and learning }\end{array}$ \\
\hline $72 \%$ & 34. & Monitor and evaluate the progress and needs of clients \\
\hline $61 \%$ & 36. & $\begin{array}{l}\text { Identify communities and populations in need of mental } \\
\text { health services }\end{array}$ \\
\hline $63 \%$ & 46. & $\begin{array}{l}\text { Mobilize community support for mental health } \\
\text { services and target populations }\end{array}$ \\
\hline $61 \%$ & 47. & $\begin{array}{l}\text { Organize new mental health services or programs in } \\
\text { communities }\end{array}$ \\
\hline
\end{tabular}


Agreement

Task

$61 \%$ 49. Organize task forces

$82 \%$ 50. Participate in community groups and ta sk forces

$63 \%$ 59. Plan goals and measurable objectives for mental health agencies, delivery systems, or services

$81 \%$ 60. Plan goals and measurable objectives with clients

$74 \%$ 61. Plan intervention strategies for working with clients

$67 \%$ 62. Plan intervention strategies for working with communities, organizations, and systems

$70 \%$ 63. Plan services for a client (e.g., normalization, rehabilitation, social services, treatment)

$63 \%$ 64. Coordinate mental health programs and agencies

$65 \%$ 65. Establish priorities for allocating limited resources (e.g. , money, personnel, time)

$61 \%$ 69. Manage a budget for a mental health agency or program

$62 \%$ 74. Supervise personnel

$77 \%$ 75. Supervise/monitor the provision of services to clients

$61 \%$ 76. Advocate on behalf of clients for improved benefits

$72 \% \quad 77$. Coordinate services for clients to insure continuity of care

73\% 84. Provide follow-up services

$62 \%$ 86. Provide screening services

$78 \%$ 88. Provide therapeutic intervention services to facilitate behavior change, conflict resolution, and growth

$81 \% 90$. Form working relationships with other professionals

70\% 91. Provide leadership to agencies or community groups

$85 \%$ 92. Write reports

On the "Skills and Areas of Knowledge" que stionnaire, 86 of the 
items, or 65 percent, were suggested by the responses of participants as components of the core of social work education in this field in ten years. For the 86 items, the mean strength of agreement was 78 percent, 7 percent higher than on the RFT questionnaire.

Within the skills category, 26 skills, or 58 percent of the items, were suggested as elements of this core of education. These items, listed with their strengths of agreement, were as follows:

\begin{tabular}{|c|c|c|}
\hline Agreement & & Skill \\
\hline $64 \%$ & 1. & Advocacy skills \\
\hline $86 \%$ & 2. & Analytical skills \\
\hline $93 \%$ & 4. & Assessment skills \\
\hline $71 \%$ & 6. & Case management skills \\
\hline $94 \%$ & 7. & Communication skills \\
\hline $83 \%$ & 8. & Conceptualization skills \\
\hline $87 \%$ & 9. & Consultation skills \\
\hline $83 \%$ & 10. & Coordination skills \\
\hline $82 \%$ & 13. & Diagnostic skills \\
\hline $68 \%$ & 14. & Evaluation skills \\
\hline $79 \%$ & 17. & Group facilitation skills \\
\hline $62 \%$ & 18. & Interpretation skills \\
\hline $87 \%$ & 19. & Interviewing skills \\
\hline $90 \%$ & 20. & Leadership skills \\
\hline $76 \%$ & 25. & Observation skills \\
\hline $63 \%$ & 27. & Organizing skills \\
\hline $80 \%$ & 29. & Personal coping skills \\
\hline
\end{tabular}




\begin{tabular}{lll} 
Agreement & \multicolumn{1}{c}{ Skill } \\
$76 \%$ & 32. Planning skills \\
$93 \%$ & 33. Problem-solving skills \\
$79 \%$ & 34. Program management skills \\
$63 \%$ & 35. Public relations skills \\
$91 \%$ & 38. Relationship-building skills \\
$84 \%$ & 42. Therapeutic intervention skills \\
$72 \%$ & 43. Training skill s \\
$64 \%$ & 44. Writing skills \\
$73 \%$ & 45. Identification skills
\end{tabular}

Within the areas of knowledge category, 60 areas of knowledge, or 68 percent of the items, were suggested as part of this core of education. These items, listed with their strengths of agreement, were as follows:

Agreement Area of Knowledge
$94 \%$
5. Psychology
$94 \%$
7. Social Psychology
$84 \%$
8. So ciology
$81 \%$ 9. Abnormal psychology/psychopathology
$89 \%$ 11. Child rearing
$87 \%$ 13. The Family
$92 \% \quad 15$. Groups
$86 \%$ 16. Human growth and development
$88 \%$ 17. Human sexuality
$71 \% \quad 18$. Law and legal systems 


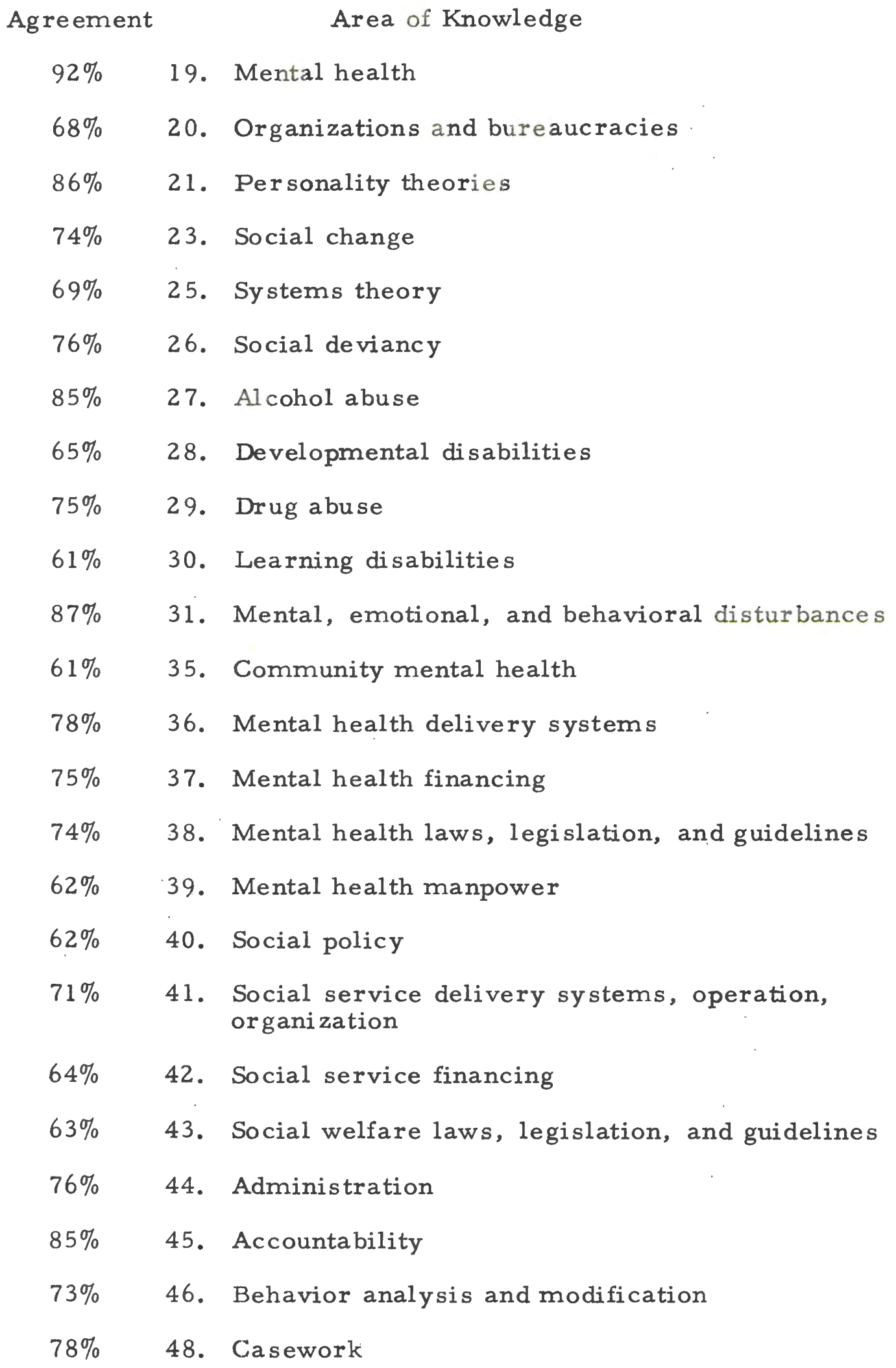




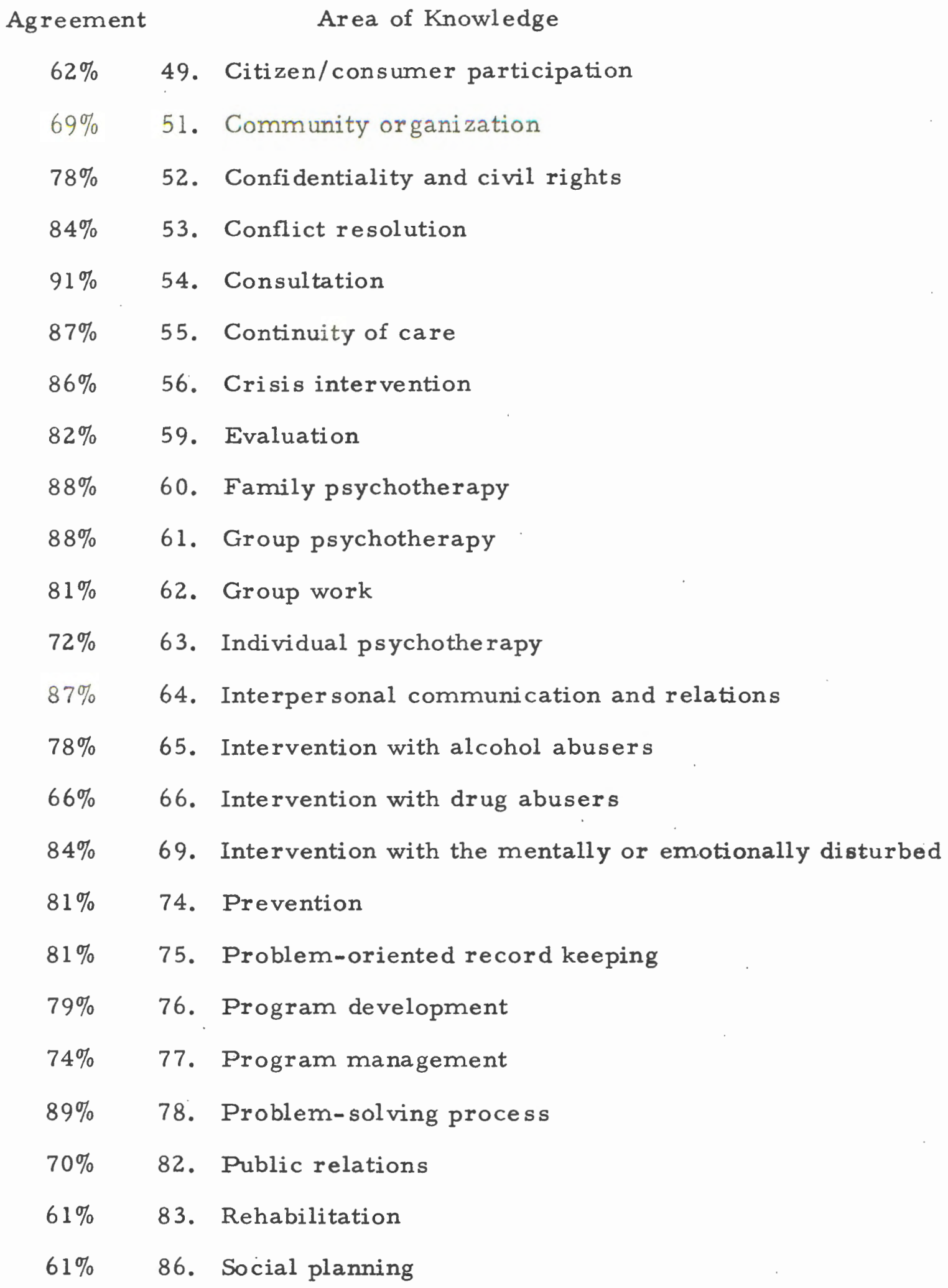


Agreement Area of Knowledge

$67 \%$ 87. Social work principles and code of ethics

$81 \% \quad 88$. Supervision

Training Priorities

For the purposes of determining training priorities, the data was analyzed by classifying the components of the future generalizing core of Master's level social work practice and education on the basis of the mean responses for the items. Items were grouped into ranked clusters within each category when the mean responses for at leas $t$ two items fell into the following mean sets: a) $4.8-4.7$; b) $4.6-4.5$; c) $4.4-4.3$; d) $4.2-4.1$; and 3) $4.0-3.9$. The items in the se clusters were considered priorities for training Master's level social workers specializing in community mental health as a field of practice. The use of mean response sets in this analysis, as previously explained, was an arbitrary decision. It was a result of a need to utilize a measure which was both sensitive to the overall distribution of responses and which would facilitate classification of the components of the generalizing core into ranked groups.

Analysis revealed that, by utilizing these criteria, 53 of the 146 items which defined the generalizing core of practice and education in this field, or 36 percent of the items, could be grouped into two clusters within each category. Further, 22 additional items could be grouped into a third cluster in two categories. The data also revealed that the average of the mean responses for the clusters in the RFT questionnaire was considerably lower than the average of the mean 
responses for the first two clusters in the SK questionnaire, or 4.0 as compared to 4.4 .

On the "Roles, Functions, and Tasks" questionnaire, 10 items, or 17 percent, could be grouped into first priority training clusters, and an additional 22 items, or 37 percent, could be grouped into second priority training clusters. The 32 items in the two clusters thus represented 54 percent of all the components of the suggested future core of social work practice.

Within the role category, two items grouped in the first cluster, and an additional seven items grouped in the second cluster. The nine items represented 64 percent of the core roles suggested by the data. The average of the mean responses for both clusters was 4.0 . These items were as follows:

\begin{tabular}{|c|c|c|}
\hline & Mean & Role \\
\hline \multirow{2}{*}{ Cluster I } & 4.2 & 4. Assessor \\
\hline & 4.1 & 8. Consultant \\
\hline \multicolumn{3}{|c|}{$\ldots-\ldots-\ldots-\ldots$} \\
\hline \multirow{7}{*}{ Cluster II } & 3.9 & 1. Administrator \\
\hline & 3.9 & 6. Case Manager \\
\hline & 3.9 & 7. Coordinator \\
\hline & 3.9 & 9. Developer \\
\hline & 3.9 & 13. Group Facilitator \\
\hline & 3.9 & 22. Supervisor \\
\hline & 3.9 & 23. Therapist \\
\hline
\end{tabular}

Within the function category, three items grouped in the first cluster, and an additional two items grouped in the second cluster. The five items represented 63 percent of the core functions suggested 
by the data. The average of the mean responses for both clusters was 4.0. These items were as follows:

\begin{tabular}{|c|c|c|c|}
\hline & Mean & & Function \\
\hline & 4.2 & 36. & $\begin{array}{l}\text { Service Deliverer in MED } \\
\text { program settings }\end{array}$ \\
\hline Cluster I & 4.1 & 28. & $\begin{array}{l}\text { Manager of MED program } \\
\text { settings }\end{array}$ \\
\hline & 4.1 & 35. & $\begin{array}{l}\text { Service Deliverer in } \\
\text { comprehensive mental health } \\
\text { program settings }\end{array}$ \\
\hline Cluster II & 3.9 & 27. & $\begin{array}{l}\text { Manager of comprehensive } \\
\text { mental health program }\end{array}$ \\
\hline & 3.9 & 32. & $\begin{array}{l}\text { Service Enabler for MED } \\
\text { program settings }\end{array}$ \\
\hline
\end{tabular}

Within the task category, five items grouped in the first cluster, and an additional 13 items grouped in the second cluster. The 18 items represented 47 percent of all the core tasks suggested by the data. The average of the mean responses for the two clusters was again 4.0. These items were as follows:

\begin{tabular}{|c|c|c|}
\hline Mean & & Task \\
\hline 4.3 & 90. & $\begin{array}{l}\text { Form working relationships } \\
\text { with other profes sionals }\end{array}$ \\
\hline 4.2 & 15. & $\begin{array}{l}\text { Provide case consultation to } \\
\text { mental health services or } \\
\text { community resources }\end{array}$ \\
\hline 4.2 & 50. & $\begin{array}{l}\text { Participate in community } \\
\text { groups and task forces }\end{array}$ \\
\hline 4.1 & 61. & $\begin{array}{l}\text { Plan intervention strategies } \\
\text { for working with clients }\end{array}$ \\
\hline 4.1 & 90. & Write reports \\
\hline
\end{tabular}


$\underline{\text { Mean }}$

4.0

4. 0

4. 0

4. 0

3.9

3.9

Cluster II 3.9

3.9

3.9

3.9

3.9

3.9

3.9

Task

3. Analyze a relationship with a client

29. Engage in ongoing personal and professional growth and learning

34. Monitor and evaluate the progress and needs of clients

91. Provide leader ship to agencies or community groups

8. Assess client needs for mental health services

9. Assess mental health services and delivery systems

16. Provide consultation about resources to mental health service providers or community groups

20. Provide program consultation to community groups or mental health agencies

63. Flan services for a client

74. Supervise personnel

75. Supervise/monitor the provision of services to clients

77. Coordinate services for clients to insure continuity of care

88. Provide therapeutic intervention services

On the "Skills and Areas of Knowledge" questionnaire, 5 items, or 6 percent, could be grouped into first priority clusters; 16 items, or 19 percent, could be grouped into second priority clusters; and 22 items, or an additional 26 percent, could be grouped into third priority clusters. The 43 items in the three clusters thus represented 51 percent of all the components of the suggested future core of social work education. 
Within the skills category, two items grouped in the first cluster, six items grouped in the second cluster, and seven items grouped in a third cluster. The 15 items represented 50 percent of the core skills suggested by the data. The average of the mean responses for the first two clusters was 4.4 and for all three clusters was 4.3 . These items were as follows:

\begin{tabular}{|c|c|c|}
\hline & Mean & Skill \\
\hline \multirow{2}{*}{ Cluster I } & 4.7 & 7. Communication skills \\
\hline & 4.5 & 4. Assessment skills \\
\hline \multirow{5}{*}{ Cluster II } & 44 & 10 Tntomurioning al-i11a \\
\hline & & 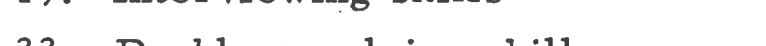 \\
\hline & 4.4 & 33. Problem-solving skills \\
\hline & 4.3 & 9. Consultation skills \\
\hline & 4.3 & 42. Therapeutic intervention skills \\
\hline \multicolumn{3}{|c|}{$\begin{array}{l}\mathrm{r} \\
\mathrm{r}\end{array}$} \\
\hline \multirow{7}{*}{ Cluster III } & 4.2 & 2. Analytical skills \\
\hline & 4.2 & 8. Conceptualization skills \\
\hline & 4.2 & 20. Leadership skills \\
\hline & 4.2 & 38. Relationship-building skills \\
\hline & 4.1 & 10. Coordination skills \\
\hline & 4.1 & 13. Diagnostic skills \\
\hline & 4.1 & 32. Planning skills \\
\hline
\end{tabular}

Within the areas of knowledge category, 3 items grouped in the first cluster, 12 items grouped in the second cluster, and an additional 15 items grouped in a third cluster. The 30 items represented 45 percent of the core areas of knowledge suggested by the data. The average of the mean responses for the first two clusters was 4.4 and for all three clusters was 4.3. These items were as follows: 


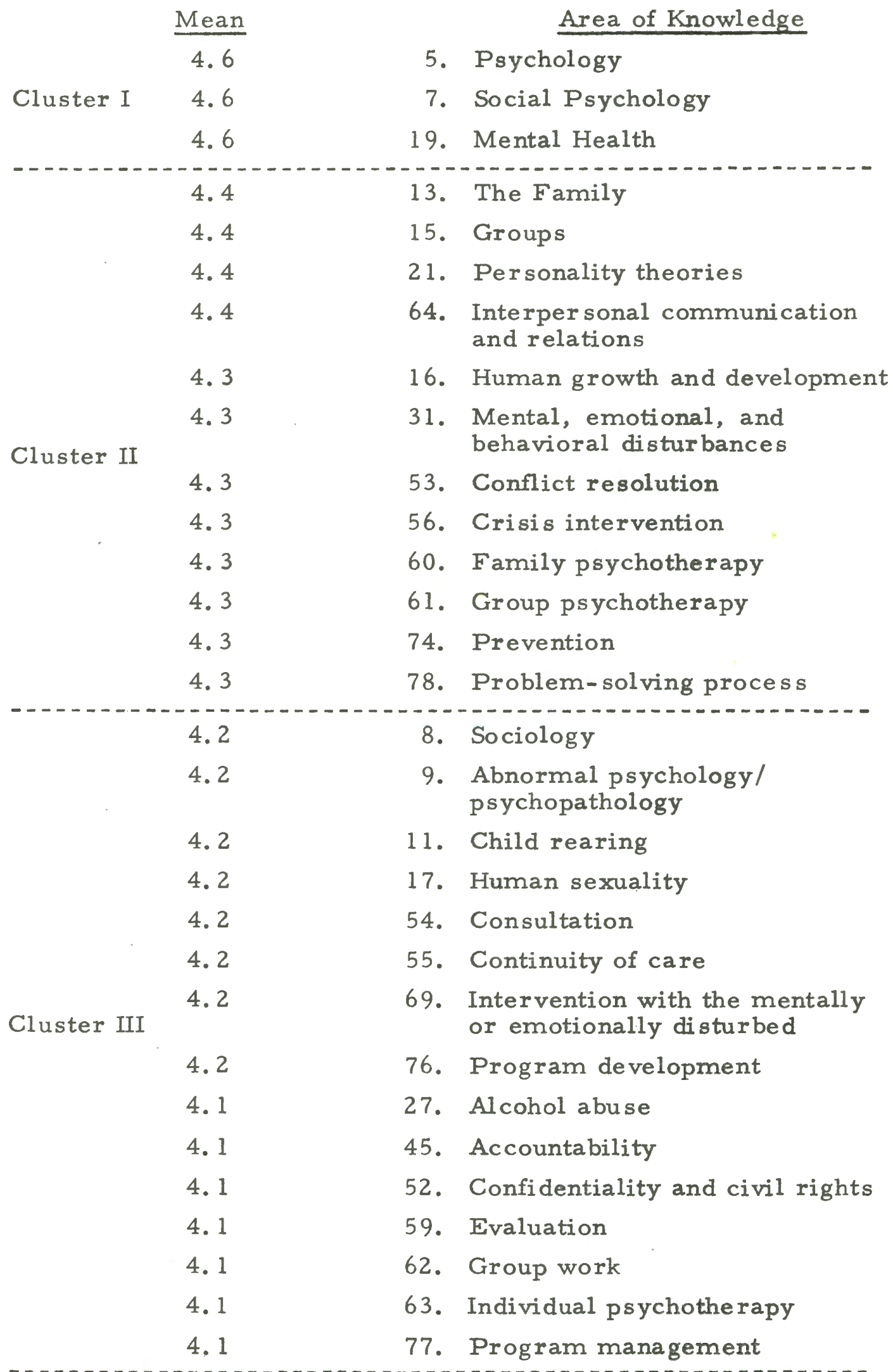




\section{SOCIAL WORKERS AND NON-SOCIAL WORKERS}

The responses of social workers and non-social workers were analyzed independently by employing the same procedures which were utilized in analyzing their combined responses. Initially, the responses collected on round three were separated by social work and non-social work orientation and compared to the data collected from these two groups on round two to determine which group was most tenacious in holding to its collective views between the two rounds. This partially satisfied the fifth objective of the research study. The responses were then analyzed to identify those items on which the two groups, considered separately, were unable to form group judgments, and also to identify those items on which the separate groups were able to form judgments, while the combined groups were unable to form such judgments.

The data was next utilized to define the generalizing core of social work practice and education suggested by the responses of each group and to determine if differences existed in these definitions. This accomplished the sixth objective of the research study. Finally, the data was analyzed to determine the clusterings of items within each category, as indicated by the responses of the separate groups, that would suggest priorities for training Master's level social workers, and to determine how the composition of the clusters suggested by each group differed from each other and from the clusters suggested by the combined responses. This accomplished the seventh objective 
of the research study.

\section{Comparison With Round II}

The data indicated that there was no consistent pattern in the responses of social workers and non-social workers on round three as compared to round two. On the "Roles, Functions, and Tasks" questionnaire, social workers were less tenacious than non-social workers in holding to their views between rounds. As a result, on this questionnaire the amount of convergence on the mode of responses from the social work group exceeded the average amount of convergence for the combined group by over one-half, or 9 percent, as compared to 5.9 percent, of convergence. Further, on the RFT questionnaire, the social work group had the lowest mean number of deviations from the combined mode.

On the "Skills and Areas of Knowledge" questionnaire, nonsocial workers were less tenacious in holding to their views between rounds than social workers. On this questionnaire, the non-social work group had the lowest mean number of deviations from the mode. Thus, group positions were reversed on the two questionnaires. However, for the round three responses of social workers on the RFT questionnaire, the percent at the mode was highest and the mean deviations were lowest, in terms of absolute figures, for either questionnaire.

Data collected from the social work and non-social work groups on both rounds and on both questionnaires is reflected in Table IX. The following formula was used in conjunction with this data to determine the tenacity rates of the two groups: 
TABLE IX

COMPARISON OF RESPONSES OF SOCIAL WORKERS

AND NON-SOCIAL WORKERS

ON ROUNDS II AND III

SOCIAL WORKERS

$\begin{array}{cc}\text { Percent } & \text { Modal } \\ \text { Responses } & \text { Deviations Per } \\ \text { At Mode } & \text { Questionnaire }\end{array}$

NON-SOCIAL WORKERS

$$
\text { Percent Modal }
$$

Responses Deviations Per

At Mode Questionnaire

QUESTIONNAIRE

\begin{tabular}{lcccc}
\hline RFT Round III & $52.8 \%$ & 60.9 & $44.4 \%$ & 71.4 \\
RFT Round II & $43.8 \%$ & 72.5 & $40.8 \%$ & 76.4 \\
Net Change & $+9.0 \%$ & -11.6 & $+3.6 \%$ & -5.0 \\
\hline SK Round III & $46.4 \%$ & 71.2 & $51.4 \%$ & 65.9 \\
SK Round II & $42.6 \%$ & 76.4 & $44.1 \%$ & 74.3 \\
Net Change & $+3.8 \%$ & -5.2 & $+6.3 \%$ & -8.4
\end{tabular}

TABLE X

TENACITY RATES OF SOCIAL WORKERS

AND NON-SOCIAL WORKERS

SOCIAL NON-SOCIAL WORKERS WORKERS

COMBINED

RFT Questionnaire

84. 1

93.4

89.6

SK Que stionnaire

93.3

88. 7

90.8 
FORMULA I

TENACITY RATE

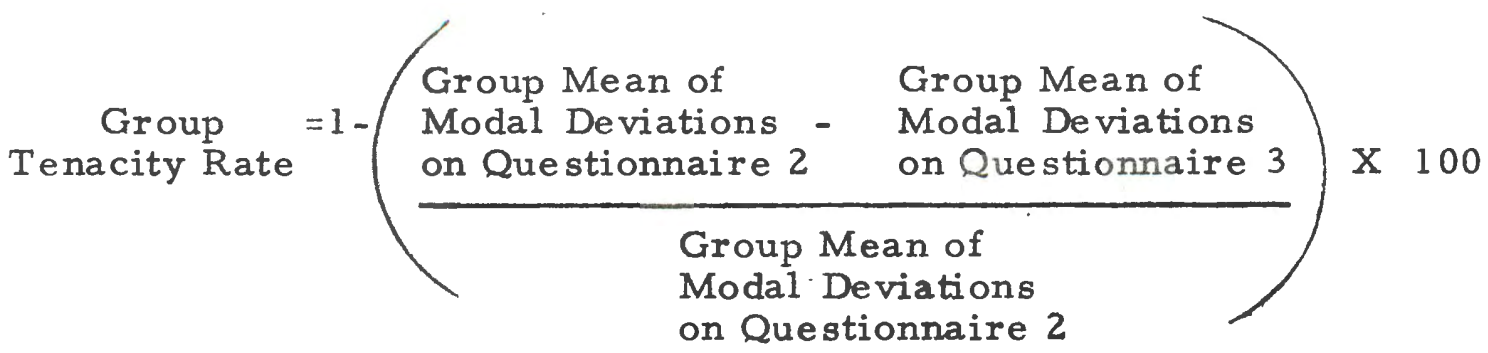

The lower the tenacity rate, the less the tenacity with which group views were held to between rounds. Computed rates for the groups are reflected in Table $X$. On the basis of this data, no general conclusions could be drawn about the tenacity of the two groups across questionnaires.

Group Judgments

The process of dichotomizing the scale and applying the three criteria regarding group judgments revealed a great many differences on both questionnaires between the judgments of the two groups and the judgments of the combined responses. There was, however, more disagreement between the groups on the "Roles, Functions, and Tasks" questionnaire than on the "Skills and Areas of Knowledge" questionnaire, by a factor of two to one, or 65 differences to 32 differences. Moreover, on the RFT questionnaire, social workers were much more decisive as a group in forming judgments about the items than nonsocial workers. On the SK questionnaire, however, non-social workers were more decisive than social workers. Thus, on the basis of the data reflected in Table XI, no cross-questionnaire generalizations 
could be made about the ability of either group to form judgments. An item-by-item analysis of disagreements between the two groups revealed that on 31 items in the RFT questionnaire there was a substantial difference of opinion between the groups. On this questionnaire, all 27 of the new judgments of the social work group, and four of the six new non-judgments of the group resulted from a higher distribution of responses on the $4-5$ end of the scale than those of the non-social work group. In addition, 11 of the 14 new judgments of the non-social work group and 17 of the 18 new non-judgments of this group were a result of a higher distribution of responses on the 1-2-3 end of the scale than those of the social work group. Further analysis indicated that on 29 of the items characterized by this pattern, there was a 25 percent difference between the groups in the percentage distribution of responses on the two points of the scale. This 25 percent response distribution difference also was exhibited by two items not characterized by the above pattern. The discrepancies on the 31 items, which ranged between 25 and 50 percent with a mean of 34 percent, were considered "substantial" difference of opinion. An item-by-item analysis of the disagreements on the SK questionnaire revealed only two items on which there was substantial difference of opinion, averaging 27 percent. These, again, were characterized by higher 4-5 response distribution by the social work group than the non-social work group. However, while none of these differences were substantial, 14 of the 18 new non-judgments of the social work group on this questionnaire were the result of a higher distribution of responses from this group on the 1-2-3 end of the scale 
GROUP JUDGMENTS OF SOCIAL WORKERS AND NON-SOCIAL WORKERS AS COMPARED TO COMBINED RESPONSES

SOCIAL WORKERS NON-SOCIAL WORKERS

\begin{tabular}{|c|c|c|c|c|c|c|}
\hline $\begin{array}{l}\text { QUESTION- } \\
\text { NAIRE }\end{array}$ & $\mathrm{N} \mathrm{J}$ & $\mathrm{N} \mathrm{N} \mathrm{J}$ & $\begin{array}{c}\text { Net } \\
\text { Change }\end{array}$ & $\mathrm{N} \mathrm{J}$ & $\mathrm{N} \mathrm{N} \mathrm{J}$ & $\begin{array}{l}\text { Net } \\
\text { Change }\end{array}$ \\
\hline RFT Total & 27 & 6 & +21 & 14 & 18 & -4 \\
\hline Roles & 2 & 1 & +1 & 1 & 3 & -2 \\
\hline Functions & 1 & 0 & +1 & 0 & 2 & 0 \\
\hline Tasks & 24 & 5 & +19 & 13 & 13 & 0 \\
\hline SK Total & 2 & 18 & -16 & 9 & 3 & +6 \\
\hline Skills & 1 & 4 & -3 & 2 & 3 & -1 \\
\hline $\begin{array}{l}\text { Areas of } \\
\text { Knowledge }\end{array}$ & 1 & 14 & -13 & 7 & 0 & +7 \\
\hline
\end{tabular}

N J = New Judgments

N N J = New Non-Judgments 
than those of the non-social work group. No patterns suggested themselves in the responses of the non-social work group.

The social work group thus rated the disputed items higher than the non-social work group on the RFT questionnaire; that is, on the 4-5 end of the scale. On the SK questionnaire, the social work group tended to rate the disputed items more often on the 1-2-3 end of the scale than the non-social work group. Consequently, once again no cross-questionnaire generalizations could be made about the responses of either group.

\section{Generalizing Core}

The differences of opinion between social workers and non-social workers on the question of group judgments were almost entirely reflected in differences in group definitions of the future generalizing core of Master's level social work practice and education in the field of community mental health. Of the 65 disagreements on group judgments with the combined responses for the RFT questionnaire, 48, or 74 percent, were reflected in differing views of the components of the core of practice in ten years. Similarly, of the 32 differences on group judgments with the combined responses for the SK que stionnaire, 20 , or 63 percent, were reflected in differing views of the components of the core of education in ten years. These differing views indicated that the social work group had a broader definition of the core of practice and a narrower definition of the core of education than the combined responses. On the other hand, the non-social work group had a narrower definition of the core of practice and only a slightly broader definition of the core of education than the combined responses. 
On the "Roles, Functions, and Tasks" questionnaire, the differences in the views of social workers and non-social workers regarding the generalizing core of practice were, with only four exceptions, differences in the responses of the social work group broadening, and in the responses of the non-social work group narrowing, the definition of this core. The responses of social workers on this questionnaire indicated that 27 items would be included in the core of practice defined by the combined responses, as follows:
Agreement
Role
$66 \%$
$70 \%$
10. Diagnostician
25. Writer

\section{Function}
$61 \%$
29. Manager of MRDD program settings
Tasks
$75 \%$
$71 \%$
$66 \%$
$61 \%$
$66 \%$
$71 \%$
$61 \%$
$70 \%$
$75 \%$
1. Analyze a decision-making process (e.g., administrative, legislative, or political
4. Analyze a system or organization
6. Analyze the structure of a community, county, or the state
13. Assess the training needs of mental health personnel
19. Provide expert testimony
30. Provide a community education program
31. Train clients in coping, management, and maintenance skills
32. Train personnel in mental health agencies
40. Develop comprehensive mental health service centers 
Agreement
$61 \%$
$70 \%$
$75 \%$
$61 \%$
$75 \%$
$71 \%$
$71 \%$
$66 \%$
$66 \%$
$75 \%$
$61 \%$
$70 \%$
$85 \%$
$70 \%$
$85 \%$
41. Develop an emergency mental health service
42. Develop a mental health information and referral service
44. Develop policies, procedures, and guidelines for mental health services and agencies
45. Develop programs to prevent mental and emotional disturbances, developmental disabilities, mental retardation, or alcohol and drug addiction
53. Plan a budget for a mental health agency or program
54. Plan and design a coordinated system of mental health services
55. Plan and design the program of a mental health agency
58. Plan an evaluation design for a mental health service or delivery system
66. Establish standards of performance for mental health agencies, personnel, and services
68. Explain programs of mental health agency to personnel
70. Modify a plan, policy, or program on the basis of research and evaluative feedback
71. Monitor the implementation of laws, regula- tions, policies, or procedures
73. Recruit, hire, and organize personnel in a mental health agency
80. Negotiate contracts with clients
82. Provide assessment services
In addition, these same responses indicated that two items would be excluded from the definition of core tasks, as follows:

Tasks 
Tasks

62. Plan intervention strategies for working with communities, organizations, and systems

76. Advocate on behalf of clients for improved benefits and services

Therefore, if only the views of social workers were considered, there would be a net increase of 25 in the number of items defining the future core of Master's level social work practice in this field. This would result in a total of 85 of the 129 items in the RFT questionnaire, or 66 percent.

The responses of non-social workers on the RFT questionnaire, in contrast to those of social workers, suggested that 17 items would be excluded from the core of practice defined by the combined responses, as follows:

\section{Role}

4. Assessor

17. Organizer

18. Planner

Functions

31. Service Enabler for comprehensive mental health program settings

34. Service Deliverer in A\&DP program settings

\section{Tasks}

2. Analyze a policy, program, or budget

7. Conduct a diagnostic analysis

18. Provide consultation regarding a target population 
Tasks

34. Monitor and evaluate the progress and needs of clients

36. Identify communities and populations in need of mental health services

46. Mobilize community support for mental health services and target populations

47. Organize new mental health services or programs in communities

49. Organize task forces

59. Plan goals and measurable objectives for mental health agencies, delivery systems, or services

66. Establish priorities for allocating limited resources

69. Manage a budget for a mental health agency or program

74. Supervise personnel

In addition, these same responses indicated that two items would be included in the definition of core tasks, as follows:

Agreement

$64 \%$

$60 \%$
Tasks

78. Mediate between client and service systems

70. Mobilize community resources on behalf of clients

Therefore, if only the views of non-social workers were considered, there would be a net decrease of 15 in the number of items defining the future core of Master's level social work practice in this field. This would result in a total of 45 of the 129 items in the RFT questionnaire, or 35 percent, which is only slightly more than one-half as many items 
as were suggested by the responses of social workers.

On the "Skills and Areas of Knowledge" questionnaire, the differences in the views of social workers and non-social workers regarding the generalizing core of education were, with only two exceptions, differences in the responses of the social work group narrowing, and the responses of the non-social work group broadening, the definition of this core. Thus, the responses of social workers suggested that 14 items would be excluded from the core of education defined by the combined responses, as follows:

Skill

18. Interpretation skills

27. Organizing skills

Area of Knowledge

30. Lea rning disabilities

35. Community mental health

39. Mental health manpower

40. Social Policy

41. Social service delivery systems

43. Social welfare laws, legislation, and guidelines

49. Citizen/consumer participation

51. Community organization

62. Group work

81. Rehabilitation

86. Social planning

87. Social work principles and code of ethics 
In addition, these same responses indicated that one area of knowledge would be included in this definition, as follows:

\section{Agreement Area of Knowledge}

12. Environmental/ecological psychology

Therefore, if only the views of social workers were considered, there would be a net decrease of 13 in the number of items defining the future core of Master's level social work education in this field. This would result in a total of 73 of the 133 items in the SK que stionnaire, or 55 percent.

The responses of non-social workers on the SK questionnaire, in contrast to those of social workers, indicated that four items would be included in the core of education defined by the combined responses, as follows:

Agreement

$67 \%$

\begin{tabular}{ll} 
& \multicolumn{2}{c}{ Area of Knowledge } \\
$64 \%$ & 50. Client/consumer advocacy \\
$63 \%$ & 67. Intervention with the developmentally disabled \\
$61 \%$ & 68. Intervention with the mentally retarded
\end{tabular}

In addition, these same responses suggested that one item would be excluded from this definition, as follows:

Skill

14. Evaluation skills 
Therefore, if only the views of non-social workers were considered, there would be a net increase of three in the number of items defining the future core of Master's level social work education in this field. This would result in a total of 89 of the 133 items in the SK questionnaire, or 67 percent, which is nearly one-fourth again as many items as were suggested by the responses of social workers.

\section{Training Priorities}

The analysis of the responses of social workers and non-social workers to determine training priority clusters revealed major disagreements between the two groups regarding the overall composition of these clusters on the "Roles, Functions, and Tasks" questionnaire and minor, but nevertheless apparent, disagreements regarding the composition of these clusters on the "Skills and Areas of Knowledge" questionnaire. The responses on the RFT questionnaire further indicated substantial differences in the group ratings of 28 of the 53 items which were considered priorities by the two groups, or 53 percent. These were reflected in differences of 0.5 or more in the mean responses of the two groups for these 28 items, and were also reflected in a 0.5 difference between the two groups in the average of the mean responses for all the training priorities on this questionnaire. The group responses on the SK questionnaire indicated only two substantial differences between the two groups, and no difference between groups in the average of the mean responses for all the training priorities.

On the "Roles, Functions, and Tasks" questionnaire, the responses of social workers and non-social workers suggested quite 
different groupings of items in the first two priority clusters. The responses of the social work group indicated that 10 items could be grouped into first priority clusters, while an additional 18 items could be grouped into second priority clusters. The 28 items represented 33 percent of the components of the core of practice defined by the responses of this group. The responses of the non-social work group also suggested that 10 items could be grouped into first priority clusters and an additional 15 in second priority clusters. The 25 items represented 56 percent of the items in the core of practice defined by the responses of this group.

The average mean response of the 28 items clustered by social workers on the RFT questionnaire was 4.4 , while the average mean response of the 25 items clustered by non-social workers was 3.9. Moreover, there were only 12 priority items held in common by the two groups, while 41 items were not held in common at all. Of the se latter items, there were 17 substantial differences between the mean responses of the two groups. The average difference on these 17 items was 0.6 , and all were characterized by a lower mean response by the non-social work group than the social work group. Consequently, of the 39 differences between the clusters suggested by the responses of the two groups and those suggested by the combined responses, only five, or 13 percent, represented shifts of items between clusters, while 10, or 26 percent, represented the addition of new items, and 24, or 62 percent, represented the deletion of items from the clusters. The magnitude of differences between the two groups that is reflected by this data indicated a need for a direct comparison of the composi- 
tions of the training priority clusters suggested by each group on this questionnaire.

Within the roles category, the responses of social workers grouped three items in the first cluster and two items in the second cluster, with an average mean response for the five items of 4.3 , as follows:

\begin{tabular}{lll} 
& Mean & \multicolumn{1}{c}{ Role } \\
& 4.5 & 4. Assessor \\
Cluster I & 4.3 & 8. Consultant \\
& 4.3 & 22. Supervisor \\
& 4.1 & 8. Administrator \\
Cluster II & 4.1 & 23. Therapist \\
& &
\end{tabular}

In the same category, the responses of non-social workers grouped four items in the first cluster and five items in the second cluster, with an average mean response for the nine items of 3.8. Thus, the difference between the two groups on this category was 0.5. These items were as follows:

$\begin{array}{lcc} & \text { Mean } & \text { Role } \\ & 4.0 & \text { 8. Consultant } \\ \text { Cluster I } & 3.9 & \text { 6. Case Manager } \\ & 3.9 & \text { 7. Coordinator } \\ & 3.9 & 13 . \text { Group Facilitator } \\ \text { Cluster II } & 3.8 & \text { 2. Advocate } \\ & 3.8 & \text { 9. Developer }\end{array}$




$\begin{array}{ccc} & \text { Mean } & \text { Role } \\ & 3.7 & \text { 1. Administrator } \\ \text { Cluster II } & 3.7 & \text { 12. Evaluator } \\ & 3.7 & 23 .\end{array}$

Within the functions category, the responses of social workers grouped two items in the first cluster and two items in the second cluster, with an average mean response for the four items of 4.4 , as follows:

\begin{tabular}{|c|c|c|c|}
\hline \multicolumn{4}{|r|}{ Function } \\
\hline \multirow{2}{*}{ Cluster I } & 4.5 & 35. & $\begin{array}{l}\text { Service Deliverer in comprehensive } \\
\text { mental health settings }\end{array}$ \\
\hline & 4.5 & 36. & $\begin{array}{l}\text { Service Deliverer in MED program } \\
\text { settings }\end{array}$ \\
\hline \multirow{2}{*}{ Cluster II } & 4.3 & 28. & Manager of MED program settings \\
\hline & 4.3 & 29. & $\begin{array}{l}\text { Service Enabler for MED program } \\
\text { settings }\end{array}$ \\
\hline
\end{tabular}

In the same category, the responses of non-social workers grouped three items in the first cluster and two in the second cluster, with an average mean response for the five items of 3.8 . There was thus a 0.6 difference between the two groups on this category. These items were as follows:

Mean Function

4. 0 36. Service Deliverer in MED program

Cluster I settings

3.9 28. Manager of MED program settings 
Mean Function

Cluster I $3.925 . \begin{aligned} & \text { Service Deliverer in comprehensive } \\ & \text { settings }\end{aligned}$

3. 7 36. Manager of A\&DP program settings

Cluster II

3. 7 37. Service Deliverer in MRDD program setting $s$

Within the task category, the responses of social workers grouped 5 items in the first category and 14 items in the second category, with an average mean response for the 19 items of 4.2 , as follows:

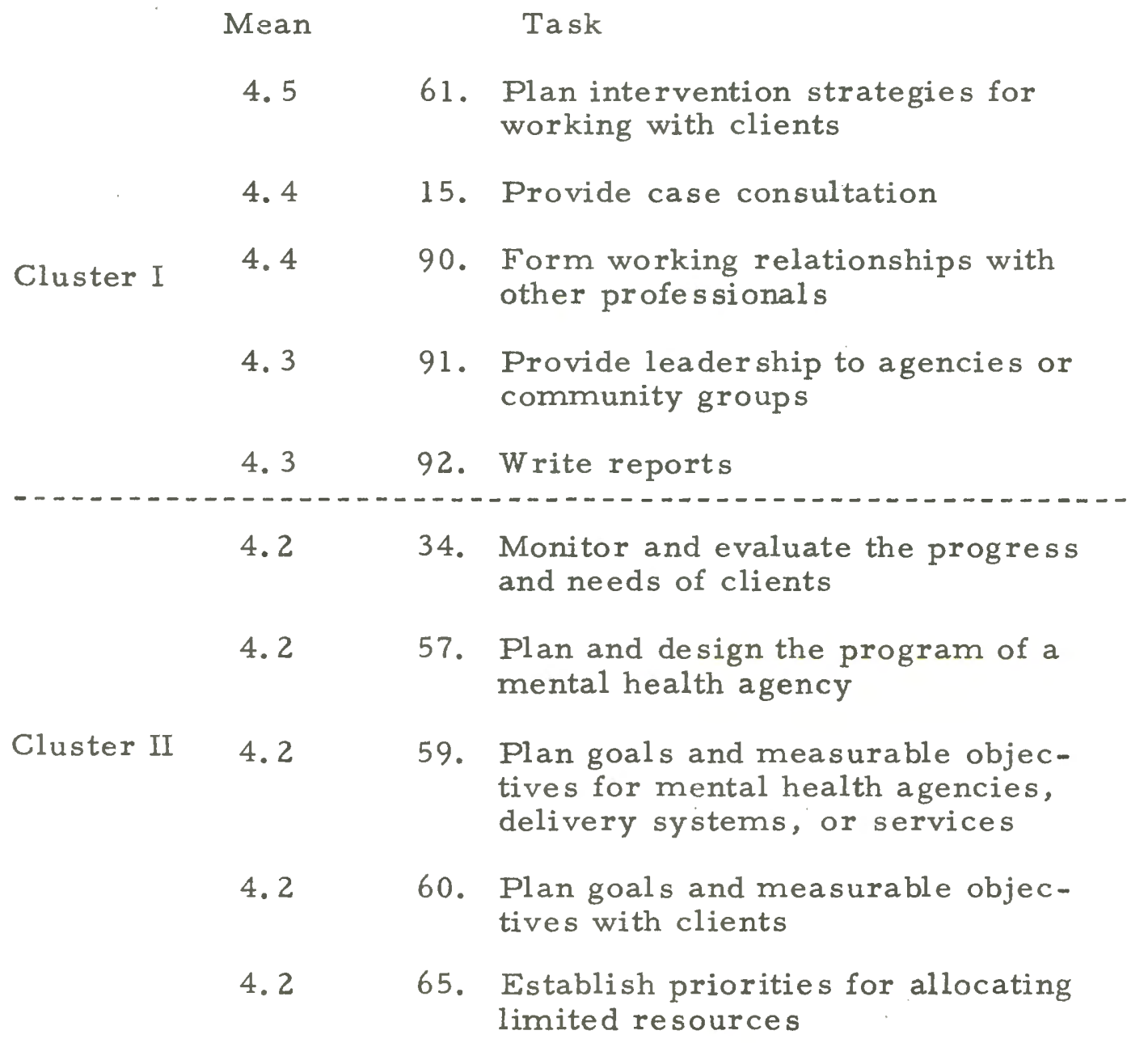


Mean Task

\begin{tabular}{|c|c|c|c|}
\hline & 4.2 & 74. & Supervise personnel \\
\hline & 4.2 & 88. & $\begin{array}{l}\text { Provide therapeutic intervention } \\
\text { services }\end{array}$ \\
\hline & 4.1 & 3. & Analyze a relationship with a client \\
\hline & 4.1 & 16. & Provide consultation about resources \\
\hline & 4.1 & 29. & $\begin{array}{l}\text { Engage in ongoing personal and } \\
\text { professional growth }\end{array}$ \\
\hline Cluster II & 4.1 & 50 . & $\begin{array}{l}\text { Participate in community groups } \\
\text { and task forces }\end{array}$ \\
\hline & 4.1 & 54. & $\begin{array}{l}\text { Plan and design a coordinated } \\
\text { system of mental health services }\end{array}$ \\
\hline & 4.1 & 66. & $\begin{array}{l}\text { Establish standards of performance } \\
\text { for mental health agencies, } \\
\text { personnel, and services }\end{array}$ \\
\hline & 4.1 & 75. & $\begin{array}{l}\text { Supervise/monitor the provision of } \\
\text { service to clients }\end{array}$ \\
\hline
\end{tabular}

In this same category, the responses of non-social workers grouped three items in the first category and eight in the second, with an average mean response rate for the 11 items of 4.0 , as follows:

$\begin{array}{lll} & \text { Mean } & \text { Task } \\ & 4.3 & \text { 50. } \begin{array}{l}\text { Participate in community groups and } \\ \text { task forces }\end{array} \\ \text { Cluster I } & 4.2 & \begin{array}{l}\text { 90. Form working relationships with } \\ \text { other profes sionals }\end{array} \\ & 4.1 & \text { 15. Provide case consultation } \\ & 4.0 & \text { 92. Write reports } \\ & 3.9 & \text { 3. Analyze a relationship with a client } \\ & 3.9 & \text { 8. Assess client needs for mental }\end{array}$




\begin{tabular}{|c|c|c|c|}
\hline & Mean & & Task \\
\hline & 3.9 & 9. & $\begin{array}{l}\text { Assess mental health services and } \\
\text { delivery systems }\end{array}$ \\
\hline & 3.9 & 29. & Engage in ongoing growth \\
\hline Cluster II & 3.9 & 63. & Plan services for a client \\
\hline & 3.9 & 77. & $\begin{array}{l}\text { Coordinate services for clients to } \\
\text { insure continuity of care }\end{array}$ \\
\hline & 3.9 & 84. & Provide follow-up services \\
\hline
\end{tabular}

On the "Skills and Areas of Knowledge" questionnaire, the responses of social workers and non-social workers suggested essentially similar groupings of items in the three priority clusters, with several important differences in each category. The responses of the social work group indicated that 38 items could be grouped in three priority clusters. These items represented 52 percent of the components of the core of practice defined by the responses of this group. The responses of the non-social work group indicated that 34 items could be grouped in three priority clusters. These items represented 38 percent of the components of the core of education defined by the responses of this group.

The average of the mean responses for the items clustered by the two groups were virtually identical. Further, there were 41 priority items held in common, while only 21 items were not held in common at all. Of these latter items, there were only two items on which the mean response differences of the groups was 0.5. Consequently, of the 45 differences between the clusters suggested by the responses of the two groups and those suggested by the combined responses, 27 , or 
60 percent, represented shifts of items between clusters, while only nine, or 20 percent, represented the introduction of new items into the clusters, and another nine, or 20 percent, represented the deletion of items from the clusters.

Within the skills category, there were ten differences between the clusters suggested by the responses of the two groups and those suggested by the combined responses. The responses of the social work group indicated three changes within the clusters, the addition of one item and the deletion of one item, as follows:

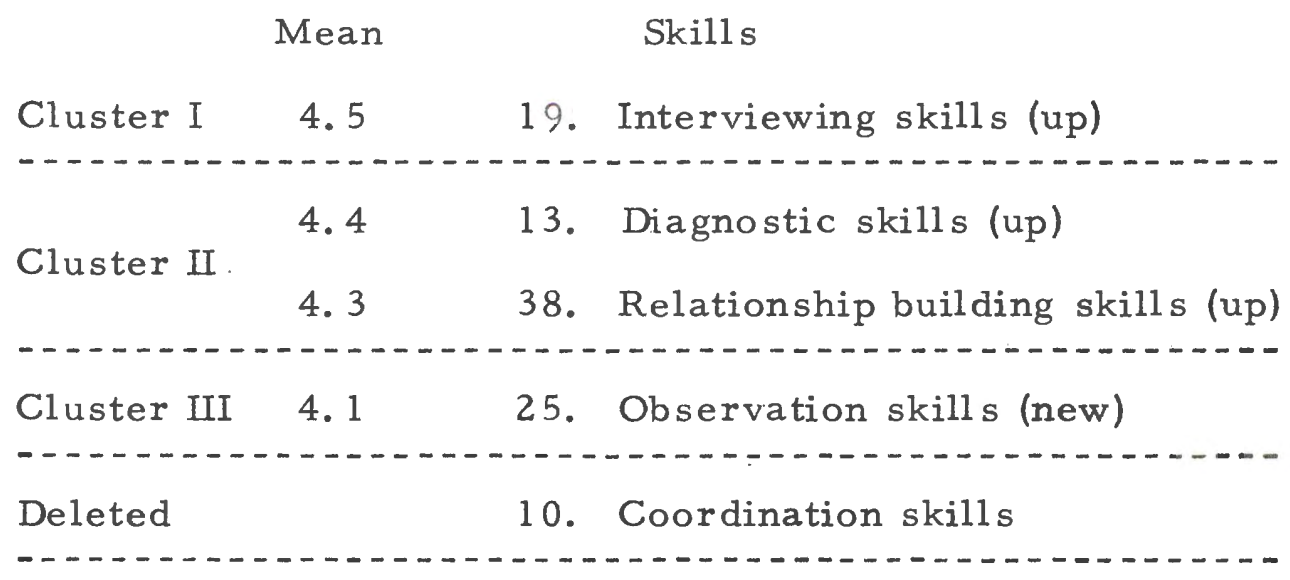

In the same category, the responses of the non-social work group indicated one change within the clusters, the addition of three new items, and the deletion of one item, as follows:

\begin{tabular}{lcc} 
& \multicolumn{2}{c}{ Mean } \\
Cluster II & 4.4 & 4. Assessment skills (down) \\
& 4.1 & 6. Case management skills (new) \\
Cluster III & 4.1 & 17. Group facilitation skills (new) \\
& 4.1 & 45. Identification skills (new)
\end{tabular}


Skills

Deleted 13. Diagnostic skills

Within the areas of knowledge category there were 33 differences between the clusters suggested by the responses of the two groups and those suggested by the combined responses. The responses of the social work group indicated ten changes within the clusters, the addition of three items, and the deletion of two items, as follows:

\begin{tabular}{|c|c|c|c|}
\hline & Mean & & Area of Knowledge \\
\hline & 4.5 & 16. & Human growth and development (up) \\
\hline Cluster I & 4.5 & 21. & Personality theories (up) \\
\hline & 4.5 & 60. & Family psychotherapy (up) \\
\hline$\cdots-\cdots$ & $-\cdots-$ & $-\cdots$ & 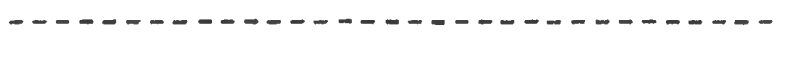 \\
\hline & 4.4 & 11. & Child rearing (up) \\
\hline & 4.4 & 69. & $\begin{array}{l}\text { Intervention with the mentally or } \\
\text { emotionally disturbed (up) }\end{array}$ \\
\hline Cluster II & 4.4 & 78. & Problem-solving process (up) \\
\hline & 4.3 & 15. & Groups (down) \\
\hline & 4.3 & 54. & Consultation (up) \\
\hline & 4.3 & 59. & Evaluation (up) \\
\hline & 4.2 & 74. & Prevention (down) \\
\hline & 4.1 & 36. & Mental health delivery systems (new) \\
\hline Cluster III & 4.1 & 38. & $\begin{array}{l}\text { Mental health laws, legislation, and } \\
\text { guidelines (new) }\end{array}$ \\
\hline & 4.1 & 48. & Casework (new) \\
\hline Deleted & & 27. & Alcohol abuse \\
\hline & & 62. & Group work \\
\hline
\end{tabular}


In the same category, the responses of the non-social work group indicated 11 changes within the clusters, the addition of two items, and the deletion of five items, as follows:

\begin{tabular}{lll} 
& Mean & \multicolumn{1}{c}{ Area of Knowledge } \\
Cluster I & 4.5 & 15. Groups (up) \\
& 4.5 & 64. Interpersonal communication and \\
relations (up)
\end{tabular}

45. Accountability

63. Individual psychotherapy

Deleted

59. Evaluation

69. Intervention with the mentally or emotionally disturbed

77. Program management 


\section{PLANNERS, MANAGERS, AND DEVELOPERS}

The responses of planners, managers, and developers were analyzed independently by employing the same procedures which were utilized in analyzing their combined responses. Initially, the responses collected on round three were separated by occupational groupings and compared to the data collected from these groups on round two to determine which group was most tenacious in holding to its collective views between the two rounds. This completely accomplished the fifth objective of the research study. The responses were then analyzed to identify those items on which the three groups, considered separately, were unable to form judgments, and also to determine thase items on which the separate groups were able to form judgments, while the combined groups were unable to form such judgments.

The data was next utilized to define the generalizing core of social work practice and education suggested by the responses of each group and to determine if differences existed in these definitions. This accomplished the eighth research objective of the study. Finally, the data was analyzed to determine the clusterings of items within each category, as indicated by the responses of the separate groups, that would suggest priorities for training Master's level social workers, and to determine how the composition of the clusters suggested by each group differed from each other and from the clusters suggested by the combined responses. This accomplished the ninth and last objective 
of the research study.

Comparison With Round II

The data indicated that, as with social workers and non-social workers, there was no consistent pattern in the responses of the three groups on round three as compared to round two. On the "Roles, Functions, and Tasks" questionnaire, managers and developers were equally tenacious in holding to their views between rounds, while planners were the least tenacious group. Their tenacity rate of 82.1 was the lowest rate on either questionnaire in the present comparison or in the social work/non-social work comparison. Further, on round three for this questionnaire, the planner group had the lowest mean number of deviations from the mode of the three groups, while the manager group had the highest mean number of deviations. On both rounds, the managers had the highest deviations from the mode, in absolute numbers, for either questionnaire.

On the "Skills and Areas of Knowledge" questionnaire, the managers were the least tenacious group in holding to their views, followed by the developers and planners, in that order. The planner group, which was the least tenacious of the groups on the RFT questionnaire, was thus the most tenacious group on the SK questionnaire. In this same questionnaire, the managers had the lowest mean number of deviations from the modal response, while the developers had the highest. Consequently, no general conclusions could be drawn about the tenacity of the groups across questionnaires. This data is summarized on Tables XII and XIII. 
COMPARISON OF RESPONSES OF PLANNERS, MANAGERS, AND DEVELOPERS ON ROUNDS II AND III

\section{PLANNERS}

\section{Percent}

Responses

At Mode

\section{Modal}

Deviations per

Questionnaire

\section{MANAGERS}

$\begin{array}{cc}\text { Percent } & \text { Modal } \\ \text { Responses } & \text { Deviations per } \\ \text { At Mode } & \text { Questionnaire }\end{array}$

\section{DEVELOPERS}

$\begin{array}{cc}\text { Percent } & \text { Modal } \\ \text { Responses } & \text { Deviations per } \\ \text { At Mode } & \text { Questionnaire }\end{array}$
NAIR E

\begin{tabular}{lllllll}
\hline RFT Round III & $51.8 \%$ & 62.2 & $45.9 \%$ & 69.9 & $46.9 \%$ & 68.5 \\
RFT Round II & $44.9 \%$ & 75.8 & $40.1 \%$ & 77.2 & $41.3 \%$ & 75.7 \\
Net Change & $+6.9 \%$ & -13.6 & $+5.8 \%$ & -7.3 & $+5.6 \%$ & -7.2 \\
\hline SK Round III & $50.8 \%$ & 65.4 & $48.8 \%$ & 63.4 & $46.6 \%$ & 71.1 \\
SK Round II & $45.7 \%$ & 72.2 & $43.5 \%$ & 70.9 & $41.4 \%$ & 78.0 \\
Net Change & $+5.1 \%$ & -6.8 & $+5.3 \%$ & -7.5 & $5.2 \%$ & -6.9
\end{tabular}

TABLE XIII

TENACITY RATES OF PLANNERS, MANAGERS, AND DEVELOPERS

PLANNERS MANAGERS DEVELOPERS COMBINED

$\begin{array}{lllll}\text { RFT Questionnaire } & 82.1 & 90.5 & 90.5 & 89.6 \\ \text { SK Questionnaire } & 91.6 & 89.4 & 91.2 & 90.8\end{array}$

90.8 
Group Judgments

As in the case of the social work and non-social work groups, the process of dichotomizing the scale and applying the criteria regarding group judgments revealed a great many differences on both questionnaires between the three occupational groups and the combined questionnaire responses. Further, unlike the earlier comparison, the amount of disagreement on both questionnaires was virtually identical.

On the "Roles, Functions, and Tasks" questionnaires, managers as a group were much more indecisive than either the planners or the developers. Moreover, on this questionnaire, the developers were somewhat more decisive in forming judgments as a group than were the planners. On the "Skills and Areas of Knowledge" questionnaire, managers as a group were again the most indecisive, but only slightly moreso than developers. Thus, on the SK questionnaire, the planner group was the most decisive of the three groups. These patterns are reflected in Table XIV.

On the basis of this data it could be concluded that, on both questionnaires, managers were the most indecisive of the three groups in forming group judgments. The data did not permit cross-questionnaire generalizations about the ability of the other two groups to form judgments.

An item-by-item analysis of the disagreements between the three groups revealed that on the RFT questionnaire, 18 of the 20 new judgments, and four out of the six new non-judgments of the developer group were a result of a higher distribution of responses on the 4-5 end of the dichotomized scale than those of the other two groups combined. 
GROUP JUDGMENTS OF PLANNERS, MANAGERS, AND DEVELOPERS AS COMPARED TO COMBINED RESPONSES

\section{PLANNERS}

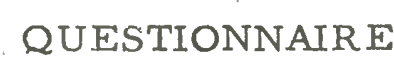

\begin{tabular}{|c|c|c|c|c|c|c|c|c|c|}
\hline QUESTIONNAIRE & $\mathrm{N} \mathrm{J}$ & $\mathrm{N} \mathrm{N} \mathrm{J}$ & $\begin{array}{l}\text { Net } \\
\text { Change }\end{array}$ & $\mathrm{N} \mathrm{J}$ & $\mathrm{N} N \mathrm{~J}$ & $\begin{array}{l}\text { Net } \\
\text { Change }\end{array}$ & $\mathrm{N} \mathrm{J}$ & $\mathrm{N} \mathrm{N} \mathrm{J}$ & $\begin{array}{l}\text { Net } \\
\text { Change }\end{array}$ \\
\hline RFT Total & 14 & 5 & +9 & 12 & 17 & -5 & 20 & 6 & +14 \\
\hline Roles & 0 & 1 & -1 & 1 & 4 & -3 & 1 & 0 & +1 \\
\hline Functions & 1 & 1 & 0 & 0 & 0 & 0 & 0 & 2 & -2 \\
\hline Tasks & 13 & 3 & +10 & 11 & 13 & -2 & 19 & 4 & +15 \\
\hline SK Total & 13 & 9 & +4 & 13 & 22 & -9 & 7 & 14 & -7 \\
\hline Skills & 2 & 5 & -3 & 4 & 8 & -4 & 3 & 2 & +1 \\
\hline $\begin{array}{l}\text { Areas of } \\
\text { Knowle dge }\end{array}$ & 11 & 4 & +7 & 9 & 14 & -5 & 4 & 12 & -8 \\
\hline
\end{tabular}

MANAGERS

DEVELOPERS

$\mathrm{N} \mathrm{J}=$ New Judgments

N N J = New Non-Judgments 
At the same time, while the new judgments of both the planner and manager groups were almost evenly split between the $1-2-3$ point and the 4-5 point, all five of the new non-judgments of the planner group and 14 of the 17 new non-judgments of the manager group were the result of a higher distribution of responses on the 1-2-3 end of the scale than those of the other two groups, respectively, combined.

On the SK questionnaire, five of the seven new group judgments formed by the developers were similarly a result of a higher distribution on the 4-5 end of the scale, while there was no pattern in their new non-judgments. At the same time, 11 of the 13 new judgments, and seven of the nine new non-judgments of the planner group also resulted from such a higher distribution on the 4-5 end of the scale. On the other hand, 9 of the 11 new judgments, and 19 of the 22 new non-judgments of the manager group resulted from a higher distribution on the 1-2-3 end of the scale than those of the other two groups combined.

On the basis of this data, it was possible to conclude that on both questionnaires the developer group generally rated the disputed items higher than the other two groups. Further, on both questionnaires, the manager group generally rated the disputed items lower than the other two groups combined. No cross-questionnaire generalization was possible concerning the responses of the planner group.

The item-by-item analysis further suggested that the differences between the groups in forming group judgments often were reflective of major differences of opinion. Thus, on the RFT questionnaire 
there were 27 items on which there was a substantial difference in the distribution of responses on the items between at least two groups. "Substantial" was again defined as a 25 percent difference in response distribution, either between the 1-2-3 point and the 4-5 point or within these points. On 6 of these 27 items, there was a substantial difference between one group and both of the other groups. In two cases this was the planner group; and in the other four, the manager group. Interestingly enough, in all six cases, the response distributions of the other two groups were greater on the $4-5$ end of the scale, while the distributions of the planners or managers, respectively, were more toward the 1-2-3 end of the scale. By including these 6 items, it was found that on the 27 items, there were 16 substantial differences of opinion, averaging 29 percent, between planners and managers; 10 such differences, averaging 31 percent, between managers and developers; and $7 \mathrm{such}$ differences, averaging 29 percent, between developers and planners. Thus, there were almost four times as many major disagreements between the managers and the other two groups as there were between these two groups. On the "Skills and Areas of Knowledge" questionnaire, the amount of substantial disagreement between groups on disputed items was even greater than on the RFT questionnaire. Thus, there were 38 items on which there was at least a 25 percent difference in response distributions, and four of these items involved substantial differences between one group and both of the other two groups. Again, the planner and manager groups were the focus of these differences, each in two instances. Unlike the RFT questionnaire, 
however, the responses of planners or managers, respectively, were distributed more toward the 4-5 end of the scale in three of the se four cases. By including these four items, it was found that on the 38 items there were 21 substantial differences of opinion, averaging 33 percent, between planners and managers; 17 such differences, averaging 29 percent, between managers and developers; and 4 such differences, averaging 27 percent, between developers and planners. Thus, there were over nine times as many major disagreements between the managers and the other two groups as there were between these two groups.

\section{Generalizing Core}

As in the case of the social work and non-social work groups, most of the substantial differences of opinion between the three occupational groups on the question of group judgments were reflected in differing group definitions of the future generalizing core of Master's level social work practice and education in the field of community mental health. Of 74 disagreements on group judgments with the combined responses on the RFT questionnaire, 52, or 69 percent, were reflected in differing views of the components of the core of practice in ten years. Of 78 disagreements on group judgments with the combined responses on the SK questionnaire, 45 , or 58 percent, were reflected in differing views of the components of the core of education in ten years. These differing views indicated that the planner group had a broader definition of the core of education than the combined responses, that the manager group had a narrower definition of both the core of practice and the core of education than 
the combined responses, and that the developer group had a broader definition of the core of practice than the combined responses.

On the "Roles, Functions, and Tasks" questionnaire, the principal differences in the views of the three groups regarding the generalizing core of practice were, with only eight exceptions, differences in the responses of the manager group narrowing, and the responses of the developer group broadening, the definition of this core. The responses of planners on this questionnaire indicated that seven items would be included in the core of practice defined by the combined responses, as follows:

\begin{tabular}{|c|c|c|}
\hline Agreement & & Task \\
\hline $67 \%$ & 6. & $\begin{array}{l}\text { Analyze the structure of a community, county, } \\
\text { or the state }\end{array}$ \\
\hline $66 \%$ & 37. & $\begin{array}{l}\text { Identify people in need of mental health or } \\
\text { social services }\end{array}$ \\
\hline $79 \%$ & 52. & $\begin{array}{l}\text { Write proposals for funding of a mental health } \\
\text { service }\end{array}$ \\
\hline $66 \%$ & 53. & $\begin{array}{l}\text { Plan a budget for a mental health agency or } \\
\text { program }\end{array}$ \\
\hline $61 \%$ & 54. & $\begin{array}{l}\text { Plan and design a coordinated system of } \\
\text { mental health services }\end{array}$ \\
\hline $61 \%$ & 72. & $\begin{array}{l}\text { Negotiate contracts with funding bodies or } \\
\text { service providers }\end{array}$ \\
\hline $61 \%$ & 78. & Mediate between client and service systems \\
\hline
\end{tabular}

In addition, these same responses suggested that five items would be excluded from this definition, as follows:

Role

24. Trainer 
Function

31. Service Enabler for comprehensive mental health program settings

Task

2. Analyze a policy, program, or budget

47. Organize new mental health services or programs in communities

59. Plan goals and measurable objectives for mental health agencies, services, or delivery systems

Therefore, if only the views of planners were considered, there would be a net increase of two in the number of items defining the future core of Master's level social work practice in this field. This would result in a total of 62 of the 129 items in the RFT questionnaire, or 48 percent.

The responses of managers on the RFT questionnaire indicated that 14 items would be excluded from the core of practice defined by the combined responses, as follows:

\section{Role}

12. Evaluator

17. Organizer

18. Planner

Task

7. Conduct a diagnostic analysis

46. Mobilize community support for mental health services and target populations

47. Organize new mental health services or programs in communities 
Task

49. Organize task forces

62. Plan intervention strategies for working with communities, organizations, and systems

63. Plan services for a client

64. Coordinate mental health programs and agencies

69. Manage a budget for a mental health agency or program

76. Advocate on behalf of clients

77. Coordinate services for clients to insure continuity of care

86. Provide screening services

In addition, these same responses indicated that seven items would be included in this definition, as follows:

Agreement

Task

\begin{tabular}{|c|c|c|}
\hline $65 \%$ & 1. & Analyze a decision-making process \\
\hline $65 \%$ & 4. & Analyze a system or organization \\
\hline $66 \%$ & 40. & $\begin{array}{l}\text { Develop comprehensive mental health service } \\
\text { centers }\end{array}$ \\
\hline $71 \%$ & 44. & $\begin{array}{l}\text { Develop policies, procedures, and guidelines } \\
\text { for mental health agencies and services }\end{array}$ \\
\hline $64 \%$ & 58. & $\begin{array}{l}\text { Plan an evaluation design for a mental health } \\
\text { service or delivery system }\end{array}$ \\
\hline $64 \%$ & 73. & $\begin{array}{l}\text { Recruit, hire, and organize personnel in a } \\
\text { mental health agency }\end{array}$ \\
\hline$\%$ & 82. & Provide Assessment services \\
\hline
\end{tabular}

Therefore, if only the views of managers were considered, there would be a net decrease of seven in the number of items defining the 
future core of Master's level social work practice in this field. This would result in a total of 53 of the 129 items in the RFT questionnaire, or 41 percent.

The responses of developers on the RFT questionnaire, in contrast to those of managers, indicated that 18 items would be included in the core of practice defined by the combined responses, as follows:

Agreement

$61 \%$

$65 \%$

$61 \%$

$70 \%$

$80 \%$

$65 \%$

$61 \%$

$61 \%$

$65 \%$

$61 \%$

$61 \%$

$61 \%$

\section{Function}

29. Manager of MRDD program settings

Task

6. Analyze the structure of a community, county, or the state

14. Provide administrative consultation

30. Provide a community education program

31. Train clients in coping, management, and maintenance skills

40. Develop comprehensive mental health service centers

42. Develop a mental health information and referral service

44. Develop policies, procedures, and guidelines for mental health services

52. Write proposals for funding a mental health service

53. Plan a budget for a mental health agency or program

68. Explain programs of a mental health agency to personnel

70. Modify a plan, policy, or program on the basis of evaluative feedback 
Agreement

$$
61 \%
$$$$
65 \%
$$$$
70 \%
$$$$
65 \%
$$

$75 \%$

$61 \%$
Task

71. Monitor the implementation of law regulations, policies, or procedures

73. Recruit, hire, and organize personnel in a mental health agency

78. Mediate between clients and service systems

79. Mobilize community resources on behalf of client

80. Negotiate contracts with clients

82. Provide assessment services

In addition, these same responses indicated that one item would be excluded from this definition, as follows:

\section{Function}

34. Service Deliverer in A\&DP program setting $\mathrm{s}$

Therefore, if only the views of developers were considered, there would be a net increase of 17 in the number of items defining the future core of Master's level social work practice in this field. This would result in a total of 77 of the 129 items in the RFT questionnaire, or 60 percent, which is one-half again as many items as were suggested by the responses of managers, and one-fourth again as many items as were suggested by the responses of planners.

On the "Skills and Areas of Knowledge" questionnaire, the principal differences in the views of the three groups regarding the generalizing core of education were, with only four exceptions, differences in the responses of the planner group broadening, and the responses of the manager group narrowing, the definition of this core. 
The responses of planners on this questionnaire indicated that ten items would be included in the core of practice defined by the combined responses, as follows:

Agreement

Skill

\begin{tabular}{|c|c|c|}
\hline $73 \%$ & 12. & Development skills \\
\hline \multirow[t]{2}{*}{$67 \%$} & 24. & Negotiation skills \\
\hline & & Area of Knowledge \\
\hline $73 \%$ & 14. & Government \\
\hline \multirow[t]{2}{*}{$72 \%$} & 24. & Social structure and institutions \\
\hline & & Area of Knowledge \\
\hline $62 \%$ & 33. & Poverty \\
\hline $62 \%$ & 50. & Client/consumer advocacy \\
\hline $73 \%$ & 67. & Intervention with the developmentally disabled \\
\hline $62 \%$ & 68. & Intervention with the mentally retarded \\
\hline $64 \%$ & 71. & Normalization and life span planning \\
\hline $78 \%$ & 85. & Social forecasting \\
\hline
\end{tabular}

In addition, these same responses indicated that two items would be excluded from this definition, as follows:

Skill

18. Interpretation skills

Area of Knowledge

30. Learning Disabilities

Therefore, if only the views of planners were considered, there would 
be a net increase of eight in the number of items defining the future core of Master's level social work education in this field. This would result in a total of 94 of the 133 items in the SK questionnaire, or 71 percent.

The responses of managers on the SK questionnaire, in contrast to those of planners, indicated that 19 items would be excluded from the core of education defined by the combined responses, as follows:

\section{Skill}

14. Evaluation skills

17. Group facilitation skills

18. Interpretation skills

27. Organizing skills

32. Planning skills

34. Program management skills

35. Public relations skills

Area of Knowledge

18. Law and legal systems

28. Developmental disabilities

38. Mental health laws

39. Mental health manpower

40. Social policy

41. Social service delivery systems

42. Social service financing

46. Behavior analysis and modification

49. Citizen/consumer participation 
Area of Knowledge

65. Intervention with alcohol abusers

66. Intervention with drug abusers

83. Rehabilitation

In addition, these same responses indicated that two items would be included in this definition, as follows:

Agreement Skill

$73 \%$ 30. Personal management skills

$66 \%$ 37. Record-keeping skills

Therefore, if only the views of managers were considered, there would be a net decrease of 17 in the number of items defining the future core of Master's level social work education in this field. This would result in a total of 69 of the 133 items in the SK questionnaire, or 52 percent, which is only two-thirds as many items as were suggested by the responses of planners.

The responses of developers on the SK questionnaire indicated that five items would be included in the core of education defined by the combined responses, as follows:

Agreement Skill

$62 \%$ 28. Outreach skills

Area of Knowledge

12. Environmental/ecological psychology

$62 \%$ 67. Intervention with the developmentally disabled

$66 \%$ 68. Intervention with the mentally retarded 
Agreement

$62 \%$
Ski11

71. Normalization and life span planning

In addition, these same responses indicated that seven items would be excluded from this definition, as follows:

\section{Skill}

27. Organizing skills

Area of Knowledge

20. Organizations and bureaucracies

35. Community mental health

40. Social policy

43. Social welfare laws, legislation, and guidelines

49. Citizen/consumer participation

87. Social work principles and code of ethics

Therefore, if only the responses of developers were considered, there would be a net decrease of two in the number of items defining the future core of Master's level social work education in this field. This would result in a total of 84 of the 133 items, or 63 percent, which is one-fourth again as many items as were suggested by the responses of managers.

\section{Training Priorities}

The analysis of the responses of planners, managers, and developers to determine training priority clusters revealed some major disagreements between the three groups on the "Roles, Functions, and Tasks" questionnaire regarding the overall 
composition of these clusters. In contrast to the social work/nonsocial work comparison, this analysis also revealed major disagreements on the "Skills and Areas of Knowledge" que stionnaire regarding the composition of these clusters. The responses on the RFT questionnaire further indicated substantial differences in the group ratings of 22 of the 74 items which were considered priorities by the three groups, or 30 percent. These were reflected, for the 22 items, in a difference of 0.5 or more in the mean responses of two of the groups. Moreover, the group responses on the SK questionnaire indicated substantial differences in the group ratings of 28 of the 104 items which were considered priorities by the three groups, or 27 percent. These, too, were reflected, for the 28 items, in a difference of 0.5 or more in the mean responses of two of the groups. There were no substantial differences between the three groups on either questionnaire in the average of the mean responses for all the training priorities.

On the "Roles, Functions, and Tasks" questionnaire, the responses of planners, managers, and developers suggested somewhat different groupings of items in the first two priority clusters. The responses of the planner group indicated that 13 items could be grouped in first priority clusters, while an additional 18 items could be grouped into second priority clusters. The 31 items represented 50 percent of the components of the core of practice defined by the responses of this group. The responses of the manager group indicated that 8 items could be grouped into first priority clusters, and an additional 12 items could be grouped into second priority clusters. 
These 20 items represented 38 percent of the components of the core of practice defined by the responses of this group. Finally, the responses of the developer group indicated that 7 items could be grouped into first priority clusters, while an additional 17 items could be grouped into second priority clusters. These 24 items represented 31 percent of the components of the core of practice defined by the responses of this group.

The average of the mean responses of items clustered by the planner group, the manager group, and the developer group were virtually identical at 4.0,4.1, and 4.1, respectively. Moreover, there were 9 priority items held in common by all three groups, and a total of 21 priority items held in common by at least two groups, while 20 items in these clusters were not held in common at all. Further, there were 18 items for which there were substantial differences in the mean responses on the items between at least two groups; and on four of the items there were substantial differences in the mean responses on the items between at least two groups; and on four of the items there were substantial differences in the mean responses on the items between one group and both of the other two. The average difference of the se 22 total cases was 0.6 .

All seven of the substantial differences between planners and managers were characterized by a lower mean response by the manager group than the planner group. Further, all eight of the differences between managers and developers were similarly characterized by a lower mean response by the manager group than the developer group. At the same time, the differences between 
planners and developers were evenly split in each group between high and low responses. Consequently, of the 56 differences between the clusters suggested by the responses of the three groups and those suggested by the combined responses, only 13, or 23 percent, represented shifts of items between clusters, while 5, or 9 percent, represented the addition of new items, and 38 , or 68 percent, represented the deletion of items from the clusters. The magnitude of the differences between these three groups that is reflected by this data indicated a need for a direct comparison of the compositions of the training priority clusters suggested by each group.

Within the roles category, the responses of planners grouped six items in the first cluster and four items in the second cluster, with an average mean response for the ten items of 4.1 , as follows:

\begin{tabular}{lll} 
& Mean & \multicolumn{1}{l}{ Role } \\
4.2 & 22. Supervisor \\
4.1 & 2. Advocate \\
& 4.1 & 6. Case Manager \\
& 4.1 & 7. Coordinator \\
& 4.1 & 4. As sessor \\
& 4.1 & 23. Therapist \\
& 4.0 & 8. Consultant \\
& 4.0 & 13. Group Facilitator \\
& 3.9 & 9. Developer \\
& 3.9 & 17. Organizer
\end{tabular}


In the same category, the responses of managers grouped four items in the first cluster and two items in the second cluster, with an average mean response for the six items of 3.9 , as follows:

\begin{tabular}{lll} 
& Mean & \multicolumn{1}{l}{ Role } \\
& 4.1 & 4. Assessor \\
Cluster I & 4.0 & 8. Consultant \\
& 3.9 & 1. Administrator \\
& 3.9 & 7. Coordinator \\
Cluster II & 3.8 & 22. Supervisor \\
& 3.7 & 23. Therapist
\end{tabular}

Finally, also in this category, the responses of developers grouped two items in the first cluster and seven items in the second cluster, with an average mean response for the nine items of 4.0 , as follows:

\begin{tabular}{rrr} 
& Mean & \multicolumn{1}{l}{ Role } \\
Cluster I & 4.4 & 4. Assessor \\
4.3 & 8. Consultant \\
4.1 & 9. Developer \\
4.0 & 1. Administrator \\
4.0 & 12. Evaluator \\
3.9 & 6. Case Manager \\
3.9 & 13. Group Facilitator \\
3.9 & 18. Planner \\
3.9 & 23. Therapist
\end{tabular}


Within the functions category, the responses of planners grouped three items in the first cluster and four items in the second cluster, with an average mean response for the seven items of 4.1 , as follows:

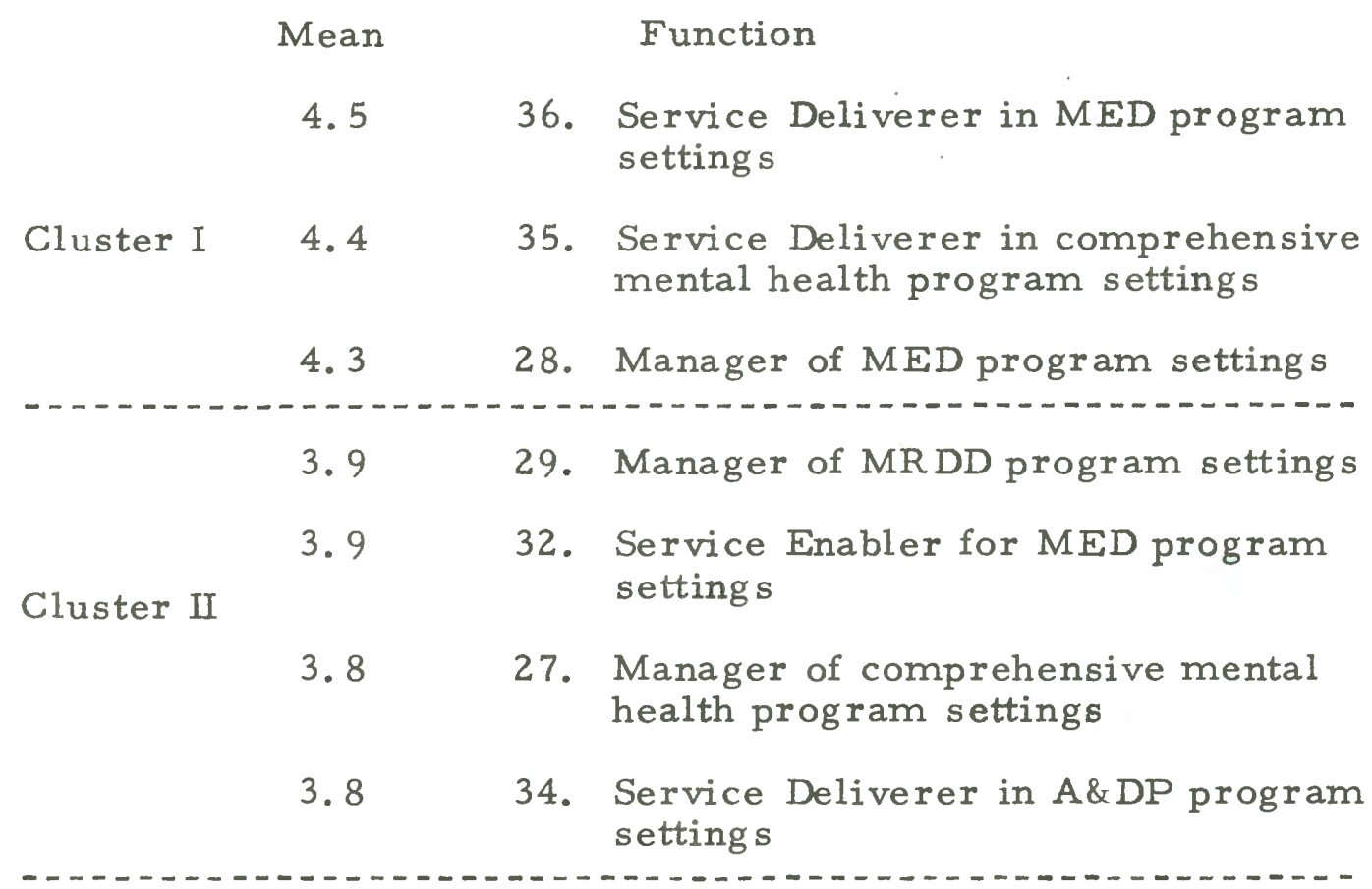

In this same category, the responses of managers grouped two items in the first cluster and three items in the second cluster, with an average mean response for the five items of 4.1 , as follows:

\begin{tabular}{|c|c|c|c|}
\hline & Mean & & Function \\
\hline \multirow[t]{2}{*}{ Cluster I } & 4.3 & 36. & $\begin{array}{l}\text { Service Deliverer in MED program } \\
\text { settings }\end{array}$ \\
\hline & 4.2 & 35. & $\begin{array}{l}\text { Service Deliverer in comprehensive } \\
\text { mental health program settings }\end{array}$ \\
\hline & 4.0 & 32. & $\begin{array}{l}\text { Service Enabler for MED program } \\
\text { settings }\end{array}$ \\
\hline Cluster II & 3.9 & 27. & $\begin{array}{l}\text { Manager of comprehensive mental } \\
\text { health program settings }\end{array}$ \\
\hline
\end{tabular}


Mean Function

Cluster II 3.9 28. Manager of MED program settings

Finally, also in this category, the responses of developers grouped two items in the first cluster and five items in the second cluster, with an average mean response for the seven items of 4.0 , as follows:

\begin{tabular}{|c|c|c|c|}
\hline \multirow{3}{*}{ Cluster I } & \multicolumn{3}{|r|}{ Function } \\
\hline & 4.1 & 26. & Manager of A\&DP program settings \\
\hline & 4.1 & 28. & Manager of MED program settings \\
\hline & & --- & 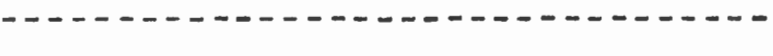 \\
\hline \multirow{5}{*}{ Cluster II } & 3.9 & 27. & $\begin{array}{l}\text { Manager of comprehensive mental } \\
\text { health program settings }\end{array}$ \\
\hline & 3.9 & 31 & $\begin{array}{l}\text { Service Enabler for comprehensive } \\
\text { mental health program settings }\end{array}$ \\
\hline & 3.9 & 32. & $\begin{array}{l}\text { Service Enabler for MED program } \\
\text { settings }\end{array}$ \\
\hline & 3.9 & 35. & $\begin{array}{l}\text { Service Deliverer in comprehensive } \\
\text { mental health program settings }\end{array}$ \\
\hline & 3.9 & 36. & $\begin{array}{l}\text { Service Deliverer in comprehensive } \\
\text { mental health program settings }\end{array}$ \\
\hline
\end{tabular}

Within the tasks category, the responses of planners grouped four items in the first cluster and eight items in the second cluster, with an average mean response for the 12 items of 4.2 , as follows:

Mean Task

4. 5 50. Participate in community groups

Cluster I and task forces

4. 590 . Form working relationships with other professionals 
Mean Task

4.3 61. Plan intervention strategies for working with clients

Cluster I

4. 32 . Write reports

\begin{tabular}{|c|c|c|c|}
\hline & 4.1 & 3. & Analyze a relationship with a client \\
\hline & 4.1 & 8. & $\begin{array}{l}\text { Assess client needs for mental } \\
\text { health services }\end{array}$ \\
\hline & 4.1 & 15. & Provide case consultation \\
\hline & 4.1 & 29. & $\begin{array}{l}\text { Engage in ongoing personal and } \\
\text { professional growth }\end{array}$ \\
\hline & 4.1 & 63. & Plan services for a client \\
\hline Cluster II & 4.1 & 74. & Supervise personnel \\
\hline & 4.1 & 75. & $\begin{array}{l}\text { Supervise/monitor the provision of } \\
\text { services to clients }\end{array}$ \\
\hline & 4.1 & 77. & $\begin{array}{l}\text { Coordinate services for clients to } \\
\text { insure continuity of care }\end{array}$ \\
\hline & 4.1 & 88. & $\begin{array}{l}\text { Provide therapeutic intervention } \\
\text { services }\end{array}$ \\
\hline & 4.1 & 91. & $\begin{array}{l}\text { Provide leadership to agencies or } \\
\text { community groups }\end{array}$ \\
\hline
\end{tabular}

In the same category, the responses of managers grouped two items in the first cluster and seven items in the second cluster, with an average mean response for the nine items of 4.0 , as follows:

Mean Task

Cluster I
4.2
92. Write reports

4.1

90. Form working relationships with other professionals 


\begin{tabular}{|c|c|c|}
\hline :an & & $T^{\prime}: i n k$ \\
\hline .0 & 15. & Provide case consultation \\
\hline .0 & 61. & $\begin{array}{l}\text { Plan intervention strategies for } \\
\text { working with clients }\end{array}$ \\
\hline .9 & 3. & Analyze a relationship with a client \\
\hline .9 & 25. & Maintain records \\
\hline .9 & 29. & $\begin{array}{l}\text { Engage in ongoing personal and } \\
\text { professional growth }\end{array}$ \\
\hline .9 & 65. & $\begin{array}{l}\text { Establish priorities for allocating } \\
\text { limited resources }\end{array}$ \\
\hline .9 & 91. & $\begin{array}{l}\text { Provide leadership to agencies or } \\
\text { community groups }\end{array}$ \\
\hline
\end{tabular}

category, the responses of developers grouped st cluster and five items in the second cluster, 2 response for the eight items of 4.2, as follows:

an Task

4 15. Provide case consultation

3 50. Participate in community groups and task forces

390 . Form working relationships with other professionals

2

34. Monitor and evaluate the progress and needs of clients

2 63. Plan services for a client

19 9. Assess mental health services and delivery systems

1 64. Coordinate mental health programs and agencies 
Main T'isk

4. 0 15. Provide case consultation

4. 0 61. Plan intervention strategies for working with clients

3.9 3. Analyze a relationship with a client

Cluster II 3.9 25. Maintain records

3.9 29. Engage in ongoing personal and professional growth

3.9 65. Establish priorities for allocating limited resources

3.9 91. Provide leadership to agencies or community groups

nally, also in this category, the responses of developers grouped ree items in the first cluster and five items in the second cluster, th an average mean response for the eight items of 4.2 , as follows:

\begin{tabular}{|c|c|c|c|}
\hline \multicolumn{4}{|c|}{ Mean } \\
\hline \multirow{3}{*}{ Cluster I } & 4.4 & 15. & Provide case consultation \\
\hline & 4.3 & 50 & $\begin{array}{l}\text { Participate in community groups } \\
\text { and task forces }\end{array}$ \\
\hline & 4.3 & 90. & $\begin{array}{l}\text { Form working relationships with } \\
\text { other professionals }\end{array}$ \\
\hline & 4.2 & 34. & $\begin{array}{l}\text { Monitor and evaluate the progress } \\
\text { and needs of clients }\end{array}$ \\
\hline & 4.2 & 63. & Plan services for a client \\
\hline & 4.1 & 9. & $\begin{array}{l}\text { Assess mental health services and } \\
\text { delivery systems }\end{array}$ \\
\hline & 4.1 & 64. & $\begin{array}{l}\text { Coordinate mental health programs } \\
\text { and agencies }\end{array}$ \\
\hline
\end{tabular}



Mean Task

Cluster II 4.1 16. Provide consultation about resources

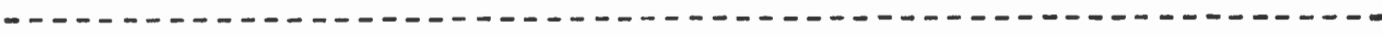

On the "Skills and Areas of Knowledge" questionnaire, the responses of the planners, managers, and developers suggested somewhat different groupings of items in the first three priority slusters. The responses of the planner group indicated that 7 items zould be grouped into first priority clusters, while an additional 18 tems could be grouped into second priority clusters, and 29 items in :hird priority clusters. The 54 items represented 57 percent of the zomponents of the core of education defined by the responses of this yroup. The responses of the manager group indicated that 5 items zould be grouped into first priority clusters, while an additional 8 tems could be grouped into second priority clusters, and 12 items zould be grouped into third priority clusters. These 25 items represented 36 percent of the components of the core of education defined गy the responses of this group.

The average of the mean responses of items clustered by the slanner group, the manager group, and the developer group were rirtually identical at 4.3,4.4, and 4.5, respectively. However, :here was a difference of 0.6 between the planner group and the leveloper group for the skills category. There were 18 priority tems held in common by all three groups and a total of 31 priority tems held in common by at least two groups, while only 26 items in hese clusters were not held in common at all. Further, there were :5 items for which there were substantial differences in the mean 
esponses on the items between at least two groups, and on three of the ems there were substantial differences in the mean responses on the ems between one group and both of the other two. The average ifference of these 28 total cases was 0.6 .

Of the substantial differences between planners and managers, 1 out of 15 were characterized by a lower mean response by the lanager group than the planner group. Further, all three of the dbstantial differences between managers and developers were milarly characterized by a lower mean response by the manager roup than the developer group. Finally, the substantial differences stween planners and developers were evenly split in each group stween high and low responses. Consequently, of the 95 differences etween the clusters suggested by the three groups and those suggested the combined responses, 37, or 39 percent, represented shifts of ems between clusters, while 19, or 20 percent, represented the Idition of new items; and 39, or 41 percent, represented the deletion items from the clusters. The magnitude of the differences between e three groups that is reflected in this data, while not as great as on e RFT questionnaire, still indicated the need for direct comparison the compositions of the training priority clusters suggested by each :oup.

Within the skills category, the responses of planners grouped ro items in the first cluster, six items in the second cluster, and six ems in the third cluster, with an average mean response for the 14 ems of 4.0 , as follows: 
Mean Skill

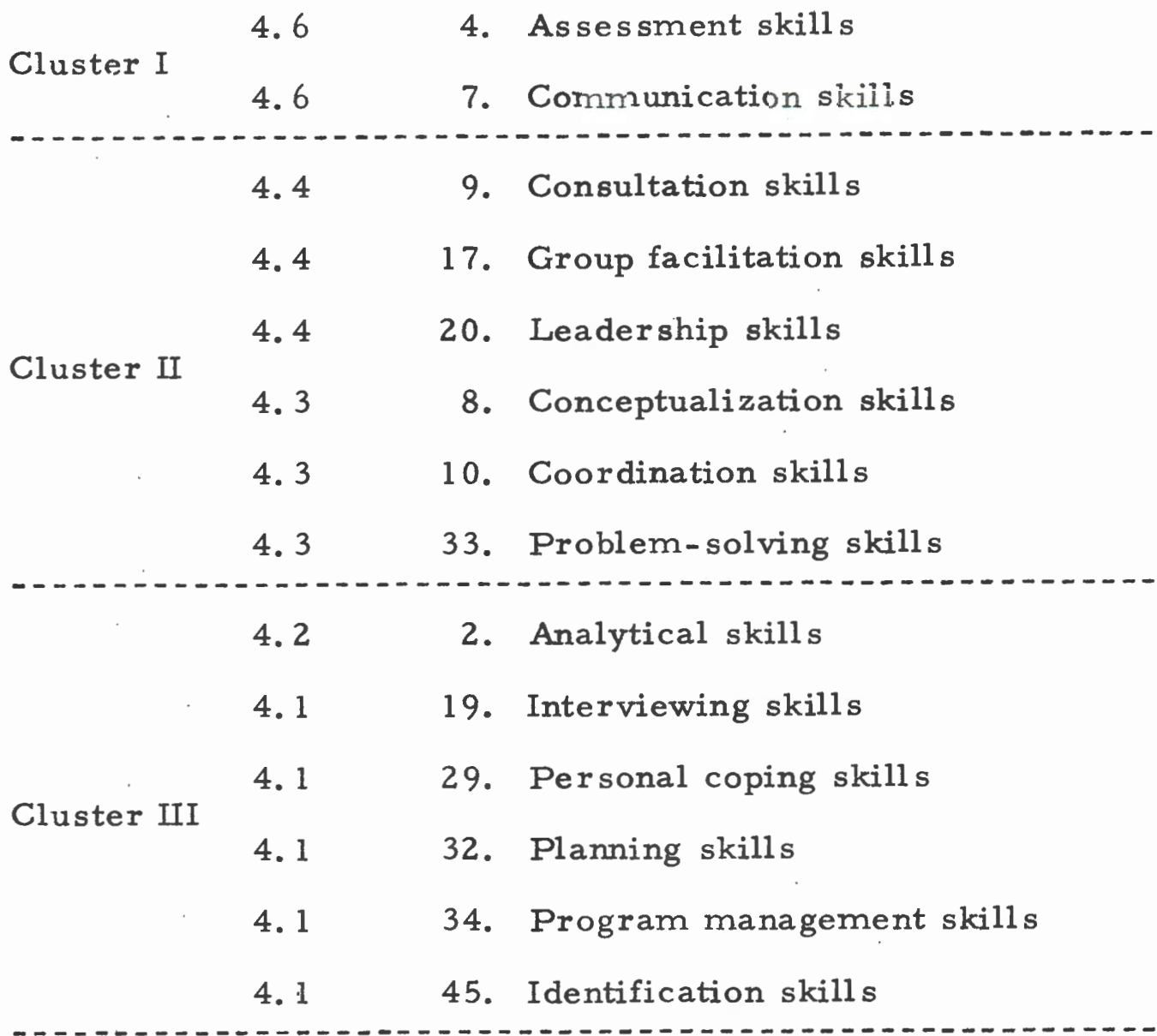

in the same category, the responses of managers grouped two items in :he first cluster, three items in the second cluster, and seven items . $n$ the third cluster, with an average mean response for the 12 items of 4.3 , as follows:

\begin{tabular}{|c|c|c|c|}
\hline & Mean & & Skill \\
\hline Cluctor T & 4.6 & 7. & Communication skills \\
\hline 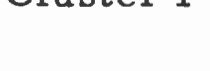 & 4.5 & 19. & Interviewing skills \\
\hline & 4.3 & 4. & As ses sment skills \\
\hline I & 4.3 & 8. & Conceptualization skills \\
\hline
\end{tabular}


Mean Skill

Cluster II 4.3 33. Problem-solving skills

\begin{tabular}{|c|c|c|c|}
\hline & 4.2 & 2. & Analytical skills \\
\hline & 4.2 & 25. & Observation skills \\
\hline 8 & 4.2 & 38. & Relationship-building skills \\
\hline Cluster III & 4.2 & 42. & Therapeutic intervention skills \\
\hline & 4.1 & 9. & Consultation skills \\
\hline & 4.1 & 10. & Coordination skills \\
\hline & 4.1 & 29. & Personal coping skills \\
\hline
\end{tabular}

nally, also in this category, the responses of developers grouped o items in the first cluster, four items in the second cluster, and o items in the third cluster, with an average mean response for the ght items of 4.6 , as follows:

Mean Skill

$\begin{array}{lll}\text { Cluster I } & 4.7 & \text { 7. Communication skills } \\ & 4.7 & \text { 19. Interviewing skills } \\ & 4.6 & \text { 13. Diagnostic skills } \\ & 4.6 & 42 . \text { Therape utic intervention skills } \\ \text { Cluster II } & 4.5 & 4 . \text { As sessment skills } \\ & 4.5 & \text { 33. Problem-solving skills } \\ & 4.4 & \text { 38. Relationship-building skills } \\ & 4.3 & 9 . \text { Consultation skills }\end{array}$


Within the areas of knowledge category, the responses of lanners grouped 5 items in the first cluster, 12 items in the second luster, and 23 items in the third cluster, with an average mean esponse for the 40 items of 4.2 , as follows:

\begin{tabular}{|c|c|c|c|}
\hline & Mean & & Area of Knowledge \\
\hline & 4.6 & 5. & Psychology \\
\hline & 4.6 & 53. & Conflict resolution \\
\hline Cluster I & 4.6 & 76. & Program development \\
\hline & 4.5 & 7. & Social psychology \\
\hline & 4.5 & 19. & Mental health \\
\hline & 44 & 15 & Grouns \\
\hline & 4.4 & 55. & Continuity of care \\
\hline & 4.4 & 64. & $\begin{array}{l}\text { Interper sonal communication and } \\
\text { relations }\end{array}$ \\
\hline & 4.4 & 74. & Prevention \\
\hline Cluster II & 4.3 & 21 & Personality theories \\
\hline & 4.3 & 36. & Mental health delivery systems \\
\hline & 4.3 & 45. & Accountability \\
\hline & 4.3 & 54. & Consultation \\
\hline & 4.3 & 59. & Evaluation \\
\hline & 4.3 & 77. & Program management \\
\hline & 4.3 & 78. & Problem-solving process \\
\hline & - & $\cdots$ & 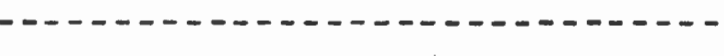 \\
\hline Cluster IIII & 4.2 & 13. & The Family \\
\hline & 4.2 & 27. & Alcohol abuse \\
\hline
\end{tabular}


Mean

4.2

4.2

4.2

4.2

4.2

4.2

4.1

4.1

4.1

4. 1

4. 1

Cluster III

31. Mental, emotional, and behavioral disturbances

38. Mental health laws, legislation, and guidelines

41. Social service delivery systems

51. Community or ganization

61. Group psychotherapy

62. Group work

9. Abnormal psychology/psychopathology

11. Child rearing

16. Human growth and development

17. Human sexuality

24. Social structure and institutions

4.1

25. Systems theory

4.1

40. Social policy

4.1

52. Confidentiality and civil rights

4. 1

56. Crisis intervention

4. 1

60. Family psychotherapy

4.1

65. Intervention with alcohol abusers

4.1

69. Intervention with the mentally or emotionally disturbed

4. 1 75. Problem-oriented record keeping

4.1 83. Rehabilitation

4. 1 88. Supervision 
$\mathrm{n}$ this same category, the responses of managers grouped three tems in the first cluster, five items in the second cluster, and five tems in the third cluster, with an average mean response for the 13 tems of 4.5 , as follows:

\begin{tabular}{|c|c|c|c|}
\hline \multicolumn{2}{|c|}{ Mean } & \multicolumn{2}{|r|}{ Area of Knowledge } \\
\hline & 4.7 & 5. & Psychology \\
\hline \multirow[t]{2}{*}{ Cluster I } & 4.7 & 7. & Social psychology \\
\hline & 4.7 & 19. & Mental health \\
\hline 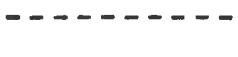 & $-\cdots$ & $-\cdots$ & -------------1 \\
\hline \multirow{5}{*}{ Cluster II } & 4.6 & 13. & The Family \\
\hline & 4.5 & 9. & $\begin{array}{l}\text { Abnormal psychology/psycho- } \\
\text { pathology }\end{array}$ \\
\hline & 4.5 & 21. & Personality theories \\
\hline & 4.5 & 64. & $\begin{array}{l}\text { Interpersonal communication and } \\
\text { relations }\end{array}$ \\
\hline & 4.5 & 87. & $\begin{array}{l}\text { Social work principles and code of } \\
\text { ethics }\end{array}$ \\
\hline \multicolumn{4}{|c|}{ - } \\
\hline \multirow{5}{*}{ Cluster III } & 4.3 & 15. & Groups \\
\hline & 4.3 & 16. & Human growth and development \\
\hline & 4.3 & 48. & Casework \\
\hline & 4.3 & 56. & Crisis intervention \\
\hline & 4.3 & 60. & Family psychotherapy \\
\hline
\end{tabular}

'inally, also in this category, the responses of developers grouped 2 :ems in the first cluster, 5 items in the second cluster, and 13 items 1 the third cluster, with an average mean response for the 20 items f 4. 4, as follows: 
Mean Area of Knowledge

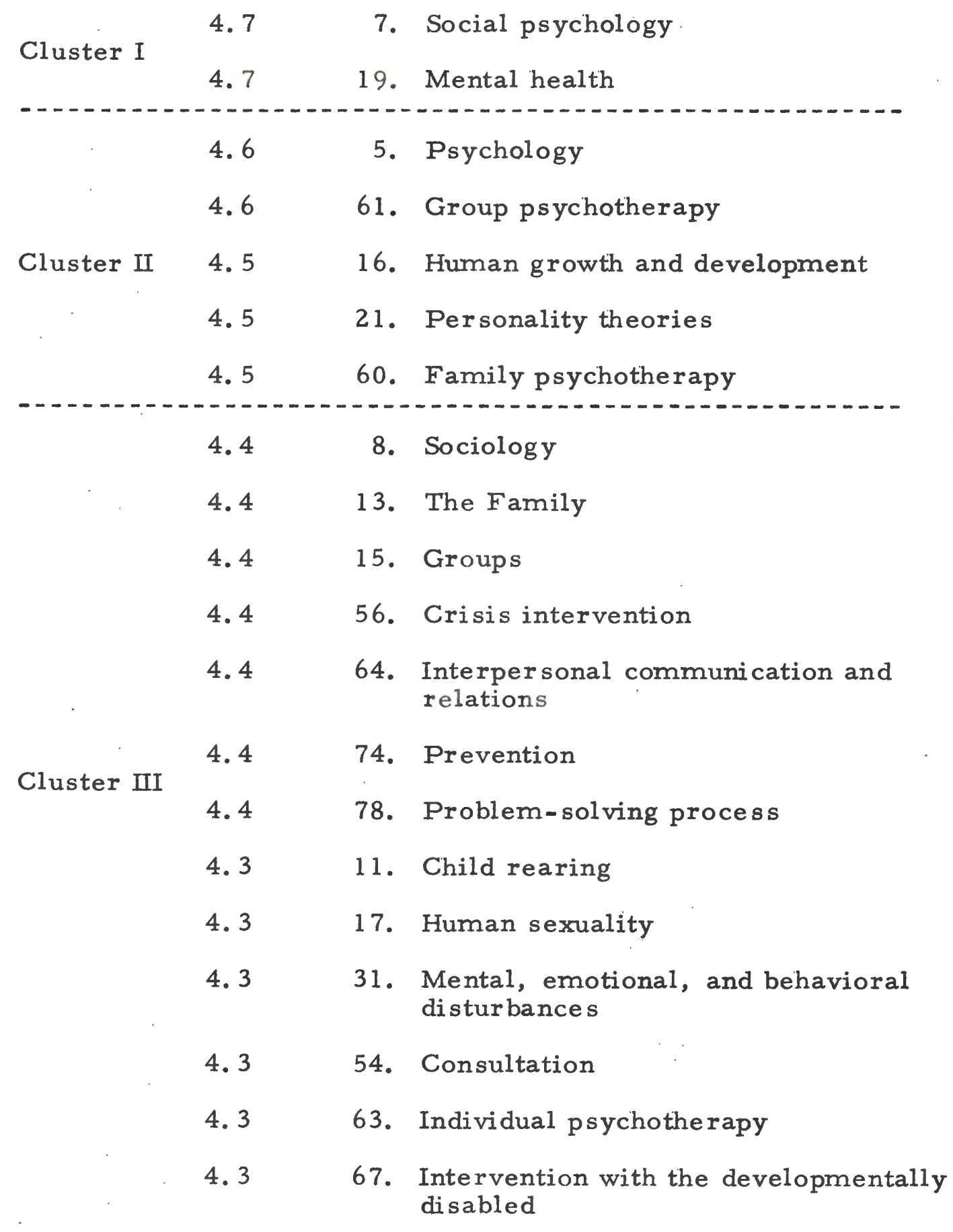




\section{CHAPTER V}

\section{SUMMARY AND CONCLUSIONS}

\section{SUMMARY OF THE RESEARCH FINDINGS}

iound I

The first questionnaire of this research survey was sent to 160 . rental health practitioners who were purposefully chosen as members $f$ the study's population. It was returned by 80 participants, or 51 ercent of the population. As the data was analyzed for content rather han tabulated, the non-respondents on this first round were not ampled to determine the possibility of bias.

The content analysis of the responses received from participants $\mathrm{n}$ this round involved a four-step editing process. This resulted in sts of 25 roles, 12 functions, 92 tasks, 45 skills, and 88 area s of nowledge. Inclusion of items was based on consensus between the esearchers. Consequently, the researchers believed that these lists ccurately represented the opinions of respondents regarding the ractice and educational needs of Master's level social workers who rill be involved in the field of community mental health in Oregon over ze next ten years.

The data generated on the first round suggested that Master's evel social workers active in this field in the future will be performing multitude of roles, functions, and tasks. Social work practice will sus involve a wide variety of activities encompassing the provision of 
"direct" services, such as case management, therapeutic intervention, service coordination, and case consultation; the management of services, such as program administration and personnel supervision; the provision of "indirect" services, such as program development, planning, and community organization. Further, the data suggested that these social workers will need to possess a broad range of skills and a broad foundation of knowledge commensurate with the range of activities they will be involved in.

One participant commented on the results of this first round as follows:

It seems a matter of interest that your respondents feel that social workers will be doing and concerned with most everything.... That doesn't seem very helpful in pointing out professional direction, does it?

After reviewing the data resulting from the first round of the survey, the researchers' answer to this observation was, in all honesty, "no." This was not to say that this data was not valuable, however. By this point, the research had produced a picture of future social work practice and educational needs with greater specificity than any study found in the literature. Nevertheless, it was difficult to develop a general characterization of the nature of that future practice from this data.

The responses to the first round, in broad terms, did confirm the point of view that there will continue to be role bluring in practice among the professions in this field, at least as far as social workers are concerned. Further, the general picture of practice suggested by this data did not differ greatly from that presented by manpower analysts such as Wittman (SREB 1974a), who argued that this field 
needs social workers who can intervene on both the micro and macro levels. Indeed, it tended to reaffirm the view of some analysts that social work professionals function as, or are expected to function as, "jacks of all trades and masters of none." Considered at this broad level, however, the data did not shed a great deal of light on either professional direction or priorities for training social workers. Therefore, it was the researchers' conclusion that it was necessary, in order to clarify training is sues in this field, to carry the study well beyond this first round.

$\underline{\text { Round II }}$

Two questionnaires with a total of 262 items were developed out of the responses to the first round, and each was sent to a random sample of one-half of the population. Participants were asked to rate every item on a five-point frequency of occurrence scale, with 1 representing "Very Infrequent" and 5 representing "Very Frequent." The 129-item "Roles, Functions, and Tasks" questionnaire was returned by 50 of the 78 participants to whom it was mailed, or 64 percent, for a loss of 28 participants. The "Skills and Areas of Knowledge" questionnaire was returned by 64 of the 80 participants to whom it was mailed, or 80 percent, for a loss of 16 of the participants. The non-respondents on the "Roles, Functions, and Tasks" questionnaire, because of their greater numbers, were randomly sampled, using an abbreviated questionnaire, in order to determine the possibility of any bias in their responses which could have skewed the tabulated data on this round. On the basis of a return of seven out of seven questionnaires, or 100 percent, it was concluded by the 
researchers that there were no discernable patterns on non-response bias, and that the responses to the complete questionnaire could be generalized for the entire sample.

The distribution of modal responses on second round questionnaires was, with only one exception, limited to the 3,4 , and 5 points of the five-point frequency scale. The researchers initially considered the possibility that this uneven distribution could have resulted from an insufficiently flexible scale which encouraged respondents to avoid responses at the extreme ends of the scale and to favor the middle. In this case, it would have effectively become a three-point scale. However, the one modal response at point 1 on the two questionnaires was not congruent with the 4-14 percent modal response distribution at point 5. Nor was the zero distribution rate at point 2 congruent with the 57-60 percent modal response distribution at point 4. Therefore, the researchers concluded that the uneven distribution of modal responses was not primarily, if at all, attributable to problems within the rating scale.

The researchers interpreted the fact that only one mode fell below point 3 , which represented Occasional frequency of occurrence, as an affirmation that the lists developed from responses to the first round did indeed represent an accurate representation of the opinions of participants which were expressed on that round. Further, it was concluded that there was a considerable amount of initial agreement, averaging 42-43 percent, about the general character of the future practice and educational needs of social workers in this field. Finally, as the one item which did have a mode of 1 was the prescription and 
supervision of psychotropic medications, the researchers concluded that participants believed there was at least one clear limit to role blurring within professional practice in this field.

\section{Round III}

The questionnaires for the third round were identical in every respect to the second round questionnaires except that participants were asked to reconsider their ratings of items in light of the modal responses to the items. These questionnaires were mailed only to those participants who actually responded on the second round. Subsequently, there was a further loss of one on the "Roles, Functions, and Tasks" questionnaire for an overall return rate of 64 percent, adjusted to account for changes in the employment of participants. There was, in addition, a loss of three responses on the "Skills and Areas of Knowledge" questionnaire for an overall return rate of 76 percent.

The modal responses of participants on the third round were identical to those on the second round, with the exception of broken ties. The re-ratings of respondents resulted in a 5-6 percent convergence of responses on the modes, and a greater total movement toward the modal response on both questionnaires than was reflected in actual convergence on the mode. The final distribution of responses on the mode averaged 48-49 percent for each questionnaire.

The researchers did not consider that either the final distribution of responses on the mode or the change in responses and convergence on the mode were very great. On the basis of the overall pattern of movement within the questionnaires, the researchers concluded that 
one reason for the incremental nature of this change may have been fatigue, related to questionnaire length, which appeared to have greater impact on the re-rating of items and the convergence of responses on this round than had been originally hoped for or anticipated.

Group Judgments. Analysis of the distribution of responses on the third round indicated that for 41 of the 129 items on the RFT questionnaire, or 32 percent, no judgment could be said to have been made by the group as a whole regarding the rating of these items. On the SK questionnaire, the data indicated that for 24 of the 133 items, or 18 percent, no judgment could be said to have been made by the group as a whole regarding the rating of these items. For the remaining items in each questionnaire, there was at least a 60 percent unipolar distribution of participant responses on either the 1-2-3 side of the scale or the 4-5 side of the scale. Such a distribution was considered indicative of a group judgment.

The differences between the two questionnaires on the issue of group judgments could, the researchers believed, have been attributable to either the composition of the population samples who received the questionnaires, to the structure of the instruments, or to the actual content of each questionnaire. An analysis of the identifying data provided by respondents indicated that there were no distinguishing differences between the groups who actually returned the two questionnaires. Furthermore, the questionnaires were almost identical in length and in all other matters of format. Therefore, the researchers concluded that the participants were considerably more decisive about 
educational concerns; that is, skills and areas of knowledge, than they were about practice concerns; that is, roles, functions, and tasks. Generalizing Core. Items on round three which group judgments had rated on the 4-5 end of the scale were considered components of the future generalizing core of Master's level social work practice and education in the field of community mental health. Thus, 14 roles, 8 functions, and 38 tasks, or 47 percent of the items in the RFT questionnaire, with a mean strength of agreement of 71 percent, were considered to have defined the core of social work practice in this field in ten years. Similarly, 26 skills and 60 areas of knowledge, or 68 percent of the items in the SK questionnaire, with a mean strength of agreement of 78 percent, were considered to have defined the core of social work education in this field in ten years. The researchers concluded that the relatively higher proportion of items in the functions and areas of knowledge categories, and relatively lower proportion of items in the task category, were indications that the participants believed that Master's level social workers will carry out a broad variety of functions while performing a limited number of tasks in this field, and that a broad educational background will be necessary for this future practice.

The picture of the mainstream of social work practice and educational needs in the field of community mental health, which was suggested by this generalizing core, had a much sharper focus than the picture presented by the data generated on the first round. In fact, almost one-half of the items on the second questionnaire had been eliminated to arrive at this definition. This sharper focus, however, 
still indicated that Master's level social workers, as a group, will be not only providing direct services, but managing services, and providing indirect services as well.

At one level, this generalizing core confirmed the picture which was suggested by Briggs (1973), that graduate-trained social workers in ten years will be middle managers, supervisors, or specialist consultant-planners in social problem areas. These roles and activities were certainly suggested as part of the mainstream of social work practice defined by this core, and commensurate skills and areas of knowledge were likewise proposed as part of the future core of social work education. Nevertheless, many of the roles, functions, tasks, skills, and areas of knowledge of social workers were also indicated in terms of the actual provision of direct services as case managers and therapists.

The generalizing core of practice and education which was defined by the participants' responses on the third round suggested that social workers both will be increasingly involved in the management of services and in providing indirect services and will continue to be involved in providing direct services. Further, this picture suggested that social work practice will focus primarily on services for MED populations and comprehensive services for all populations, and secondarily on services for A\&DP populations. According to this picture, social work will have no general, consistent involvement with MRDD target populations.

The preceding conclusions represented important projections about the future of social work practice in this field. The generalizing 
core provided an empirically-based forecast of the mainstream of practice and social work educational needs in this field which was at once similar to and different from the projections of manpower analysts and social work educators that were found in the review of the literature. Despite the importance of these conclusions for clarifying the is sue of the professional direction of social workers in the field of community mental health, however, the definition of this generalizing core did not clarify the issue of appropriate priorities for training social workers for practice in this field.

Training Priorities. Analysis of the mean responses on the third round indicated that 53 of the 146 items which defined the future generalizing core of practice and education could be grouped into two or three ranked clusters within each category. These clusters suggested appropriate priorities for training Master's level social workers specializing in this field of practice. On the RFT questionnaire, 32 items, or 25 percent of the items in the questionnaire, could be grouped into two priority clusters in each category with a mean response of 4.0 . These clusters included 9 roles, 5 functions, and 18 tasks, with two roles, three functions, and five tasks grouped in the first cluster. On the SK questionnaire, 43 items, or 32 percent of the items in the questionnaire, could be grouped into three priority clusters in each category with an average mean response of 4.3 . These clusters included 15 skills and 30 areas of knowledge, with two skills and three areas of knowledge grouped in the first cluster.

The number of items in these training priority clusters was slightly more than one-third as many items as defined the previously 
described generalizing core. Consequently, the profile of social work practice and educational needs which these clusters presented was far sharper than pictures developed in earlier levels of data analysis. This profile indicated that the highest training priorities are preparing social workers to carry out service delivery, management and service enabling functions in MED programs, and to carry out service delivery and management functions in programs for all target populations.

According to this profile, social workers, in carrying out service delivery functions, will be assessing service needs of clients, analyzing relationships with clients, planning services and intervention strategies for working with clients, providing services, coordinating services for clients, monitoring and evaluating client progress, and providing case consultation. They will be involved in assessor, case manager, consultant, coordinator, and therapist roles while performing these activities. In carrying out management functions, social workers will be providing leadership to agencies, supervising personnel, and supervising the provision of services to clients. They will be involved in administrator and supervisor roles while performing these activities. In carrying out service enabling functions, social workers will be assessing mental health services and delivery systems, participating in community groups and task forces, and providing resource and program consultation. They will be involved in consultant, developer, and group facilitation roles while performing these activities. Further, in carrying out all these functions, social workers will be forming working relationships with other professionals, writing reports, and engaging in ongoing personal and 
professional growth.

The profile indicated that in order, to cope with the demands of their practice, Master's level social workers will need to be trained to effectively utilize analytical assessment, communication, conceptualization, consultation, coordination, diagnostic, interviewing, leadership, planning, problem-solving, relationship-building, and therapeutic intervention skills. This list suggested that the primary focus of their activities will be on carrying out the service delivery function; secondarily, the service enabling function; and tertiarily, the management function. Further, the profile suggested that social workers will need a firm foundation in the disciplines of psychology and social psychology and, to a lesser degree, sociology, with substantiai knowledge about child rearing, the family, groups, human growth and development, interpersonal communication, mental health, personality theories, psychopathology, and sexuality. In addition, they will need to have knowledge about the problem areas of mental, emotional, and behavioral disturbances and alcohol abuse; about the practice concepts of accountability, confidentiality, conflict resolution, continuity of care, crisis intervention, prevention, and problem solving; and about the practice modalities of consultation, evaluation, group work, individual, family, and group psychotherapy, program development, and program management.

The profile which resulted from the priorities for training Master's level social workers specializing in this field further suggested that the primary roles, functions, and tasks of social work practice, and the primary skills and areas of knowledge focused on by 
social work education will be concerned with the direct delivery of services. Social work involvement in the management of services and in providing indirect services, while suggested as essential elements of the mainstream of social work practice and educational needs, were consequently viewed as secondary activities of social workers involved in this field. Thus, this profile stands in direct contradiction to the projections of manpower analysts who suggest that management and indirect service roles, functions, and tasks will, in ten years, constitute the primary activities of social work practice, and will require a commensurate focus for Master's level social work education.

Social Workers and Non-Social Workers

A comparative analysis of the subgroups of social workers and non-social workers who participated in this study indicated that a number of substantial differences of opinion existed between the two groups. These differences helped to explain some of the anomalies in the data analysis of the combined responses.

The initial step of this comparative analysis indicated that the se two groups exhibited no consistent pattern in their responses across the two questionnaires in terms of their tenacity of holding to original views between rounds. Thus, on the RFT questionnaire, social workers were less tenacious in holding to their round two views and had a higher percentage of distributions at the mode than non-social workers. On the SK questionnaire, however, non-social workers were less tenacious in holding to their original views and had a higher percent of respanses at the mode. 
Group Judgments. Analysis by subgroup of the distribution of responses on the third round indicated that no cross-questionnaire generalizations could be made about the ability of either group to form judgments. Thus, on the RFT questionnaire, the social work group was more decisive, while on the SK questionnaire, the non-social work group was more decisive. Further, on the RFT questionnaire, there were substantial differences of opinion between the two groups on 31 of the disputed items. These were reflected in at least a 25 percent difference between the groups in the distribution of responses on the dichotomized scale. Almost all these differences were characterized by non-social workers consistently rating the disputed items lower than social workers. On the SK questionnaire, there were only two substantial differences of opinion. Response patterns on a number of items, in contrast to the RFT questionnajre, indicated that social workers frequently rated disputed items lower on this questionnaire than non-social workers.

Generalizing Core. On the RFT questionnaire, there were 48 disagreements over group judgments that were reflected in differing definitions of the core of social work education suggested by the two groups. On the SK questionnaire, there were 20 disagreements over group judgments that were reflected in differing definitions of the core of social work education suggested by the two groups. These differences indicated that the responses of the social work group suggested a broader definition of the core of practice and a narrower definition of the core of education than the combined responses. At the same time, the responses of the non-social work group suggested a narrower 
definition of the core of practice and a slightly broader definition of the core of education than the combined responses.

On the RFT questionnaire, the responses of social workers included 27 items in the definition of the core of practice which were not included by the combined responses. The items involved analytical, development, personnel hiring, planning, standard setting, and training activities; diagnostic and writing roles; and management functions in MRDD programs. At the same time, these responses deleted client advocacy activities from this core. In contrast to social workers, the responses of non-social workers on the RFT questionnaire deleted 17 items from the definition of the core of practice which had been included by the combined responses. The items involved analytical, diagnostic, identification, management, mobilization, organization, planning, and supervisory activities; assessor, organizer, and planner roles; and service enabler functions in programs for all populations and service delivery functions in programs for A\&DP populations.

The responses of social workers suggested a core of practice defined by almost twice as many items as the core defined by the responses of non-social workers. Further, the core suggested by the social work group had, in general, a greater emphasis on the provision of indirect services and the management of services and, in particular, a greater emphasis on assessment and diagnostic activities, than did the core of practice suggested by the non-social work group.

On the SK questionnaire, the differences of opinion between the 
two groups were not as great as on the RFT questionnaire. The responses of the social work group deleted 14 items from the definition of the core of education which were included by the combined responses. These items involved macro or societal concerns such as community mental health, social policy, and social welfare laws; indirect service concerns such as citizen participation, mental health manpower, and social service delivery systems; indirect service skills and methods such as organizing skills, community organization, group work, and social planning; and social work principles and ethics. The responses of non-social workers, on the other hand, included four items in the definition of this core of education which were not included by the combined responses. These items involved outreach skills, client advocacy, and intervention with MRDD populations. At the same time, evaluation skills was deleted from this core by the non-social work responses.

The responses of social workers on the SK questionnaire thus indicated a belief on the part of this group that social workers will not need to learn about macro concerns, indirect service concerns, and indirect service methods. Yet the responses of non-social workers indicated a belief that social workers in this field will need to learn about these concerns. Further, the responses of non-social workers indicated a belief that social workers will need to possess outreach and organizing skills, while social workers did not indicate that these particular direct and indirect service skills will be a part of the future core of education.

The researchers could not find any explanation in differences 
within the questionnaire samples or within the structure of the two questionnaires which could account for the seeming inconsistencies in the responses of the social work group across the two questionnaires. On the RFT questionnaire, social workers thus emphasized indirect service activities as part of the core of social work practice, while on the SK questionnaire, this group de-emphasized knowledge and certain skills related to indirect services as part of the core of social work education. The researchers therefore concluded that, compared to non-social workers, the social work group believed that, in ten years, social workers will be performing a wider range of activities yet will require a quantitatively and qualitatively narrower educational foundation; that is, compared to the views of the non-social work group, they will do more and know less. This narrower educational foundation suggested by the social work group excluded organizing and outreach skills and knowledge about macro concerns such as social policy, about indirect service concerns such as community organizing and social planning, and about certain direct service concerns such as advocacy. Interestingly enough, it has been these very skills and concerns which have been foci of major importance and controversy in social work practice and education during the last fifteen years (Grosser 1973; Gurin 1973; Kahn 1973).

Training Priorities. Analysis of the mean responses of social workers and non-social workers on the two questionnaires revealed major disagreements between the two groups concerning priorities for training Master's level social workers. On the RF'T questionnaire there were substantial differences of 0.5 in the mean responses of 
social workers and non-social workers on 28 of the 53 items which were considered priorities by the two groups. As a result, there was a 0.5 difference between the average mean responses for all the training priorities suggested by the responses of social workers on this questionnaire and for all those suggested by non-social workers. Further, 41 out of the 53 items in the two priority clusters were not considered common priorities by the two groups.

On the RFT questionnaire, the responses of social workers indicated that they believed that it was most important to train social workers to be competent in a relatively narrow range of roles, which included assessor and supervisor, while non-social workers suggested a broader range of roles that excluded assessor and supervisor, but included advocate, case manager, coordinator, developer, evaluator, and group facilitator. The responses of the social work group further indicated a belief that future social workers will primarily be carrying out service delivery functions, and secondarily carrying out management and service enabling functions, all of which will be concentrated almost exclusively in programs for MED populations. The responses of the non-social work group indicated that they included management as a primary function for social work practice but excluded the service enabling function altogether. Moreover, the responses of the nonsocial work group suggested that training for service delivery and management functions must be broadened to include an involvement in programs for $A \& D P$ and MRDD populations.

The responses of the social work group on the RFT questionnaire indicated that, in their view, it will be essential to prepare future 
social workers to perform a limited range of direct service activities, including providing therapeutic intervention, and a number of planning and supervisory activities. At the same time, the responses of the non-social workers indicated that, in their view, it will be essential that future social workers be prepared to perform a broader range of direct service activities, including coordination and follow-up and excluding therapeutic intervention. Their responses also indicated that it is not essential that social workers be prepared to perform most of the indirect services activities or any of the management activities which the social work group indicated will be necessary.

On the SK questionnaire, there was considerably less disagreement between the two groups regarding the composition of the training priority clusters. Thus, only 21 out of 62 items in the three priority clusters were not considered common priorities by the two groups. Further, there were only two priority items on which there were differences in mean responses of over 0.5 between the groups.

On the SK questionnaire, the social work group placed slightly greater emphasis on diagnostic, interviewing, and relationshipbuilding skills than did the combined responses, while deleting coordination skills. At the same time, the non-social work group placed greater emphasis on case management, group facilitation, and identification skills while deleting diagnostic skills.

In terms of areas of knowledge, the social work group placed greater emphasis than the combined responses on casework, child rearing, consultation, evaluation, family therapy, human development, intervention with MED populations, mental health laws, mental health 
delivery systems, and personality theories. Further, they placed less emphasis than the combined responses on groups and prevention while deleting group work from their priorities altogether. At the same time, the non-social work group placed more emphasis than the combined responses on continuity of care, groups, group work, interpersonal communication, program development, and social work principles and ethics. Further, they placed less emphasis than the combined responses on conflict resolution, crisis intervention, family therapy, human development, MED populations, and problem solving while deleting accountability, evaluation, individual psychotherapy, intervention with MED populations, and program management from their priorities altogether.

On the SK questionnaire, the responses of social workers in general thus treated assessment, diagnosis, and therapy-related skills and knowledge as higher priority areas than did the responses of the non-social work group. At the same time, the responses of the nonsocial work group treated case management and group work-related skills and knowledge as higher priority areas than did the responses of the social workers.

Discussion. There were, then, major differences of opinion between social work and non-social work subgroups in this study over the questions of the future generalizing core of social work practice and education and of priorities for training Master's level social workers specializing in practice for this field. These disagreements were reflected both in substantial differences in response distributions and mean responses, and in the content of this core and these 
priorities. Significantly, these differences were consistent across the questionnaires, though not as great on the SK questionnaire as on the RFT que stionnaire.

In general, then, the responses of the social work group suggested four major foci of social work practice and education; that is, a) case consultation; b) therapy, including assessment and diagnosis; c) management, including supervision; and d) planning. This picture confirms the views of social work educators such as Gurin (1973, p. 194), who suggested the need to prepare Master's level social workers for two major types of responsibilities: the "therapeutic" and the "administrative." In contrast, the responses of non-social workers suggested three major foci of social work practice and education; that is, a) case consultation; b) case management, including advocacy and coordination; and c) group work, including community organization. This picture could be considered an integration of a more traditional view of social work practice, emphasizing casework and group work, with a modern view of the profession's present concerns for client advocacy and community organization.

The differences between the social work group and the non-social work group over the issues of professional orientation and training priorities thus had the character of two essentially divergent views of social work practice and education in this field. This understanding led the researchers to conclude that the previously summarized composite views on these issues, resulting from combining their responses, represented more of a compromise--an unhappy marriage 
of opposing views--than they represented a consensus on a common point of view characterized by minor disagreements.

Planners, Managers, and Developers

A comparative analysis of the responses of the subgroups of planners, managers, and developers who participated in this study indicated that some substantial differences of opinion existed between the three groups, but less so than between social workers and nonsocial workers. As with the preceding comparison, the data initially indicated that the groups exhibited no consistent pattern in their responses across the two questionnaires in terms of the comparative tenacity of each group in holding to their views between rounds.

Group Judgments. Analysis by occupational subgroups of the distribution of responses on the third round indicated that, on both questionnaires, managers were the most indecisive of the three groups in forming group judgments. The data did not permit cross-questionnaire generalizations about the ability of the other two groups to form judgments. However, a comparison of the differences between the three groups revealed that on both questionnaires, the developer group generally rated disputed items higher than the other two groups, and the manager group generally rated disputed items lower. No crossquestionnaire generalizations could be made about the planner group.

On the RFT questionnaire, there were 27 items on which there were substantial differences of opinion between at least two groups, as reflected in a 25 percent difference in the distribution of responses on the dichotomized scale. Further, there were four times as many disagreements between the planner and developer groups and the 
manager group as there were between the two groups. On the SK questionnaire, there were 38 items on which there were substantial differences of opinion between at least two groups, as reflected in a 25 percent difference in the distribution of responses. On this questionnaire, there were seven times as many major disagreements between the planner and developer groups and the manager group as there were between the two groups. The researchers concluded from this data that the manager group was not only collectively more indecisive than the other two groups, but that there was substantially more disagreement between the collective views of this group and the collective views of the other groups.

Generalizing Core. On the RFT questionnaire, there were 52 disagreements over group judgments that were reflected in differing definitions of the future core of social work practice suggested by the three groups. On the SK questionnaire, there were 45 disagreements over group judgments that were reflected in differing definitions of the future core of social work education suggested by the three groups. These differing views indicated that the planner group had a broader view of the core of education than the combined responses, that the manager group had a narrower definition of the entire generalizing core of practice and education than the combined responses, and that the developer group had a broader view of the core of practice than the combined responses.

On the RFT questionnaire, no clear pattern emerged in the content of the responses of planners relative to the core of practice. On this same questionnaire, the content of the responses of the 
manager group relative to the core of practice was similarly mixed. The responses of this group suggested more social work involvement in development, evaluation, and personnel hiring activities, and also excluded involvement in certain direct service activities such as advocacy, coordination, and diagnosis, and involvement in organizing, mobilizing, and management activities as well. The content of the responses of developers on this questionnaire indicated a general broadening of the scope of the future core of practice, as these items involved activities not only in providing direct services, but in managing services and in providing indirect services as well.

On the SK questionnaire, the content of the responses of the planner group similarly indicated a general broadening of the scope of the core of education. Their responses suggested inclusion in this core of macro concerns such as government, social structure, and poverty, as well as direct and indirect service concerns. The content of the responses of the manager group on this questionnaire indicated a general narrowing in scope of the core of education, particularly in relation to areas of knowledge. These excluded items involved both the management skills of evaluation and program management, and the indirect service skills of group facilitation, organizing, planning, and public relations. Finally, the content of the responses of the developer group on this questionnaire presented no clear pattern of responses, though there seemed to be more focus on micro concerns and direct service skills and less focus on macro areas of knowledge and indirect service skills.

The researchers concluded that there were major differences 
between the perspectives of the three groups which were reflected in differing definitions of the future generalizing core of practice and education. These differences principally resulted from an implied belief in the responses of the manager group that social work practice and educational needs will involve less emphasis on management and indirect service activities, skills, and knowledge than the combined responses suggested.

Training Priorities. Analysis by occupational subgroups of the mean responses on the third round indicated that there were some major disagreements between the three groups regarding the composition of the training priority clusters for both questionnaires. There were, however, considerably fewer disagreements on a proportional basis than between the social worker and non-social worker subgroups. On the RFT questionnaire, there were substantial differences of 0.5 or more between at least two groups in the mean response ratings of 22 of the 74 items that were suggested as priorities by the three groups. On the SK questionnaire, there were substantial differences between at least two groups in the mean response ratings of 28 of the 104 items which were suggested as priorities by the three groups.

On the RFT questionnaire, almost all of the substantial differences between the groups were characterized by a lower mean response by the manager group than the other two groups. Similarly, on the SK questionnaire, the majority of the substantial differences between the groups were characterized by a lower mean response by the manager group than the other two groups. 
On the RFT questionnaire, the responses of planners suggested a relatively wide variety of roles that future social workers would need to be trained for, which included advocate, case manager, developer, group facilitator, and organizer roles, and which emphasized supervisor and therapist roles. The responses of the manager group excluded all of the former list of roles from their priorities, but included the administrator role and indicated that supervisor and therapist roles were considered less important than the planners saw them as. The responses of the developer group encompassed all of the roles included by the other two groups, except for supervisor and coordinator roles, and also deemphasized the role of therapist. These responses further included the roles of evaluator and planner as priority items.

The responses of planners and managers differed little on priority items within the functions category. However, the responses of the planner group indicated that training for manager functions in MRDD programs and for service deliverer functions in A\&DP programs was important, while the responses of managers did not. The responses of developers, on the other hand, emphasized training for management functions more than service delivery functions, and included management of $A \& D P$ programs as a priority item.

The responses of planners and managers regarding training priorities within the tasks category differed only in that planners included activities such as coordinating services for clients, planning services, supervising personnel, and providing therapeutic intervention. Further, the responses of the developers indicated less 
emphasis on providing services and in providing leader ship to community groups than the other two groups, while they placed more emphasis on assessing mental health delivery systems, coordinating programs, and consulting about resources. As with the manager group, the responses of the developers did not indicate that, as primary activities, social workers will need to be trained to provide therapeutic services or to supervise personnel.

On the SK questionnaire, the responses of planners suggested a wide variety of skills as training priorities. These items placed high emphasis on assessment skills and included group facilitation, identification, leadership, planning, and program management skills. The responses of managers placed considerably more emphasis on interviewing skills and slightly less emphasis on as sessment skills. The items suggested by these responses did not, however, include the other skills suggested above by planners as priorities, but instead included observation, relationship building, and therapeutic intervention skills in their group of training priorities. The responses of developers similarly emphasized the importance of interviewing skills more than did the planner group. The items suggested by these responses also did not involve the skills indicated above which the planner group included as priorities. Further, these responses excluded analytical, conceptualization, and coordination skills as priorities. The responses of developers did, however, include diagnostic, relationship-building, and therapeutic intervention skills instead.

The responses of the planner group on the SK questionnaire 
suggested as educational priorities a generally broader base of knowledge than was indicated by the priorities of the combined responses. These items included both micro and macro concerns, as well as direct service, management, and indirect service concerns. The responses of managers, on the other hand, suggested a relatively narrow range of training priorities in this area. They focused principally on micro and direct service concerns and excluded macro, management, and indirect service concerns from their list of priorities. The responses of the developers similarly emphasized micro and direct service concerns and deleted macro, management, and indirect service concerns. The responses of this latter group, however, placed greater emphasis on individual, group, and family psychotherapy than did those of the other two groups.

On the RFT questionnaire, planners in general placed more emphasis on therapy and supervisory aspects of social work practice than did the other two groups, while all were in agreement in emphasizing case consultation as a primary component of future social work practice than did the other two groups, while all were in agreement in emphasizing case consultation as a primary component of future social work practice. On the SK questionnaire, the planner group suggested a broader emphasis on macro, management, and indirect service aspects of social work education than the other two groups. Further, the developer group placed more emphasis on the therapy aspects of education than the other two groups. All three groups were, however, in agreement in emphasizing communication skills, psychology, social psychology, and mental health as the 
highest training priorities in social work education for practice in this field. Across questionnaires, the researchers consequently concluded that the differences between the three groups with regard to training priorities resulted principally from a belief, implied in the responses of the planner group in contrast to the other two groups, that management and indirect service roles, functions, tasks, skills, and areas of knowledge will be high priorities in terms of both practice activities and educational concerns.

Discussion. The differences between the three occupational groups in this study over the questions of the future generalizing core of social work practice and the priorities for training Master's level social workers specializing in practice for this field suggested substantial differences of opinion between groups which were, by and large, not consistent across the two questionnaires. The planner group seemed to have a broader perspective on social work practice and educational needs than the other two groups, while the manager group seemed to have a more limited perspective than the other two groups. However, there was no consistent pattern of content differences between the three groups. Thus, as a result of this comparative data analysis of occupational subgroup responses, the researchers were unable to conclude that the response differences between the three groups, like the response differences between social workers and non-social workers, resulted from essentially divergent, identifiable visions of future social work practice and educational needs. 


\section{CONCLUSIONS}

Problems Encountered in the Study

It was the belief of the researchers that the research objectives of this study had been more than satisfactorily accomplished, and that this was due to the particular research methodology which had been employed. There were, however, several major problems encountered in the course of the study. These were: a) the lack of participation of a significant part of the population; b) the absence of greater change in response distributions between the second and third rounds; and c) the unanticipated length of time which the research required.

Participation. The researchers concluded that the lack of participation was partially related to the composition of the population and partially related to methodological concerns and problems in the data collection instruments. First, the overall lowe st response rate on both questionnaires was among the manager group. Other researchers (Koetz 1974) have reported similar problems with this group. Second, there was a lower response rate among non-social workers than social workers. This occurred despite efforts to insure that members of the former group would feel that their responses were as valid as those of social workers. As a result of this differential response rate, however, the results of the study were not any more biased toward the views of social workers, since their absolute numbers were smaller than non-social workers. Nevertheless, the 
final results did not reflect as broad a representation of respondents as had been desired. Judd, as cited earlier, had warned that this differential response rate was a potential problem associated with panel formation in the modified Delphi technique.

The personal contact which the researchers had hoped would generally increase participation and reduce the attrition rate on returns did seem to have an effect on the first round. This effect was evident in the high return rate of the planner group. Over the long run, however, the participation of this group declined. More importantly, though, the participation of the other two groups, particularly the developer group, increased spontaneously and without benefit of further personal contact, other than follow-up phone calls.

The researchers believed that the general lack of participation on the first round was ultimately attributable to the nature of the first instrument. Thus, the return rate on the second round was considerably greater than the first, while in the University of Virginia and Washington studies, the attrition had steadily increased throughout the first three rounds. This fact led the researchers to conclude that the particular open-ended questionnaire format employed had demanded too much from participants.

The researchers had no real explanation as to why, on the second round, the sample loss was so much greater on the RFT questionnaire than the SK questionnaire. It was possible, however, that the participants were generally more certain about educational issues than practice issues, and therefore more willing to participate in a questionnaire focusing on the former concerns. This explanation 
would be congruent with the indication that respondents were generally more decisive about forming group judgments on the RFT questionnaire than on the SK questionnaire.

Finally, there was a very low rate of attrition on the third round. This fact suggested to the researchers that the lack of participation on the second round was more related to que stionnaire length than to the three-round nature of the study.

Convergence. The researchers believed that the absence of greater movement toward either consensus and convergence on the mode or toward dissensus and divergence could be attributable to several causes. It was thought that perhaps the responses on the second round indicated that a substantial pool of consensus already existed among participants in the study and that respondents perceived that there was too little disagreement to be worth the effort required to reconsider item ratings. One fact, however, tended to mitigate the ability of this argument to explain the lack of greater movement. This factor was that modal responses on the second round, while considerable, were really not very high. These modal responses had averaged 43 percent on the two questionnaires. The researchers consequently believed that there was sufficient divergence from the mode on each questionnaire to encourage a careful reconsideration of the rating of each item. Further, some participants did reconsider many of their ratings, though these reratings tended to occur more often at the beginning of the questionnaire and then at the end.

On the basis of the preceding argument and the evidence suggested by the internal pattern of responses on the third round, the 
researchers concluded that the lack of greater change of responses and convergence on the mode was more related to the length of the questionnaire than to the fact that a generalized consensus existed among participants previous to initiation of the survey. The researchers thus believed that if the questionnaire had been shorter, more effort on the part of respondents would have been put into a careful reconsideration of item ratings on the third round, and greater change and convergence would have occurred as a result. Time. The researchers believed that the excessive length of time which the research required was partially an inherent problem in the methodology and partially a result of too broadly defined a research problem. The unanticipated amount of time required by the data collection was largely caused by the time necessary to develop the second round questionnaires. This editing process contributed to a turn-around time between round one and round two questionnaires of nearly three months, as compared to the one month reported in the University of Virginia and Washington State studies. The researchers believed that the cause of this delay was that there was simply too much information to work with for the manpower which was available to do the editing job. They subsequently thought that if there had been fewer variables considered, the editing time, and consequently the turn-around time between rounds, could have been cut down considerably.

The researchers did not conclude on the basis of this argument that the Delphi technique necessarily requires fewer variables to be successful. They did believe, however, that for the degree of 
specificity which was desired in this study, the consideration of five variables not only required an excessive amount of time in terms of inter-round editing but also resulted in two lengthy and potentially fatiguing questionnaires. Consequently, the length of the questionnaire, already mentioned as a possible factor in the lack of greater participation on the second round and greater movement on the third round, was also considered a major factor in the long turn-around time between rounds. The researchers concluded that for the detail desired on this study, there were too many variables to facilitate the development of a shorter questionnaire which might have resulted in a higher and faster return rate, more movement between rounds two and three, and less time involved in actual data collection and questionnaire turn-around.

\section{Discussion of Research Findings}

The researchers concluded that a modified Delphi technique could be successfully employed to forecast future social work practice and educational needs and to discriminate between components of the forecast to suggest appropriate priorities for training social workers for this practice. This conclusion was, of course, tempered by the limitation that the Delphi was designed as a consensus formation procedure and not as a discriminative tool. Yet the study did demonstrate that, on these issues, the Delphi technique can discern both agreements and disagreements within a population.

The analysis of the data indicated that there was considerable consensus within the entire population regarding certain components 
of this forecast of future social work practice and educational needs. Agreement was further demonstrated in the considerable amount of consistency between categories within each questionnaire, and the considerable consistency as well between the two questionnaires, regarding the general character of practice and educational needs. Of equal importance, however, the data analysis revealed the existence of two essentially divergent views of future practice and educational needs, one held by social workers and one held by nonsocial workers. These two views seemed to have a major impact within each group on the distribution of responses for many components of this forecast. As a result, the future generalizing core of Master's level social work practice and education, as well as the priorities for training Master's level social workers specializing in this field of practice, were defined quite differently by the responses of the two groups.

In summary, the intent of this research study was to provide some empirical data in order to facilitate the development of Master's level social work training programs in the field of community mental health. It was the belief of the researchers that the data produced by this study could be utilized for such a purpose if several thoughts were kept in mind.

First, the results of the study were necessarily limited to social work practice in the state of Oregon. Second, the forecast produced by the study was necessarily a picture of what social workers will be doing as an aggregate, not what the individual social worker will be doing. Third, the data indicated that the professional direction and 
training priorities suggested by the collective responses to the third round were, to a large degree, a compromise between the views of social workers and non-social workers, and would need to be treated accordingly. With these cautions in mind, the researchers believed that the data could be utilized to facilitate the development of futureoriented, competency-based social work training programs in this field.

\section{Implications for Further Research}

There are a number of problems in social work education which, on the basis of the results of this study, the researchers believed would be fruitful areas of research. For example, this research succeeded, for all intents and purposes, in defining the competencies needed for social work practice in this field in ten years. However, research is still required regarding the optimum formats for operationalizing these competencies in an actual training program. The researchers believed that such questions as "What would be the performance criteria for the se competencies?" and "How would the se competencies be measured? "were indeed knotty problems.

There is a wealth of research which could be conducted utilizing this same research design, such as research forecasting the beliefs of social work educators rather than practitioners. Other examples are research which would focus on generic social work practice in all fields or social work practice at different degree levels. Certainly, too, the replication of this study in a state in which the community health movement is more developed might produce some interesting 
comparative data. There was simply no question to the researchers that the successful use of the modified Delphi technique in this study, despite its limitations and the problems encountered in the research, indicated that this technique holds great promise as a research technology that can be used to open many doors for social work education in the areas of curriculum planning and evaluation. 


\section{SOURCES CONSULTED}

Andrew, G. "Forecasting Social Work Practice as a Base for Curriculum Development." Journal of Education for Social Work 10 (Fall 1974): 3-8.

Arkava, M. L. "Social Work Practice and Knowledge: An Examination of Their Relationship." Journal of Education for Social Work 3 (Fall 1967): 5-13.

Arkava, M. L. and Brennen, E. C. "Toward a Competency Examination for the Baccalaureate Social Worker." Paper presented to the Council of Social Work Education Annual Program Meeting, Atlanta, Ga., March 1974.

Asch, S. E. "Effects of Group Pressure Upon the Modification and Distortion of Judgments." In Readings in Social Psychology, pp. 174-183. Edited by E. E. Maccoby, T. M. Newcomb, and E. L. Huntley. New York: Henry Holt, 1958.

Bandler, B. "Community Mental Health and the Educational Dilemmas of the Mental Health Professions." Journal of Education for Social Work 8 (Fall 1972): 5-18.

Barker, R. L. and Briggs, T. L. Differential Use of Social Work Manpower. New York: National Association of Social Workers, 1968.

Barker, R. L. and Briggs, T. L. "Perspective on Social Work Manpower in Service Delivery Approaches." In Social Work Manpower Utilization in Mental Health Programs, pp. 15-23. Edited by T. Carlsen. Syracuse, N. Y.: Syracuse University Press, 1969.

Barker, R. L. and Briggs, T. L., eds. Manpower Research on the Utilization of Baccalaureate Social Workers: Implications for Education. Washington, D. C.: U. S. Government Printing Office, 1972.

Bisno, H. Structure and Quality in Social Work Education: Report of the Task Force. New York: Council on Social Work Education, 1974.

Berkman, T. D. Practice of Social Workers in Psychiatric Hospitals and Clinics. New York: National Association of Social Workers, 1952. 
Blade, B. J. "Compul sive Mental Health Services: Setting Social Policy." Social Work 12 (January 1967): 51-58.

- "Social Work in Health and Mental Health Services." Social Casework 52 (April 1971): $211-219$.

Bloom, B. L. Community Mental Health: A Historical and Critical Analysis. Morristown, New Jersey: General Learning Press, 1973.

Bray, J. D. 1973--A Turning Point for Mental Health Programs in Oregon. Salem, Oregon: Oregon Mental Health Division, 1973.

Briggs, T. L. "Social Work Manpower: Developments and Dilemmas of the 1970s." In Educating MSW Students to Work with Other Social Welfare Personnel, pp. 4-31. Edited by M. Purvine. New York: Council on Social Work Education, 1973.

Boehm, W. W. "Education for Social Work." In Encyclopedia of Social Work, Vol 1, pp. 257-273. Edited by R. Morris. New York: National Association of Social Workers, 1971.

Caplan, G. "The Role of the Social Worker in Preventive Psychiatry." In Support Systems and Community Mental Health, pp. 111-133. New York: Behavioral Publications, 1971.

Carlsen, T., ed. Social Work Manpower Utilization in Mental Health Programs. Syracuse, N. Y.: Syracuse University Press, 1969.

Clark, E. "The Development of Psychiatric Social Work." Bulletin of the Menniger Clinic 30 (June 1966): 161-173.

Coleman, J. "Workers in the Field of Mental Health." Annals of Academy of Political and Social Science. (March 1953): 81-88.

Collins, R. Children's Psychiatric Day Treatment Center, University of Oregon Medical School, Portland, Oregon. Lecture, March 1974.

Council on Social Work Education. Summary Information on Master of Social Work Programs: 1974. New York: Council on Social Work Education, 1974.

Cyphert, F. and Gant, W. "The Delphi Technique: A Tool for Collecting Opinions in Teacher Education." The Journal of Teacher Education 21 (Fall 1970): 417-425.

Dalkey, N. C.; Rourke, D. L.; Lewis, R.; and Snyder, D. Studies in the Quality of Life. Legington, Mass.: D. C. Heath and Co., 1972 . 
Dangerfield, David. Kings View, Mental Health Center, Portersville, California. Personal Communication, April, 1975.

Dolgoff, R. Report to the Task Force on Social Work Practice and Education. New York: Council on Social Work Education, 1974.

Dunn, J. "Consolidated Grant Application for Social Work Training Project in Community Mental Health. " Portland, Oregon: Portland State University, 1974. (Xeroxed.)

Federico, R. E. The Social Welfare Institution. Lexington, Mass.: D. C. Heath and Co., 1973.

Fellin, P. A. "Long Range Planning: Implications for Social Work Education." Journal of Education for Social Work 10 (Spring 1974): $27-33$.

Glide, L. J. "Social Science Education: Traditional or Competency Based?" The Southern Quarterly 4 (January 1975): 95-107.

- "Social Work Education: Traditional or Competency Based?" Paper presented to Council on Social Work Education Annual Program Meeting, Chicago, Illinois, March, 1975.

Glide, L. J. and Clinch, R. W. "Education and Practice: Partners in Providing Quality Professional Education." Paper presented to Council on Social Work Education Annual Program Meeting, Atlanta, Ga., March 1974.

Gottesfeld, H. The Critical Is sues of Community Mental Health. New York: Behavioral Publishers, 1972.

Gottesfeld, H. ; Rhee, C. and Parker, G. "A Study of the Role of Paraprofessionals in Community Mental Health." Community Mental Health Journal 6 (August 1970): 285-291.

Greenwood, E. "The Attributes of a Profession." Social Work 2 (July 1957): 45-55.

Grosser, C. "A Polemic on Advocacy: Past, Present, and Future." In Shaping the New Social Work, pp. 77-96. Edited by A. J. Kahn. New York: Columbia University Press, 1973.

Gurin, A. "Education for Changing Practice." In Shaping the New Social Work, pp. 169-198. Edited by A. J. Kahn. New York: Columbia Univer sity Press, 1973.

Hede, E. J.; Gomez, A. G.; and Adams, G. L. A Guide to Mental Health Services. Pittsburg: University of Pittsburg Press, 1973. 
Helmer, O. and Rescher, N. "On the Epistemology of the Inexact Sciences." Management Science 6 (October 1959): 25-52.

Henry, W. E.; Sims, J. H.; and Spray, S. C. The Fifth Profession. San Francisco: Jossey-Bass, 1971.

Hilgard, E. R. and Riecken, H. W., eds. The Behavioral and Social Sciences: Outlooks and Needs. Englewood Cliffs, New Jersey: Prentice-Hall, 1970.

Joint Commission on Mental Illness and Mental Health. Action for Mental Health. New York: Basic Books, 1961.

Judd, R. C. "Use of Delphi Methods in Higher Education." Technological Forecasting and Social Change 4:2 (1972): 133-187. (Reprint.)

Kadushin, A. "Supervisor-Supervisee: A Survey." Social Work 19 (May 1974): 288-297.

Kahn, A. J. "A Policy Base for Social Work Practice: Societal Perspectives." In Shaping the New Social Work, pp. 3-25. Edited by A. J. Kahn. New York: Columbia University Press, 1973.

Kennedy, J. F. Message from the President of the United States Relative to Mental Illness and Mental Retardation. 88th Congress, 1st session, U. S. House of Representatives Document No. 58, U. S. Government Printing Office, 1963.

Koetz, E. State of Oregon Mental Health Division, Salem, Oregon. Interview, May, 1974.

Krugman, M. "Study of Current Trends in the Use and Coordination of Professional Services of Psychiatrists, Psychologists, and Social Workers in Mental Hygiene Clinics and Other Psychiatric Agencies and Institutions." American Journal of Orthopsychiatry 20 (January 1952): 1-62.

Levenson, A. and Reff, S. "Community Mental Health Center Staffing Patterns." Community Mental Health Journal 6 (April 1970): $118-125$.

Linstone, H. A. "On Discounting the Future." Technological Forecasting and Social Change 4 (April 1973): 335-338.

Linstone, H. A. and Turoff, M. , eds. The Delphi Method. Reading, Mass.: Addison-Wesley Publishing Co., 1975. (In press.)

Longress, J. Portland State University School of Social Work, Lecture, November, 1973. 
Lowenberg, F. M. Doctoral Students in Schools of Social Work. New York: Council on Social Work Education, 1972.

- Time and Quality in Graduate Social Work Education--

Report of the Special Committee to Study the Length of Graduate Social Work Education. New York: Council on Social Work Education, 1972.

Lowenberg, F. and Dolgoff, R., eds. Teaching of Practice Skills in Undergraduate Programs in Social Welfare and Other Helping Services. New York: Council on Social Work Education, 1971.

Maier, R. F. "As sets and Liabilities in Group Problem Solving: the Need for an Integrative Function." Psychological Review 74 (July 1967): 239-249.

Main, M. W. "Restructuring Social Work Education: Knowledge, Curriculum, Instruction." Journal of Education for Social Work 7 (Spring 1971): 31-38.

Mental Health Planning Board for the Mental Health Division of the Oregon State Board of Control. The Ultimate Goal, a Plan for Today. Salem, Oregon: Oregon State Board of Control, 1965.

Miller, D. A. "Consultation-Workshop re Consolidation of NIMH Grant, June 14, 1974." Portland, Oregon: Portland State University, 1974. (Xeroxed.)

Mueller, B. J. and James, B. J. "Social Work Practice and Community Mental Health." Community Mental Health Journal 8 (March 1972): 178-188.

Parad, H. J. and Rapoport, L. "Advanced Social Work Educational Programs in Community Mental Health." In Handbook of Community Mental Health, pp. 347-368. Edited by S. E. Golann and C. Eisdorfer. New York: Appleton-Century-Crofts, 1972.

Pasamanick, B.; Scarpitti, F.; and Dinitz, S. Schizophrenics in the Community. New York: Appleton-Century-Crofts, 1967.

Pattison, E. M. and Elpers, J.R. "A Developmental View of Mental Health Manpower Trends." Hospital and Community Psychiatry 23 (November 1972): 325-328.

Pincus, A. and Minahan, A. Social Work Practice: Model and Method. Itasca, Illinois: F. E. Peacock Publishers, Inc., 1973.

Pins, A. M. "Changes in Social Work Education and Implication for Practice." Social Work 16 (April 1971): 5-15. 
Portland State University School of Social Work. Summary of SelfStudy 1974. Portland, Oregon: Portland State University, 1974.

Powell, M. "A Program Leading to a Master of Science Degree in Community Mental Health." Community Mental Health Journal 5 (June 1969): 215-218.

Powell, T. J. and Riley, J. "The Basic Elements of Community Mental Health Education." Community Mental Health Journal 6 (June 1970): 196-202.

Rasp, A. "Consensus Formation on Educational Outcomes Using a Modified Delphi Technique." Olympia, Washington: Office of Superintendent of Public Instruction, 1972. (Mimeographed.)

Reichert, K. "Current Developments and Trends in Social Work Education in the United States." Journal of Education for Social Work 6 (Fall 1970): 39-50.

Rice, E. P. "Educational Qualifications for Social Workers in Public Health Programs." American Journal of Public Health 52 (February 1962): $317-324$.

Richan, W. C. "The Social Work Profession and Organized Social Welfare." In Shaping the New Social Work, pp. 147-168. Edited by A. J. Kahn. New York: Columbia University Press, 1973.

Ripple, L. Report to the Task Force on Structure and Quality in Social Work Education. New York: Council on Social Work Education, 1974.

, ed. Innovations in Teaching Social Work Practice. New York: Council on Social Work Education, 1970.

Rosenblum, G. and Hassol, L. "Training for New Mental Health Roles." Mental Hygiene 52 (January 1968): 81-86.

Rushing, W. A. The Psychiatric Professions. Chapel Hill: University of North Carolina Press, 1964.

st. George-Henry, C. "The Application of Generic Principles and Theory to the Practice of Generic Social Work in the Field." Journal of Education for Social Work 10 (Winter 1974): 27-33.

Santa Clara County. "Proposed Mental Health Career Ladder." Santa Clara, Calif.: Santa Clara County, 1974. (Xeroxed.)

Scheibe, M.; Skutsch, M.; and Schofer, J. "Experiments in Delphi Methodology." In The Delphi Method, pp. 357-391. Edited by H. A. Linstone and M. Turoff. Reading, Mass.: AddisonWesley Publishing Co., 1975. (In press.) 
Schorr, A. L. "Moving Toward the Future." Social Work 16 (April 1971): 2 .

Siporin, M. "Doctoral Education for Direct Service Practice in Social Work." Journal of Education for Social Work 9 (Fall 1973): $78-86$.

Southern Regional Education Board. Proceedings of the Planning Workshop. Atlanta, Ga.: Southern Regional Education Board, April, 1974.

- A Challenge to Social Work Education. Atlanta, Ga.: Southern Regional Education Board, July, 1974.

Specht, H. "The Deprofessionalization of Social Work." Social Work 17 (March 1972): 3-15.

Spray, S. "Mental Health Professions and the Division of Labor in a Metropolitan Community." Psychiatry 31 (February 1968): 51-60.

Teare, R. J. and McPheeters, H. L. Roles and Functions for Mental Health Workers. Atlanta, Ga.: Southern Regional Education Board, 1969.

Teare, R. J. and McPheeters, H. L. Manpower Utilization in Social Welfare. Atlanta, Ga.: Southern Regional Education Board, 1970.

Teare, R. J. and McPheeters, H. L. "The Middle Level Mental Health Worker: His Role." Hospital and Community Psychiatry 23 (November 1972): 329-335.

Toffler, A. Future Shock. New York; Random House, 1970.

Wittman, M. Consolidation of Social Work Training Grants at the Master's Level Into a Single Grant Category Entitled: Social Work Training in Community Mental Health. Washington, D. C.: National Institute of Mental Health, 1972.

Weaver, W. T. "The Delphi Forecasting Method." Phi Delta Kappan 5 (January 1971): 267-271.

Woodward, L., ed. Psychiatric Social Workers and Mental Health. New York: National Association of Social Workers, 1960.

Yolles, S. F. "The Comprehensive National Mental Health Program: An Evaluation." In Comprehensive Mental Health, the Challenge of Evaluation. Edited by L. M. Roberts; N. S. Greenfield; and M. H. Miller. Madison: The University of Wisconsin Press, 1968. 
Zander, A. ; Cohen, A. R. ; and Statland, E. Role Relations in the Mental Health Professions. Ann Arbor: Univer sity of Michigan, 1957. 
APPENDIX A

RESEARCH INSTRUMENTS 


\section{Training Social Workers for Community Mental Health: A Research Study}

by

Mark Clay and William Thomas

The School of Social Work at Portland State University is presently involved in establishing an NIMH-funded training project at the Master's degree level in community mental health ( $\mathrm{CMH}$ ). The Project's faculty members have decided that

- one criteria for its success will be the development of a close working relationship with the community mental health system in Oregon, both to keep the school informed of changes in the field and to insure that the training project is responsive to the manpower needs of that system. They believe that maintaining continuing ties between the educational institution and the practice comunity is particularly important to the success of this program. They have been concerned, however, that because of other priorities the school has not been sufficiently responsive to the mental health cormunity in planning its prograns in recent years. In an effort to improve this relationship, faculty of the Project held a workshop in June with CMH planners, administrators and staff to discuss the Project's curriculum and field program. At this workshop, a.proposal for a research study was presented which would be conducted for the project as part of a Master's thesis. This study was seen by the participants as a much needed bridge between mental health practitioners and the School of Social Work and was endorsed by them. The purpose of the study, which is outlined in the following pages, will be to determine what the practice community sees as the training priorities for Master's level social workers in preparing them for future positions in the CMH delivery system in Oregon. 
Research Design: This research study is designed to produce a composite picture of what the CMH practice community believes Master's level social workers will need to know, what skills they will need to possess and what tasks and jobs they must be prepared to perform to be effective members of the CMH system in oregon over the next ten years. A survey method known as the Delphi technique will be utilized as the basic research design. This is a technique that has been developed for achieving consensus among groups of experts about future events or trends, and it has been used widely for forecasting goals for educational institutions. As applied to this study, the technique will involve a series of three questionnaires. The initial questionnaire will be open-ended and will require responses to four questions. The first question will ask participants to briefly describe the jobs they believe social workers will be fllling in the CMH system in Oregon over the next decade. The second question will ask them to list tasks they think will be involved in these jobs. The third and fourth questions will ask them to list skills and areas of knowledge which they believe will be needed to carry out these jobs. The researchers will compile these statements into four master lists which will form the basis of the second questionnaire. In this questionnaire, participants will be asked to rate each item on a one to six scale, according to their opinion of how representative each job or task is of the activities Master's level șocial workers will be engaged in and how important each skill or area of knowledge will be to the performance of these activities. These responses will be compiled and the modal response on each item will be determined. This information, together with the participant's responses on the second questionnaire, will then be returned as the third questionnaire. Participants will be asked to reconsider their rating of each item in light of the modal response to the item. They will further be asked to briefly state, if they so desire, any reasons 
them with a composite picture of what activities the public CMH practice community envisions Master's level social workers engaging in over the next ten years. The data the study provides will be utilized by the Mental Health Division's manpower section, which is currently engaged in a comprehensive manpower study for the state. It should also be of interest to the several groups presently concerned with continuing education and interdisciplinary training for comunity mental health. The researchers further believe that the study may serve as a prototype of a useful research design for engaging in manpower analysis and determining training priorities for other professional groups in the state.

It is the desire of the researchers that the results of the study will ultimately prove significant in enabling the School of Social Work to be more responsive to the CMH practice community. This responsiveness, they hope, will in turn contribute to the School's ability to train, as prospective employees of oregon's mental health system, competent social workers who can effectively participate in the development and delivery of comprehensive, community-based mental health services. Time Frame:

Researchers.will establish contact with the Administrator, Executive Council and staff of the State Mental Health Division, the President of the county CMH Program Director's Association, the Directors of the county CMr Programs, the State Hospital Superintendents, and the Directors of the state-funded Child Treatment Centers --September - October 1974

Prepare and mail the first questionnaire to participants-October 1974

Prepare and mail the second questionnaire --November 1974

Prepare and mail the third questionnaire --December 1974

Prepare and mail a summary of findings to participants -January - February 1975

$10-14-74$ 


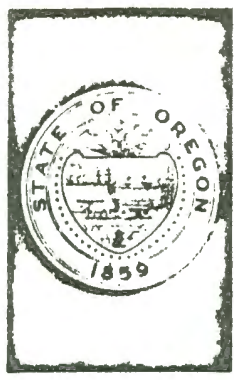

\title{
MENTAL HEALTH DIVISION
}

\author{
DEPARTMENT OF HUMAN RESOURCES
}

\section{CENTER STREET N.E.}

\section{SALEM, OREGON}

97310

TOM MCCALL GOVERNOR

J. D. BRAY, M.D. Division Adminiutrefor

- - .

DEPARTMENT OF HUMAN RESOURCES

CIEIGHTON PENWELL Director

DIVISIONS Children's Sorvices Comrections Employment reallh Montal Hoalth Vocational Rohabilitition Woitore

I am writing to urge your particlpation in an upcoming research study. Within the next week, you, and posslbly some of your staff, will recelve a questionnaire from two students in the School of Social Work at Portland State University. This questionnaire is part of a study whlch they are conducting for their Master's thesis with the purpose of determining appropriate training priorlties for Master's level soclal workers involved in the field of community mental health. Over the next several months, you will receive two additional questionnaires, each of which, they estimate, will require twenty to thirty minutes of your time.

This research study is part of a larger effort on the part of the School of Social Work to Increase its responsiveness to the manpower needs of Oregon's community mental health system. The students have been asked to present their findings and recommendations to the Dean and faculty of the School, and intend to provide a conplete summary of this information to all participants in the study.

As you may know, the Mental Health Division's Manpower Development and Ut1lization Office has recelved a grant from the National Institutes of Mental Health to conduct a comprehensive anslysis of Oregon's manpower needs in the field of community mental health. These students are closely coordinating their study with that office to prevent unnecessary duplication, and w1ll make their findings avallable for this project. 
Community MH Program Directors, et al.

Page 2

October 30, 1974

In my estimation, the study appears to be well designed and thought out, and deserving of support. It may well produce information that proves valuable to local community mental health programs, to the Division and to the School of Social Work. I hope you will take the time to participate in this study, and wlll urge your staff to do Ilkewlse if they are saked to participate.

sincerely,

ar M. romeroy, m.u.

Director, Region 2

JMP :hgP

Attachment 


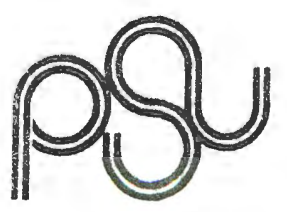

October 14, 1974

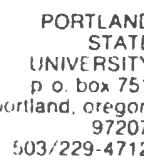

school of social work

\section{Dear}

A new training project has been established $a_{i}$ the School of Social Work this fall to increase the School's responsiveness to the manpower needs of Oregon's community mental health ( $\mathrm{CMH}$ ) system. As part of this effort, we are requesting your participation, as a working expert in this field, in a rescarch study. It is being conducted for the School with the approval of the Dean and Faculty. We described this study, which is the basis of our Master's thesis, in a presentation to the October 3rd joint staff meeting of the office of Programs for Mental Retardation and Developmental Disabilities.

The purpose of the study is to determine appropriate training priorities for Master's level social workers in this field by surveying the opinions of $\mathrm{CMH}$ practitioners regarding what they believe these professionals must be prepared to do. As we indicated in our presentation, a brad spectrum of practitioners in the public sector, including planners, program administrators and program staff, is being asked to respond to a three part survey which utilizes the Delphi technique of consensus formation. This forecasting technique involves a series of questionnaires interspersed with feedback that preserves the anonymity of individual responses. Our survey is designed to produce a composite plcture of what the practice community believes Master's level social workers. will need to know, what skills they will need to posess and what tasks and jobs they must be prepared to perform in order to be effective members of Oregon's CMH system over the next decade.

The survey process requires the use of three questionnaires:

1) The first questionnaire, which is enclosed with this letter, a sks you to list tasks, skills and areas of knowledge which you think will be involved in the jobs Master's level sociar workers may be performing in the CMH system. We would appreciate the return of this questionnaire by October 31. In order to validate the results of this questionnaire, follow-up interviews will be conducted with a small sample of the study's participants.

2) The second questionnaire, which you will receive in November, will ask you to rank order lists of, tasks, skills and areas of knowledge, which will be developed from responses to the first questionnaire, in terms of their importance to the performance of these jobs.

3) The third and final questionnaire, which you will receive in December or January, will show the modal response for each item, compiled from the ratings on the second questionnaire, as compared to your responses. You will be asked to consider revising your responses in light of thl s additional information. 
As indicated, feedback to participants is built into the survey process itself. In addition, a summary of the study's findings, maintaining the confidentiality of individual responses, will be mailed to you early next year. This summary will include the composite profile of training priorities derived from the third questionnaire. It will also include, as possible, comparisons between respanses of planners, administrators and staff; between responses of the different professions represented in the study; between responses of participants with M. or E.D.", M.R. and D.D., and A. and D.P. program concentrations; and between responses of participants involved in predominantly rural and urban Community Mental Health Programs.

The study is being co-ordinated with Mental Health Division's Manpower Development office, and the information in this summary will be made avallable to that office for its preparation of a comprehensive manpower needs analysis for Oregon. Further, recommendations based on the findings of the study will be prepared and presented to the Community Mental Health Project and the Dean and Faculty of the School of Social Work.

We appreciate your willingness to participate in this study. Thank you for assisting us in what we believe to be both a unique approach to determining professional training priorities and an important contribution to the future preparation of social workers for Oregon's community mental health system.

Very truly yours,

William B. Thomas

Mark L. Clay

* Mental or Emotional Disturbances

Mental Retardation and Developmental Disabilities

Alcohol and Drug Problems 
SOCLA L WORKE RS IN COMMUNITY MENTAL, HIEALTH

Questionnaire \# 1

Professional Affiliation and Degrec, if applicable

(e.g. Education, Nursing, Psychiatry, Psychology, Social Work etc.)

Purpose

The purpose of this questionnaire is to obtajn your opinions and predictions about the future activities of social workers in the field of community mental health. It is composed of four open-ended questions which ask you to speculate on the following subjects:

1) the future jobs which you see Master's level social workers performing in community mental health;

2) the tasks involved in these jobs;

3 ) the areas of knowledge involved in these jobs;

4) the skills needed to carry out these jobs.

Definition of Terms

For the purposes of this study, the above terms are defined as follows:

Job: A role or position occupied by the personnel within an organization

Task: A discrete, purposeful piece of work which is performed as part of a job A rea of Knowledge: A theory, principle, concept or method, or factual information

Skill: The ability to apply one's knowledge effectively in the performance of tasks

Inst ructions

In response to each question, please list as many items as you are able to. Attempt to make your responses as specific as possible, since specific statements will produce more useful data than broad general ones. If additional space is needed to complete your answer to any question, please use the space provided on page four.

BEFORE YOU RESPOND TO THE QUESTIONS ON THE FOLLOWING PAGES, we would like you to think for a moment about the future of the community mental health system in Oregon in the decade 1975-1985. Imagine the structure and organization of the system, the needs and probtems it will be addressing, and the programs and services it will encompass. Then think about the various jobs which you believe Master's level social workers may be performing in the different functional areas within the system, i. e. providing direct services; facilitating and administering services; planning, developing and evaluating services.

With this frame of reference in mind, please respond to the questions which follow from your perspective as a planncr, an administrator or a staff member involved in community mental health. 
1) What jobs do you think Master's level social workcrs will lx. performing in Oregon's (:NH system during the decade 1975-1985?

For euch item, please give a brief, hehavioral description of the joh, indicating both role and organization. lior example: liamlly therapist in a chlldren's treatment center Administrator of an alcoholic recovery program Program evaluator in a CMH center

2) What tasks do you believe will be involved in these jobs?

For each item, please state both the action and its purpose as specifically as possible. For example: Conducting a home visit as part of a pre-committment screening

Providing consultation about program design to a drug center

Planning a sheltered workshop for retarded adults. 
3) What areas of knowledge do you helieve a person will necel to be familiar with to carry out these jobs?

Examples of possible theorics, principle's, concepts, methods or factual information might be: Social learning theory; principtes of administration; concept of continuity of care; community organization methods; or incidence of mental reta rdation in Oregon .

4) What skills do you believe will be needed to carry out these jobs?

Please attempt to identify both categories of skills and the component skills within each category. For example: Interviewing skills - the ability to paphrase, the ability to gather information...

Grantwriting skills - the ability to write clearly and consisely, the ability to project a budget...

Planning skills - the ability to analyze a policy, the abllity to formulate objectives... 
Additional Space

Comments about the questiomaire:

PLEASE RETURN THE COMPLETED QUESTIONNAIRE BY OCTOBER 31, 1974

To: William B. Thomas

P.S.U. Harter House

P.O. 751

Portland, Oregon 97207 


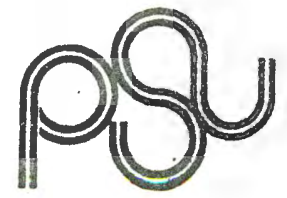

21 Jonuary 1975

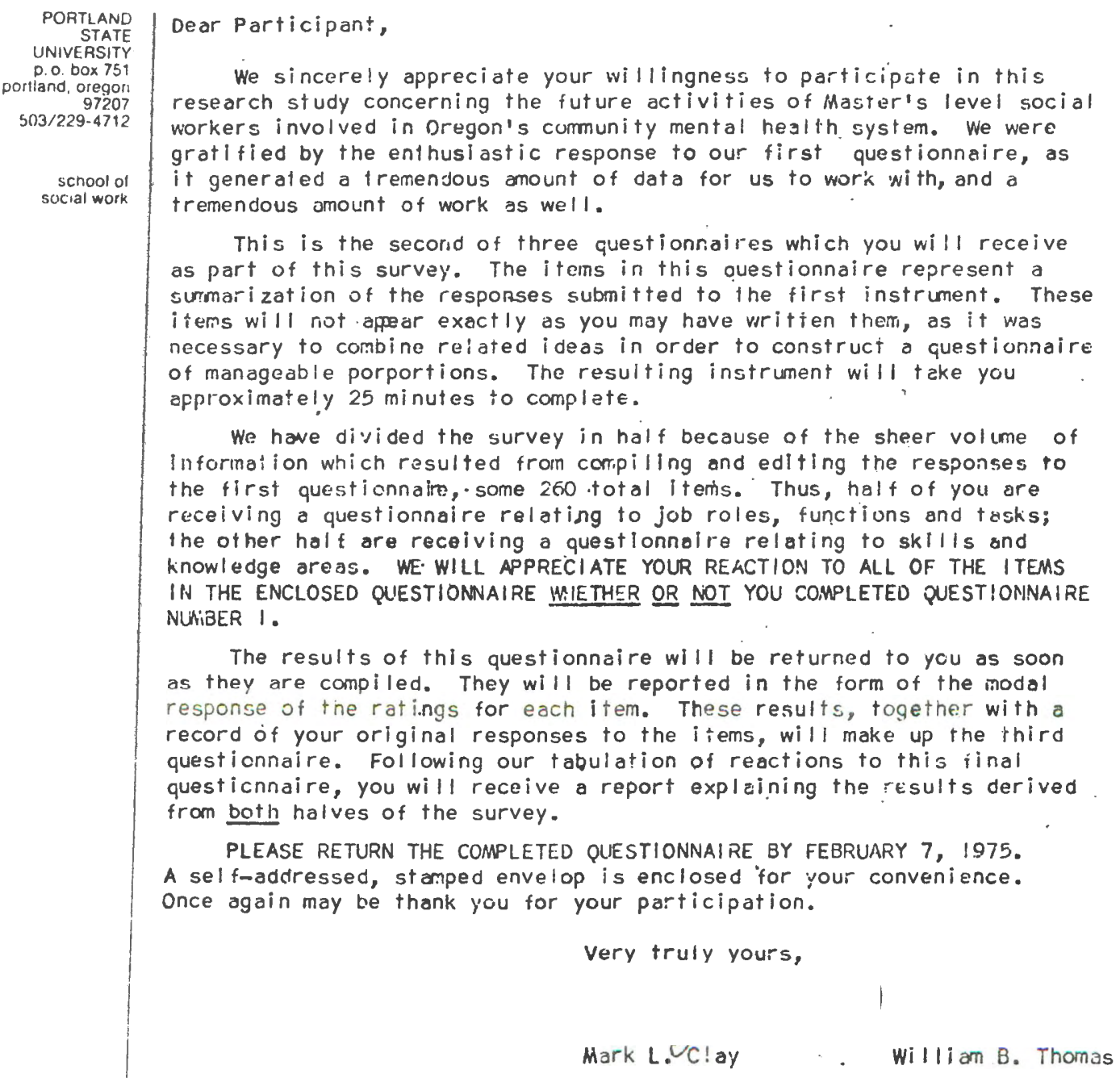


The following glossary is provided for your information should you find you have questions about the meanings of certain terms used throughout the questionnaire.

clients: individuals, couples, familles or groups

Colleges: community colleges, four-year colleges, universities

Mental Health Services: comprehensive services for mentally and emofionally disturbed, mentally retarded and developmentally disabled, and alcohol and drug abusers, or services for any of these populations alone

Mental Health Settings include all of the following: Resldential, Day outpotlent, Community, and Planning.

1) Residential/inmatient settings le.g. treatment center, hospital, training center, group hame, hal f-way house, detoxificotion center, rehablilitation center)

2) Day/partial hospltallzation settings (e.g. day treatment, dropin center, special classroom, sheltered workshop, activity center, methadone maintenancel

3) Outpatient setting (e.g. counselling service, evaluation center, crisis center, clinicl

4) Communlty settings (e.g. hotlines, school consultation, parent training, cormunity education)

5) Planning settings (e.g. Mental Health Division)

Personnel: professionals, paraprofessionals, volunteers or trainees

Public: Municipal, County, regional or state

Target Populations: adolescents; alcohol and drug abusers; children; elderly; low-income groups; mentally or emotionally disturbed; mentally retarded and developmentally disabled; minorities 
SOCIAL WORKERS IN COMMUNITY MENTAL HEALTH

Questionnalre \#2-Roles, Functions, and Tosks

General instructions

Purpose

The purpose of this survey is to obtain your opinions and predictions about the future activities of Master's level sociol workers who will be involved in the field of cormunity mental health in oregon. Thus, we pose our questions in terms of 10 years from the present. Further, we are interested in the activities of these social workers as a group, that is with Master's level social workers involved in all aspects of the community mental health system and with differing amounts of experience.

\section{The Questionnaire}

This questionnaire is divided into three parts. In the first part, Roles, you will be asked to indicate how frequently you belleve Master's level social workers as a group will be performing certain roles within their jobs. By roles we mean major patterns of behavioral expectations contained in jobs throughout the community mental hesith system. In the second part of the questionnaire, Functions, you will be asked to indicate how frequently you belleve Master's level soclal workers as a group will be performing certain functions through their jobs. By functions we mean the major classifications of activities, related to system performance, into which jobs can be grouped. In the third part, Tasks, you will be asked to indicate how frequently you believe Master's level soclal workers as a group will be performing certain tasks as part of their jobs. By tasks we mean the discrete, gool-directed activitles which make up jobs.

We recognize that professlonals from disciplines other than soclat work, and social workers of different degree levels (BA/BS, DSW, PhD), may also be performing these roles, functlons and tasks. However, as this questionnaire is only measuring your projections concerning the activities of Master's level soclal workers, you may disregard the frequency with which you believe other professionals may be performing the role, function or task as you formulate your response to each item.

Rating the Items

You will rate all of the items in this questionnaire with the following five-point scale:

$$
\begin{aligned}
& 5 \text { - Very Frequently } \\
& 4 \text { - Frequently (often) } \\
& 3 \text { - Occasionally } \\
& 2 \text { - Infrequently (seldom) } \\
& 1 \text { - Very Infrequently }
\end{aligned}
$$

For each item, simply circle the number which most closely approximates your projection. 
SOCIAL WORKERS IN COMMUNITY MENTAL HEALTH

Questionnaire *2-Roles, Functions and Tasks

Title of your Current Job

Age

Sex

Your Highest Academic or

Professional Degree and Field

Year Degree

obtalned

PART 1: ROLES

INSTRUCTIONS

This part of the questionnaire is made up of 25 items which have to do with Job roles in the fleld of community mental health. These roles cojld be performed in both public and private mental health settings concerned with elther comprehensive mental health services or services to a particular target population. Further, we realize that in many cases a single job might require the performance of several roles. Following each 1 tem we have listed examples of jobs which would involve the performance tof the role.

The following scale is to be used in rating all 25 items.

$\begin{array}{ccccc}1 & 2 & 3 & 4 & 5 \\ \text { Very Infrequentiv } & \begin{array}{c}\text { Infrequently } \\ \text { (seldom) }\end{array} & \text { occasionally } & \text { Frequently Very frequently } \\ \text { (often) }\end{array}$

Please indicate your rating for each item by circling the number which most closely approximates your response to the question below.

TEN (10) YEARS FROM NOW, HOW EREOUENTLY WILL MASTER'S LEVEL SOCIAL WORKERS WHO ARE INVOLVED IN OREGON'S COMMUNITY MENTAL HEALTH SYSTEM BE PERFORMING THE FOLLOWING ROLES?

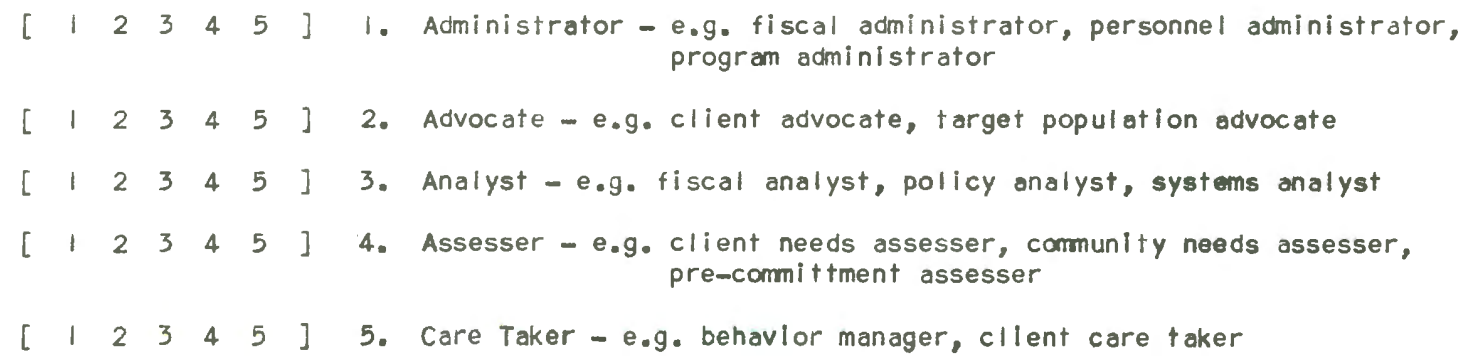




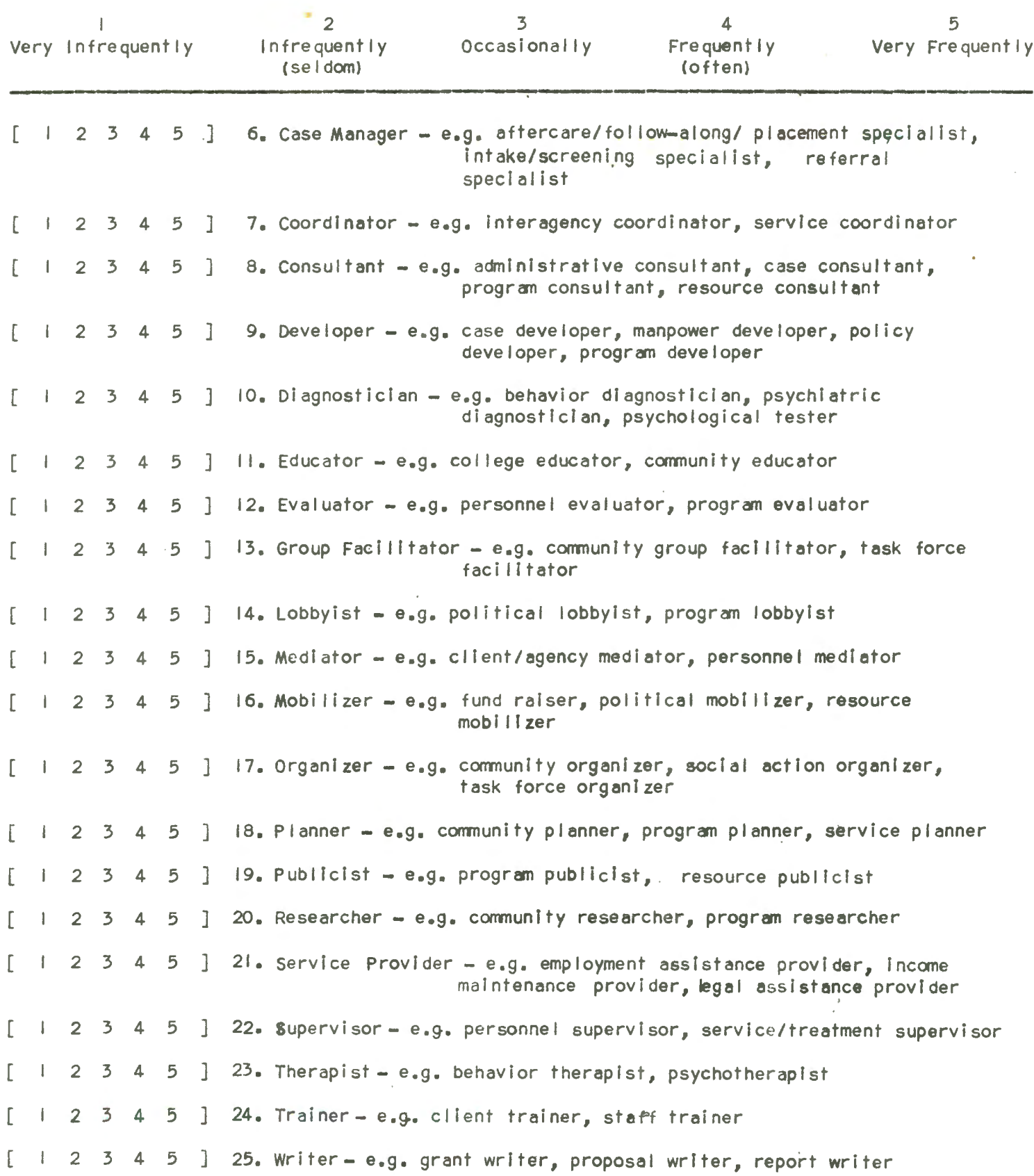


PART 11: FUNCTIONS

INSTRUCTIONS

This part of the questionnaire is made up of 12 items which have to do with the functions of jobs in the cormunity mental health system. The three functions identified in this questionnaire are Manager, Service Enabler, and Service Deliverer. We are interested in the performance of these job functions through public and private mental health settings both in relationship to the provision of comprehensive mental health services, and in relationship to the current organizotion of services in the community mental health system by target population. These target populations are alcohol and drug problems (A\&DP), mentally or emotionally disturbed (MED), and mentally retarded and developmentally disabled (MRDD).

The following scale is to be used in rating all 12 items.

$\begin{array}{ccccc}1 & 2 & 3 & 4 & 5 \\ \text { Very Infrequentiy } & \begin{array}{c}\text { Infrequently } \\ \text { (seldom) }\end{array} & \text { occasionally } & \begin{array}{c}\text { Frequently } \\ \text { (often) }\end{array} & \text { Very Frequently }\end{array}$

Please indicate your rating for each item by circling the number whlch most closely approximates your response to the question below.

TEN (10) YEARS FROM NOW, HOW FREOUENTLY WILL MASTER'S LEVEL SOCIAL WORKERS WHO ARE INVOLVED IN OREGON'S COMUUNITY MENTAL HEALTH SYSTEM BE PERFORMING THE FOLLOWING FUNCTIIONS?

MANAGER: includes such roles as Administrator; interagency Coordinator; Evaluator; and Supervisor

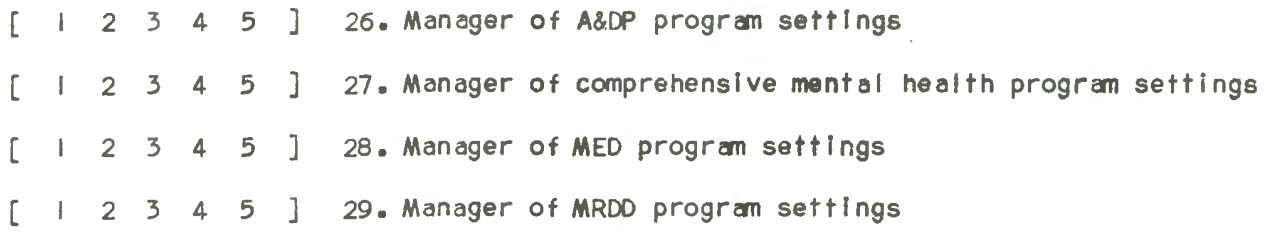

SERVICE ENABLER: includes such roles as community needs Assesser; administrative and program Consultant; Developer; college Educator; Lobbyist; Organizer; Publicist; Planner; Researcher; and stoff Trainer.

$\left[\begin{array}{llllll}1 & 2 & 3 & 4 & 5\end{array}\right]$ 30. Service Enabler for A\&DP program settlings

[ $\left.1 \begin{array}{lllll}1 & 2 & 3 & 4 & 5\end{array}\right]$ 31. Service Enabler for comprehensive mental health program settings

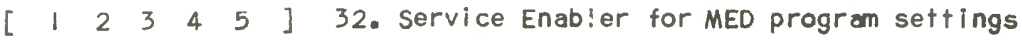

$\left[\begin{array}{lllllll}1 & 2 & 3 & 4 & 5\end{array}\right]$ 33. Service Enabler for MRDD program settings 


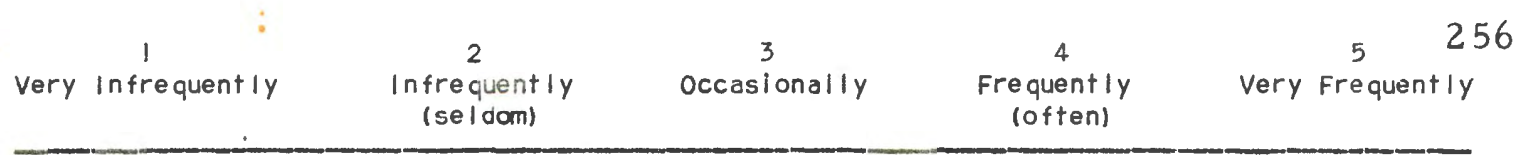

SERVICE DELIVERER: includes such roles as Advocate; precommittment Assesser; Care Taker; Case Manager; case Consultant; services Coordinator; Dlagnostician; community Educator; Mediator; Service Provider; Theraplst; client Trainer

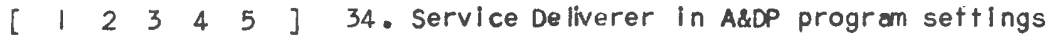

[ $\left.\begin{array}{llllll}1 & 2 & 3 & 4 & 5 & 35\end{array}\right]$. Service Deliverer in comprehensive mental health program settings

[ $1 \begin{array}{lllllll} & 2 & 3 & 4 & 5 & 36\end{array}$. Service Deliverer in MED program settings

$\left[\begin{array}{lllllll}1 & 2 & 3 & 4 & 5 & 3\end{array}\right.$ 37. Service Deliverer in MRDD program settings

PART 11I: TASKS

INSTRUCTIONS

This part of the questionnaire includes 92 items which have to do with the tasks that make up jobs within the community mental health system. These tasks could be performed for jobs in both public and private mental health settings concerned with either comprehensive mental health services or services to a particular target population. The items are divided into 12 categories which reflect a common purpose for all of the tasks in the group. These categorles are Analytical Tasks, Assessment Tasks, Consultation Tasks, Data Collection Tasks, Education and Training Tasks, Evaluation Tasks, Identification Tasks, Organization and Development Tasks, PIanning Tasks, Program Menagement Tasks, Service Delivery Tasks, and systems Maintenance Tasks.

The following scale is to be used in rating all 92 items.

$\begin{array}{ccccc}1 & 2 & 3 & 4 & 5 \\ \text { Very Infrequently } & \text { Infrequently } & \text { occasionally } & \text { Frequently } & \text { Very Frequently } \\ \text { (seldom) } & & & \end{array}$

Please indicate your rating for each item by circling the number which most closely approximates your response to the question below.

TEN (10) YEARS FROM NOW, HOW FREOUENTLY WILL MASTER'S LEVEL SOCIAL WORKERS WHO ARE INVOLVED IN OREGON'S COMMUNITY MENTAL HEALTH SYSTEM BE PERFORMING THE FOLLOWING TASKS? 


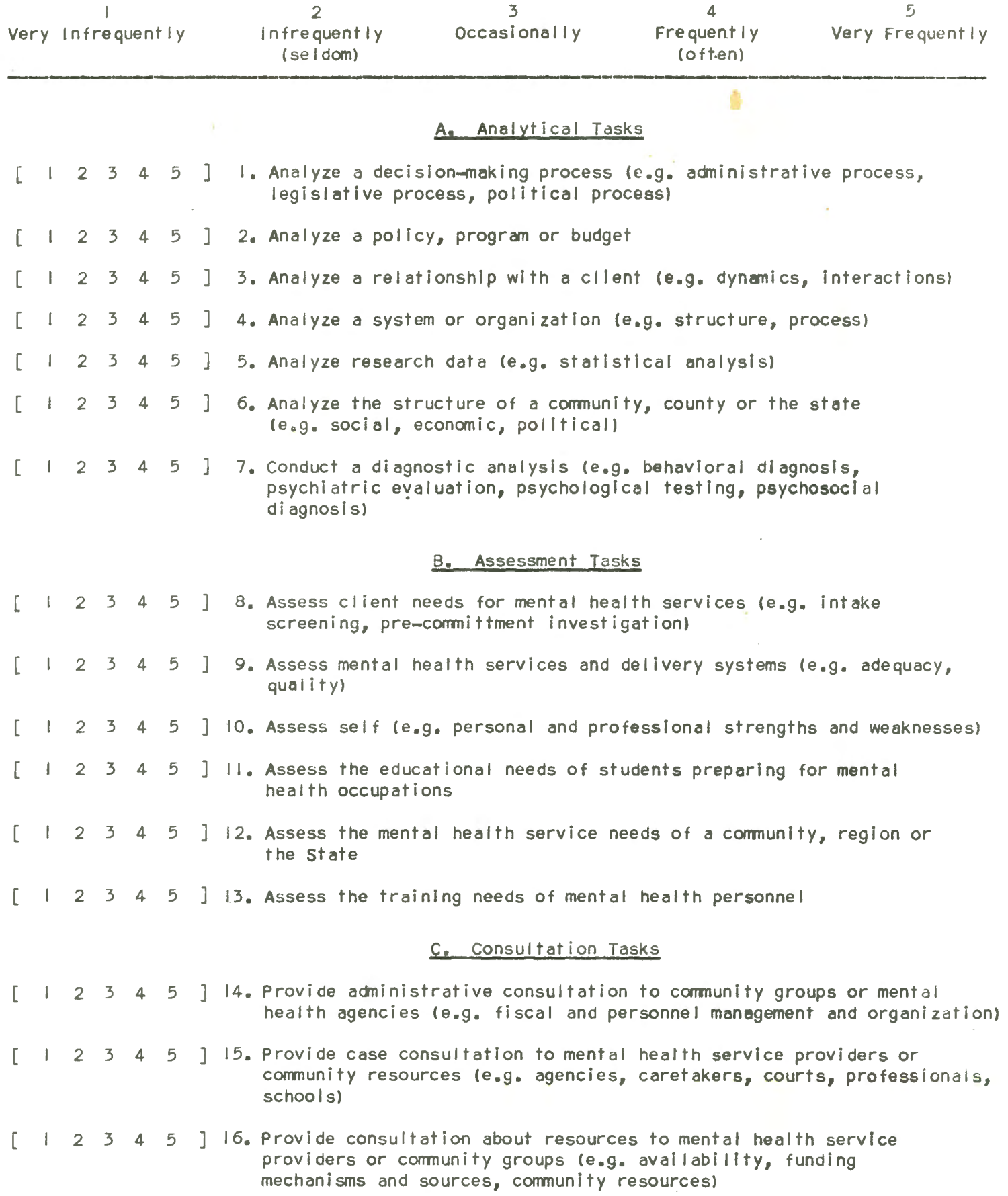

\section{Consultation Tasks}

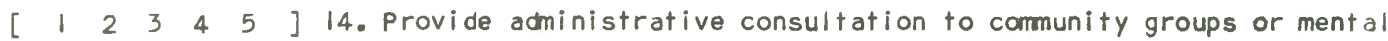
health agencies (e.g. fiscal and personnel management and organization)

[ $\left.1 \begin{array}{lllll} & 2 & 3 & 4 & 5\end{array}\right]$ 15. Provide case consultation to mental health service providers or community resources (e.g. agencies, caretakers, courts, professionals, schools)

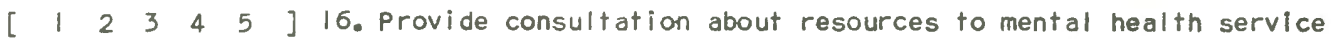
providers or community groups (e.g. availability, funding mechanisms and sources, community resources) 


$\begin{array}{cccc}1 & 2 & 3 & 4 \\ \text { Very Infrequently } & \text { Occasionally } & \begin{array}{c}4 \\ \text { (seldom) }\end{array} & \begin{array}{c}5 \\ \text { (oftent }\end{array}\end{array}$

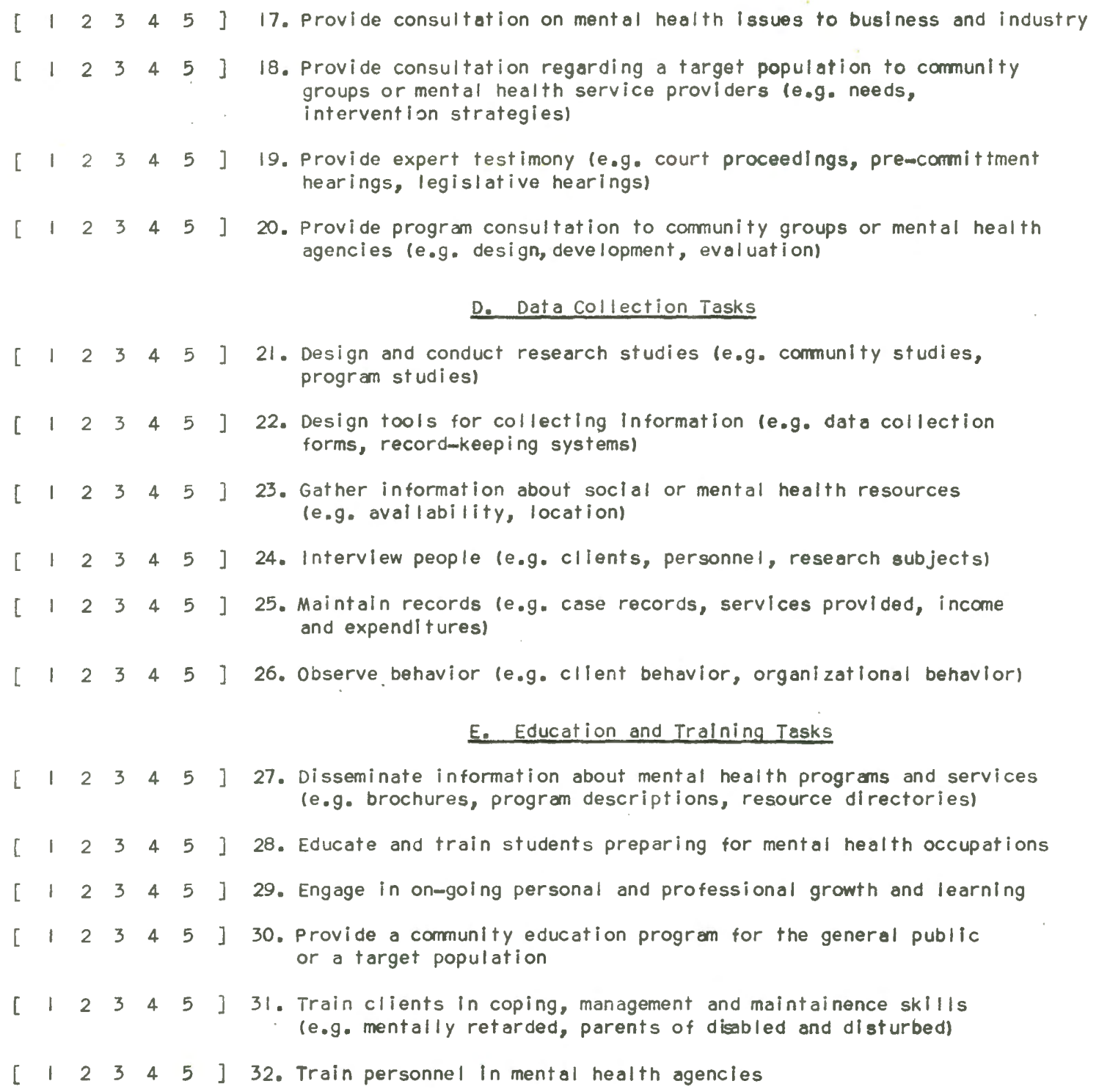




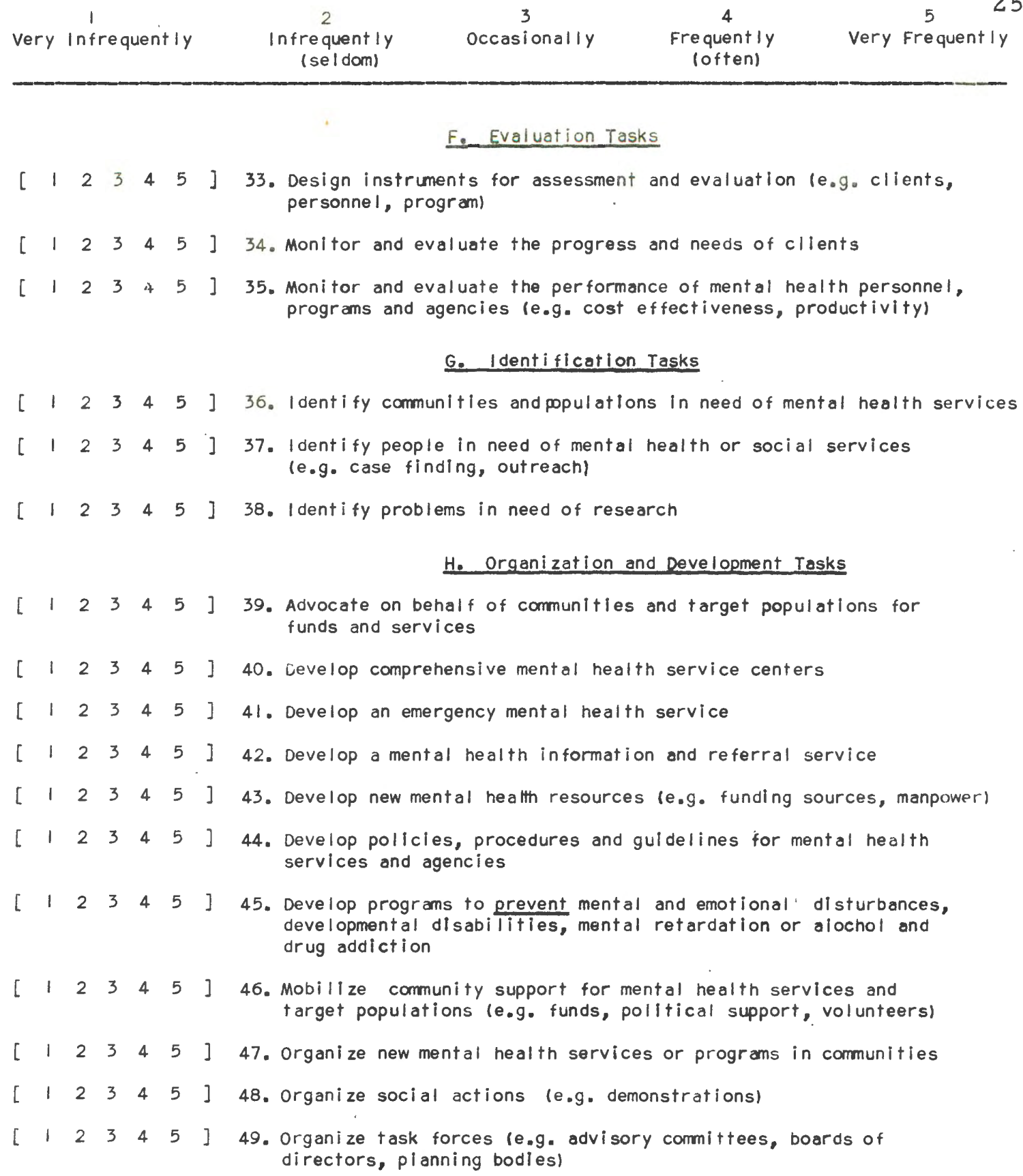




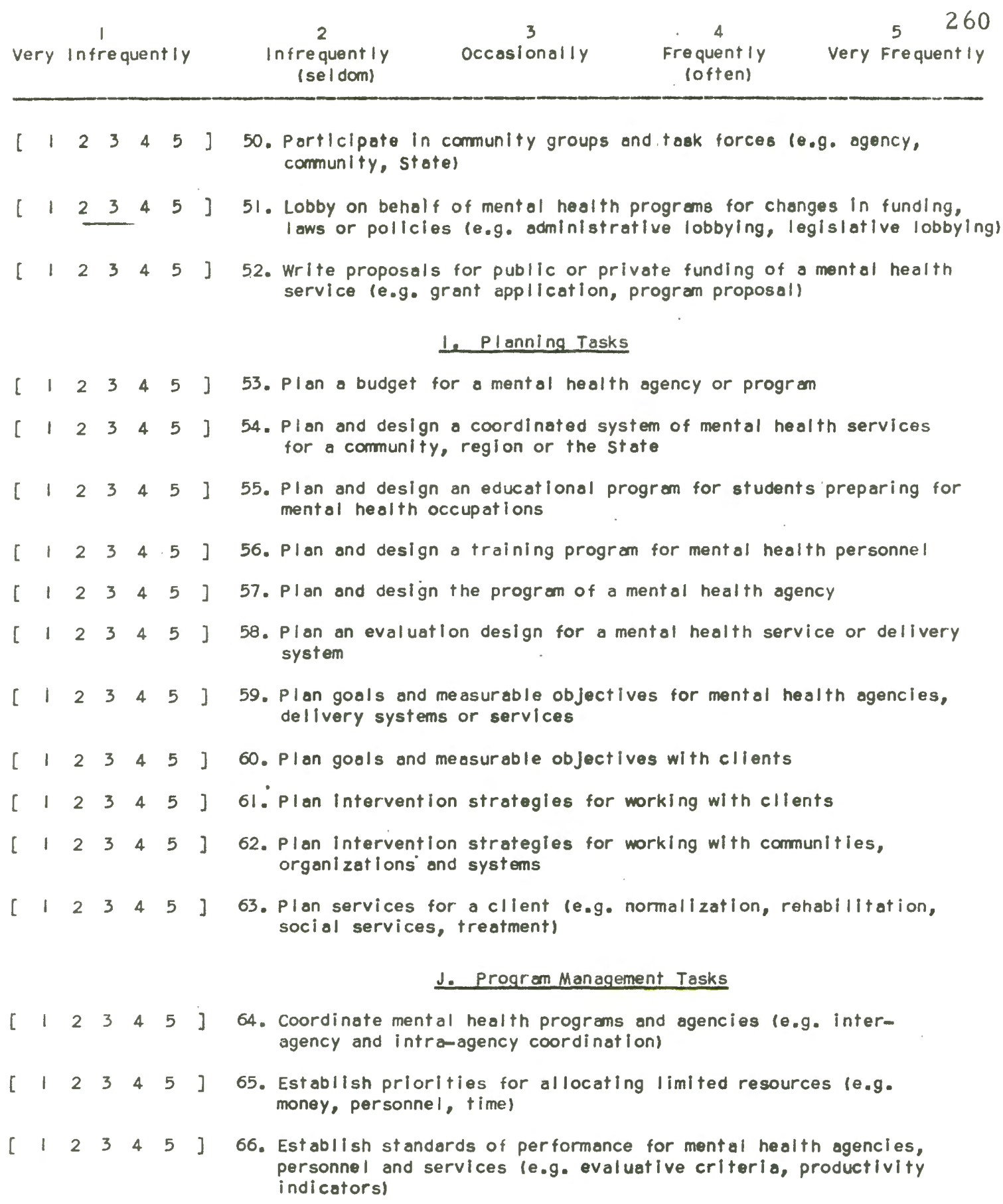




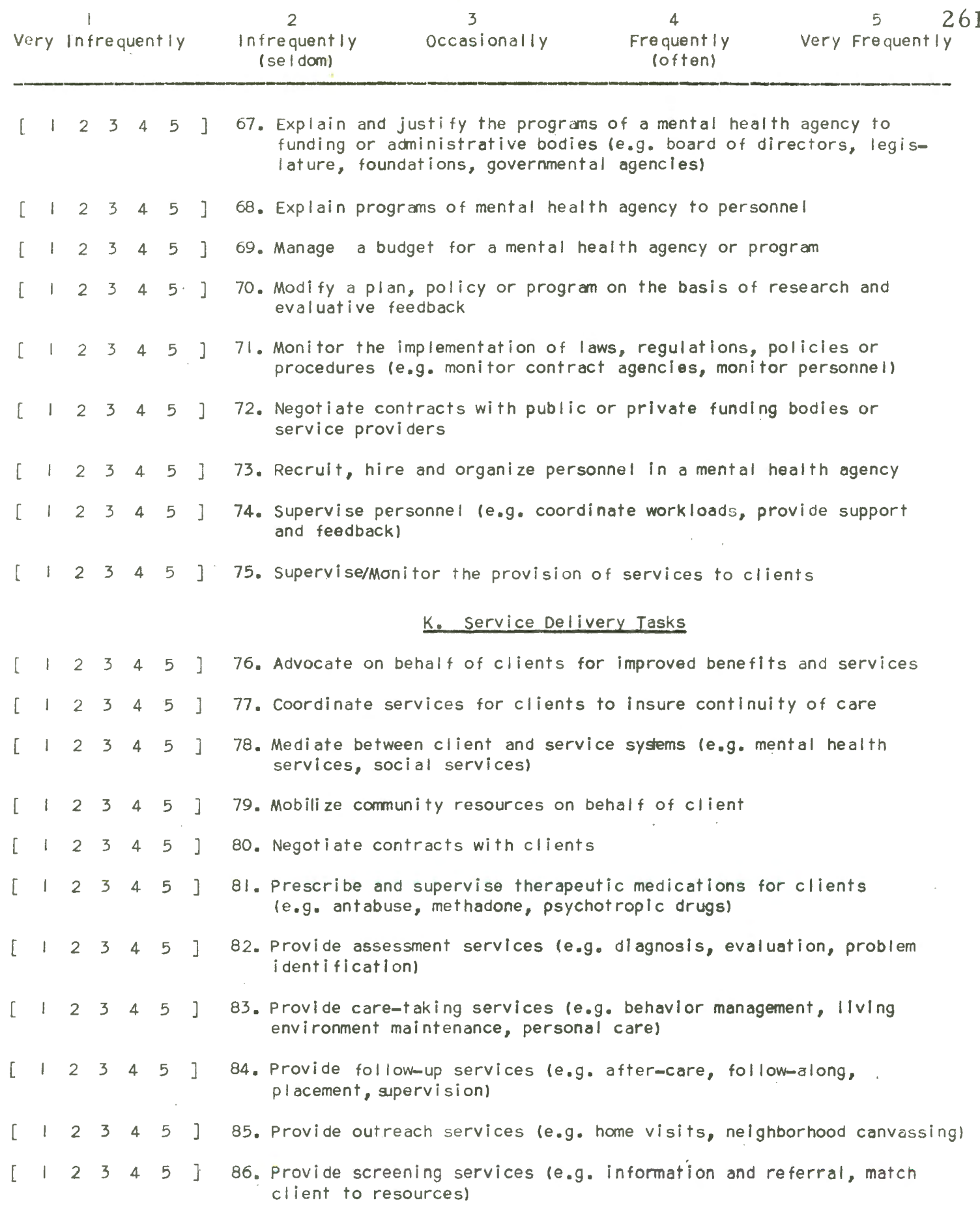




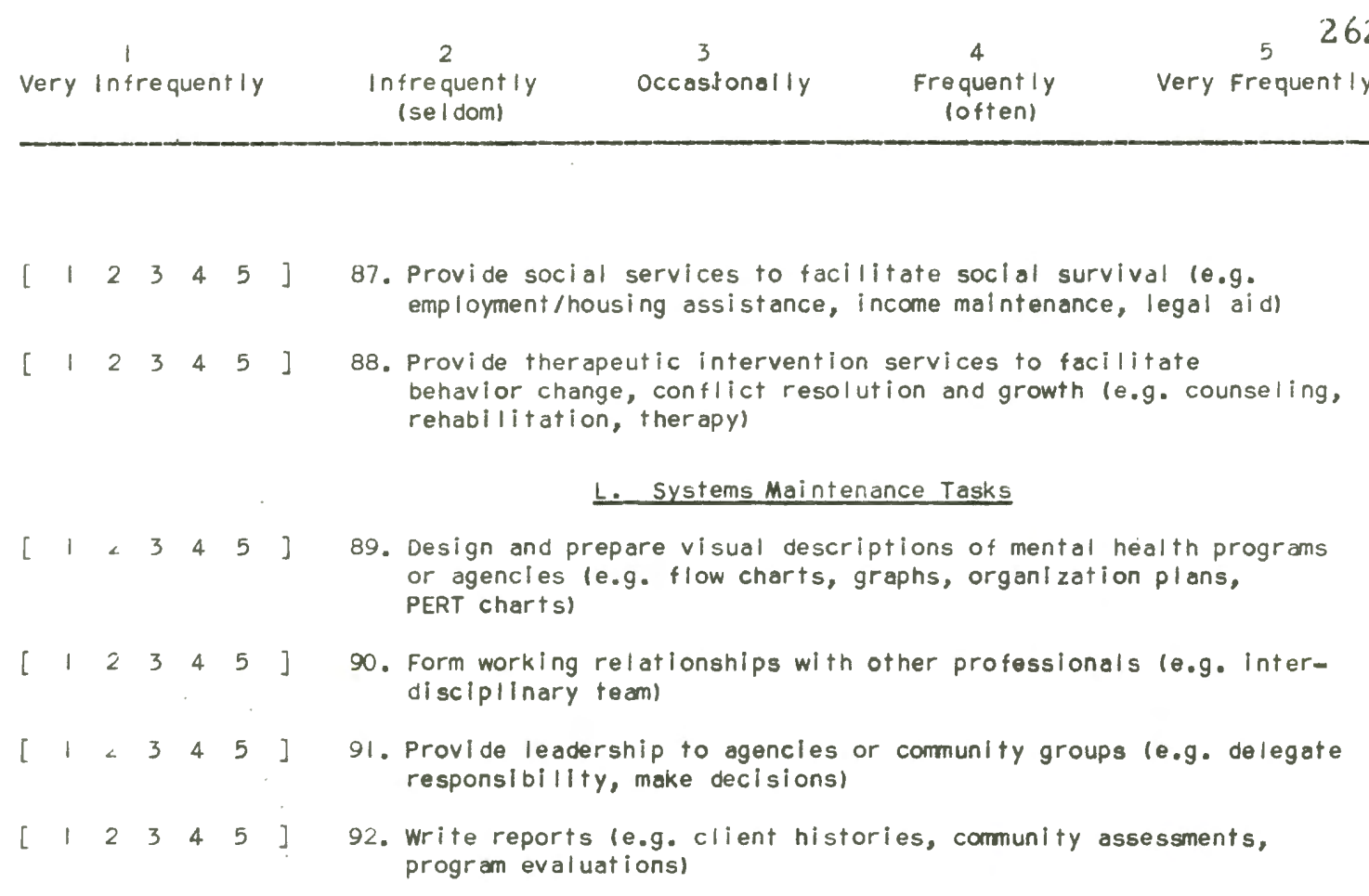


SOCIAL WORKERS IN COMMUNITY MENTAL HEALTH

Questionnalre *2-Skills and Knowledge Areas

General Instructions

\section{Purpose}

The purpose of this survey is to obtain your opinions and predictions about the future activities of Master's level soclal workers who will be involved in the field of community mental health in oregon. Thus, we pose our questions in terms of 10 years from the present. Further, we are interested in the activities of these social workers as a group, that is with Master's level social workers involved in all aspects of the community mental health system and with differing amounts of experience.

\section{The Questionnaire}

This questionnaire is divided into two parts. In the first part, skills, you will be asked to indlcate how frequently you belleve Master's level social workers as a group will be utilizing certain skills as they perform their jobs within the community mental health system. By skill we mean the ability to effectively apply some process in the performance of a task, i.e. the discrete, goal-directed activities which make up Jobs. In the second part of the questionnaire, knowledge Areas, you will be asked to indicate how frequently you believe Master's level social workers as a group will be utilizing certain knowledge areas as they perform their jobs within the community mental health system. By knowledge aroas we refer to disciplines, constructs, theories, concepts, methods, principles, strategles and empiricatly derived information.

We recognize that professionals from disciplines other than social work, and soclal workers of different degree levels (BA/BS, DSW, PhD) may also be utilizing these skllls and knowledge areas in performing their jobs. However, as this questionnaire is only measuring your projections concerning the activities of Master's level social workers, you may disregard the frequency with which you believe other professlonals may be utillzing the skill knowledge area as you formulate your response to each 1 tem.

\section{Rating the 1 tems}

You will rate all of the items in this questionnaire with the following five-point scale:

$$
\begin{aligned}
& 5 \text { - Very Frequent ly } \\
& 4 \text { - Frequently (often) } \\
& 3 \text { - Occasionally } \\
& 2 \text { - Infrequently (seldom) } \\
& 1 \text { - Very Infrequently }
\end{aligned}
$$

For each item, simply circle the number which most closely approximates your projection.

PLEASE RETURN THE QUESTIONNAIRE IN THE ENCLOSED ENVELOPE BY FEBRUARY 7, 1975. 
SOCIAL WORKERS IN COMMUNITY MENTAL HEALTH

Questionnaire *2-skills and Knowledge Areas

Title of your Current Job

Age Sex Sex

Year Degree

obtained

\section{INSTRUCTIONS}

This part of the questionnaire is made up of 45 items which have to do with skills that are involved in the field of community mental health. These skills could be utilized in performing jobs within both public and private mental health settings concerned with either comprehensive mental health services or services to a particular target population. Further, each item might be utilized in performing tasks, as part of those jobs, which have a number of different purposes. Following each item, therefore, we have listed examples of related tasks to suggest possible areas of application for each skill.

The following scale is to be used in rating all 45 items.

$\begin{array}{ccccc}1 & 2 & 3 & 4 & 5 \\ \text { Very Infrequentiy } & \begin{array}{c}\text { Infrequently } \\ \text { (seldom) }\end{array} & \text { occasionally } & \begin{array}{c}\text { Frequently } \\ \text { (often) }\end{array} & \text { Very Frequently }\end{array}$

Please indicate your rating for each item by circling the number which most closely approximates your response to the question below.

TEN (10) YEARS FROM NOW, HOW EREOUENTLY WILL MASTER'S LEVEL SOCIAL WORKERS WHO ARE I MVLLVED IN OREGON'S COMMUNITY MENTAL HENLTH SYSTEM BE UTILIZING THE FOLLOWING SKILLS?

[ $\left.1 \begin{array}{llllll} & 2 & 3 & 4 & 5\end{array}\right]$ 1. Advocacy skills-e.g. applied to clients, consumers, target populations

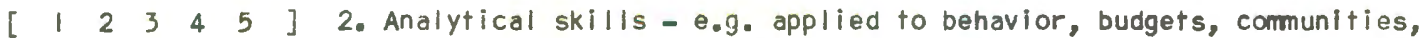
policies, political processes, relationships, research data, systems

[ $\left.\begin{array}{llllll}1 & 2 & 3 & 4 & 5\end{array}\right]$ 3. Arbitration skills - e.g. applied to personnel

[ $\left.\begin{array}{llllll}1 & 2 & 3 & 4 & 5\end{array}\right]$ 4. Assessment skills - e.g. applied to cllent or cormunity service needs, problems, service adequacy, training needs

[ $\left.\begin{array}{llllll}1 & 2 & 3 & 4 & 5\end{array}\right]$ 5. Care-taking skills - e.g. app/iod to behavior monagement, client personal care, living environment maintenance 


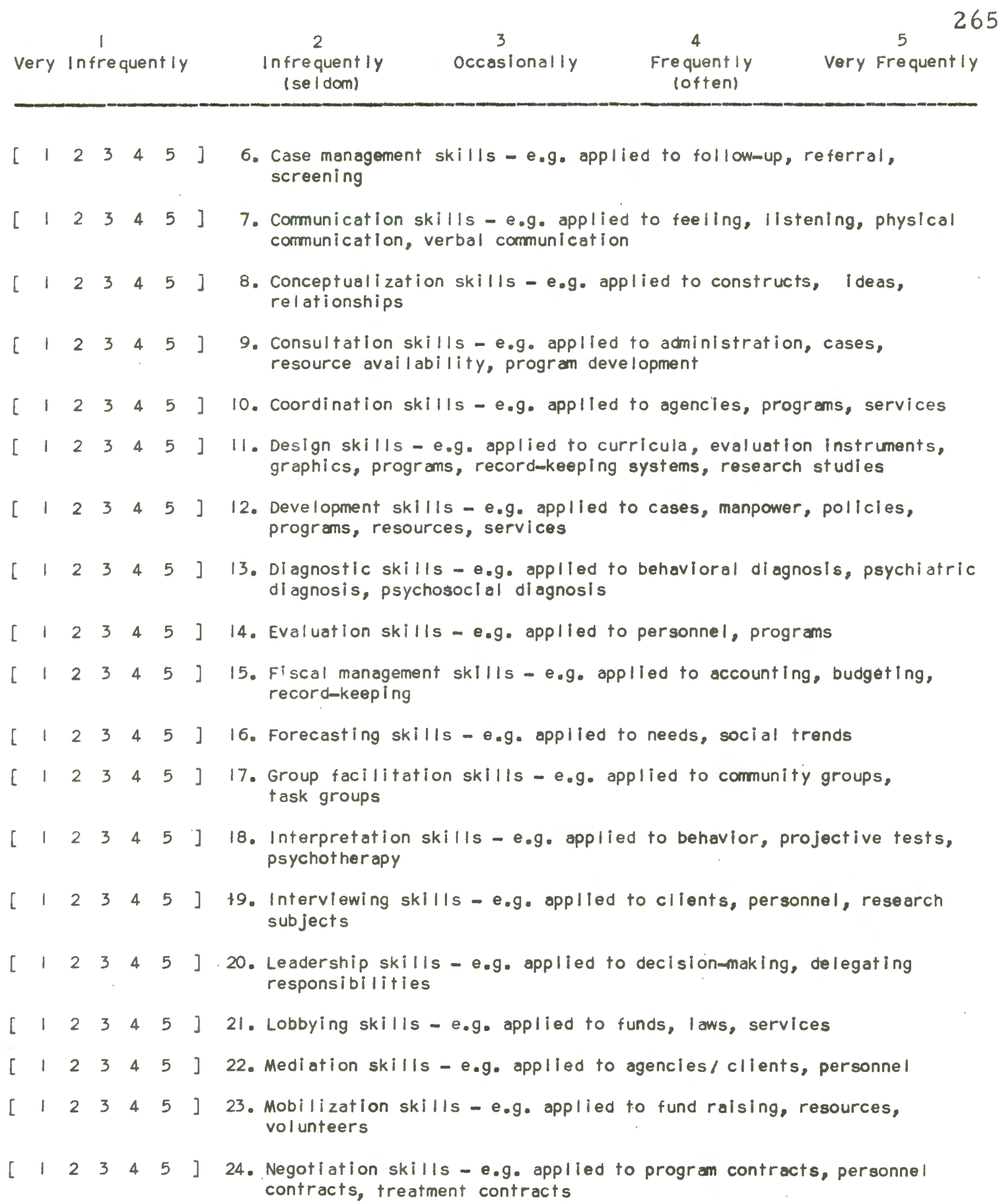




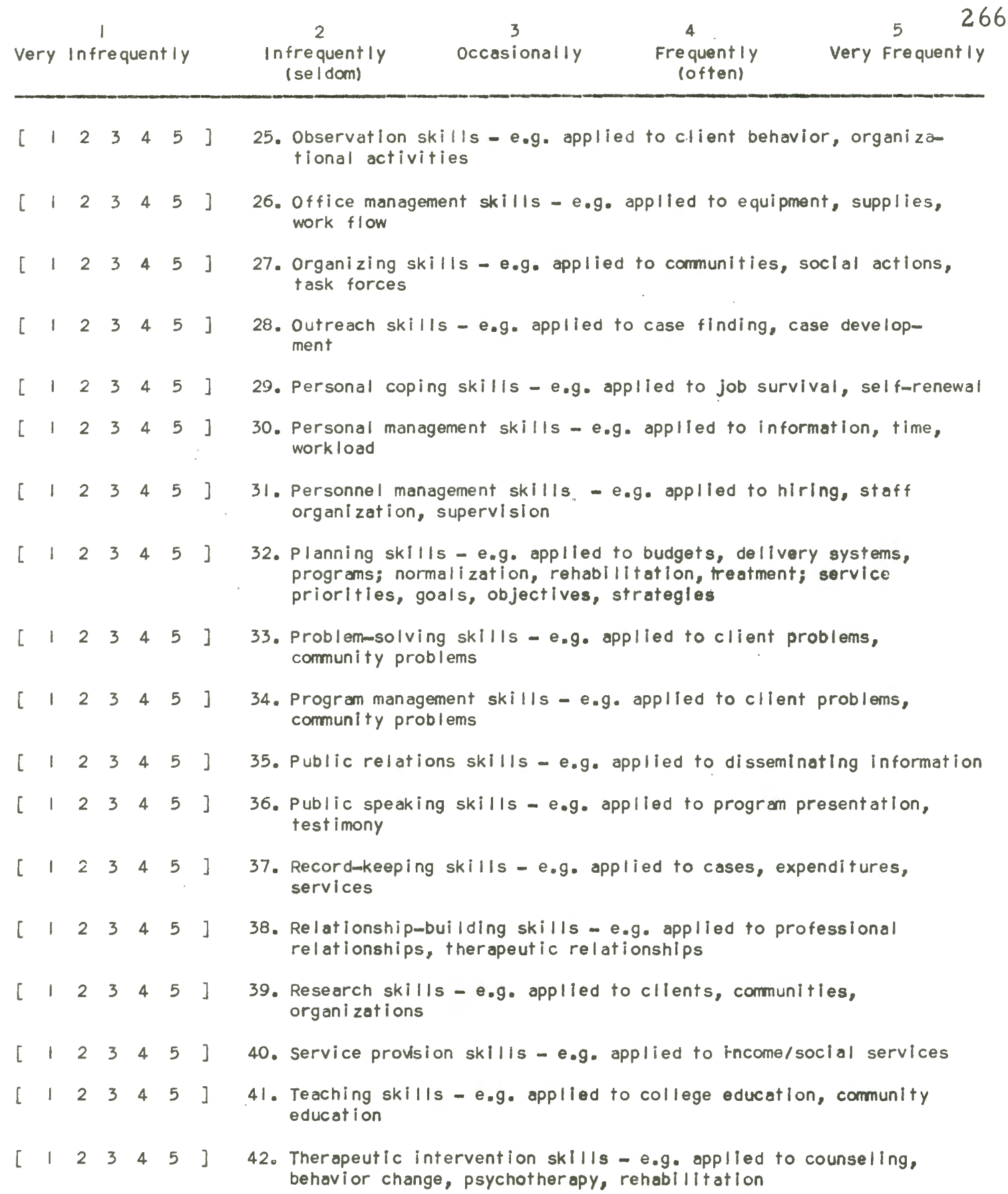




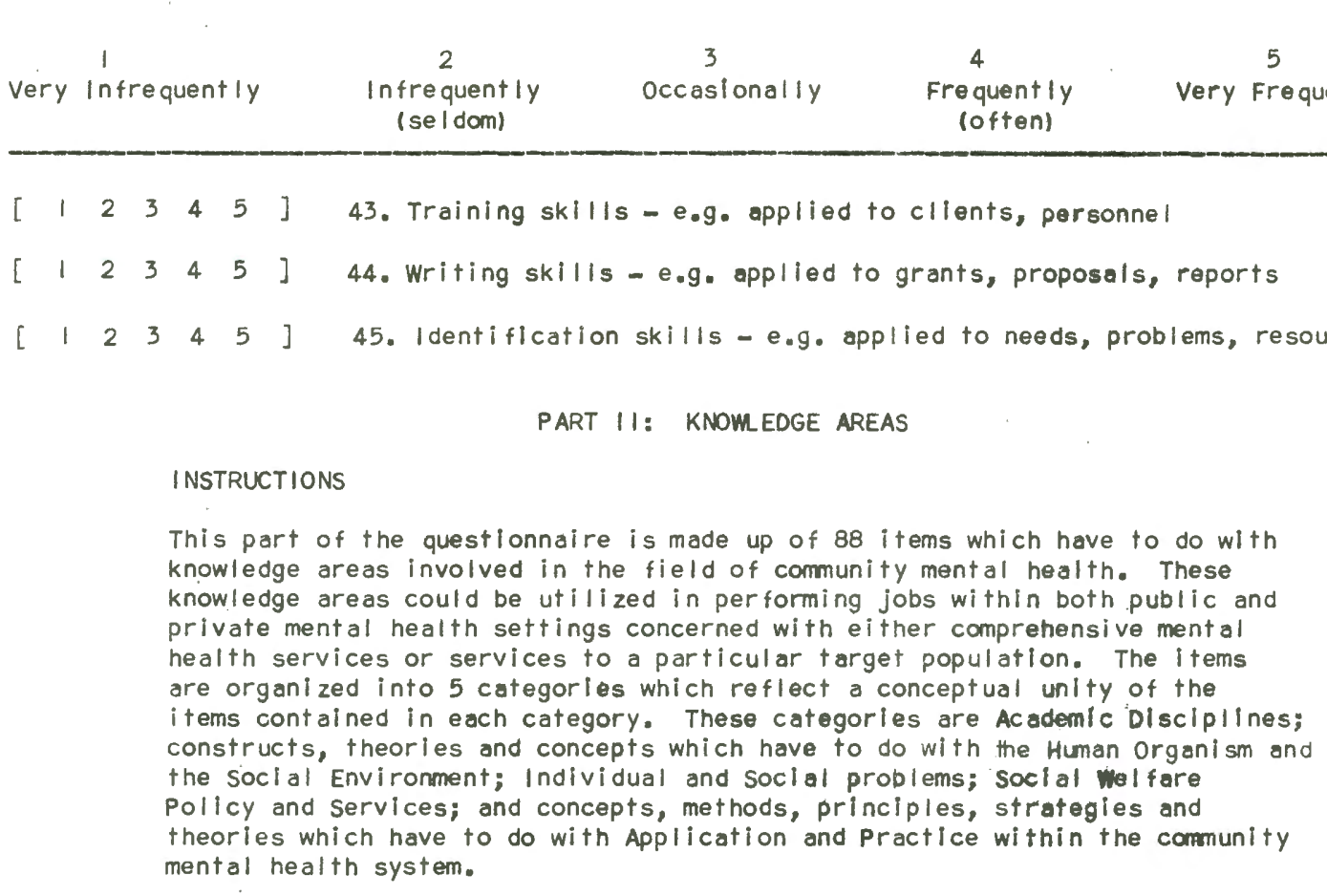

The following scale is to be used in rating all 88 items.

$\begin{array}{ccccc}1 & 2 & 3 & 4 & 5 \\ \text { Very Infrequently } & \begin{array}{c}\text { Infrequent|y } \\ \text { (seldom) }\end{array} & \text { Occasionally } & \begin{array}{c}\text { Frequent|y } \\ \text { (often) }\end{array} & \text { Very Frequently }\end{array}$

Please indicate your rating for each Item by circling the number which most closely approximates your response to the question below.

TEN (10) YEARS FROM NOW, HOW FREQUENTLY WILL MASTER'S LEVEL SOCIAL WORKERS WHO ARE INVOLVED IN OREGON'S COMMUNITY MENTAL HEALTH SYSTEM BE UTILIZING KNOWLEDGE FROM THE FOLLOWING AREAS?

\section{A. Academic Disciplines}

\begin{tabular}{|c|c|c|c|c|c|c|}
\hline 1 & 2 & 3 & 4 & 5 & ] & 1. Anthropology \\
\hline 1 & 2 & 3 & 4 & 5 & ] & 2. Economics \\
\hline 1 & 2 & 3 & 4 & 5 & 7 & 3. Philosophy \\
\hline 1 & 2 & 3 & 4 & 5 & 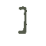 & 4. Political Science \\
\hline 1 & 2 & 3 & 4 & 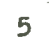 & & 5. Psychology \\
\hline
\end{tabular}




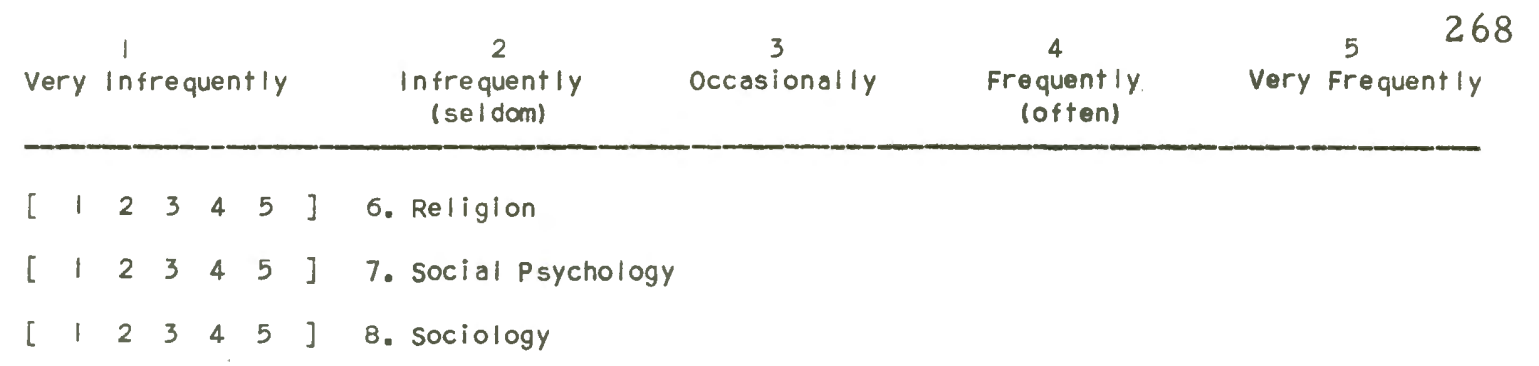

\section{B. The Human Organism and the Soci al Environment Constructs, Theories and concepts}

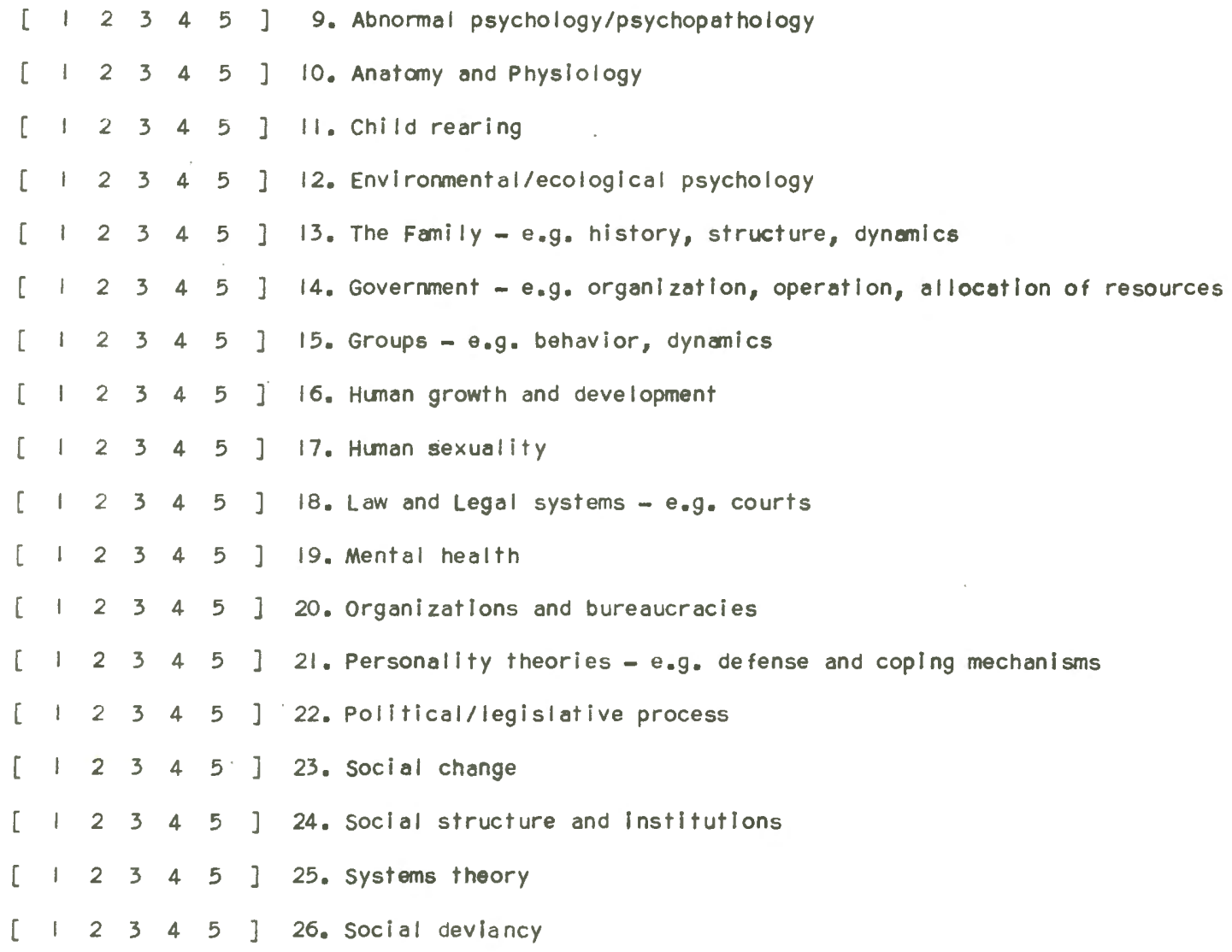




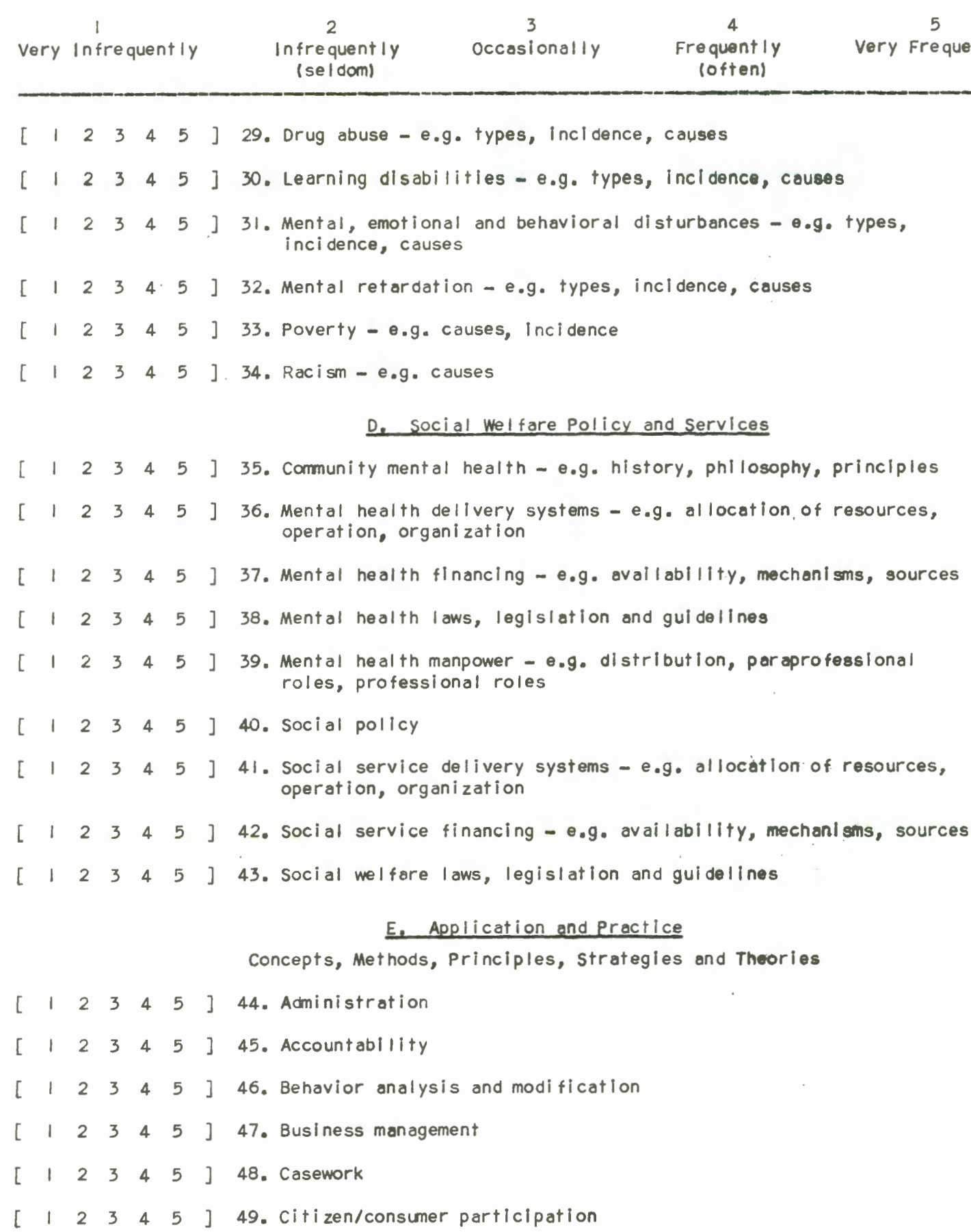




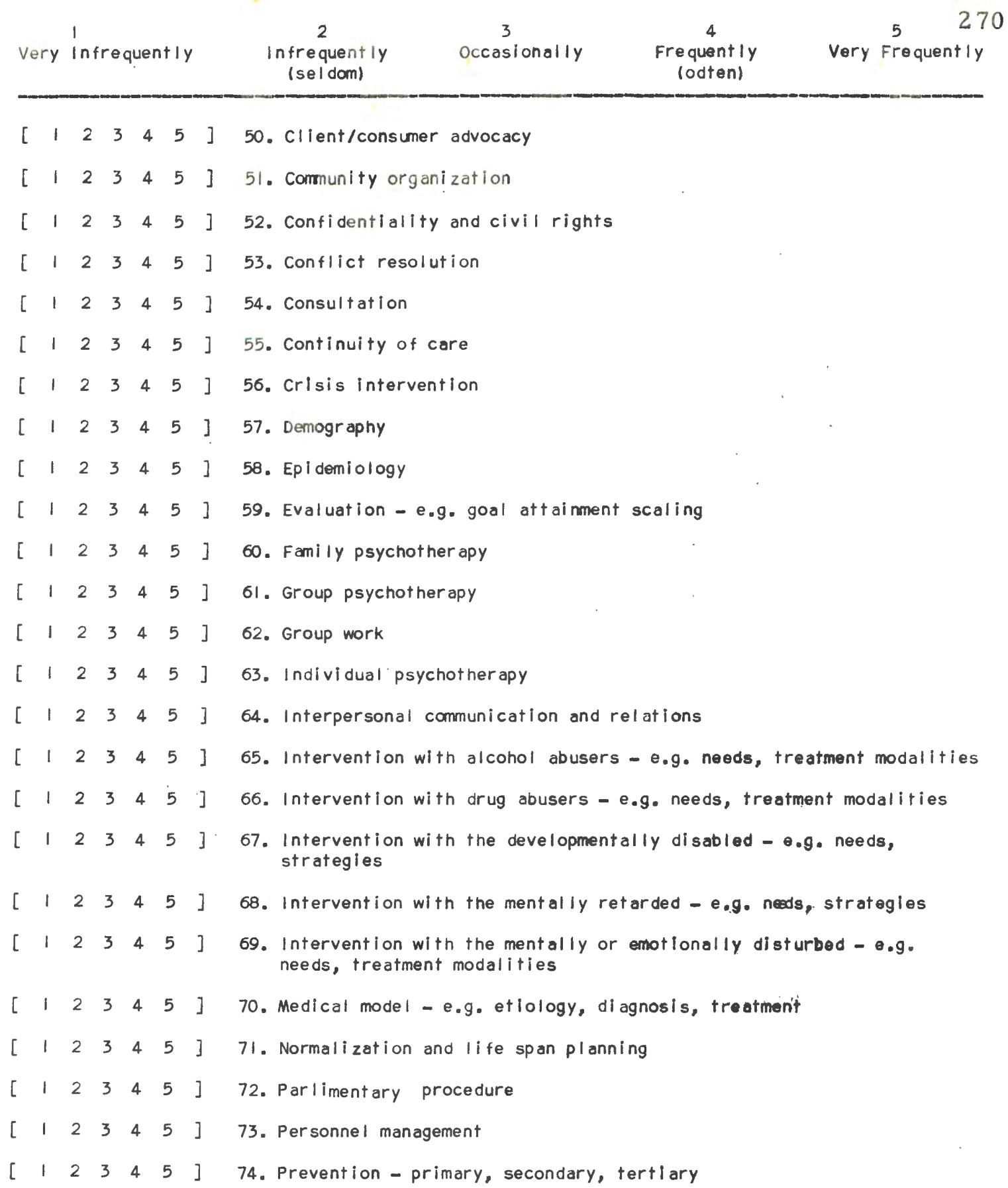




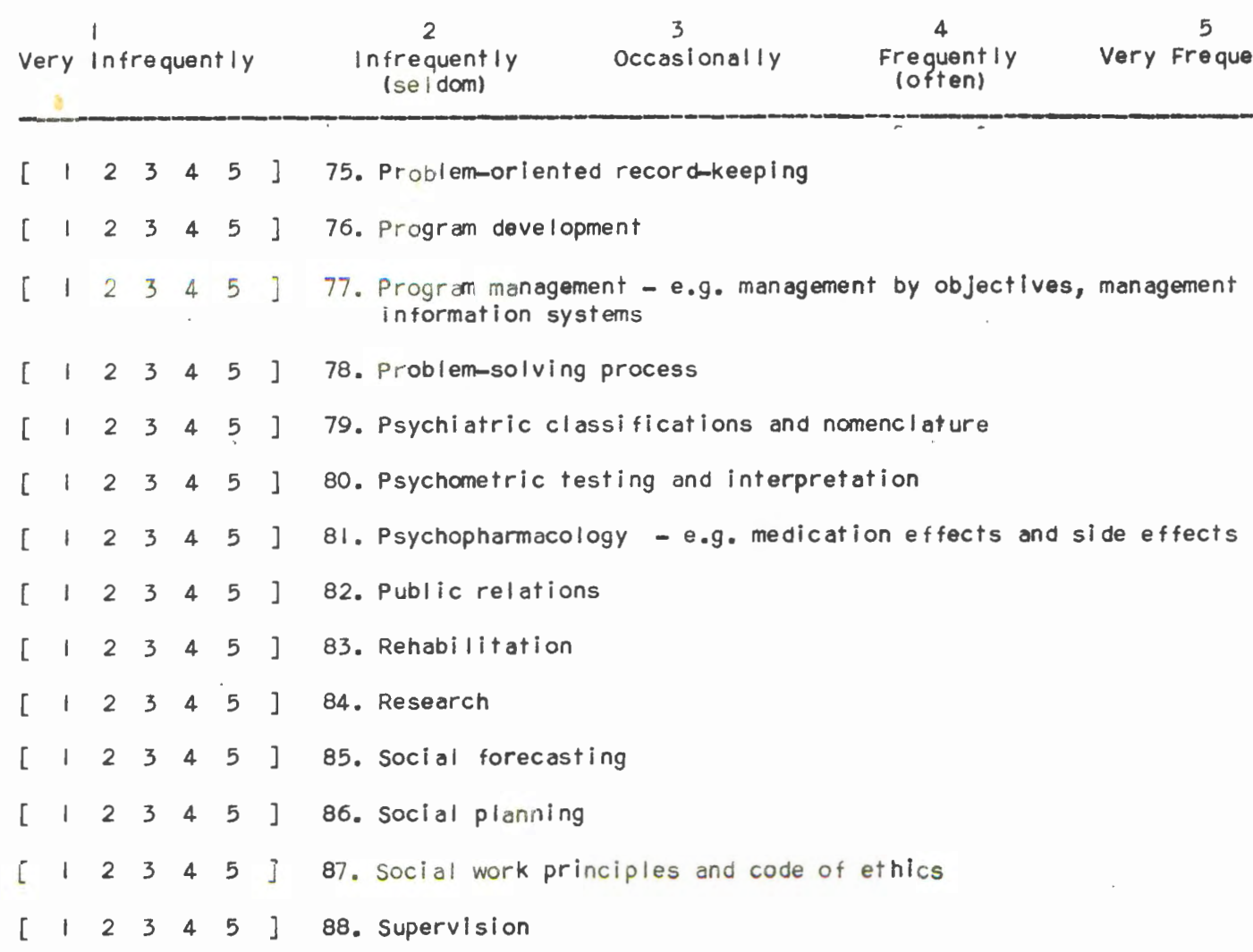


Dear Mental Health Professional.

Within the last two weeks, you received a questionnaire as part of our research study concerning Social Workers and Community Mental Health. As of the above date, we have not yet recelved your reply to the questionnaire. If you have already returned it, then may we take this opportunity to thank you for doina so. If you have not yet completed the questionnaire, could we ask that you take the time in the next day or two to respond to it? The questionnaire should take no more than twenty to twenty-five minutes to complete.

Our intent in this studv is to accurately reflect the views of mental health professionals throughout Oregon and at all levels of involvement in the community mental health field. To accomplish these goals, we need to have as many returns on our questionnafres as possible.

He believe that this research will produce information that could be of use and value to you, and it provides an opportunity to compare your views on this subject with those of other professionals in the state. There are probably other research studies you are participating in as well, and we know that there are many other demands on vour time. We feel, though, that this is an fmportant study, and we would like to complle the survey responses and return the results to you as soon as possible.

Please return the questionnaire in the stamped, self-addressed envelope which was provided no later than Friday, February 21. Thank you very much for your time and consideration.

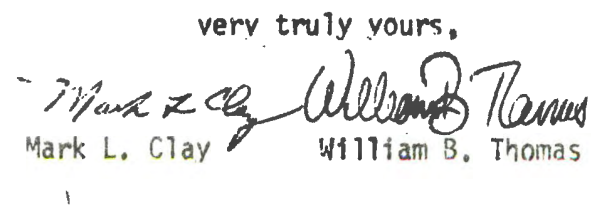


Questionnoire 2A - Roles, Functions and Tasks

The following instructions were inchded in the three sections of the original questionnaire. They are enclosed for your reference.

PART I: ROLES

\section{INSTRUCTIONS}

This part of the questionnaire is made up of 24 items which have to do with job roles in the field of community mental health. These roles could be performed in both public and private mental health settings concerned with either comprehensive mental health services or services to o particular target population. Further, we reallize that, in many cases, a single job might require the performance of several roles. Following each item we have listed examples of Jobs which would involved the performence of the rol.e.

\section{PART 11: FUNCTIONS}

\section{INSTRUCTIONS}

This part of the questionnaire is made up of $12 \mathrm{items}$ which have to do with the functions of jobs in the community mental health system. The three functions identified in this questionnaire ore Manager, Service Enabler, and Service Provider. We are interested in the performance of these job functions through public and private mental health settings bofh in relationship to the provision of comprehensive mental health services, and in relationship to the current organization of services in the community mental health system by target population. These target populations are alcohol and drug problems (A\&DP), mentally or emotionally disturbed (MED), and mentally retarded and developmentally disabled (MRDO).

PART III: TASKS

\section{INSTRUCTIONS}

This part of the questionnaire is made up of 92 items which have to do with the tasks that make up jobs within the cormunity mental health system. These tasks could be performed for jobs in both public and private mental health settings concerned with either comprehensive mental health services or services to a particular target population. The items ore divided into 12 categories which reflect a common purpose for all of the tasks in the group. These categories are Analytical Tasks, Assessment Tasks, Consultation Tasks, Data Collection Tasks, Education and training Tasks, Evaluation Tasks, Identification Tasks, Organization and Development Tasks, Planning Tasks, Program Management Tasks, Service Delivery Tasks, and Systems Mointenance Tosks. 
SOCIAL WORKERS IN COMMUNITY MENTAL HEALTH

Questionnaire \#2A-Roles, Functions and Tasks

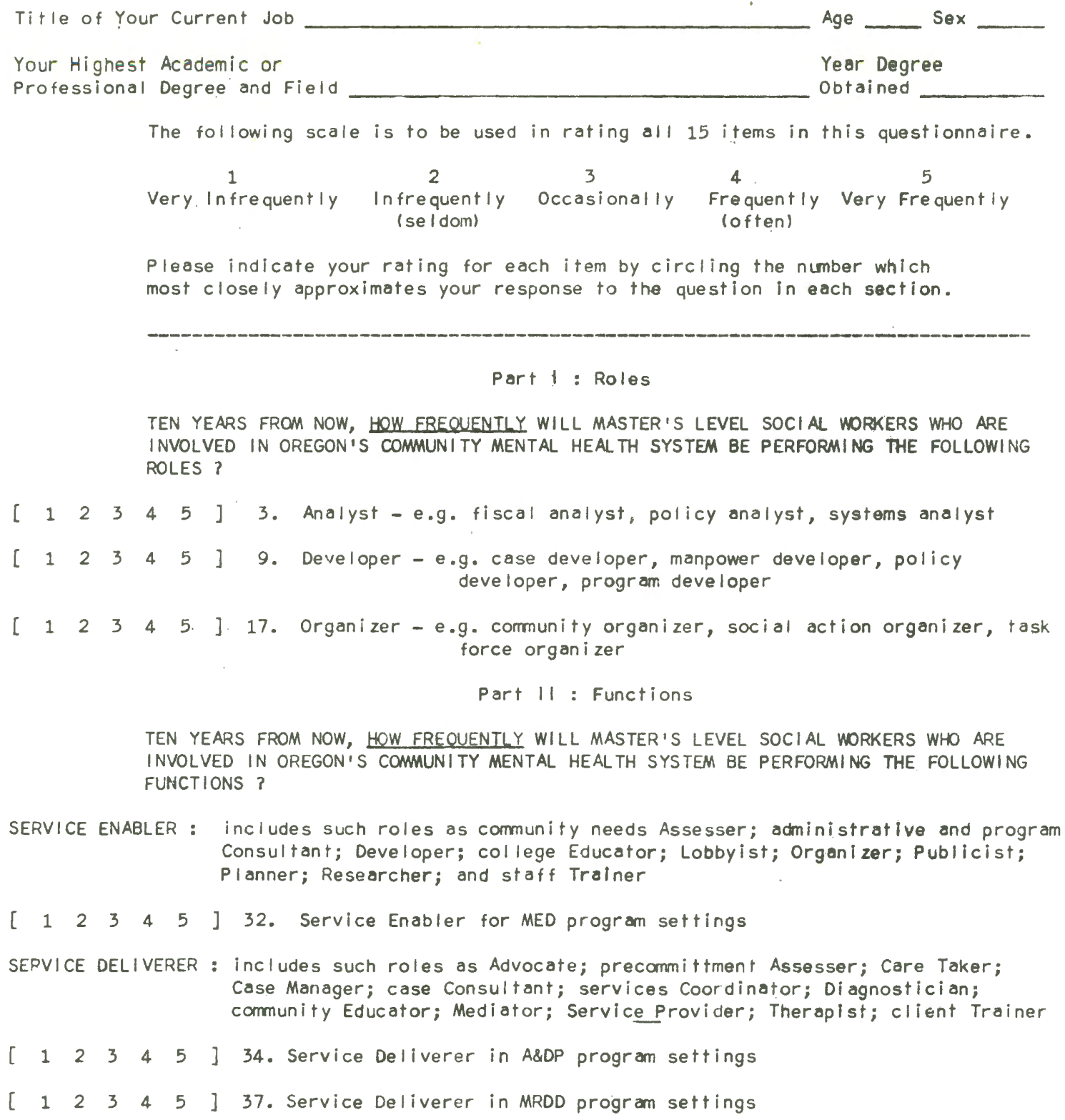

TEN YEARS FROM NOW, HOW EREQUENTLY WILL MASTER'S LEVEL SOCIAL WORKERS WHO ARE INVOLVED IN OREGON'S COMMUNITY MENTAL HEALTH SYSTEM BE PERFORMING THE FOLLOWING ROLES ?

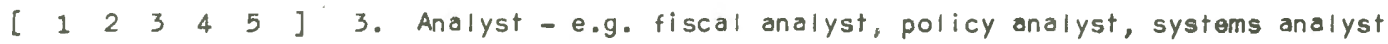

$\left[\begin{array}{lllllll}1 & 2 & 3 & 4 & 5 & 9\end{array}\right]$. Developer - e.g. case developer, manpower developer, policy developer, program developer

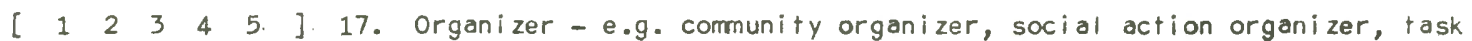
force organizer

$$
\text { Part } 11 \text { : Functions }
$$

TEN YEARS FROM NOW, HOW FREOUENTLY WILL MASTER'S LEVEL SOCIAL WORKERS WHO ARE INVOLVED IN OREGON'S COMMUNITY MENTAL HEALTH SYSTEM BE PERFORMING THE FOLLOWING FUNCTIONS ?

SERVICE ENABLER : includes such roles as community needs Assesser; administrative and program Consultant; Developer; college Educator; Lobbyist; Orgenizer; Publicist; Planner; Researcher; and staff Trainer

$\left[\begin{array}{lllllll}1 & 2 & 3 & 4 & 5 & 32\end{array}\right]$. Service Enabler for MED program settings

SEPVICE DELIVERER : includes such roles as Advocate; precommittment Assesser; Care Taker; Case Manager; case Consultant; services Coordinator; Diagnostician; community Educator; Mediator; Service Provider; Therapist; client Trainer

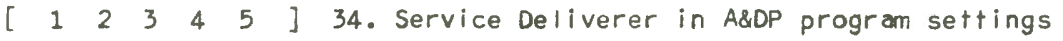

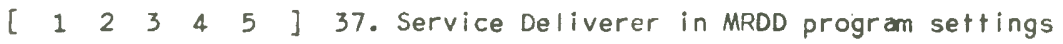




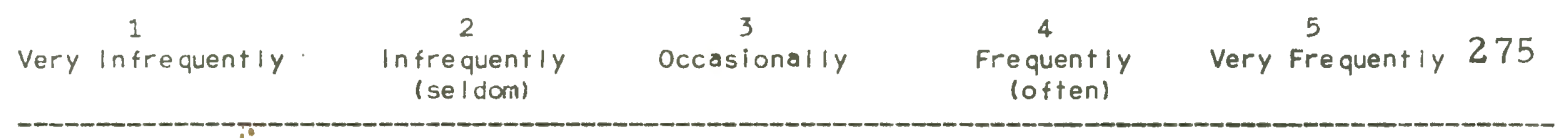

Part 111: Tasks

TEN YEARS FROM NOW, HOW FREOUENTLY WILL MASTER'S LEVEL SOCIAL WORKERS WHO ARE INVOLVED IN OREGON'S COMMUNITY MENTAL HEALTH SYSTEM BE PERFORMING THE FOLLOVING TASKS ?

\section{A. Analytical Tasks}

[ $\left.\begin{array}{llllll}1 & 2 & 3 & 4 & 5\end{array}\right]$ 3. Analyze a relationship with a client ( e.g. dynamics, interactions ) E, Education and Troining Tasks

$\left[\begin{array}{llllll}1 & 2 & 3 & 4 & 5\end{array}\right]$ 32. Train personnel in mental health agencies G. Identification Tasks

$\left[\begin{array}{llllllll}1 & 2 & 3 & 4 & 5 & 38\end{array}\right]$. Identify problems in need of research He Organization and Development Tasks

$\left[\begin{array}{llllll}1 & 2 & 3 & 4 & 5 & \text { ] }\end{array}\right.$ 45. Develop programs to prevent mental and emotional disturbances, developmental disabilities, mental retardation or alcohol and drug addiction

$\left[\begin{array}{llllll}1 & 2 & 3 & 4 & 5 & \text { ] }\end{array}\right.$ 49. Organize task forces $($ e.g. advisory cormittees, boards of directors, planning bodies)

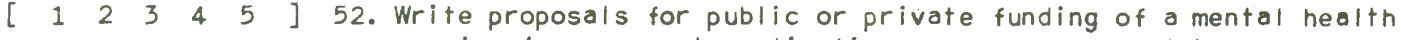
service ( e.g. grant application, program proposal)

\section{J. Program Management Tasks}

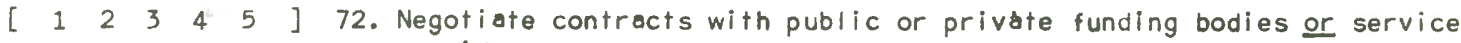
providers

$\left[\begin{array}{llllll}1 & 2 & 3 & 4 & 5\end{array}\right]$ 74. Supervise personnel (e.g. coordinate workloods, provide support and feedback )

\section{Systems Maintainence Tasks}

$\left[\begin{array}{llllll}1 & 2 & 3 & 4 & 5 & \text { ] }\end{array}\right.$ 90. Form working relationships with other professionals 1 e.g. Interdisciplinary team ) 


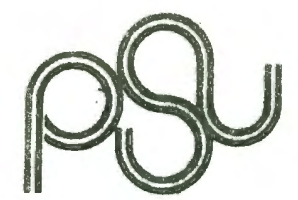

March 15, 1975

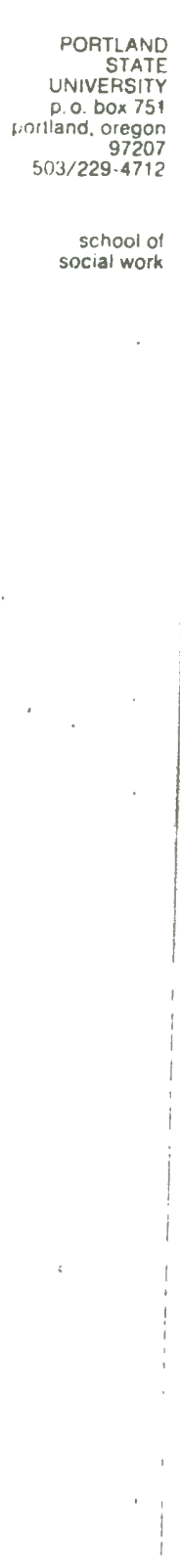

Dear

Thank you for returning the second part of our Delphi survey concerning the future activities of Master's level soclal workers in the field of community mental health. Enclosed with this letter is the third and final questionnaire which we are requesting that you complete. This last questionnaire is an essential part of the research study. It is thus vital that we have a $100 \%$ rate of return of this instrument to insure that the time which you have already invested in this process has been well spent.

One of our objectives in using the Delphi forecasting technique as a research design is to determine the strength of consensus on ratings of the items in the study. Accordingly, in this instrument we have indicated the rating which was selected most often for each item in the second questionnaire. We think that you will find it interesting to compare your ratings of the items with the modal responses of your colleagues throughout the state.

The purpose of this final step in the Delphi process is to provide you with an opportunity to reconsider your rating of each 1 tem with the knowledge of the modal response to the 1tem. In the enclosed questionnaire, the modal response is indicated by a black diamond around the appropilate rating, and your response is indicated by a red " $Y$ " directly on the rating. Items marked with two black diamonds had two ratings with an equal number of responses.

Please mark the items in this questlonnatre as follows:

1) Where you wish to change one of your previous responses in light of the modal response, simply circle the new rating.

2) Where you do not desire to change a previous rating after considering this information, simply do nthing.

After we have compiled the responses to this final questionnaire, we w111 provide you with a summary of the results and implications of both halves of the study, that is of both Part A: "Roles, Functions and Tasks " and of Part B: "Skills and Knowledge Areas ".

PLEASE RETURN THE COMPLETED QUESTIONNAIRE BY APRIL 2, 1975. A stamped, self-addressed envelope is enclosed for your convenience. Once again may we thank you for your time and energy in assisting us with this research.

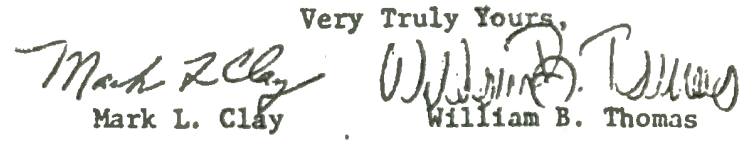


SOCIAL WORKERS IN COMMUNITY MENTAL HEALTH

Questionnaire *3-Roles, Functions and Tasks

Title of your Current Job

Your Highest ACademic or

Professional Degree and Field

PART 1: ROLES

INSTRUCTIONS

This part of the questionnaire is made up of 25 items which have to do with job roles in the field of community mental health. These roles could be performed in both public and private mental health settings concerned with elther comprehensive mental health services or services to a particm ular target population. Further, we realize that in many cases a single job might require the performance of several roles. Following each item we have listed examples of jobs which would involve the performence of the role.

The following scale is to be used in rating oll 25 items.

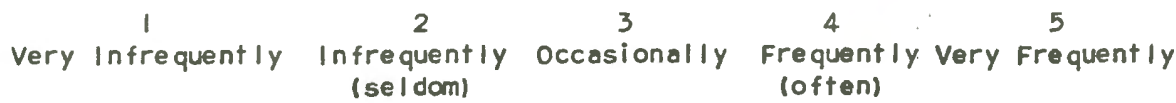

On 1tems where you wish to change your response to the question belor in light of the modal response, please circle the new reting.

On items where you do not desire to change jour rating after considering this inforwation, plesse do nothing.

TEN (10) YEARS FROM NOW, HOW FREOUENTLY WILL MASTER'S LEVEL SOCIAL WORKERS WHO ARE INVOLVED IN OREGON'S COMMUNITY MENTAL HEALTH SYSTEM BE PERFOPMING THE FOLLOWING ROLES?

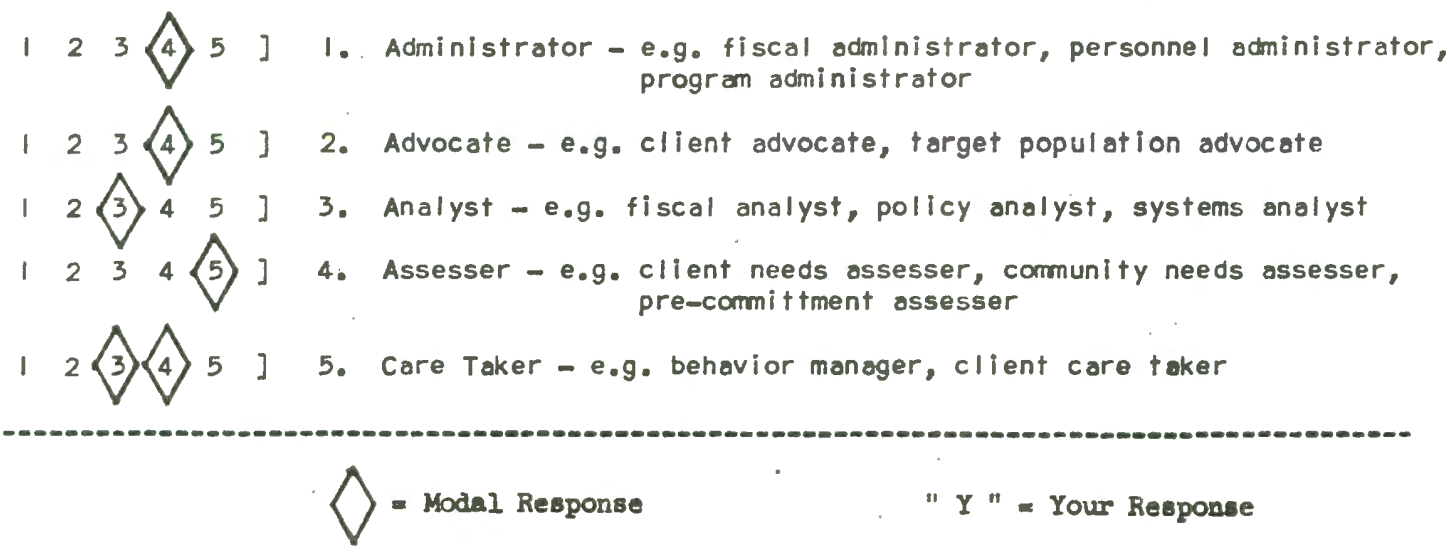




\begin{tabular}{|c|c|c|c|c|}
\hline 1 & 2 & 3 & 4 & 5 \\
\hline Very Infrequently & $\begin{array}{c}\text { Infre quent Iy } \\
\text { (seldom) }\end{array}$ & Occasionally & $\begin{array}{l}\text { Frequently } \\
\text { (often) }\end{array}$ & Very Frequentiy \\
\hline
\end{tabular}

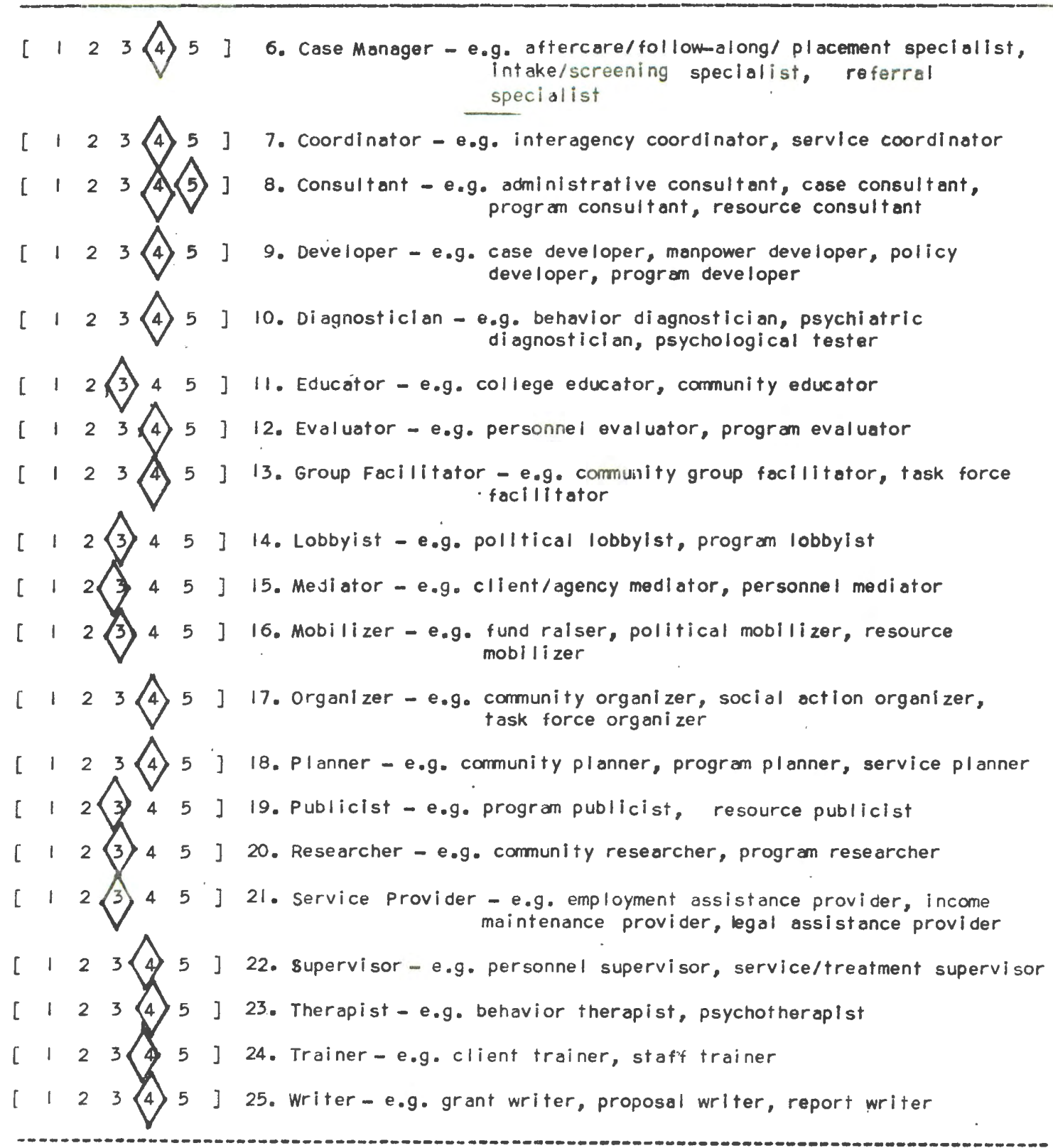

$$
\bigcup=\text { Modal Response } \quad \text { "Y" = Your Response }
$$


PART 11: FUNCTIONS

INSTRUCTIONS

This part of the questionnaire is made up of 12 items which have to do with the functions of jobs in the community mental health system. The three functions identified in this questionnalre are Manager, Service Enabler, and Service Dellverer. We are Interested in the performance of these Job functions through pubilic and privote mental health settings both in relationship to the provision of comprehensive mental health services, and in relationship to the current organization of services in the communlty mental health system by target population. These target populations are alcohol and drug problems (A\&OP), mentally or emotionally disturbed (MED), and mentally retarded and developmentally disabled (MRDO).

The following scale is to be used in rating all 12 items.

$\begin{array}{ccccc}1 & 2 & 3 & 4 & 5 \\ \text { Very Infrequently } & \text { infrequently } & \text { occasionally } & \text { Frequentiy very frequently } \\ \text { (often) } & \text { (seldom) } & \end{array}$

On items where you wish to change your response to the question below in light of the modal response, please circle the new rating.

On 1tems where you do not desire to change your rating after considering this inforwation, please do nothing.

TEN (10) YEARS FROM NOW, HOW FREOUENTLY WILL MASTER'S LEVEL SOCIAL WORKERS WHO ARE INVOLVED IN OREGON'S COMMUNITY MENTAL HEALTH SYSTEM BE PERFOPMING THE FOLLOWING FUNCTIONS?

MANAGER: includes such roles as Administrotor; interagency Coordinator; Evaluator; and supervisor

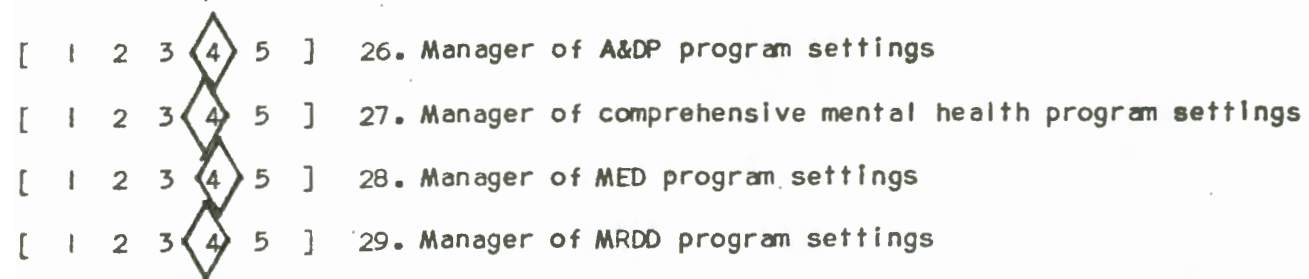

SERVICE ENABLER: includes such roles as community needs Assesser; administrative and program Consultant; Developer; College Educator; Lobbylst; Organizer; Publiclst; Planner; Researcher; and staff Trainer.

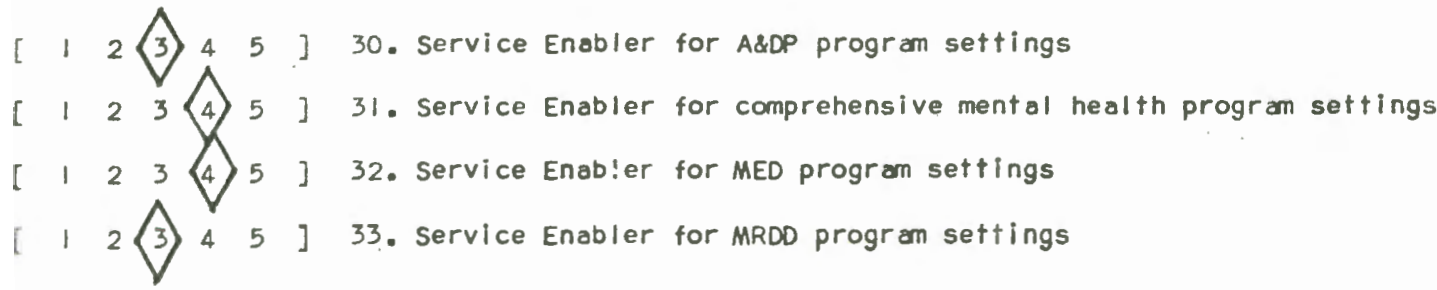




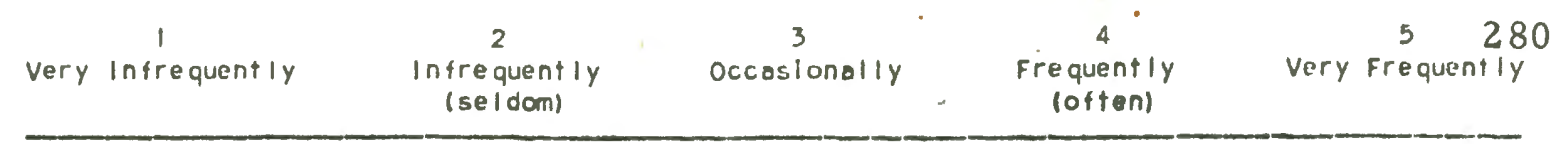

SERVICE DELIVERER: includes such roles os Advocote; precommlttment Assesser; Core Taker; Case Manager; case Consultant; services Coordinator; Dlagnostician; communlty Educator; Mediator; Service Provide; Theraplst; client Trainer

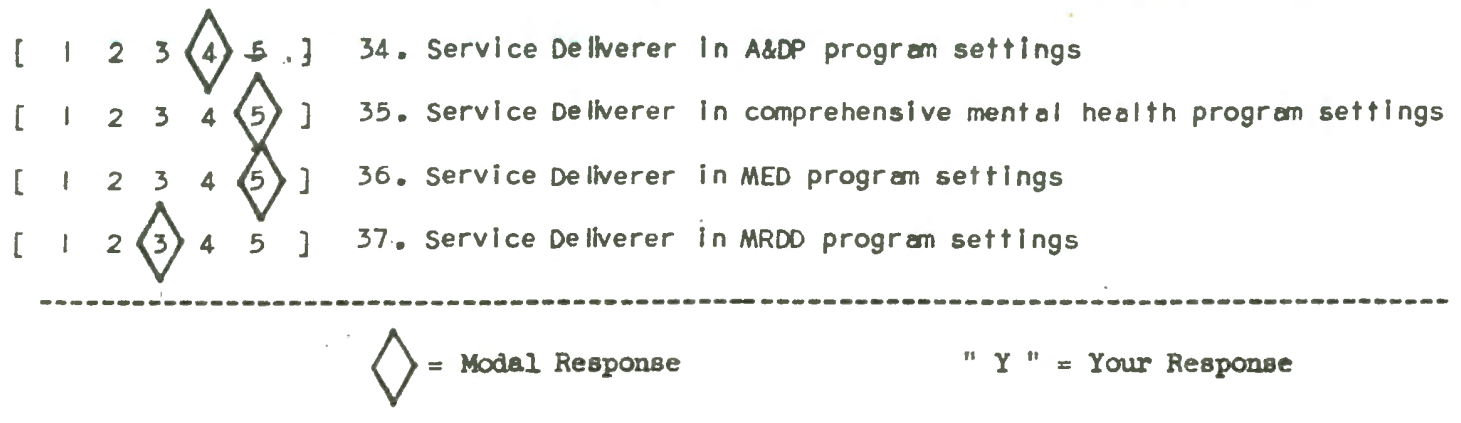

PART III: TASKS

INSTRUCTIONS

This part of the questionnaire. includes 92 items which have to do with the tasks that make up jobs within the community mental health system. These tasks could be performed for jobs in both public and private mental health settings concerned with either comprehensive mental health services or services to a particular target population. The items are divided into 12 categories which reflect a cormon purpose for all of the tasks in the group. These categories are Analytical Tasks, Assessment Tasks, Consultation Tasks, Data Collection Tasks, Education and Training Tasks, Evaluation Tasks, Identification Tasks, Organization and Development Tasks, Planning Tasks, Program Management Tasks, Service Dellvery Tasks, and systems Maintenance Tasks.

The following scale is to be used in rating all 92 items.

$\begin{array}{ccccc}1 & 2 & 3 & 4 & 5 \\ \text { Very Infrequently } & \begin{array}{c}\text { Infrequently } \\ \text { (seldom) }\end{array} & \text { occasionally } & \text { frequently } & \text { Very frequently } \\ \text { (often) } & & \end{array}$

On items where you wish to change your response to the question belon in light of the modal response, please circle the new rating.

On 1tems where you do not desire to change your rating arter considering this infermation, please do nothing.

TEN (10) YEARS FROM NOW, HOW FREQUENTLY WILL MASTER'S LEVEL SOCIAL WORKERS WHO ARE I NVOLVED IN OREGON'S COMMUNITY MENTAL HEALTH SYSTEM BE PERFORMING THE FOLLOWING TASKS? 


\begin{tabular}{cccc}
1 & 2 & 3 & 4 \\
Very Infrequently & $\begin{array}{c}2 \\
\text { (seldom) }\end{array}$ & occosionally & $\begin{array}{c}581 \\
\text { Frequently } \\
\text { (often) }\end{array}$ \\
\hline
\end{tabular}

\section{A. Analytical Tasks}

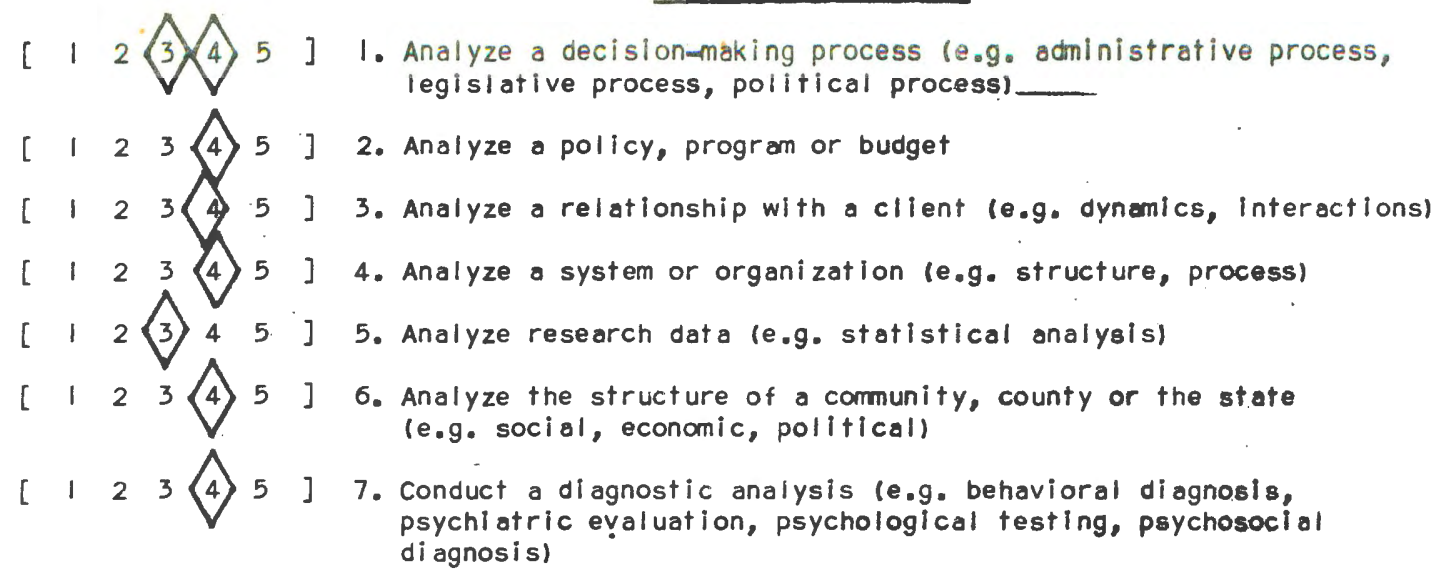

\section{B. Assessment Tasks}

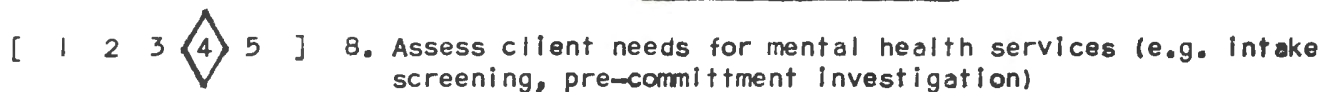

[ 123445 ] 9. Assess mental health services and delivery systems (e.g. adequacy, $\left[\begin{array}{lll}1 & 2 & 3\end{array} 45\right.$ ] 10 . Assess self (e.g. personal and professional strengths and weaknesses)

[ $12\langle 345$ ] 11 . Assess the educational needs of students preparing for mental

$\left[\begin{array}{lllll}1 & 2 & 3 & 4 & 5\end{array}\right]$ 12. Assess the mental health service needs of a community, region or

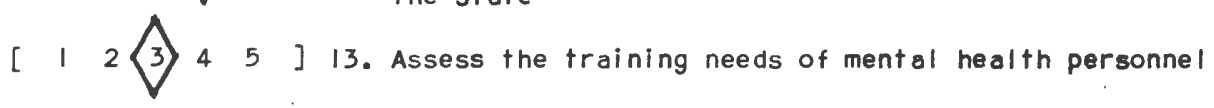

\section{Consultation Tasks}

[ 123 4 4 [ 14. Provide administrative consultation to community groups or mental health agencies (e.g. fiscal and personnel management and organizotion)

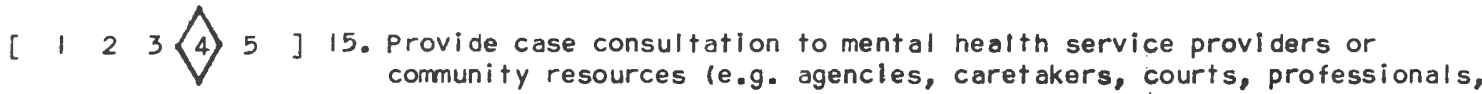
schools)

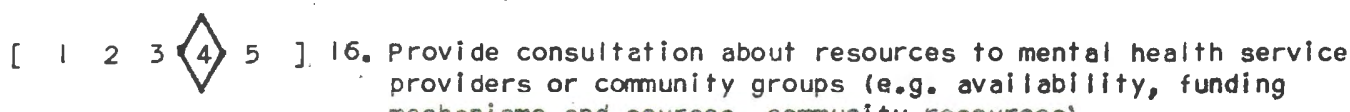
mechanisms and sources, community resources) 


\begin{tabular}{ccccc}
1 & 2 & 3 & 4 & 5 \\
Very Infrequently & $\begin{array}{c}2 \\
\text { (seldom) }\end{array}$ & occaslonally & $\begin{array}{c}4 \\
\text { Frequently } \\
\text { (often) }\end{array}$ & $\begin{array}{c}5 \\
\text { Very frequently }\end{array}$ \\
\hline
\end{tabular}

$\left.\begin{array}{lllllll}{[} & 1 & 2 & 3 & 4 & 5\end{array}\right]$

17. Provide consultation on mental health issues to business and industry

18. Provide consultation regarding a target populatlon to community groups or mental health service providers (e.g. needs, intervention strategies)

19. Provide expert testimony (e.g. court proceedings, pre-comittment hearings, legislative hearings)

20. Provide program consultation to community groups or mental health agencies (e.g. design, development, evaluation)

\section{Data Collection Tosks}

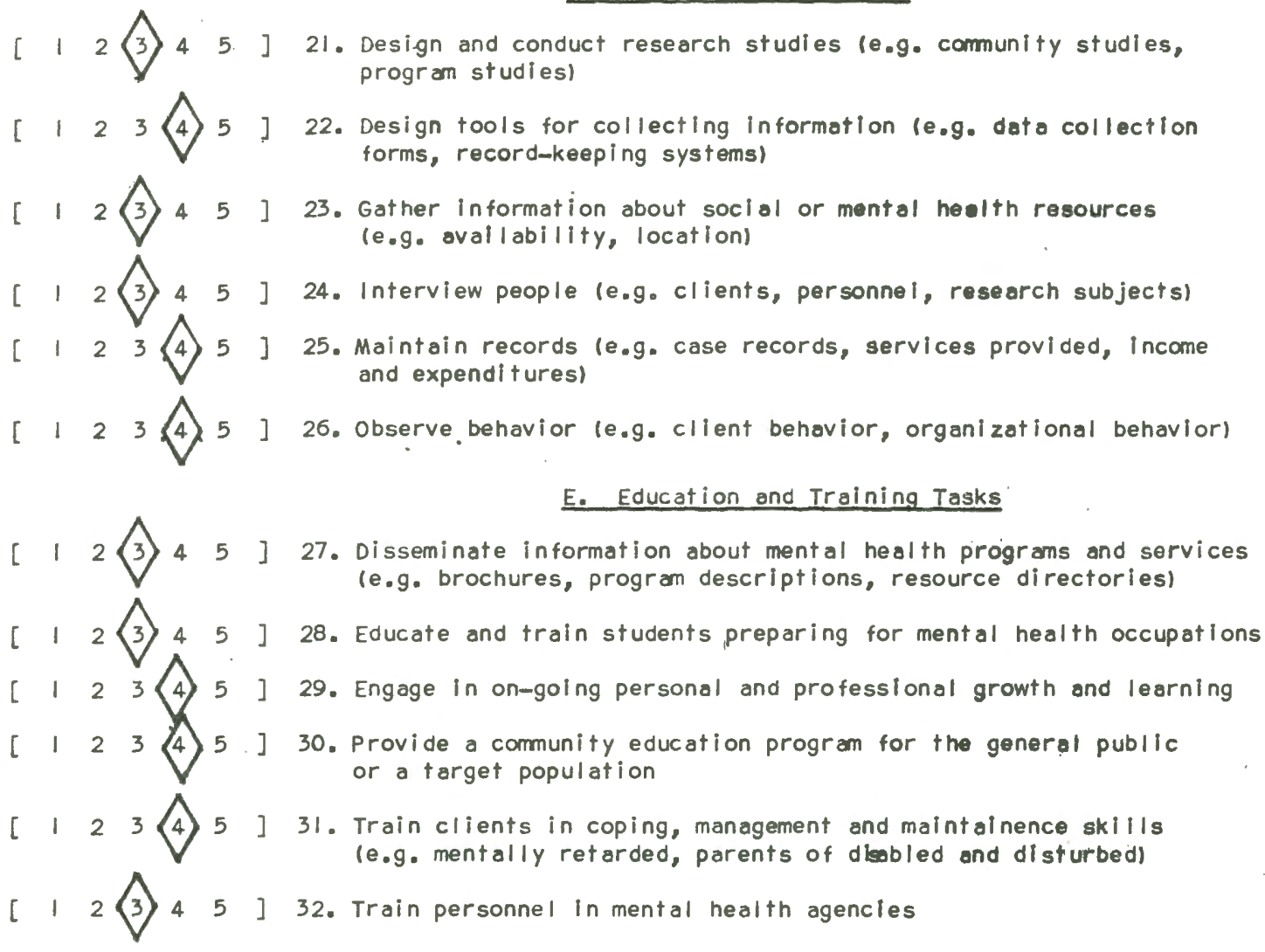




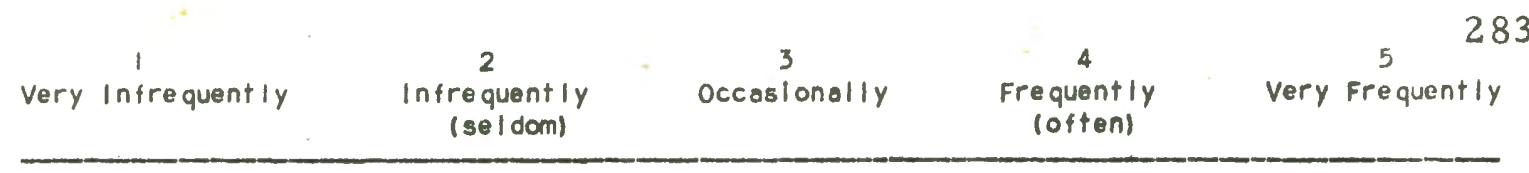

\section{F. Evaluation Tasks}

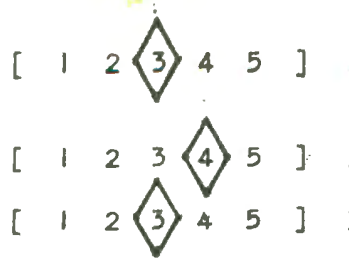

33. Design instruments for assessment and evaluation (e.g. clients, personnel, program)

34. Monitor and evaluate the progress and needs of clients

35. Monitor and evaluate the performance of mental health personnel, programs and agencies (e.g. cost effectiveness, productivity)

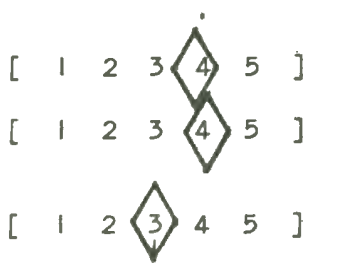

\section{G. Identiflcation Tasks}

36. Identify communities andpopulations in need of mental health services

37. Identify people in need of mental health or social services (e.g. case finding, outreach)

38. Identify problems in need of research

\section{H. Organization and Deve lopment Tasks}

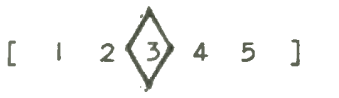

39. Advocate on behalf of communities and target populations for funds and services

$\left[\begin{array}{llllll}1 & 2 & 3 & 5 & 3\end{array}\right]$

40. Develop comprehensive mental health service centers

41. Develop an emergency mental health service

42. Develop a mental health information and referral service

43. Develop new mental health resources (e.g. funding sources, manpower)

$\left[\begin{array}{lllll}1 & 2 & 3 & 4 & 5\end{array}\right]$

44. Develop policies, procedures and guidelines for mental health services and agencies

45. Develop programs to prevent mental and emotional disturbances, developmental disabilities, mental retardation or alochol and drug addiction

46. Mobillze cormunity support for mental health services and target populations (e.g. funds, polltical support, volunteers)

[ $123\langle 45$ ] 47. Organize new mental health services or programs in communities

[ 12 3 345 ] 48 . Organize social actions (e.g. demonstrations)

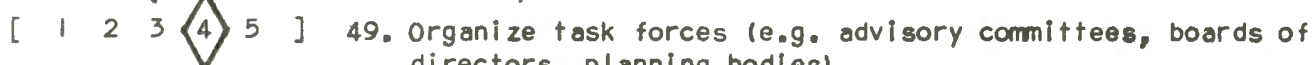
directors, planning bodles)

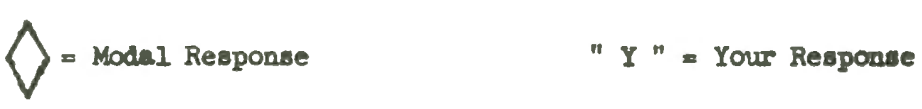




\begin{tabular}{|c|c|c|c|c|}
\hline 1 & 2 & 3 & & 5 \\
\hline Very Infrequently & $\begin{array}{c}\text { Infrequent Iy } \\
\text { (seldom) }\end{array}$ & occasionally & $\begin{array}{c}\text { Frequent Iy } \\
\text { (often) }\end{array}$ & Very Frequently \\
\hline
\end{tabular}

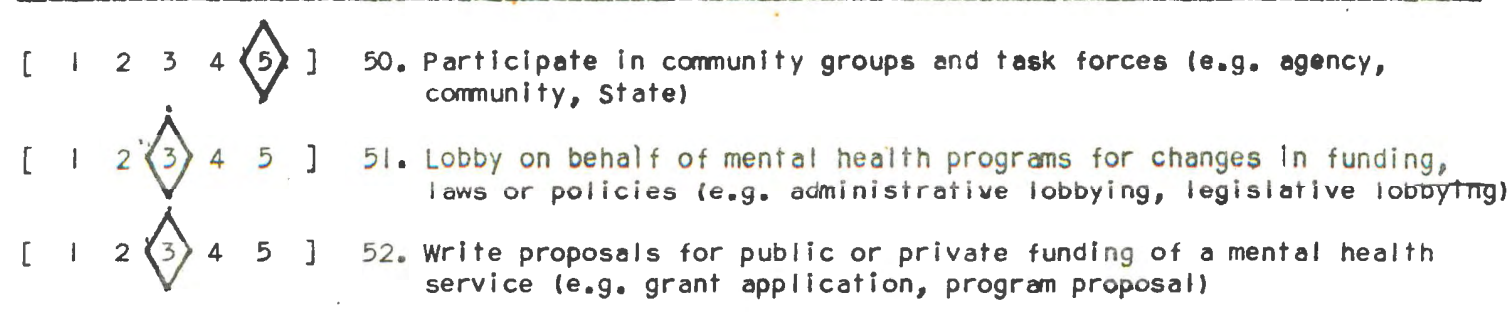

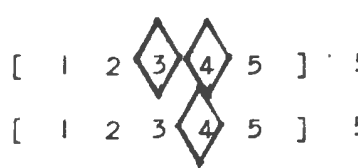

$\left[\begin{array}{lllll}1 & 2 & 3 & 5 & 5\end{array}\right]$

$\left[\begin{array}{lllll}1 & 2 & 3 & 5 & 5\end{array}\right]$

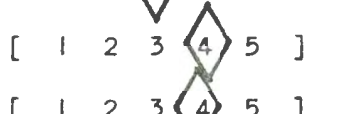

$\left[\begin{array}{llllll}1 & 2 & 3 & 4 & 5\end{array}\right]$

$\left[\begin{array}{llllll}1 & 2 & 3 & 4 & 5\end{array}\right]$

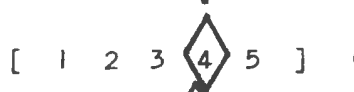

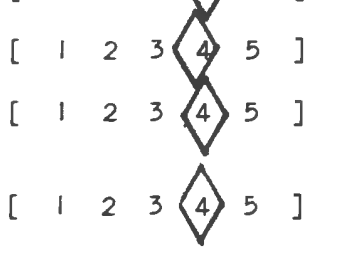

$\left[\begin{array}{lll}1 & 2 & 3\end{array}\right.$

$\left[\begin{array}{llllll}1 & 2 & 3 & 4 & 5\end{array}\right]$

$\left[\begin{array}{lll}1 & 2 & 3\end{array} 4_{5}\right]$

\section{Planning Tasks}

53. Plan a budget for a mental health agency or program

54. Plan and design a coordinated system of mental health services for a community, reglon or the state

55. Plan and design an educational program for students preparing for mental health occupations

56. Plan and design a training program for mental health personnel

57. Plan and design the program of a mental health agency

58. Plan an evaluation design for a mental health service or delivery system

59. Plan goals and measurable objectives for mental health ogencles, delivery systems or services

60. Plan goals and measurable objectives with clients

61. Plan intervention strategies for working with clients

62. Plan intervention strategies for working with communities, organizations and systems

63. Plan services for a client (e.g. normalization, rehabilitation, social services, treatments

\section{J. Program Management Tasks}

64. Coordinate mental health programs and ogencies le.g. interagency and intra-agency coordinations

65. Establish priorities for allocating limited resources le.g. money, personnel, timel

66. Establish standards of performance for mental heatth agencies, personnel and services (e.g. evaluative criteria, productivity indicators) 


$$
\begin{aligned}
& \begin{array}{cccc}
1 & 2 & 3 & 4 \\
\text { Very Infrequently } & \text { Occasionally } & 5 & \begin{array}{c}
285 \\
\text { (seldom) }
\end{array} \\
\hline
\end{array} \\
& {\left[\begin{array}{llllll}
1 & 2 & 3 & 4 & 5
\end{array}\right]} \\
& {\left[\begin{array}{lll}
1 & 2 & 3 \\
1 & 2 & 3
\end{array} \widehat{4}_{5} \frac{5}{5}\right]} \\
& {\left[\begin{array}{lll}
1 & 2 & 3
\end{array}\right.} \\
& {\left[\begin{array}{llllll}
1 & 2 & 3 & 4 & 5
\end{array}\right]} \\
& {\left[\begin{array} { l l l } 
{ 1 } & { 2 } & { 3 } \\
{ 1 } & { 2 } & { 3 }
\end{array} \left\langle4{ }_{5}\right.\right. \text { ] }} \\
& {\left[\begin{array}{lll}
1 & 2 & 3
\end{array} \widehat{4}_{5}\right]}
\end{aligned}
$$

\section{K. Service Delivery Tasks}


1

Very infrequent Iy

2
Infre quent Iy (seldom)
4 Frequent Iy (often)
5286

Very Frequently

87. Provide social services to facilitate social survival le.g. employment/housing assistance, income maintenance, legal aid)

88. Provide therapeutic intervention services to facilitate behavior change, confllct resolution and growth le.g. counseling, rehablilitation, ther apyl

\section{Systems Mointenance Tosks}

$\left[\begin{array}{lll}1 & 2\langle 3 & 5\end{array}\right]$

89. Design and prepare visual descriptions of mental health programs or agencies le.g. flow charts, graphs, organization plans, PERT charts)

$\left[\begin{array}{llll}1 & 2 & 3 & 4\end{array}\right.$

90. Form working relationships with other professionals (e.g. interdisciplinary teaml

$\left[\begin{array}{lll}1 & 2 & 3 \\ 5\end{array}\right]$

91. Provide leadership to agencies or community groups (e.g. delegate responsiblility, make decisionsl

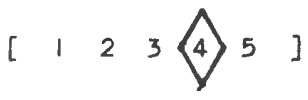

92. Write reports (e.g. client histories, communlty assessments, program evaluationsl

\section{\imodal Response}

"Y" = Your Response

Comments on the Questionnaire or an the Study : 
SOCIAL WORKERS IN COMUUN ITY MENTAL HEALTH

Questionnaire \#3-skills anu knowledge Areos

Title of your Current Job

Your Highest Academic or

Professional Degree and Fleld

PART 1: SKILLS

\section{INSTRUCTIONS}

This part of the questionnaire is made up of 45 items which have to do with skills that are involved in the field of community mental health. These skills could be utilized in performing jobs within both public and private mental health settings concerned with either comprehensive mental health services or services to a particular target population. Further, each item might be utilized in performing tasks, as part of those jobs, which have a number of different purposes. Following each itam, therefore, we have listed examples of related tasks to suggest possible areas of application for each skill.

The following scale is to be used in rating all 45 items.

$\begin{array}{ccccc}1 & 2 & 3 & 4 & 5 \\ \text { Very infrequently } & \begin{array}{c}\text { infrequently } \\ \text { (seldom) }\end{array} & \text { occasionally } & \text { Frequently } & \text { Very frequently } \\ & & \text { (often) } & \end{array}$

On Items where you wish to change your response to the question below in light of the modal response, please circle the new rating.

On 1tems where you do not desire to change your rating after considering this information, please do nothing.

TEN (10) YEARS FROM NOW, HOW FREQUENTLY WILL MASTER'S LEVEL SOCIAL WORKERS WHO ARE I NVOLVED IN OREGON'S COMMUNITY MENTAL HEALTH SYSTEM BE UTILIZING THE FOLLOWING SKILLS?

$$
\begin{aligned}
& {\left[\begin{array}{lll}
1 & 2 & 3 \\
5
\end{array}\right] \begin{array}{l}
\text { 1. Advocacy skills-e.9. applied to clients, consumers, target } \\
\text { populations }
\end{array}} \\
& \text { [ } 1233\langle 5 \text { ] 2. Analytical skills - e.g. applied to behovior, budgets, cormunities, } \\
& {\left[\begin{array}{llllll}
1 & 2 & 3 & 5
\end{array}\right] \text { 3. Arbitration skills - e.g. applied to personnel }} \\
& \text { [ } \left.1 \begin{array}{lllll}
1 & 2 & 3 & 4 & 5
\end{array}\right] \text { 4. Assessment skills - e.9. applied to client or community service }
\end{aligned}
$$




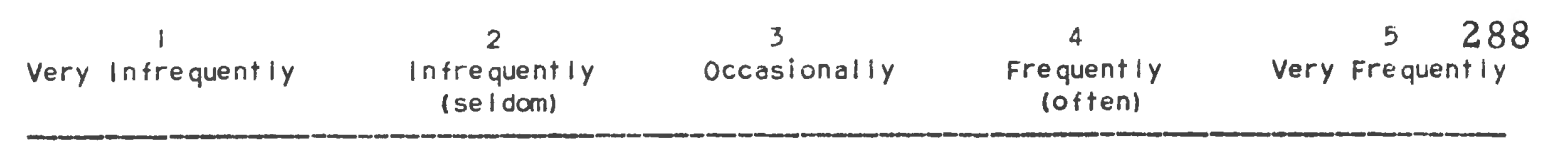

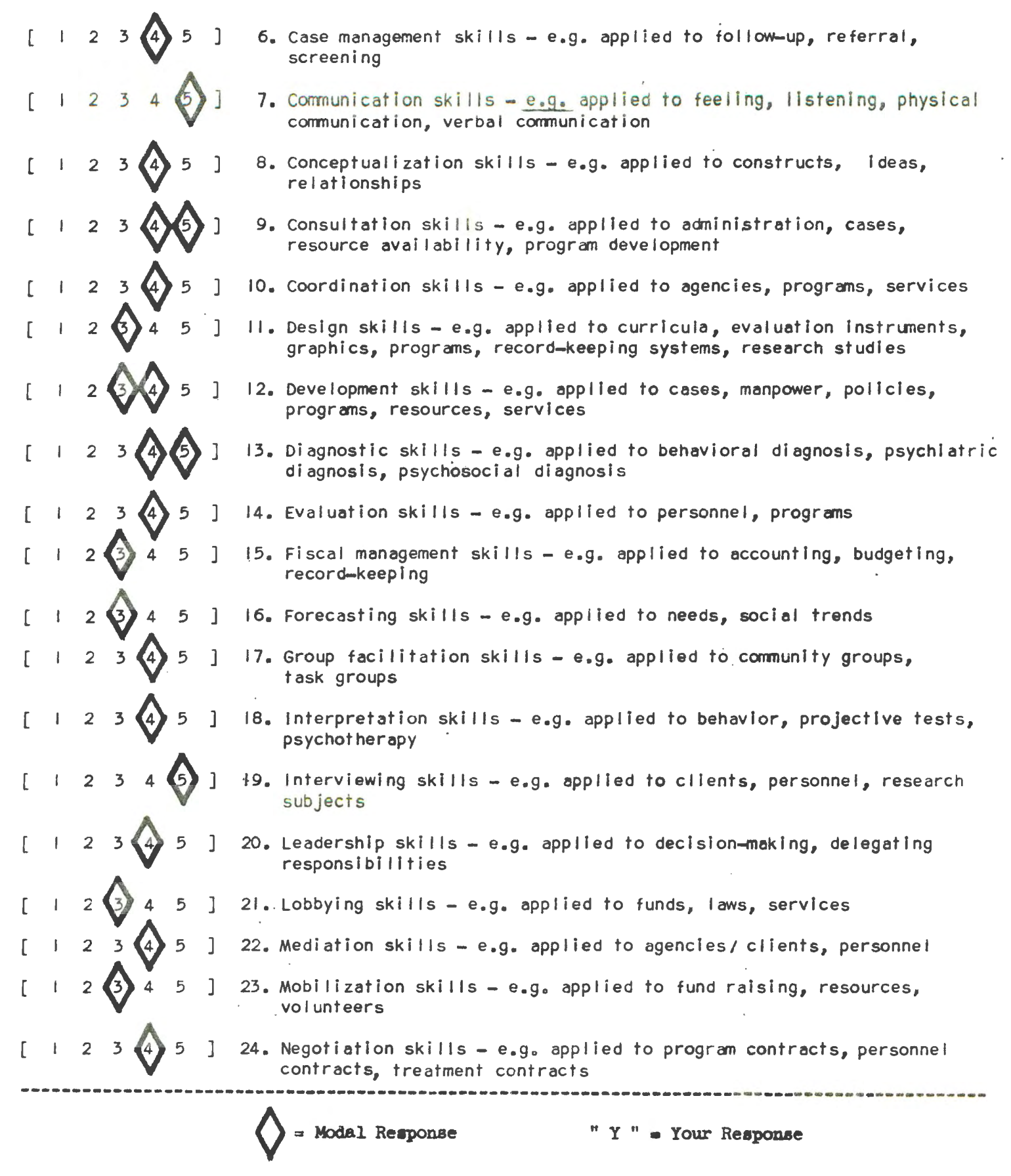




\begin{tabular}{|c|c|c|c|c|}
\hline$\frac{1}{\text { very Infrequentiy }}$ & $\begin{array}{c}2 \\
\text { Infrequent |y } \\
\text { (seldom) }\end{array}$ & ${ }^{3}$ occasionally & $\begin{array}{l}4 \\
\text { Frequent Iy } \\
\text { (often) }\end{array}$ & $\begin{array}{cc}5 & 289 \\
\text { Very Frequently }\end{array}$ \\
\hline
\end{tabular}

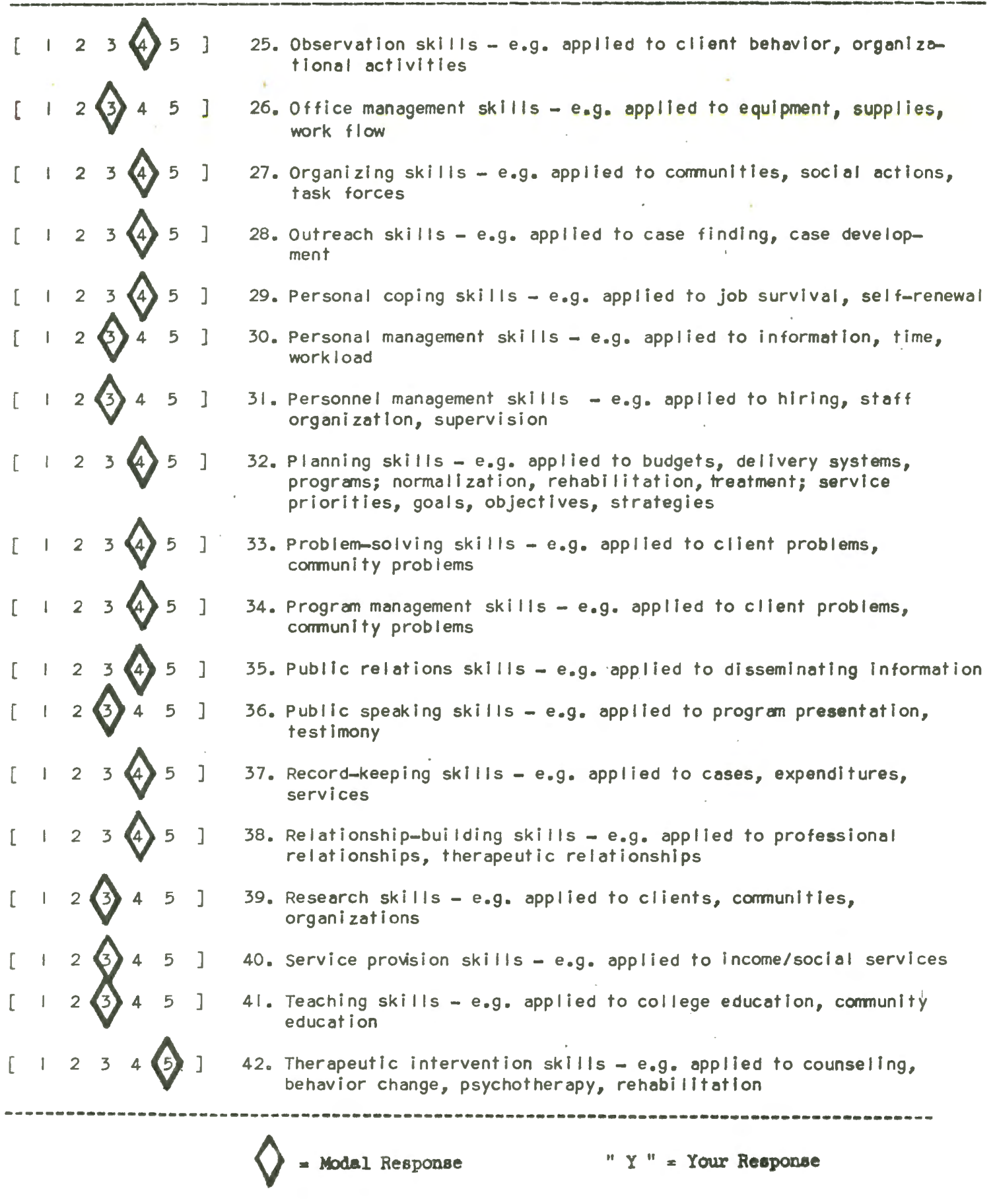




\begin{tabular}{|c|c|c|c|c|}
\hline 1 & 2 & 3 & 4 & 290 \\
\hline Very Infrequent Iy & $\begin{array}{c}\text { Infrequent Iy } \\
\text { (se Idom) }\end{array}$ & occosionally & $\begin{array}{c}\text { Frequent ty } \\
\text { (often) }\end{array}$ & Very Frequent ly \\
\hline
\end{tabular}

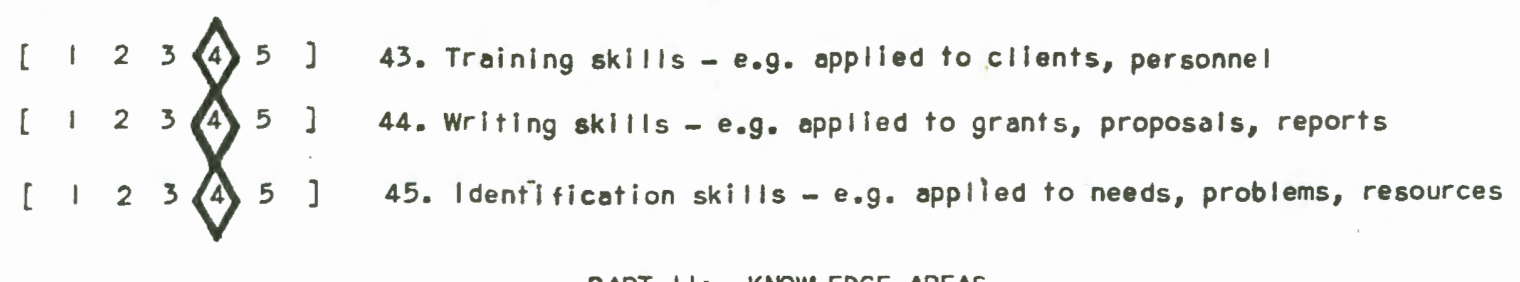

PART 11: KNOWEDGE AREAS

INSTRUCTIONS

This part of the questionnaire is made up of 88 items which have to do with knowledge areas involved in the field of community mental health. These knowledge areas could be utilized in performing jobs within both public and private mental health settings concerned with either comprehensive mental health services or services to a particular target population. The items are organized into 5 categories which reflect a conceptual unity of the items contained in each category. These categories are ACademic DIsciplines; constructs, theories and concepts which have to do with the Human Organism and the Social Environment; Individual and Social problems; Soclal Welfare Policy and Services; and concepts, methods, principles, strategies and theories which have to do with Application and Practice within the community mental health system.

The following scale is to be used in rating all 88 items.

$\begin{array}{ccccc}1 & 2 & 3 & 4 & 5 \\ \text { Very Infrequently } & \begin{array}{c}\text { Infrequently } \\ \text { (seldom) }\end{array} & \text { Occasionally } & \begin{array}{c}\text { Frequently } \\ \text { (often) }\end{array} & \text { Very Frequently }\end{array}$

On 1tems where you wish to change your response to the question below in light of the modal response, please circle the new rating.

On 1tems where you do not desire to change your rating after considering this information, please do nothing.

TEN (10) YEARS FROM NOW, HOW FREQUENTLY WILL MASTER'S LEVEL SOCIAL WORKERS WHO ARE INVOLVED IN OREGON'S COMUUNITY MENTAL HEALTH SYSTEM BE UTILIZING KNOWLEDGE FROM THE FOLLOWING AREAS?

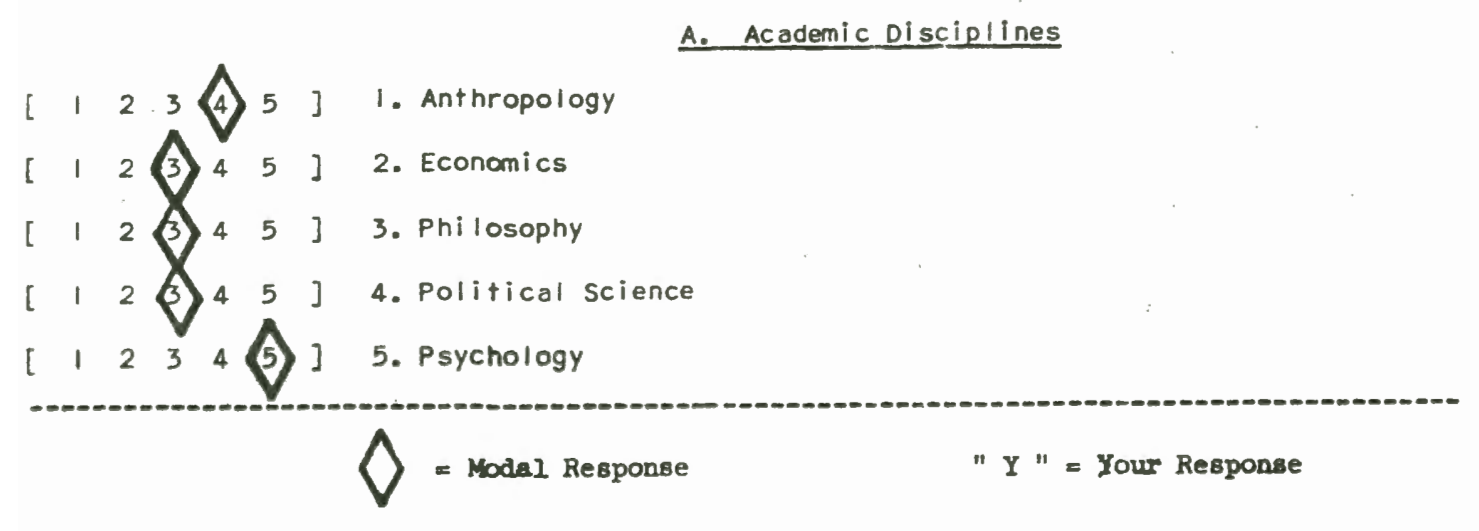




\begin{tabular}{ccccc}
1 & 2 & 3 & 4 & 5 \\
Very Infrequently & $\begin{array}{c}2 \\
\text { (seldom) }\end{array}$ & Occasionally & $\begin{array}{c}5 \\
\text { frequently } \\
\text { (often) }\end{array}$ \\
\hline
\end{tabular}

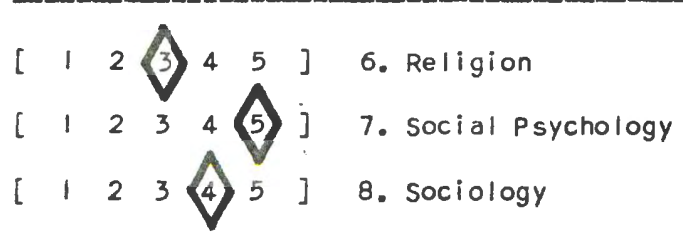

\section{B. The Human Organism and the Social Environment}

Constructs, Theories and Concepts

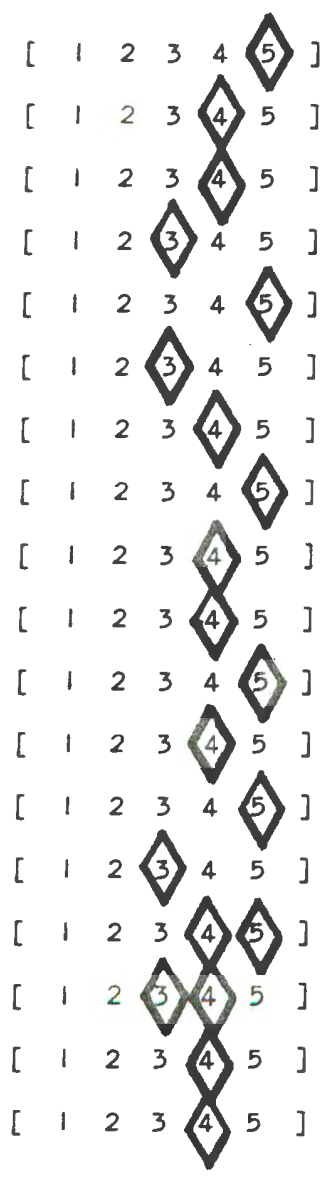

9. Abnormal psychology/psychopathology

10. Anatomy and Physiology

II. Child rearing

12. Environmental/ecological psychology

13. The family - e.g. history, structure, dynamics

14. Government - e.g. organization, operation, allocation of resources

15. Groups - e.g. behavior, dynamics

16. Human growth and development

17. Human sexuality

18. Law and Legal systems - e.g. courts

19. Mental health

20. Organizations and bureaucracies

21. Personality theories - e.g. de fense and coping mechanisms

22. Political/legislative process

23. Social change

24. Social structure and institutions

25. systems theory

26. Social deviancy

\section{c. Individual and social problems}

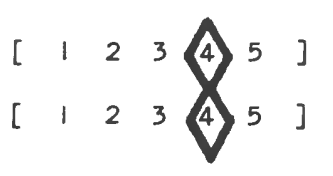

27. Alcohol abuse - e.g. types, incidence, causes

28: Developmental disabilities - e.g. †ypes, incidence, causes 


\begin{tabular}{|c|c|c|c|c|}
\hline$\frac{1}{\text { Very infrequently }}$ & $\begin{array}{c}2 \\
\text { Infrequent |y } \\
\text { (seldom) }\end{array}$ & $\begin{array}{l}3 \\
\text { occasionally }\end{array}$ & $\begin{array}{c}4 \\
\text { Frequently } \\
\text { (often) }\end{array}$ & $\begin{array}{c}5 \\
\text { Very Frequently }\end{array}$ \\
\hline
\end{tabular}

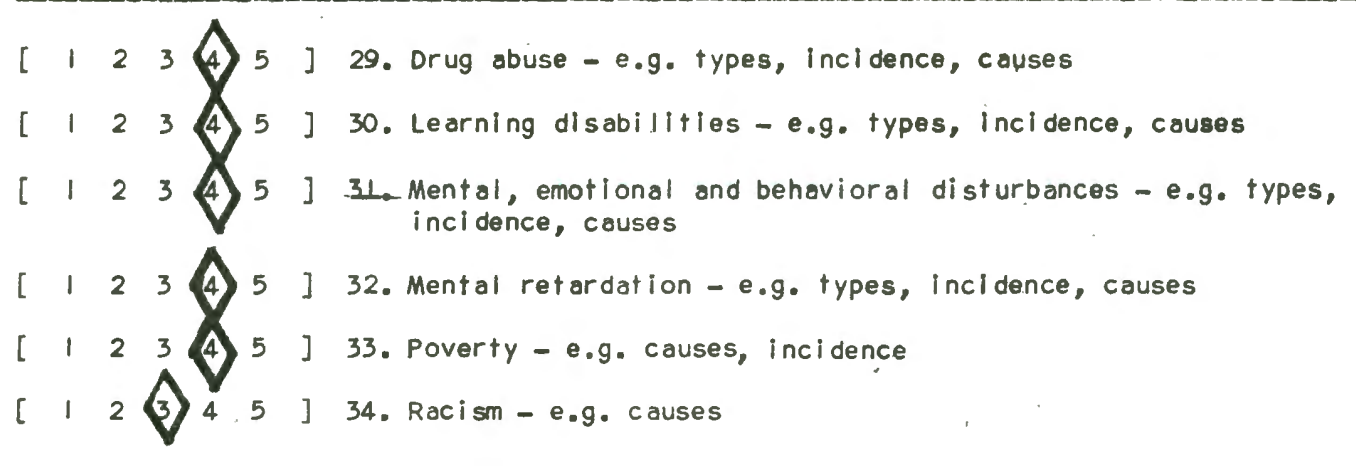

\section{Social Wel fare Policy and Services}

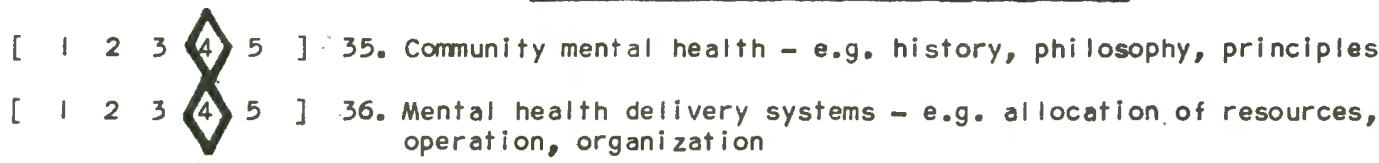

[ 12345 ] 37. Mental health financing - e.g. avoilability, mechanisms, sources

[ 12345 ] 38. Mental health laws, legislation and guidelines

[ 123345 ] 39. Mental health manpower - e.g. distribution, paraprofessional roles, professional roles

$\left[\begin{array}{llllll}1 & 2 & 3 & 4 & 5 & 5\end{array}\right]$. Social policy

$\left[\begin{array}{llllll}1 & 2 & 3 & 4 & 5\end{array}\right] 41$. Social service delivery systems - e.g. allocation of resources, operation, organization

[ 125345 ] 42. Social service financing - e.g. availability, mechanisms, sources

[ 12345 ] 43. Social welfare laws, legislation and guidelines

\section{E. Application and practice}

Concepts, Methods, Principles, Strategies and Theories

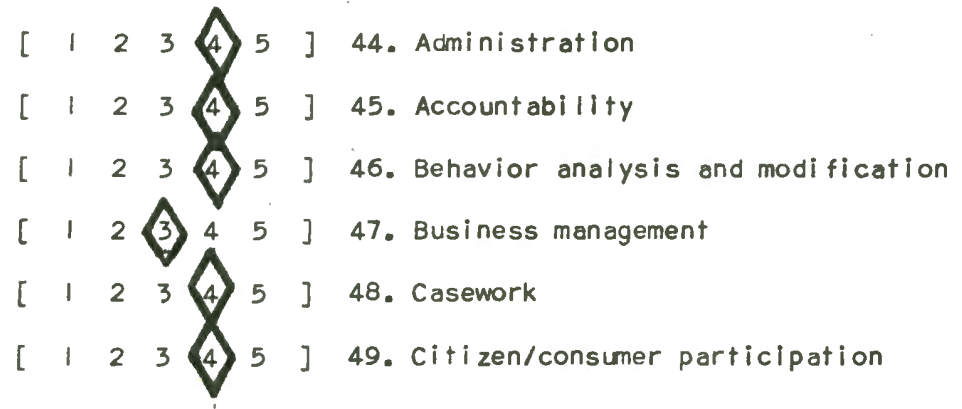

$\hat{Q}=$ Model Response $\quad$ " $Y$ " = Your Response 


\begin{tabular}{|c|c|c|c|c|c|}
\hline & 1 & 2 & $\frac{3}{0 c c a s i o n a l l y}$ & $\frac{4}{4 x}$ & $\begin{array}{cc}5 & 293\end{array}$ \\
\hline Very & Infrequentiy & $\begin{array}{c}\text { Infrequently } \\
\text { (seldom) }\end{array}$ & Dccasionally & $\begin{array}{c}\text { Frequently } \\
\text { (odten) }\end{array}$ & Very Frequent Iy \\
\hline
\end{tabular}

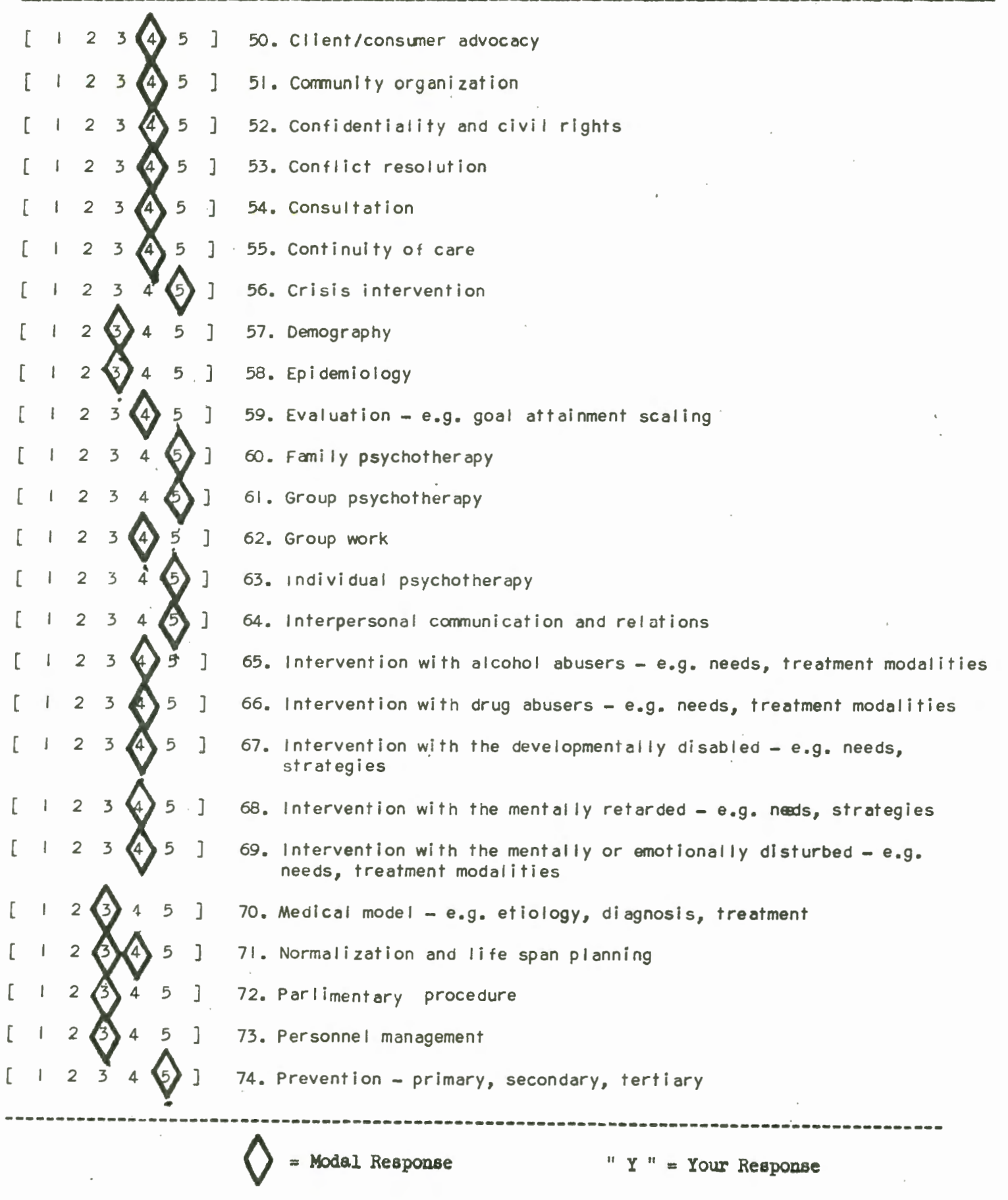




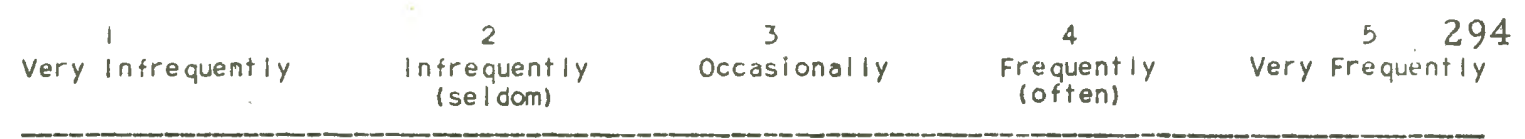

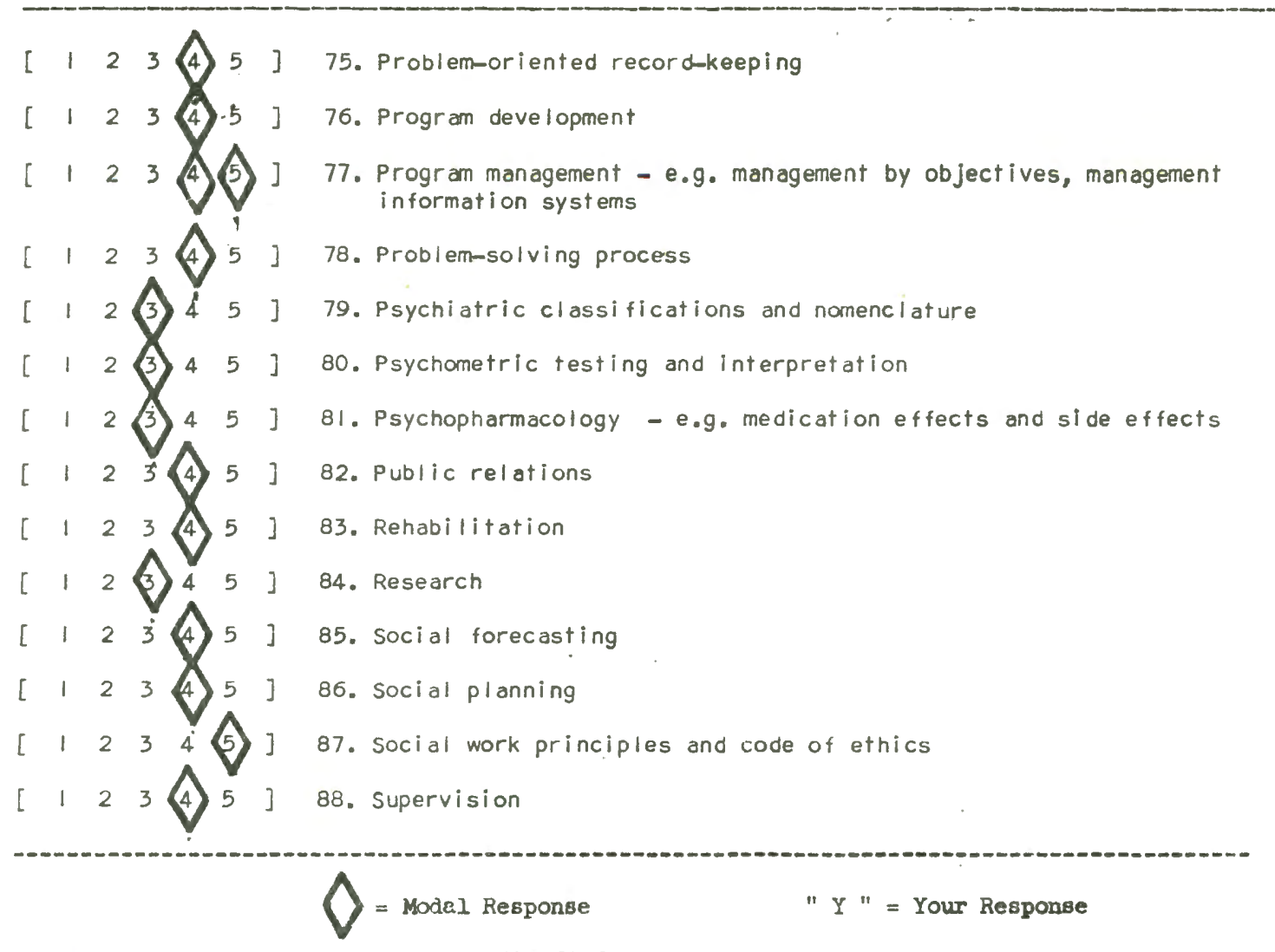

Comments on the Questionnaire or on the Study: 
APPENDIX B

SELECTED RESPONSES AND FINDINGS 
SOCIAL WORKE RS IN COMMUNITY MENTAL HEALTH

Questionnaire \# 1

Professional Affiliation and Degree, if applicable Psychiatry

( e.g. Education, Nursing, Psychiatry, Psychology, Sccial Work etc.)

Purpose

The purpose of this questionnaire is to obtain your opinions and predictions about the future activities of social workers in the field of community mental health. It is composed of four open-ended questions which ask you to speculate on the following subjects:

1) the future jobs which you see Master's level social workers performing in community mental health;

2) the tasks involved in these jobs;

3) the areas of knowledge involved in these jobs;

4) the skills needed to carry out these jobs.

Definition of Terms

For the purposes of this study, the above terms are defined as follows:

Job: A role or position occupied by the personnel within an organization

Task: A discrete, purposeful piece of work which is performed as part of a job

A rea of Knowledge: A theory, principle, concept or method, or factual information

Skill: The ability to apply one's knowledge effectively in the performance of tasks

Instructions

In response to each question, please list as many items as you are able to. Attempt to make your responses as specific as possible, since specific statements will produce more useful data than broad general ones. If additional space is needed to complete your answer to any question, please use the space provided on page four.

BEFORE YOU RESPOND TO THE QUESTIONS ON THE FOLLOWING PAGES, we would like you to think for a moment about the future of the community mental health system in Oregon in the decade 1975-1985. Imagine the structure and organization of the system, the needs and problems it will be addressing, and the programs and services it wlll encompass. Then think about the various jobs which you believe Master's level social workers may be performing in the different functional areas within the sy stem, 1. e. providing direct services; facilitating and administering services; planning, developing and evaluating services.

With this frame of reference in mind, please respond to the questions which follow from your perspective as a planner, an administrator or a staff member involved in community mental health. 
1) What jobs do you think Master's level social workers will be performing in Oregon's CMH system during the decade 1975-1985 ?

For each item, please give a bricf, behavioral description of the job, Indicating both role and organization. For example: Family therapist in a children's treatment center Administrator of an alcoholic recovery program Program evaluator in a $\mathrm{CMH}$ center

Administrator of hospital social services.

Manager of hospital ward treatment program.

Coordinator of hospital and comunity patient planning.

Supervisor of social workers at State Hospital.

Administrator of Community Mental Health Programs.

Manager of Day Treatment programs.

Administrator of Childrens Treatment Center.

Group therapist at State Hospital.

Group therapist in community mental health program.

Ward Team member at State Hospital.

Coordinator of hospital alcohol program.

Director of hospital Adolescent Program.

Individual therapist at State Hospital.

Individual therapist at community mental health program.

Pre-investigator at community mental health program.

Supervisor of community mental health program service areas.

2) What tasks do you belitve will be involved in these jobs?

For each item, please state both the action and its purpose as specifically as possible.

For example: Conducting a home visit as part of a pre-committment screening

Providing consultation about program design to a drug center

Planning a sheltered workshop for retarded adults.

Planning for improved delivery of social services.

Coordinating workloads to ensure effective delivery of social services.

Establishing communications systems between hospitals and communities.

Monitoring and evaluating the performance of staff members to upgrade skills.

Teaching social work principles and ethics.

Speaking at public meetings about community mental health program or hospital services

Planning the treatment program of day center, hospital ward, or comnunity mental

health program

Consulting with other staff about individual treatment plans.

Referring clients to appropriate resources.

Conducting group therapy

Conducting individual therapy.

Home visiting for pre-investigating or family information.

Writing plans for various treatment programs.

Meeting with community agencies to coordinate services. 
3) What areas of knowledge do you belicve a person will need to be familiar with to

carry out these jobs?

Examples of possible theories, principles, concepts, methods or factual information might be: Social learning theory; princlples of administration; concept of continuity of care; community organization methods; or incidence of mental retardation in Oregon.

Psychosocial diagnosis.

Principles of administration

Systems theory

Family dynamics

Knowledge of organization \& operation of Mental Health Division

Hospital organizational structure

Knowledge of format for proposal and grant writing

Management by objectives system

State budgeting methodology

Psychiatric nomenclature

Medical audit procedures

Principles of management

Principles of consultation

Family Therapy theory

Transactional Analysis theory

Behavior modification theory

Reality Orientation theory

Reality Therapy theory

Principles of Resocialization

Methods of evaluation

Human development

Principles of group dynamics

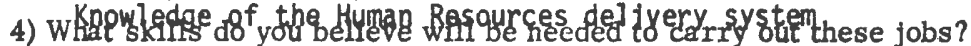

Please attempt to identify both categories of skills and the component skills within each category. For example: Interviewing skills - the ability to pa raphrase, the abllity to gather information...

Grantwriting skills - the ability to write clearly and consisely, the ability to project a budget...

Planning skills - the ability to analyze a policy, the ability to formulate objectives...

Writing skills - the ability to write clearly and succinctly - grants, reports, letters and descriptive information

Speaking skills - the ability to make oneself understood by a large group or individual - the ability to keep attention of others

Listening skills - the ability to clearly receive the verbal and non-verbal messages of others

Organizing skills - the ability to understand the relationship between items and systems and to coordinate them

Relationship skills - the ability to work together with an interdisciplinary team, and to establish constructive relationships with patients.

Intervention skills - the ability to intervene appropriately in treatment. 
TABLE XV

RESPONSES TO THE NON-RESPONSE BIAS QUESTIONNAIRE AS COMPARED TO THE COMPLETED ROLES, FUNCTIONS AND TASKS QUESTIONNAIRE

\section{RESPONSE DISTRIBUTION}

NRB

ITEM RFT Round II Questionnaire

$$
1-2-3 \quad 4-5 \quad 1-2-3 \quad 4-5
$$

Roles

$\begin{array}{rrrrrrr}\text { 3. } & 49 \% & 51 \% & 57 \% & 43 \% & 2.9 & 3.1 \\ 9 . & 26 \% & 74 \% & 14 \% & 86 \% & 3.9 & 3.9 \\ 17 . & 42 \% & 58 \% & 14 \% & 86 \% & 3.7 & 4.0\end{array}$

Functions

$\begin{array}{lllllll}\text { 32. } & 28 \% & 72 \% & 29 \% & 71 \% & 3.9 & 3.8 \\ 34 . & 40 \% & 60 \% & 29 \% & 71 \% & 3.8 & 4.0 \\ 37 . & 50 \% & 50 \% & 57 \% & 43 \% & 3.7 & 3.7\end{array}$

Tasks

$\begin{array}{rrrrrrr}\text { 3. } & 22 \% & 78 \% & 29 \% & 71 \% & 4.0 & 3.9 \\ \text { 32. } & 50 \% & 50 \% & 29 \% & 71 \% & 3.5 & 3.6 \\ 38 . & 68 \% & 32 \% & 71 \% & 29 \% & 3.0 & 3.3 \\ \text { 45. } & 48 \% & 52 \% & 43 \% & 57 \% & 3.5 & 3.6 \\ \text { 49. } & 40 \% & 60 \% & 43 \% & 57 \% & 3.7 & 4.1 \\ \text { 52. } & 54 \% & 44 \% & 43 \% & 57 \% & 3.5 & 3.9 \\ 72 . & 56 \% & 44 \% & 43 \% & 57 \% & 3.3 & 3.4 \\ 74 . & 26 \% & 74 \% & 14 \% & 86 \% & 4.0 & 4.3 \\ 90 . & 20 \% & 80 \% & 0 \% & 100 \% & 4.2 & 4.3\end{array}$

